\title{
FLEXIBLE WORKING ARRANGEMENTS IN MALAYSIA AND THE PARTICIPATION OF WOMEN IN THE LABOUR FORCE
}

\author{
By \\ GEETHA SUBRAMANIAM
}

A thesis

submitted to the Victoria University of Wellington

in fulfilment of the requirements for the Degree of

Doctor of Philosophy

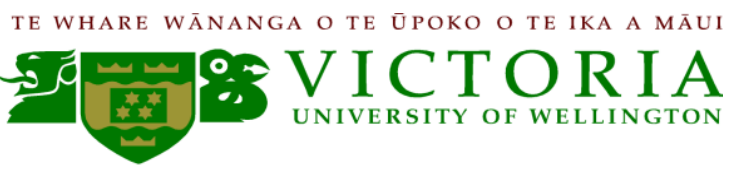

2011 


\begin{abstract}
The aim of this thesis is to shed light on possible reasons for the stagnation in the participation rate of women in the Malaysian workforce by focusing on the phenomenon of flexible working arrangements. This is researched in the context of the possibility of flexible working arrangements helping women achieve work-life balance and how such work affects their well-being. Using a mixed method approach, the study addresses three main questions:are Malaysian women interested in flexible working arrangements? would flexible working arrangements be useful in bringing more women into the labour force? and what impacts do flexible working arrangements have on their well-being?

The study was conducted in the Klang Valley, which has a total population of over seven million people and is the heartland of Malaysia's industry and commerce. It employed both quantitative and qualitative methods. For the quantitative approach, self-administered questionnaires were distributed to women employees working in seven organisations which have flexible working arrangements and seven organisations with fixed working arrangements. A random sample of 415 female employees from 14 selected organisations in the services sector were identified. To complement the statistical data, 30 women were interviewed.
\end{abstract}

Findings from the logistic regression analysis revealed that flexible working arrangements at the workplace are preferred by women who are more educated, earning a higher income and are at the higher end of the occupational status. It further revealed that flexible working arrangements will encourage more women to work in paid labour since they have a better work-life balance and more empowerment.

The information gathered from the qualitative interviews concerned women's wellbeing in terms of work-life balance, empowerment and lifestyles. While most of the women experienced work-life balance barriers, some common threads and themes revealed that flexible working arrangements will be a good option towards achieving work-life balance and had a positive effect on women's well-being in terms of work-life balance and household empowerment. The qualitative interviews showed that workplace flexibility can improve the working women's work-life balance, especially among married women with young children and hence, encourage women to participate in paid labour.

In adopting a combination of theoretical approaches, it is argued that there is a greater tendency for Malaysian married women to exit the labour force after having children compared to most other countries and this is primarily due to their caring responsibilities, lack of an enabling environment and the cultural and social factors particular to Malaysia.

The study found that flexible working arrangements are very varied in type and cannot be treated as a single, comprehensive package which might be suitable for all women. Further, the implementation of flexible working arrangements at the workplace would not be alone sufficient to bring in more women into the labour force. 


\section{PUBLICATIONS AND PRESENTATIONS}

A number of conference and journal papers have been produced from this thesis. The papers are as follows:

\section{Conference Papers}

1. "Flexible Working Arrangements, Women and Work - A Malaysian Perspective".

Presented at "Equality, Diversity and Inclusiveness" Conference at Auckland University, Auckland.

7-8 February 2011.

2. "Flexibility at Workplace - Can it bring change to a working woman's lifestyle?"

Presented at "Women in Asia" Conference at the Australian National University, Canberra, Australia

29 September 2010 - 2 October 2010

3. "Working Arrangement and Its Effect on Family and Lifestyle"

Presented at the MACFEA Malaysian Association of Consumer \& Family Economics Conference in Universiti Kebangsaan Malaysia, Kuala Lumpur.

13-14 July 2010

4. "Flexibility At The Workplace - Will More Malaysian Women Join The Labour Force?"

Universiti Teknologi MARA, Kedah, Malaysia

1-2 June 2010.

\section{Other Presentations}

1. Flexible Working Arrangements and Women in Malaysia Presented in Geography, Environment and Development, GED Seminar Series at SGEES,

Faculty of Science, Victoria University of Wellington, New Zealand.

19 August 2010 


\section{Journal Publications}

1. Subramaniam, G., Maniam, B., \& Ali, E. (2011) Can Workplace Flexibility Have an Effect on Women's Lifestyles and Work-Life Balance? International Journal of Business Research (forthcoming)

2. Subramaniam,G., Maniam,B., \& Ali,E. (2011).Perceived Costs and Benefits of Workplace Flexibility - A Factor Analysis. Business Studies Journal (forthcoming)

3. Subramaniam, G., Ali, E., \& Overton, J. (2010). Are Malaysian Women interested in Flexible Working Arrangements? Business Studies Journal, 2(Special Issue), 83-98.

A number of Micro level studies were done before embarking on this research. Publications from the studies are as follows:

\section{Journal Publications}

1. Subramaniam,G., Iyer, M., G., \& Maniam,B. (2010). Do Malaysian women who opt out of the labour market want to return? - A micro level analysis. International Journal of Business Research, 10 (1), 106-113.

2. Subramaniam,G., \& .Selvaratnam, D.P. (2010). Family friendly policies in Malaysia: Where are we? Journal of International Business Research. 9(1), 43-55

3. Subramaniam,G., Saadiah Mohamad, \& Selvaratnam, D. P. (2010). why do some women leave the labour force - A micro perspective from Malaysia. Economic Bulletin, 11, 1-17.

4. Subramaniam,G., Iyer, M. G., Saadiah Mohamed \& Norlin Nor (2010). Children and Women's Decision Not To Work -A Study In Klang Valley. Malaysian Journal of Consumer \& Family Economics. 13. 18 -27. 


\section{DEDICATION}

This dissertation is dedicated to three people who had a significant impact on my life.

My dad, Subramaniam,

who allowed me to chase my dream and stood next to me until the dream came true, is my continuous source of inspiration and a constant source of silent support.

My mom, Saraswathy, who left me suddenly on 13 February 2005, in her sleep. One of her dreams was to see me as a "Doctor". She was a remarkable woman who taught me all aspects of life especially about patience and unconditional love.

My sweetheart, Prabha, who also left me all of a sudden without even saying good-bye on 17 June 1996. One day before leaving for the astral world, he spoke in length about his desire to see me pursue my $\mathrm{PhD}$.

I am so grateful to all of them who had so much faith and believed in my capability to be a "Doctor" one day. 


\section{ACKNOWLEDGEMENTS}

First and foremost, I would like to express my heartfelt gratitude to Almighty God for all His guidance and blessings to permit me to further my studies in New Zealand and for being with me throughout the challenging $\mathrm{PhD}$ journey. The completion of this thesis would not have been possible without the support of a number of people whom I would like to acknowledge and to whom I would like to extend warm thanks and gratitude.

I am particularly grateful to my $\mathrm{PhD}$ supervisors at Victoria University of Wellington and Auckland Institute of Studies, St. Helens, who have provided invaluable support and guidance throughout the research process. Thanks to my primary supervisor, Professor John Overton for his substantial input and critical suggestions which helped me to complete my thesis. His directional and constructive feedbacks have stretched me further than I thought, and even more importantly, have inspired my passion for development studies.

I would also like to thank my secondary supervisor, Ms Prue Hyman, a feminist economist, for all her useful comments and guidance that enhanced the quality of this thesis from the gender aspect. My heartiest gratefulness goes to my third supervisor, Dr Ershad Ali, for his invaluable input and for being a constant source of motivation throughout my challenging journey. He and his wife, Zulekha showered me with true hospitality, accommodating me and taking care of me like a daughter during all my trips to New Zealand.

I thank Professor Normala Amir Ishak, the Dean of the Faculty of Business Management, Universiti Teknologi MARA, for her constant support and a big thank you to Universiti Teknologi MARA, Shah Alam, Malaysia for granting me the study leave to complete my studies.

I also acknowledge the patience, cooperation and support of all the lovely women who agreed to be my participants and interviewees. A note of appreciation also goes to the Liaison Officers and the Human Resource personnel of the fourteen organisations. 
My appreciation also extends to several friends and colleagues who have helped me in the final stages of my $\mathrm{PhD}$ journey. A big note of thanks to Dr Dalice Sim, Victoria University of Wellington for going through my data analysis. Also thanks to Mr. Durairaju, Department of Statistics, Malaysia for his ready assistance in providing secondary data. I would also like to say a big thank you to my dear friends at Victoria University of Wellington, Mani Nambayah, Sandra Gogliani and Suzanne Weaver from SGEES, and Sivakumar Dorairaj, from ECS, who facilitated my thesis submission to the Faculty.

Finally, I would like to acknowledge my greatest appreciation and gratitude to my family who have made a far greater contribution then they probably realise. In particular, a big thanks to my father who is ninety-five years old but is very well aware of my late nights and the hard work I had to put in to complete my thesis. A very Big Thank You to my younger sister, Latha and brother-in-law Pathman for accommodating me and taking care of my needs in Wellington which facilitated my studies in Victoria University of Wellington. Many thanks to my niece, Shobha for her unwavering support and understanding throughout my journey, not to mention her editing work; and to my brother Prasad, for his constant encouragement. And thank you to all my other family members, namely my sisters, brothers, sisters-in-law and brothers-in-law for their patience and the motivation given to me to ensure that I persevere and keep moving forward.

\section{Thank you all.}

$* * * * * * * * * * * * * * * * * * * * * * * * * * * * * * * * * * * * * * * * * * * * * * * *$

Financial assistance from Victoria University’s PhD Thesis Submission Scholarship is also gratefully acknowledged. Two Victoria University Faculty of Science grants funded purchase of data and presentation of findings at international conferences in Canberra and Auckland.

\section{Geetha Subramaniam}

Victoria University of Wellington

2011 


\title{
TABLE OF CONTENTS
}

\author{
ABSTRACT \\ PUBLICATIONS AND PRESENTATIONS \\ DEDICATION \\ ACKNOWLEDGEMENTS \\ TABLE OF CONTENTS \\ LIST OF TABLES \\ LIST OF FIGURES \\ LIST OF APPENDICES \\ ABBREVIATIONS
}

1.0 INTRODUCTION AND OVERVIEW

1.1 Introduction

1

1.2 Background development and women in the labour market

1.2.1 Development And Women In The Malaysian labour Market

1.2.2 Why Flexible Working Arrangements

1.3 Problem Statement

1.4 Objectives Of Study

1.4..1 Main objective

1.4.2 Specific objectives

1.5 Research questions

1.6 Research methods

1.7 Significance Of Study

1.8 Structure Of Thesis

\subsection{LITERATURE REVIEW}

2.1 Introduction

2.2 Development concepts and theories - an overview

2.2.1 Mainstream development

2.2.2 Dependency theory

2.2.3 Neoliberalism and globalization 21

2.2.4 Alternative Development 24

2.3 A survey of theoretical debates on gender and development 27 models

2.3.1 Women in Development (WID)

2.3.2 Women and Development (WAD)

2.3.3 Gender and Development (WID)30

2.4 Women And labour market 
2.5 Flexible working arrangements, women and work 36

2.5.1 Flexible working arrangements 36

$\begin{array}{ll}\text { 2.5.2 Benefits of FWA } & 15\end{array}$

2.5.3 FWA and women's well-being 42

2.6 Some global examples of FWA and how they work for 43 Women.

2.7 Development theories, women and FWA - how they are 44

Related?

$\begin{array}{lll}2.8 & \text { Summary } & 45\end{array}$

3.0 OVERVIEW OF INDUSTRIALIZATION IN THE LABOUR MARKET IN MALAYSIA

3.1 Introduction $\quad 47$

3.2 Industrialisation and Development in Malaysia - A 48

Historical Overview of the Colonial Policy

3.2.1 From colonialism to the new international 50

division of labour

3.2.2 Post colonial policy 53

3.2.3 The economic transition (1970 -2000) 55

$\begin{array}{ll}\text { 3.2.4 Post NEP and labour industrialisation } & 60\end{array}$ (2000 -2010)

3.3 Women's position in Malaysia 61

3.4 Women and work in Malaysia - patterns and trends from 65 the 1970s

3.5 Women and work -the regulatory framework 76

3.6 Flexible Working Arrangements in Malaysia 80

$3.8 \quad$ Other related policies and initiatives $\quad 83$

$\begin{array}{lll}3.9 & \text { Conclusion } & 87\end{array}$

4.0 RESEARCH METHODOLOGY \& METHODS 89

$\begin{array}{llr}4.1 & \text { Introduction } & 89\end{array}$

4.2 Epistemological approach to the research 89

$\begin{array}{ll}\text { 4.2.2 The positivist approach } & 90\end{array}$

$\begin{array}{ll}\text { 4.2.2 The phenomenological approach } & 91\end{array}$

4.2.3 The feminist Lens 92

$\begin{array}{lll}4.3 & \text { The objectives of study } & 93\end{array}$

$\begin{array}{lll}4.4 & \text { Research methods } & 94\end{array}$

4.5 Definitions of variables 96

4.6 Sampling design 98

4.6.1 Sampling technique $\quad 98$

$\begin{array}{ll}\text { 4.6.2 Scope } & 101\end{array}$

$\begin{array}{lll}\text { 4.6.3 Sample size } & 101\end{array}$ 
$\begin{array}{ll}\text { 4.7 Quantitative Method } & 102\end{array}$

$\begin{array}{lll}\text { 4.7.1 Instrument } & 102\end{array}$

4.7.2 Questionnaire Administration 103

4.7.3 Statistical Analysis 103

4.7.4 Hypothesis Testing 104

$\begin{array}{lll}4.8 & \text { Qualitative Method } & 105\end{array}$

4.8.1 Introduction 105

4.8.2 Instrument 105

4.8.3 Participants 106

$\begin{array}{ll}\text { 4.8.4 Method of Analysis } & 107\end{array}$

$\begin{array}{lll}\text { 4.8.5 Procedure } & 107\end{array}$

4.9 Ethical Considerations 108

$\begin{array}{lll}4.10 \text { Summary } & 110\end{array}$

5.0 FLEXIBLE WORKING ARRANGEMENTS AND FEMALE LABOUR FORCE - A QUANTITATIVE ANALYSIS

$\begin{array}{lll}5.1 & \text { Introduction } & 111\end{array}$

5.2 Characteristics of respondents 111

5.3 The Uptake of FWA by female employees in Malaysia 125

5.3.1 Logistic Regression Theory 126

5.3.2 Logistic Regression Model 127

5.3.3 Results for Regression Analysis 128

5.3.4 Perceived Advantages and Disadvantages to 135

Respondents

5.4 Do working arrangements affect women's desire to work? 137

$\begin{array}{lll}5.5 & \text { Summary } & 139\end{array}$

6.0 THE IMPACT OF FLEXIBLE WORKING ARRANGEMENT ON WOMEN'S WELL-BEING - A QUALITATIVE ANALYSIS

$\begin{array}{lll}6.1 & \text { Introduction } & 141\end{array}$

6.2 Method 141

6.3 Quantitative analysis - MANOVA Analysis 142

6.4 Qualitative analysis - Content Analysis 144

6.4.1 Theme One - Work-life Balance 148

6.4.1.1 Managing time at home 148

6.4.1.2 Managing Family Time 151

6.4.1.3 Balancing the Demand of Work and Household 153 Chores

6.4.1.4 Managing work and caring responsibilities 158

6.4.1.5 Managing commuting to the work place 163

6.4.2 Theme Two - Work, Lifestyles and Well-being 167

6.4.3 Theme Three - Household, Economic and Social 174

Empowerment 
6.5 Costs and Benefits of FWA 180

6.6 FWA and women's well-being - Summary of findings 185

6.7 Concluding Remarks

\section{$\begin{array}{lll}7.0 & \text { CONCLUSIONS } & 187\end{array}$}

$\begin{array}{lll}7.1 & \text { Introduction } & 187\end{array}$

$\begin{array}{lll}7.2 & \text { Summary } & 187\end{array}$

7.3 FWA and working women in Malaysia - Findings 190

7.3.1 Who are the women interested in FWA in Malaysia? 191

7.3.2 How helpful is FWA to working women in 194

Malaysia?

7.3.3 How do FWA work in Malaysia? 197

7.3.4 FWA and linkages with other sectors in Malaysia 198

7.4 FWA and the Emerging Issues 199

$\begin{array}{ll}\text { 7.4.1 Choice and discrimination } & 200\end{array}$

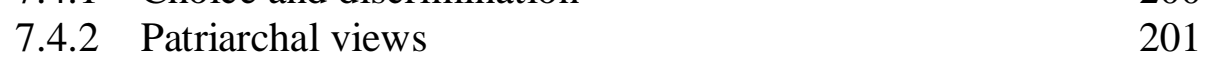

$\begin{array}{ll}\text { 7.4.3 Enabling environment } & 202\end{array}$

7.4.4 Demographic issues vs economic issues 203

7.4.5 FWA and other linkages 204

7.4.6 FWA - in retrospect 205

7.5 Policy recommendations - how can FWA bring in more 207 women into the Malaysian labour force

$\begin{array}{lll}7.6 & \text { Theoretical considerations } & 211\end{array}$

7.7 Indications of Future Research 215

$\begin{array}{lll}7.8 & \text { Concluding Remarks } & 215\end{array}$

$\begin{array}{ll}\text { REFERENCES } & 217\end{array}$

$\begin{array}{ll}\text { APPENDICES } & 231\end{array}$ 


\section{LIST OF TABLES}

Table 3.1 Female Labour Force Participation Rate by Age Group for 66 Malaysia (1970-2010)

Table 3.2 Percentage Distribution of Female Labour Force by Sector, 70 1970 - 2010

Table 3.3 Employment Distribution by Sector and Gender (\%), 72 Malaysia, 1970 - 2010

Table 3.4 Employment Distribution by Occupation and Gender (\%), $\quad 74$ Malaysia, 1970 - 2010

Table 3.5 Percentage Distribution of Economically Active Population by 75 Employment Status and Gender, Malaysia, 1970 - 2010

Table 5.1 Age Profile of Sample in Comparison to Labour Force Population

Table 5.2 Marital Status of Survey Sample in Comparison to Population

Table 5.3 Ethnicity of Survey Sample in Comparison to Working Population Sample

Table 5.4 Place of Birth of Respondents

Table 5.5

Highest Educational Level Achieved by Respondents

Table 5.7 Personal Monthly Income of Respondents 116

Table 5.8 Number of Married Respondents with Young Children 117

Table 5.9 Married Respondents with Number of Young Children 117

$\begin{array}{lll}\text { Table 5.10 Married respondents with total number of Children } & 118\end{array}$

Table 5.11 Respondents who Take Care of Elderly Parents 118

$\begin{array}{lll}\text { Table 5.12 Mode of Transport to commute to Work } & 119\end{array}$

Table 5.13 Interested in Flexible Working Arrangements (FWA) 119

$\begin{array}{lll}\text { Table 5.14 Type of Working Arrangements } & 121\end{array}$

Table 5.15 Organisation Type where Respondents Work 122

$\begin{array}{lll}\text { Table 5.16 Summary of Cross Tabulation of Selected Socioeconomic } & 124\end{array}$

Table 5.17 Items, Factors and Factor Loadings for Perceived Advantages 130

Table 5.18 Items, Factors and Factor Loadings for Perceived 131

Table 5.19 Parameter Estimates from Stepwise Logistic Regression 132

$\begin{array}{lll}\text { Table 5.20 Perceived Advantages of the Respondents } & 136\end{array}$

$\begin{array}{lll}\text { Table 5.21 Perceived Disadvantages of the Respondents } & 137\end{array}$

$\begin{array}{lll}\text { Table 5.22 Intentions of Stopping Work before Retirement Age } & 138\end{array}$

Table 5.23 Flexible Working Arrangements and More Women Going Out 138

$\begin{array}{lll}\text { Table 6.1 Summary Results From Factor Analysis } & 143\end{array}$

Table 6.2 MANOVA Table showing Significance Values for Working 145

$\begin{array}{lll}\text { Table 6.3 Main Features of the Respondents } & 146\end{array}$ 


\section{LIST OF FIGURES}

Figure 3.1 Growth Rates of GDP 57

Figure 3.2 Female Labour Force Participation Rate by Age Group for 62 Malaysia

Figure 3.3 Percentage Distribution of Female Labour Force by Sector, $1970 \quad 70$ - 2010

Figure 3.4 Employment Distribution by Sector and Gender (\%), Malaysia, 2010 


\section{LIST OF APPENDICES}

Appendix 4.1 Questionnaire for Female Employees in FWA Organisations 233

Appendix 4.2 Questionnaire for Female Employees in Non-FWA 242

Organisations

Appendix 4.3 Structured Interview Questionnaire for Employees in FWA 250

Appendix 4.4 Structured Interview Questionnaire for Employees in Non- 253

FWA

Appendix 4.5 Cover Letter For Questionnaire 255

Appendix 4.6 Consent Form for Interview Participants 256

Appendix 5.1 Cross Tabulation Tables for Work Type 258

Appendix 5.2 Logistic Regression Output 259

Appendix 5.3 Cross Tabulation Output 263

Appendix 5.4 Independent T-Test Output 265

Appendix 6.1 Demographic Profile of Interview Respondents 266 


\section{ABBREVIATIONS}

\begin{tabular}{|c|c|}
\hline APEC & Asia Pacific Economic Cooperation \\
\hline CEDAW & Committee on the Elimination of Discrimination against Women \\
\hline DOS & Department of Statistics, Malaysia \\
\hline EOI & Export Oriented Industrialisation \\
\hline EPU & Economic Planning Unit \\
\hline FLFP & Female Labour Force Participation \\
\hline FWA & Flexible Working Arrangements \\
\hline GAD & Gender and Development \\
\hline GDP & Gross Domestic Product \\
\hline GNI & Gross National Income \\
\hline HAWA & Secretariat For Women's Affairs, Prime Minister's Department \\
\hline HR & Human Resource \\
\hline HSBC & Hongkong and Shanghai Banking Corporation \\
\hline ICT & Information and Communications Technology \\
\hline ILO & International Labour Organisation \\
\hline IMF & International Monetary Fund \\
\hline ISI & Import Substitution Industrialisation (ISI) \\
\hline KPI & Key Performance Indicator \\
\hline LFPR & Labour Force Participation Rate \\
\hline LFSR & Labour Force Survey Report \\
\hline MDG & Millennium Development Goals \\
\hline MEF & Malaysian Employers Federation \\
\hline MITRANS & Malaysia Institute Of Transport \\
\hline MLFS & Malaysian Family Life Survey \\
\hline MNC & Multinational Corporation \\
\hline NACEW & National Advisory Council on the Employment of Women \\
\hline NEAC & National Economic Advisory Council \\
\hline NDP & National Development Policy \\
\hline NEM & New Economic Model \\
\hline NEP & New Economic Policy \\
\hline Non-FWA & Non-Flexible Working Arrangements \\
\hline NPW & National Policy for Women \\
\hline NVP & National Vision Policy 2020 \\
\hline OECD & Organisation for Economic Co-operation and Development \\
\hline OPP1 & First Outline Perspective Plan \\
\hline OPP3 & Third Outline Perspective Plan \\
\hline $\mathrm{RM}$ & Ringgit Malaysia - Malaysian Currency \\
\hline & $\begin{array}{c}\text { Exchange rate }-1 \mathrm{NZD}=\mathrm{RM} 2.50 \\
1 \mathrm{USD}=\mathrm{RM} 3.00\end{array}$ \\
\hline SPSS 18 & Statistical Package for the Social Sciences version 18 \\
\hline UN & United Nations \\
\hline UNDP & United Nations Development Programme \\
\hline UNESCAP & $\begin{array}{l}\text { United Nations Economic and Social Commission for Asia and the } \\
\text { Pacific }\end{array}$ \\
\hline WAD & Women and Development \\
\hline WID & Women in Development \\
\hline
\end{tabular}


WIDER- $\quad$ The United Nations University's World Institute for Development UNU Economics Research

WTO World Trade Organisation 


\section{Chapter 1}

\section{Introduction and Overview}

\subsection{Introduction}

In the 1970s, the World Bank defined development to mean "successful participation in the world market" (McMichael, 2000, p. 111) with a strategy of participating in world economy rather than specialisation in economic activities within a national framework. One of the most important characteristics of globalisation is its emphasis on cultural aspects and increased communication due to flexibility of technology to connect people around the world. However, globalisation processes which serve to connect and integrate particular places, groups and individuals, sometimes perpetuate the relative disconnection and isolation of others (Murray, 2006). By the 1990s, global economic changes began to show a deep impact on the structure and operation of labour markets worldwide, witnessing an increase in female labour force participation rates in developed as well as developing countries. A new international division of labour emerged and this global restructuring process saw the emergence of the global assembly line with research and management being controlled by the core or developed nations and assembly line work relegated to semi-peripheral or peripheral nations that occupied less privileged positions in the global economy.

Since the 1970s, the issue of women and gender in development received increasing attention within development literature (Warren, 2007). The means by which "gender" considerations were integrated into development practices and programmes included theoretical and practical strategies. Until the 1990s, development was assumed to be gender neutral and of benefit to both men and women equally (cited in Warren, 2007 by Karl, 1995). However, following the pioneering work of Boserup (1970), realisation of the differing roles played by men and women, and the social construction of gender gained recognition in the development literature. At a basic level, it has been observed that the current 
"economic development and modernisation processes that are taking place all over the world in the last two decades cannot function on men alone" (Shaban,1997, p. $125)$.

As a result, theories influencing women and their roles and gender analysis ${ }^{1}$ frameworks developed. One of the gender analysis frameworks ${ }^{1}$ which highlighted the many roles played by women was The Gender Planning Framework developed by Moser which links women's roles to the development process (Moser, 1993). Moser's approach introduces the idea of the triple roles broadly played by women in production, reproduction and community management. From then, there has been a shift from "women in development" models aiming to integrate women into development activities to "women and development" models that explain why this incorporation can have negative implications on women. The shift was towards current models which attempt to explain "gender and development" in the global market and the shift of economic roles from the family to the market and from the private sphere to the public sphere, the participation of women in the labour force became an area of concern for development theory. Against a backdrop of these global shifts, the changing roles of men and women in the family and work were also observed in Malaysia (Nagaraj \& Siti Rohani, 1998).

In the Malaysian development process, the introduction of the New Economic Policy ${ }^{3}$ in the early 1970s saw a radical structural change, from importsubstitution industrialisation (ISI) to export-oriented industrialisation (EOI). This development strategy which followed the "prescription" of the World Bank (McMichael, 2000, p.111) paved the path for the emergence of a new labour force drawing on workers, especially young women, moving from the rural areas to the cities. The labour intensive operations, often involving multinational companies especially in the electrical and electronics industries, saw an increase in female

\footnotetext{
${ }^{1}$ Gender analysis is a type of socio-economic analysis which links the existing gender relations in a particular society and development problems it needs to address. For more details refer to the "Gender Reference Guide".

${ }^{2}$ The three gender and development models, WID, WAD and GAD will be explained in more detail in Chapter Two.

${ }^{3}$ The New Economic Policy is a development policy for the period 1970 until 1990 and is explained in detail in Chapter Three.
} 
labour force participation from a mere 30 percent in 1970 to 47.8 percent by 1990 . Women workers did gain from being part of the industrialisation process but the question which arises is how much did they get and how much did they have to let go?

Changes have taken place in the employment pattern of women in tandem with the structural transformation of the economy from an agricultural-based to an industrial-based economy, especially after the 1970s. However, during the launch of the UNESCAP Economic and Social Survey of Asia and the Pacific by the United Nations Development Programme (UNDP), the UNDP Representative in Malaysia was surprised to note that "despite their high education and improved health status, Malaysian women are still under-represented in the job market with the female labour force participation rate remaining at approximately 40 percent throughout much of the past three decades" (UNESCAP, 2007). The report further suggested some immediate measures which were recommended to increase female labour force participation in Malaysia in the form of better family friendly policies and flexible working arrangements. This same concern was highlighted by the present Malaysian Prime Minster at the launch of the Seventh Women's Summit ${ }^{4}$ organised by the Ministry of Women, Family and Community Development in 2007. He reiterated that less rigid job arrangements would encourage more women into the workforce, thus boosting national productivity and economic growth.

In Malaysia and other Asian countries, there is a tendency for married women to leave employment upon marriage and the birth of children (Kaur, 2004). Inflexibility at the workplace and the home places a lot of stress on the women and the family especially for most women who put home as their main responsibility (Hill et al., 2004). One of the tools likely to be widely used to keep people in jobs will be some type of flexible working arrangements, such as flexitime, part-time work, teleworking and working from home.

\footnotetext{
4 The Women's Summit is an annual affair organised by the Ministry of Women, Family and Community Development. During the Women's Summit 2007, the Prime Minister highlighted his concerns about the low FLFP rate. Every year, a relevant theme is highlighted and in 2007, the theme was "Flexibility at the Workplace". This year the Summit highlighted women's empowerment and the theme was "Milestones to Success-Empowerment, Innovation and Passion".
} 
This chapter is divided into the following sections. Section 1.2 presents the background to this study by touching on a brief discussion on women's participation in the global labour market, followed by the labour market in Malaysia. This is followed by flexible working arrangements in the context of the study. The problem statement is explained in Section 1.3. The objectives are dealt with in Section 1.4 while the research questions in this study are set out in section 1.5. Section 1.6 looks at the research methods leading to section 1.7 which highlights the significance of the study. Section 1.8 provides the layout of the chapters in this study and finally comes to a conclusion.

\subsection{Background - Development and Women in the Global Labour Market}

The new international division of labour and changes in the global economy had an influence on the economies worldwide and the patterns of employment frequently changed from a traditional agricultural sector to modern manufacturing and services sectors. While the real impact actually has been the shift from the private, domestic domain to the paid, public domain, women throughout the world have been facing this challenging economic transformation.

In order to understand industrialisation and development in the international economy, McGee (1983, p. 23) traced and highlighted five major changes which were quite diverse and characterised the manufacturing export activities of Asian market economies. Firstly, from the technological level, development in the transportation system in terms of "container revolution" and bulk air cargo carrying of goods have greatly facilitated the growth of export industries in the market economies of Asia. Secondly, the commodity level involved mainly the electronic industry where it was possible to separate production processes and place the labour intensive assembly parts into the export processing zones of the market economies of Asia. Thirdly, the tariff policies of the developed countries have been responsible for a considerable growth of export industry in the market economies of Asia (Finger, 1975). Fourthly and critically, is the relative wage cost. Finally, weak labour power 
is notable due to two reasons; firstly, a large surplus labour force (see Froebel,1980) and secondly, relative absence of trade unions.

These developments had far-reaching consequences on the proletarianisation of the rural population in Southeast Asia. McGee (1983) noted that one interesting development that emanates from these changes is the increasing participation of women in the labour force. Many of the countries in Asia showed this pattern of economic growth trend and resulted in drawing a lot of women into the labour force (McGee, 1983; Heyzer, 1988).

\subsubsection{Development and Women in the Malaysian Labour Market}

In the early 1970s, the rapid growth of industrialisation which emerged in Malaysia was clearly showing a more divergent pattern of urbanisation, compared to the 1960s (McGee, 1983). The urbanisation process took off very slowly after Malaysia gained Independence in 1957. Through a number of development activities, this urbanisation process created a new pattern of economic participation which intensified with the establishment of free trade zones and after multinational corporations opened the door to women, especially young Malay women from the rural areas (Shaban, 1997). The other main factor which should be emphasised was the implementation of the New Economic Policy in 1970 . Jamilah (1981) claims that "since its implementation, reports on the composition of the labour force of manufacturing industries showed that more than 50 percent of the unskilled workers are Malays and in the case of firms employing a majority of female workers, most of them are Malay girls from rural areas" (Jamilah, 1981, p. 19). The majority of firms were set up in urban areas and this greatly sped up the rate and volume of single Malay female migration to urban areas. These labour-intensive firms preferred rural female labour for reasons such as: they can be dislocated from their social context, be paid lower wages than males and can be easily trained and hired (Jamilah, 1981, p. 19)

\footnotetext{
5 A disastrous riot took place in Malaysia in May 1969 due to dissatisfaction with certain ethnic issues. One part of that policy has been the enforcement of rules for new industries (with pioneer status) which ensure that 30 percent of their workforce should consist of Malay workers.
} 
As early as 1970, women in Malaysia accounted for 40 percent of the plantation workers which accounted for 16 percent of the total agricultural labour force (Boserup, 1970). Agriculture continued to be the mainstay of the economy until the introduction of the New Economic Policy in the 1970s. The spill over effect of demand side factors, such as more job opportunities and supply side factors, such as increasing enthusiasm (Boserup, 1970), increasing educational achievement (Siti Rohani, 2009, p.26) and change in attitude (Jamilah, 2009, p.85) resulted in an increase in women's participation in the labour force. With increased opportunities of education, industrialisation played a significant and mutually inter-effective role in the development of the country (Shaban, 1997). Early studies of women in the manufacturing sector in Malaysia by Hirschman and Aghajanian (1980), Jamilah (1982) and Jones (1984) also highlighted women in the manufacturing sector doing assembly line jobs which were repetitive, monotonous, unskilled and low paid.

Favourable economic conditions resulting in high rates of Gross Domestic Product (GDP) growth, and structural changes together with the government policy resulted in more employment creation, especially among women workers. The average annual growth rate for Malaysia which dropped to 2.17 percent for the 20002010 period as compared with 2.6 percent for 1980-1991, saw a population increase from 13.8 million in 1980 to 28.6 million in 2011, resulting in an increase of labour supply from 7 million in 1990 to 12.9 million in 2011 (DOS, Malaysia, 2010).

In recent years, Malaysia's continuing industrial growth has seen a tightening labour supply, higher wages and a shift to higher skilled work. Due to this relative labour shortage, women have been able to tap into this new labour market and secure better returns and conditions. Employers continue to employ women not only because of their distinct perceived characteristics such as being malleable, obedient, disciplined and conscientious (Lim, 1978; Jamilah, 1978), were evident in the 1970s, but also because they were readily available and had the required skills. As labour market pressures tightened further, some employers began to explore ways to attract more women into employment. 
The Millennium Declaration ${ }^{6}$ made a strong commitment to the right to development, to gender equality and the empowerment of women, to the eradication of the many dimensions of poverty, and to sustainable human development. This pledge became the eight Millennium Development Goals (MDG) to be achieved by 2015. In terms of MDG Target 3, i.e., "To promote gender equality and empower women", Malaysia has done well in achieving virtual gender parity in access to education for boys and girls. However, women's participation in the labour force has stagnated over the past 25 years at 45-50 percent. Besides, evidence of gender disparity in terms of earning prevailed. For example in 2007, women earned 28 percent less than men and this shows very little change compared to 1997 (UN, 2011).

Despite its rapid industrialisation and relative prosperity, Malaysia's low female labour force participation rate reflects women's multiple responsibilities and possibly more limited job opportunities (UN, 2011), resulting in women being relatively underrepresented in the labour force in comparison to most countries in the Asia Pacific region. In fact, female labour force participation rates have stagnated at a constant rate of 46 percent -47 percent in the last three decades. Latest official statistics show that the labour force participation rate (LFPR) for women was 46.4 percent in 2010 (a slight fall from 47.8\% in 1990). This is considered low in sharp contrast to the neighbouring South East Asian countries of Thailand, Brunei Darussalam, Singapore, Indonesia and Philippines where the corresponding figures are $66 \%, 60 \%, 56 \%, 52 \%$ and $49 \%$ respectively. Furthermore, females have been disproportionately concentrated in community services, working as nurses, teachers and social workers (DOS, Malaysia, 2010).

\footnotetext{
${ }^{6}$ The Millennium Development Goals (MDGs) was adopted by world leaders in the year 2000 and set to be achieved by 2015. 189 nations made a promise to free people from extreme poverty and multiple deprivations with the main aim to provide concrete, numerical benchmarks for tackling extreme poverty in its many dimensions. In Malaysia, The Millennium Development Universal Goal for primary education was achieved by 1990 , by which time nearly all children were completing primary school, greatly improving on the one-third of the population 6 years of age and over that had never attended school in 1970. Attendance of girls had already caught up with that of boys by 1970 and had increasingly exceeded that of boys at secondary and tertiary levels. Employment rates of males and females partly reflect this trend but women's multiple responsibilities and more limited job opportunities mean that women are relatively underrepresented in the labour force (UN, 2011).
} 
While the manufacturing sector became the leading sector in terms of employment between 1970 and 1980, it also was the largest sector in terms of job creation between 1985 and 1995 (Manning, 1977; Jomo \& Kanapathy, 1999). However, in the last decade, the services sector played a more important role in both male and female employment and took the lead to become the biggest employer of women in the labour force. Hence, female labour force participation was duly affected by the shift in the Malaysian government's policy from an industrial labour intensive manufacturing strategy of the 1970s and 1980s to a knowledge and service based economy in the 1990s and beyond. However, the liberalisation of the services sector will not benefit the majority of women workers who either do not have the necessary new skills or who are unable to adapt themselves from their usual jobs in the sunset manufacturing industries in Malaysia to fit into the new jobs in the knowledge economy.

Aminah (1999) noted that female labour force participation rates at all age groups showed a constant increase in the 1990s, but the scenario has slightly changed since 2002 where the female participation rate showed an upward trend in the 20-30 years age group but showed a declining rate in the 30-55 years age group. The double peak inverted " $M$ " shape which is evident in most countries became single peaked at 30 years, since the mid 1990s.

The questions to be explored in this study are whether work arrangements which are flexible will be able to meet the demands of the employers and to what extent will women employees be able to benefit from such work arrangements.

\subsubsection{Why Flexible Working Arrangements?}

Flexible working arrangements (FWA) are about people having the opportunity to make changes to the hours employees work (over a day, a week or over the year), the times they work or where they work. It is also about how careers are organised, how transitions in and out of work are managed, and how flexible work is managed in the workplace so that both the employees and businesses benefit. 
Examples of quality flexible work include: varying starting and finishing time; annualised hours or term time working; part-time working; working from home or teleworking; job sharing; selecting or influencing own rosters or shifts; flexible break provisions and flexible leave/time off provisions, both paid and unpaid (New Zealand, Department of Labour, 2006).

Even though FWA is a more common phenomenon in western countries compared to Asian countries, some countries such as Hong Kong practise it to relieve traffic congestion. As a consequence, it results in better working spirit and work performance among employees (Hau \& Chew, 2006).

Studies in Western literature have shown that "spending time with family" was one of the main reasons cited by women who stopped working (Cole, 2006; Hotchkiss, 2006). This is also reiterated in the case of Malaysia where the fact remains that inflexibility at workplace and inability to balance work-life and home career are important factors why married women leave the labour force (Kaur, 2004; Jamilah, 2009). FWA such as flexitime and part-time work may provide married women with young children who require the greatest parental time, to balance work and home (Hill, et al., 2004).

Government policies and good corporate social responsibility practices include achieving an ideal work-life balance. At a policy level, the Malaysian government is officially committed to gender equality as articulated in the National Government five year plans, especially the present one. This calls for a solution which is already being practised widely in developed countries for several decades quite successfully (Liddicott, 2003). While countries such as the United Kingdom, Northern Ireland, Europe, the United States, Australia and New Zealand ${ }^{7}$ have been incorporating workplace flexibility for a long time, this working arrangement is new in the Malaysian working environment (NACEW, 2007).

7 The National Advisory Council on the Employment of Women (NACEW) reviews literature and FWA from relevant literature in New Zealand, Australia, the United Kingdom, Northern Ireland, Republic of Ireland and Canada. This report was prepared for the New Zealand Government in October 2007. 


\subsection{Problem Statement}

Various studies on women in Malaysia reveal that economic progress and industrial development since the implementation of the New Economic Policy in 1970 have improved the socio-economic status of women in Malaysia (Siti Rohani, 2009; Ng, 1999; Husna, 1994). Female labour force participation has increased from 37.2 percent in 1970 to 47.8 percent in 1990 and showed an average of $47.8 \%$ in the 1990s until mid-2000 before dropping to 46.4 percent in 2010. As asked rhetorically by Fatimah and Sumitha (1994), is this growth rate of 28.5 percent a figure to boast about? At the same time, it is also noted that more than half of the female population is still outside the labour force.

As Malaysia's vision is to move from an upper middle income economy to a high income economy by 2020 under the New Economic Model (NEM) launched by the Prime Minister in the first quarter of 2010, the main thrust is on the development of human capital. This new model is largely aimed at shifting the country's reliance from a manufacturing base with heavy focus on low and semi-skilled labour to one which focuses on high technology and a modern service sector with skilled and educated workers who are highly paid. To become a high income economy, the required human capital must have high productivity and be creative and innovative. This speaks well for Malaysian women, who on an average have a minimum of eleven years of schooling and dominate the public and private universities. In addition, Malaysia's female literacy rate has increased from 64.7 percent in 1980 to 88.1 percent in 2009 (DOS, Malaysia, 2010) and a majority of them have a minimum of eleven years of education.

In the Ninth Malaysia Plan (2006-2010) ${ }^{8}$, the Government acknowledges the fact that women play an important role in the socio-economic development of

\footnotetext{
8 The Ninth Malaysia Plan is a comprehensive blueprint prepared by the Economic Planning Unit (EPU) of the Prime Minister's Department and the Finance Ministry of Malaysia. It basically explains how the government allocates the budget for every five years to all economic sectors in the country. These Five Year government Plans are national development initiatives which are a legacy from the British colonial rule in Malaya after the Second World War. The five-year plan began with the First Malaya Plan from 1956 to 1960 and has been continuing every five years until now. We are currently in the Eleventh Malaysia Plan (2011 - 2015).
} 
Malaysia. One of the nine strategic thrusts in relation to the participation of women is to promote greater female participation in the labour force. The recommendation was through the provision of family friendly policies and more conducive working arrangements such as flexible working arrangements including teleworking, parttime work and job sharing.

The central research question in this study is "Can FWA have an impact on women's paid labour and unpaid labour?". This was investigated in the context of whether the women are interested in the uptake of FWA at their workplace. This was discussed in a more comprehensive setting of the private domain of work-life balance and the public domain of the Malaysian labour market.

Studies in Malaysia and other parts of the world have shown that flexible working arrangements are beneficial to both employers and employees. Despite efforts made by the Government, few employers (government agencies included) implement family friendly policies such as flexitime, part-time, working from the home and childcare facilities. Fewer still are willing to retain positions for women who take leave in excess of their entitlement, let alone ensure that their seniority is intact. While the Ministry of Human Resources is encouraging the private sector to implement flexible working arrangements and part-time work, many employers are actually not responding to the call of the Ministry. This thesis argues that we need to dispel the myth that FWA are not feasible for developing nations like Malaysia.

How can FWA help working women achieve work-life balance? If more organisations implement some form of flexible working arrangements, will it help more women to participate in paid labour? Will family friendly policies such as FWA encourage more women to continue being in paid labour?

Based on the above description, some questions to be explored in this study are: whether Malaysian women are interested in work arrangements which are flexible, and if so, who are these women who are interested in the uptake of FWA? Will these work arrangements which are flexible, be able to meet the demands of the employers? Additionally, to what extent will women employees be able to benefit 
from such work arrangements? If employers do provide FWA, will more women participate in the labour force? Or will women continue to juggle work and home? Will women's socio-economic status be improved or will they be marginalised further?

As mentioned earlier, there are very few empirical studies done on this topic in Malaysia. As such, it is necessary to resort to the findings from the western countries as a guide. This study will try to fill in the gap by examining whether the new phase of high technology industrialisation in Malaysia may be able to adapt to a change in work practices which are more flexible for the employer and the women and whether this might benefit the women and their well-being.

\section{$1.4 \quad$ Objectives of Study}

The idea of wanting to investigate this issue originated from the labour statistics which show that the female labour force participation rates have shown a downward trend in the last four years. While the research relates primarily to the women in the services sector, the issues raised would be relevant to the general population of women in Malaysia. The study sought to investigate the main reasons behind the low female labour force participation rates and whether FWA may increase women's participation in the labour force. In the course of study, some underlying behaviours of working women who are trying to cope with work and family were found, which to a certain extent, explained possible causes of other women exiting the labour force.

\subsubsection{Main Objective}

The main aim of this thesis is to investigate whether flexible working arrangements may contribute to an increase in women's labour force participation in the context of the development of the Malaysian economy. It sets out to examine whether women who have a minimum of eleven years of education are interested in flexible working arrangements and then further 
examines whether there is any impact on women's life and their socioeconomic status.

\subsubsection{Specific objectives}

1. To investigate the factors which influence the desire to take up flexible working arrangements by women employees at the workplace.

2. To assess whether the availability of flexible working arrangements might contribute to the decision among women employees to participate in the labour force.

3. To examine whether flexible working arrangements may have an impact on selected indicators of women's well-being such as worklife balance, lifestyles and empowerment.

\subsection{Research Questions}

To achieve the above mentioned objectives, this study attempts to answer the following research questions:-

1. What are the factors which affect the extent to which women employees will be interested in the uptake of flexible working arrangements?

2. What are the characteristics of women who are most interested in exploiting flexible working arrangements and what sectors of the labour market are best able to offer such arrangements?

3. How do women use flexible working arrangements to juggle their other demands?

4. How do flexible working arrangements operate in Malaysia and how well are they working for women employees?

5. How is flexible work for women linked to other parts of the labour market, especially the demand for paid domestic work?

6. How do women perceive the benefits they might achieve in their wellbeing in terms of work-life balance, empowerment and lifestyles? 


\subsection{Research Methods}

This study uses a mixed method to achieve the three objectives of this thesis. To achieve the first objective, that is to investigate the factors which influence the desire to take up FWA by women employees at the workplace, a questionnaire survey was done in fourteen organisations in the services sector. Data from 396 samples was analysed using logistic regression.

Data from the same sample was used to answer the second objective to assess whether the availability of FWA might contribute to the decision among women employees to participate in the labour force. Using descriptive statistics, cross tabulation and independent t-test, this objective was achieved.

While the first and second objectives used data from quantitative research, for the third objective to examine whether FWA may have an impact on selected indicators of women's well-being such as work-life balance, lifestyles and empowerment, a qualitative study was done. A structured interview questionnaire was given to thirty identified respondents from the 396 respondents who answered the survey questionnaire.

The detailed research method and methodology applied to achieve the three objectives are explained in Chapter Four.

\subsection{Significance of Study}

This thesis hopes to present evidence of the extent to which working women in Malaysia are interested in FWA by challenging perception with statistics and also by providing sound statistical data on the factors involved.

Secondly, elements of this thesis might help organisations contemplating different work arrangement strategies in the implications of providing flexible working arrangements at their workplaces. 
Thirdly, studies have looked at FWA and its advantages and disadvantages (Liddicott, 2003; Nadeem \& Hendry, 2003; Kapler \& Almer, 2000), its implementation at firm level (Hau \& Chew, 2006) and at macro level, but these are studies at the international level. This thesis will shed some light on FWA and Malaysian women in the services sector and will significantly contribute to new knowledge by filling and reducing the gap that exists in the current literature. This study will also contribute to the body of knowledge about working arrangements in Malaysia.

Fourthly, there has been considerable debate on FWA and its implications on female labour. This study will contribute to the literature on FWA in Malaysia, not only in terms of how it will benefit female employees, but also show how it will allow women to juggle work and home.

In summary, in a developing country like Malaysia where the government is looking at how to tap their own potential human resources by using women labour, this thesis seeks to contribute policy input for the government.

\subsection{Structure of the Thesis}

Chapter One introduces the topic, the rationale for the study, the research objectives, scope of study and outlines the structure of the study.

Chapter Two reviews the literature on the meaning of development and women's work in terms of their working hours. It also sets to identify the variables concerned in formulating the framework of the thesis. Subsequently, it will discuss theoretical models which influence women and work and provide a comprehensive background for this study.

Chapter Three presents an overview of the industrialisation process in Malaysia and prepares the setting for the development and the entrance of women into the labour force. 
Chapter Four outlines the research design and describes the methods and techniques used in this study to achieve the research objectives and research questions.

Chapter Five discusses the findings of the impact of flexible working arrangements on the uptake of FWA among female employees in selected industries in the services sector. It also further discuses findings on whether it will have an impact on women participating in the labour force. Data is analysed using logistic regression and t-tests.

Chapter Six discusses findings of the impact of FWA on women's well-being based on certain selected indicators. The analysis is based on results from both quantitative analysis and qualitative interviews.

Chapter Seven summarises the findings and highlights the emerging issues with discussions and draws possible conclusions and policy recommendations.

Chapter Eight presents the conclusion and directions for future research.

In carrying out the research, an interdisciplinary perspective approach was used to examine whether FWA will enable more women to participate in the labour force in Malaysia. If more women do enter the labour force, the effects on the women is examined briefly from a gender perspective. Also, if women have FWA, the impact on women, family and the country is described from the economic view point. Finally and most importantly, as this study is examined in the context of the development process of the nation, a post modern approach comes to place in the whole dynamics of the development process, women and FWA. The following chapter reviews literature on development theories and presents past research on FWA which forms the basis of this study. 


\section{Chapter 2}

\section{Literature Review}

\subsection{Introduction}

This chapter reviews development literature and development theories, particularly with reference to women and work in the light of FWA. Three distinct theoretical models which explain women and work are outlined to provide conceptual insights into the changes in women's work at home and the workplace. The origin of FWA, the reasons for starting FWA systems, the costs and benefits of FWA and related concepts are dealt with to provide a background on FWA. By looking at women's participation in the labour force from the economic and development perspective, the review provides a background to the current research which aims to study whether FWA at the workplace will encourage women to participate in paid labour and how they may benefit women.

\subsection{Development Concepts and Theories - An Overview}

This section does not attempt to present a comprehensive discussion on development theories but rather presents an overview of development concepts and theories which are related to women and development. It sets the stage for current conditions of women and work, particularly FWA.

\subsubsection{Mainstream Development}

The concept of development is complex and multidisciplinary, being informed by different viewpoints from both Western and Third World countries. The concept of development became popular when Harry S. Truman became the President of United States in 1949 (Esteva, 1992). He actually coined the word "underdeveloped" and in his inaugural speech declared that: 
"We must embark on a bold new programme for making the benefits of our scientific advances and industrial progress available for the improvement and growth of underdeveloped areas" (Truman, 1949 cited in Esteva, 1992, p. 6).

But the problem of the underdeveloped countries is not growth, but development.

However, development is a term often associated with growth and directional change in an economy (McMichael, 2000, p. 3). Development is growth plus change and is generally characterised as changes occurring to some or all of the governing beliefs of societies (religious to secular rule), spatial patterns (rural to urban) or material means (animal to machine power) and associated with a Western lifestyle. Seers' (1969) characteristics of development are widely accepted as the reduction and elimination of poverty, inequality and unemployment within a growing economy. Such outcomes are development because they mean improved quality of life for all.

According to Todaro and Smith (2009), in economic terms, development has traditionally been defined "as the capacity of a national economy, whose initial economic condition has been more or less static for a long time, to generate and sustain an annual increase in its Gross National Income (GNI), at rates of 5 percent to 7 percent or more" (2009, p. 14). Another economic index of development commonly used is the rate of growth of income per capita. Many agree that "the complexity and the quality of developmental processes cannot be gauged using a single instrument such as Gross Domestic Product (GDP) or Gross National Income (GNI) per capita" (Greig, Hulme \& Turner, 2007, p. 37).

Further to this, the experience of the 1950s and 1960s in many developing nations showed that GNI is a narrow measure of economic welfare which had to be amended. In the 1970s, "redistribution can foster growth" was a common slogan and all policymakers placed emphasis on development to include reduction of poverty, inequality issues and unemployment (Aghion, Caroli \& Garcia-Penalosa, 1999). Todaro and Smith's (2009) definition of development as a "multidimensional 
process involving major changes in social structures, popular attitudes and national institutions" is apt in this context. That approach in their definition encompasses other dimensions of development beyond economic development to include "the whole gamut of change by which an entire social system moves away from a condition of life widely perceived as unsatisfactory toward a situation or condition of life regarded as materially and spiritually better " (Todaro and Smith, 2009, p. 15).

Based on the above discussion, it should be kept in mind that development and economic growth involve much more than a rise in per capita income and there can be no development without economic growth. Achieving full employment and economic growth was more an interventionist approach for classical economists such as Adam Smith and David Ricardo. They subscribed to free market and free trade as a means to bring benefit to everyone with specialisation as the core factor. However, the experience of the Great Depression in the 1930s resulted in Keynesian theory which instead emphasised the role of the state in achieving equilibrium. This is in line with Roosevelt's theory in the 1930s which also showed that government intervention is very important to achieve economic growth.

Underlying the approach of developmentalism is the ideology of modernisation and economic idea of dualism. Modernisation theory basically defines modernisation as a progressive and lengthy process where modern societies are more productive, with better educated children and better welfare for the needy (Reyes, 2001). To Reyes, development is a "social condition within a nation, in which the authentic needs of its population are satisfied by the rational and sustainable use of natural resources and systems" (Reyes, 2001, p. 1).

The economic theory of modernisation, which is based on Rostow's five stages of development growth model, was very popular in the 1950s but faced heavy criticisms by the end of 1960s. Rostow, one of the most influential of the neoclassical economists, believed that industrialisation was the engine of growth. While the advanced countries had passed the "take-off into self-sustaining growth" stage, the underdeveloped countries were only still in the "preconditions" and had to follow a set of rules to go to the "self-sustaining growth stage"(Todaro and Smith, 2009). 
However, Rostow's five stage economic growth model was often criticised for two reasons. Firstly, with regard to direction, the criticism centres around the assumption of ethnocentrism and the possibility that economic and social progress should work well in all countries. Critics argue that development is not necessarily unidirectional as postulated by the ethnocentricity of Rostow's growth model (Reyes, 2001, p. 113). Secondly, the development model was based on western economies such as the United States but used for developing countries (Todaro \& Smith, 2009). The critics further argued that Asian countries such as Taiwan and South Korea have achieved high development levels and too often there is a tendency to equate modernisation with becoming like the United States or Western Europe (Gillis, Perkins, Roemer \& Snodgrass, 1996).

On the other hand, both Arthur Lewis' dual sector model and the Harrod Domar Growth model showed that the modern urban industrial sector is the only way to development even though this may result in inequalities which will be a short term phenomenon. While the dual sector model was the first neo classical model to tie up with development, the Harrod Domar Growth model showed that investment from savings, whether internal or from foreign sources, is crucial for development (Todaro \& Smith, 2009). However, this model does not describe labour explicitly because it is assumed that labour is abundant in a developing country and hence female labour was also not given attention. On the other hand, the Arthur Lewis dual sector model is assumed to be self-sustaining growth and employment where the surplus labour is absorbed in the new industrial sector. But this model has criticisms based on its four assumptions ${ }^{9}$.

The modernisation school which emerged in the late 1950s combines a sociological, economic and political approach. Reyes ${ }^{10}$ (2001) highlights four principal theoretical explanations to interpret development efforts carried out

\footnotetext{
9 Please see Todaro and Smith (2009, p.118)) for the four major criticisms.

${ }^{10}$ Reyes (2001) gives a very detailed explanation of three main features of modern societies as well as three classical assumptions modernisation theory based on structuralism. Firstly, modernization is a systematic process which has to be a consistent whole and appear in a cluster rather than in isolation. Secondly, it is a transformative process whereby society has to move from a traditional structure to be totally replaced by modern values. Thirdly, it is an imminent process due to its systematic and transformative nature.
} 
especially in the developing countries which clarify concepts and set them in economic and social perspectives. The four main theories of development are modernisation, dependency, world systems and globalisation.

\subsubsection{Dependency Theory}

The Dependency theory, which evolved in the 1960s, came about with the work of Gunder Frank (Blomstrom \& Hettne, 1984). Dissatisfaction with the modernisation approach led to the emergence of another more critical school of thought, that is the dependency school. The dependency theory, which came into play towards the end of the $20^{\text {th }}$ century, has two major intellectual streams, namely a Marxist stream which were classical theories of imperialism and a structuralist stream combining elements from a neo-Marxist perspective with Keynes economic theory.

The main critique of the dependency theory is that their assumptions are based on results of nation-state (Reyes, 2001). The critique here is that free trade and free market had unequal impacts and the benefits did not reach everyone, especially women. This is also what has been highlighted by WAD analysts.

\subsubsection{Neoliberalism and Globalisation}

Slightly different is the Theory of Globalisation which argues that the main modern element for development is the cultural communication link between nations, which is provided by increasing the flexibility of technology to connect people around the world. Globalisation scholars assert that the main modern elements for development are the cultural links among nations which is mainly attributed to the increasing flexibility of technology (Kaplan, B., 1993 as cited in Reyes, 2001). Technology which possibly results in a more innovated society "does not merely add something but it changes everything” (Jane, 1982).

The globalisation and world systems theories take into account recent economic changes, both in terms of world structure and relations in the last few 
decades. Reyes (2001) summarises three principal features of globalisation. Firstly, he sees cultural factors as the most important determinant in every society. Secondly, he reiterates that with technological advances, increased global communications and international ties, the nation-state should not be a unit of analysis any more. Thirdly, with more technological advancement, social sectors will be able to connect more easily with other groups around the world (Reyes, 2001).

The crucial point to note here is that both classical and Keynesian theories looked at growth without any referral to the real meaning of development. It was only the neo classical economists that gave thought to development, economic growth, industrialisation and increased labour force and they emerged in the 1980s when the the economic crisis of the 1970s set the critics to point at the possible flaws of the Keynesian policies and eventually led to a neo liberalism approach with minimal state intervention, less government expenditure, lower taxes and lower interest rates. This monetarist approach emphasised economic liberalism which saw free market and free trade as the main means for development, in addition to deregulation, privatisation, supply side economics and radical conservatism.

However, definitions of globalisation and its merits vary in literature.

For example, Martin Khor (1995) President of the Third World Network in Malaysia, referred to globalisation as colonisation. Concurrently, Swedish journalist Thomas Larsson, in his book The Race to the Top: The Real Story of Globalization (2001) explains how globalisation causes a shrinkage, of distances getting shorter, things moving closer and easier to interact with others. These two different interpretations reflect different perspectives rooted in different world positions.

It is true that "development and economic growth which are active goals rather than natural processes" of development became a universal strategy only in mid-twentieth century with globalisation (McMichael, 2000, p. xli). In an era of rethinking development, and the world's growing concern on environment and sustainability, McMichael (2000) advocates two responses. Firstly, he "advocates a global marketplace for trade and spread wealth". Secondly, is the need to "to re- 
evaluate the economic emphasis and to recover a sense of cultural community". As McMichael argues critically, "the development debate is re-forming around a conflict between privileging the global market and privileging human communities". His argument centres around whether "we are expanding industry and wealth or are we focussing on human communities in terms of achieving social intimacy, spiritual coherence, healthy environments and sustainable material practices?" (McMichael, 2000, p. xlii).

Development can be explained differently referring to the contextual meaning but no matter how it is explained, it refers to something positive and "brings material and psychological improvements" (McMichael, 2000, p. 3). For example, from the perspective of the cybernetic age, development is associated with technological progress, and from the perspective of an economist, it means growth. Development should not be always evaluated in terms of outcomes and physical gains such as incomes, physical goods or services but also in terms of what people gain or lose and who loses out.

The emergence of the newly industrialising countries from a global perspective represented upward mobility of some countries in the economic hierarchy and also caused a redefinition of the term "development". McMichael (2000) discussed two notable trends until the 1970s. Firstly, the gap between the First World and the Third World was increasing and secondly, some Third World countries were strategising to reduce the gap by exporting manufactured products.

The 1980s debt crisis incubated a new direction in the world capitalist order requiring institutional supports. The new global regulatory system or termed as "globalisation project" by McMichael (2000), had six strands and saw the importance of multilateral agencies such as the World Bank, the International Monetary Fund (IMF) and the World Trade Organisation (WTO). The Washington Consensus of the early 1990s saw the setting up of three agencies with US treasury as the main funding body with UN Agencies, IMF and World Bank. These policies were actually structural adjustment policies to aid development. Development critics' ideas (like Seers and others) became increasingly prominent in the late 1980s 
and early 1990s along with awareness against structural adjustment programmes and other financial reforms.

\subsubsection{Alternative Development}

It was noted that problems like poverty and unemployment in the Third World were not explained by development theories. This saw the mainstream theories of development slowly moving from economic growth toward an interest in human development (Verma, 2004). Oakley and Marsden (1984) claim that alternative development is "People-based development from below" (which also entails empowerment and problem solving (Oakley \& Marsden, 1984, p.10). The term development no longer pivots on the adequacy of the market sustainability in terms of social and environment but moves to broader issues such as human community and governance (Verma, 2004, p.186). However, development indicators have evolved considerably since the 1960s and this evolution has been inter-woven with disputes on the meaning of development. A major feature of this has been the contrast between economic indicators such as per capita income on one hand and broader views of development and well-being which include social and psychological dimensions at their centre on the other hand. Most recently, a newly emerging focus is on the distinction between universal or objective well-being and subjective or context specific well-being.

For example, Nafziger (2006) compares perspectives on the meaning of development in the late 1970 s and early 1980 s to the contemporary period by focussing on the works of Seers and Sen. In his WIDER-UNU paper, he highlights two major critical differences on development literature of the times of Seers and Sen. The differences were compared in terms of universal claims and purpose of development ${ }^{11}$. According to Seers (1979), the purpose of development is to reduce

\footnotetext{
${ }^{11}$ Seers and Sen were critical of the development literature of their times. For Seers (1979), "neoclassical economics had a flawed paradigm and dependency theory a lack of policy realism". After the fall of state socialism in 1989-91, the ideological struggles among economists diminished. Neoclassicism's Washington Consensus of the World Bank, IMF, and the USA government reigned (Williamson 1993: 1329-36; 1994: 26-8). However, Sen (1999) did not focus on ideological issues
} 
poverty, inequality, and unemployment. On the other hand, for Sen (1999), development involves reducing deprivation or broadening choice.

Sen's major theme which needs to be emphasised here is that development should go beyond material progress to include social development and social justice, which he argues can be done by focussing on "functionings" and "capabilities" of individuals. Functionings can be viewed as a person's states of being and doing, which include a broad range of individual actions and conditions that a person has reason to value, being healthy and avoiding premature mortality, among others. On the other hand, capabilities can be viewed as all states of being and doing available to a person. This notion of capabilities broadens the information base used to assess economic welfare, while the "capability set" can be seen as a mathematical representation of freedom for formal analysis. Sen (1999), further emphasises the intrinsic importance of human freedom as a preeminent objective of development which is different from the role of freedom seen as an instrument of development.

Sen (1999) in his book, Development as Freedom, adds another dimension to the term "development" to assert that development should be seen as "a process expanding freedom" and hence "the well-being of human should be at centre stage as both the goal and the means for development" (Sen, 1999, p. 14). Sen points out the important interconnections between the different dimensions of women's freedom and how their ability to participate in paid labour may enhance the social standing of a woman in the household and also society. Sen believes that recognition of political, economic and social participation and leadership of women is a very crucial aspect of development. This brings us to the fundamental questions of, "What is good for a person? What is good for society? What is good for women?" (Sen, 1999, p. 195).

For example, Waring (1999) a classic feminist analyst clearly argues about how the accounting processes and the traditional economic growth theory overlooks the importance of the environment and half the world's population, namely women. Women's labour contribution has been excluded from the economic systems and in 
her book Counting for Nothing : What Men Value and What Women Are Worth she offers an explanation of the current economic systems of accounting and ways women should receive the recognition they deserve in the world economy.

Some conclusions from this section show that development remains a much debated concept, undergoing ideological, theoretical and practical evolutions.

Since 1949, the concept of development has experienced shifts in meaning, aims and outcomes in response to global changes. It has moved from its focus on economic growth to a more human centred measurement. At the same time, development goals have shifted from achieving growth, equality and employment to include provision of health care, education, skills and basic human needs.

While the modernisation theory in the early 1970s had its emphasis on economic growth and industrialisation, neoliberalism in the 1980s and 1990s went further to include labour force. Beyond the 1990s, the dependence theory critiques highlighted the unequal impact of free trade and free market which led to the globalisation theory. Eventually, the alternative development theorists such as Sen, Verma and others emphasised human development, well-being and capabilities. In addition, feminist theorists such as Waring (1999) highlighted the exclusion of women's contribution in GDP calculation and Moser (1999) highlighted women's triple roles and empowerment.

Although these structural changes and development phases have taken place only in the last few decades, two questions have emerged. Firstly, what implications do they have for women and development? Secondly, how did they impact women and development, especially in a developing country? The alternative development approach which includes dimensions of human and their well-being mirrors the WID, WAD and GAD models which will be discussed in the next section. 


\subsection{A Survey of Theoretical Debates on Gender and Development Models}

In order to understand the multidisciplinary nature of the way women and development has evolved, certain theoretical perspectives are discussed using the "women in development" (WID), "women and development" (WAD), and "gender and development" (GAD) models. These models have been around for a while but these three models are useful in explaining women and development processes. The movement to integrate women into development began in the 1970s with the first United Nations world conference in Mexico City in 1975. This movement known as Women In Development (WID), focussed on including women in existing development programmes (McMichael, 2000, p. 260).

\subsubsection{Women in Development (WID)}

The oldest and the most dominant perspective is the WID model which subscribes to the modernisation theory where the individuals are the catalysts for social change, although they were all influenced by western values (Visvanathan, 2000). Even though this approach was linked strongly to the modernisation theory, by mid 1970s, it was noted that the women did not benefit from development strategies and the development process. Critics highlight that women's productive role was emphasised and strategies implemented focussed on minimising disadvantages of women in the productive sector only. Class, race and culture were overlooked and most importantly, women's reproductive side was ignored.

The WID movement "changed gears" as Jahan (1995)(as cited in McMichael, 2000, p. 206), terms from an "integrationist approach" to an "agenda-setting approach" which involves women as decision makers who are empowered, symbolising a movement from remedies to alternatives. WID feminism tends to accept the developmentalist framework and identifies ways to improve the position of women. The impetus for pushing for more jobs in paid labour was because women's unpaid work was not contributing to livelihoods. Within the WID paradigm, women are presumed to be subordinate to men and only further 
development may lead to women's emancipation. But this perspective may not be true when comparing women in developing countries against the ideal of women in developed countries. In other words, women's role in development, their ability to work in paid labour as well as work at home with minimal help and women's role in sustaining cultural and ecological relations are complex issues, which are place specific and incapable of being reduced to universal formulas.

One of the earliest studies to look at the economic roles of women in developing countries was conducted in 1970 by Boserup who strongly argued that economic development of a nation leads ultimately towards a more intricate specialisation and division of labour outside the individual household. Boserup (1970), was one of the early liberal economists who highlighted women's occupational role outside the house. Boserup's (1970) original "Women in Development" (WID) paradigm has changed over time. If technology and macro structural changes were the focus of earlier scholars, family has become the center of attention of more recent scholars (Mason, 1984). Numerous empirical studies have been done on the effects of women's childbearing and child rearing activities on their paid work. In the light of the world wide demographic change and economic development, the salience of women's childbearing responsibilities is fast declining. What is perhaps more becoming appropriate now is how the women juggle both the paid work and the unpaid work.

In the 1950s, when scholars and policy makers had began to discuss the meaning of development for most of the world, the role of women in development was barely addressed and even less frequently understood. Only since the 1970s have development discussions focussed on the majority of the human race, women. Now the phrase "women and development" is used so widely that it seems faddish (Charlton, 1984).

By the 1970s, the growing interest in women's issues manifested in different ways. In the first of these, Boserup in her Women's Role in Economic Development (1970), helped to put women and development into an international context by clarifying both the human dimension of economic development and the policy issues raised by the development projects undertaken in the 1960s. In the second half of the 
1970s, the 1975 International Women's Year represented a turning point in women's issues. For some, it was a natural outgrowth of the new visibility of women and their role in development and concerns that had been dramatised by women's movement in the late 1960s and 1970s. For others, it was a way of responding to women's demands. The fundamental questions posed by the women's movements could not be disregarded any longer. An unprecedented amount of research programmes and policies addressing specific issues had sprung up during the 1970s (Beneria Lourdes, 1972).

The existence of hierarchy of gender roles with men at the skilled, supervisory positions and women in the unskilled, subordinate positions were evident in both developing and industrialising countries, especially in the urban sector. The development process resulted in fundamental changes in the process of work globally.

Bandrage (1984), for example, critically evaluates the liberal feminists who claimed that the WID framework was used by focussing on sexual inequality and overlooking gender inequalities which were caused by socio-economic and structural factors. However, another school of thought (Beneria and Sen, 2000), very critically conclude that discrimination against women can be overcome eventually if they are given access to technology and jobs, but they also overlooked the meaning of the term "gender".

\subsubsection{Women and Development (WAD)}

From the critiques of the WID model emerged a new school of thought known as the "Women and Development" (WAD) model in the second half of the 1970s, which drew its base from the dependency theory. This model which primarily focuses on the relationship between women and development process assumes that once international structures become more equitable, women's position would improve. The WAD model accepts women's economic contribution as important and recognises women's work in the public and private domain as central to the 
maintenance of societal structures. However, this model failed to analyse the relationship between patriarchy, modes of production, and women's suppression and relegation to the lower levels of paid work. This model which is based on dependency theory originally relates to the core-periphery dynamics where the developed nation or the First World is the core and the developing nation or the third world is the periphery.

WAD models incorporate women in the lower rung of the occupational ladder which leads to suppression. Do the women have autonomy on choosing the work? How can FWA change women's position for the better in the society? How are women constructed socially in society? This leads one to suggest that the GAD approach may be a better approach to place women in terms of family context as it involves women in the development process.

\subsubsection{Gender and Development (GAD)}

As an alternative to the WAD model, the third major theoretical track emerged in the 1980s representing the confluence of various feminist perspectives known as "Gender and Development" (GAD). The GAD model is a more holistic way of treating development as a process influenced by not only political forces but also socio-economic forces. Being a more interventionist approach, the state is expected to assume a critical role in providing programmes to support the work of social production and go beyond economic well-being.

For example, Charlton (2000) argues that Marxist-feminists link patriarchal control within the family to the gender division of labour. As men become more involved in the production for exchange or the public sphere, women tend to concentrate more on housework or the private sphere. However, she reiterates very clearly that the private/public dichotomy which exists until present times depends very much on how much power and influence the women have. Along the same line of thought is Engels' account that women's oppression was not 'natural' but it was formed from societal structures. Jamilah (1994), in her detailed study on young, 
Malay female factory workers in Malaysia refutes Engel's theory which claims that women's participation in paid labour will allow them to be freed and emancipated. On the contrary, she concurs that patriarchal ideology is further perpetuated and women are consciously made subordinate to men.

Like development studies, the field of women's studies is a combination of disciplines. As Visvanathan (2000), points out, even though the western influence had direct effects on women in terms of more opportunities from the inflow of multinational corporations, it also presented disadvantages by urbanisation and migration.

In summary, a few emerging questions can be drawn from the three models. The modernisation theory which framed the WID model suggests that the benefits of economic growth will trickle down to women but the proponents failed to acknowledge that women and men are different social constructs. So, was the word "gender" not understood by these WID proponents?

Secondly, the WAD model integrated women into the existing development process through the institutional interventionist approach to uplift the socioeconomic status of women in society. However, how does one rid the gender division of labour and the patriarchal ideology which is still prevalent in many societies?

Thirdly, the WAD model incorporates women in the lower rung of the occupational ladder which leads to suppression. Do the women have autonomy on choosing the work.

Finally in the GAD model, strategies undertaken are more holistic and more people-balanced. The transformation from WID to WAD to GAD is a manifestation of evolutionary shift in thinking about women, men and development, but the acceptance of this paradigm shift needs a change in mindset for the policies to be successful towards achieving an equitable society. If FWA can change the women's position for the better, the change in mindset of individuals and the society is also 
pertinent. This leads one to suggest that the GAD approach is a good approach in terms of women in the family context and in the whole development process.

The WID, WAD, GAD models discussed above set the stage to explain the use of flexible working arrangements (FWA) and women's participation in paid labour.

\subsection{Women and Labour Market}

Early studies done in Malaysia noted that many American industries were affected by increasing wage costs, labour shortages and workers' unwillingness to do monotonous, semi-skilled assembly line work (Lim, 1980; Jamilah, 1980). This saw the beginning of the "electronics revolution" with Central America and Asia at the receiving end. Malaysia was one of the third world countries in the early 1970s which was absorbed in international production with direct foreign participation of multinational corporations (MNCs) from the core nations. In the 1960s, the American MNCs predominated, to be superseded by the Europeans in the 1970s, followed by the Japanese and Australians (Taylor, 1994). By 1990, Indonesia, Singapore and other Asian countries established companies in Malaysia.

Other studies by Hirschman and Aghajanian (1980), Jamilah (1982) and Jones (1984), revealed the scenario of exploitation of women doing jobs which were repetitive, monotonous, unskilled and low paid in the lower rung of the manufacturing sector. It is well documented that work in the "world market factories" is organised through a formal hierarchy where assembly line operators are young, female employees who are controlled by males (Elson \& Pearson, 1981). Saffilious (1985) study on cross-country data of women's socio-economic development found that women's ability to work is the most important social resource in a nation. Earlier to this, Boserup (1970) and Ware (1981) argued that women's status depends heavily on their economic contribution in the society. Labour market segmentation and women's relegation to the lower rung is explained by feminists through Hartmann's (1976) view of women's position in the labour market. Women's low pay and segregation in "female" jobs are because of 
attitudinal and patriarchal gender division of labour allied to capital. Boulding (1977) analysed the pattern of male dominance and women's subordinate position in the family which existed as far back as the preindustrial era.

Along the same line, Edwards (1979), in an attempt to explain the persistence of sexual, racial and ethnic hierarchal divisions among American workers, focussed on labour market segmentation theory to explain the job categories women occupy. Marxist feminists explain women's position in the labour force in terms of the interacting systems of capitalism and patriarchy. The core of the argument of all schools of feminism, be it Marxist, liberal or other feminist school of thought is "it's the social forces and structures that cause women as a class to be subordinate to men" (Hyman, 1994, p.13). Isn't this the pattern of the new international division of labour which has continued and is prevalent until now?

Even though international production incorporated women into the global work field, capitalist and patriarchal institutions continued to reinforce gender subordination. Hartmann's (1976) patriarchal view is that women's position in the labour market, earning a lower pay and segregated into "female" jobs was due to the actions and attitude of men as capitalists. Martha (1975) argues that reasons for sex segregation are complex rooted and this narrow range of jobs performed by the young, single women was due to sex stereotyping. Elson and Pearson (1981) agree that "manual dexterity, docility and nimble fingers" of factory women workers which are often regarded as innate personality traits socially suitable for them resulted in their being "more submissive" and "easier to control". This is the general pattern of male dominance and women's subordinate position in the paid workforce and the family making them carry out all the household and caring work as noted in most Malaysian families.

Labour economists' note that life cycles of female participation rates vary more than males and differ between each country and are generally lower than men's at all stages of life. The "twin peak" phenomenon in most countries separated by a trough of lower rates in the central age groups varies between nations, and is closely related to marriage and the family (Durand, 1975). However, not all countries have 
this phenomenon as shown by the recent UN publication The World's Women 2010 Trends and Statistics ${ }^{12}$. Developed countries such as Japan and South Korea continue to have a double peak at ages 25-29 years although it used to be 20-24 years in 1990. The drop in participation rates has shifted to five years older and is not as sharp as before, "indicating later childbearing and childrearing as well as more women opting to continue working" (UN, 2010, p. 80). However, this is not the case in some countries with relatively better pension systems and welfare aids.

The neo-classical theory of household choice and resource allocation is useful to explain the factors which influence the female labour force participation of women. As the aim of all households should be to maximise total utility by optimal allocation of resources, some factors will have a greater influence on women's decision to participate in paid work outside the home.

Women tend to be still overrepresented in traditionally female occupations which are confined to low-skill and low-wage, with low career advancement and where, they may experience a "glass ceiling". Using the human capital model, the neo-classical economists explain that wage differentials are due to women's lower investment and their choice of jobs. However, Hesse-Biber and Carter (2000) critically argue how this model may have some shortcomings in terms of conceptual and empirical issues (Faridah Karim, 2009).

Women work due to economic and social reasons. As far back as the early 1980s, Sogner (1988), commented on the difficulty of a dependent housewife in a society where cash is becoming increasingly important especially when consumption shifts towards high priced market products. In the 1990s, Jamilah (1994) clearly spelled out that it was women from poor households in Malaysia who resorted to wage labour to supplement family income and in the course, were affected by wage differentials and gender discrimination. In this study, it was noted that poor femaleheaded households who have very little access to alternative childcare support

12 The details are discussed in Chapter Four of the report The World's Women 2010 Trends and Statistics (United Nations, 2010). The report examines the labour force participation rates of women and men and notes four distinct patterns. 
systems have a high opportunity cost of working outside and this situation actually aggravated their dual-role burden.

In a more recent study among college students, Kaufman (2005), revealed that the majority of both men and women wish to participate in paid labour. This is an indication that the dual career family is likely to continue to be common in the future. However, her study showed that gendered expectations are still prevalent when it comes to the division of labour at home and work.

Paid work is now an integral part of women's lives. Not all women leave their jobs after childbirth (Kaplan \& Granrose, 1993). Many debates and discussions on what causes women to exit the labour market point to family responsibilities either directly due to dependent care or indirectly due to employer policies (Voydanoff, 1988). However, the fact remains that inflexibility at workplace and inability to balance work-life and home career are important factors why married women leave the labour force (Kaur, 2004).

What influences a woman to leave an organisation after childbirth and not return has been a debate among organisational behaviourists and feminists and a few interesting points can be deliberated on. Theoretically, women who exit the labour force are making a rational decision anticipating the outcomes of alternative courses of action. The major assumptions in other economic theories is that people are rational when making major decisions, including quitting a job. Therefore, it is argued that women will not leave their paid jobs without a reasonable reason and a rational individual will choose the alternative that is likely to give her the greatest satisfaction. The questions which arise here is, "Is there a better choice for these women with young children other than to withdraw from the labour force?" What are the constraints for women to continue to work in paid labour?" 


\subsection{Flexible Working Arrangements, Women and Work}

\subsubsection{Flexible Working Arrangements}

The workplace of the future is one that will be driven by new energy with vision as workplace flexibility and worker-friendly management strategies which are now becoming more important. Olmsted and Smith (1994), categorise workplace flexibility into four concepts, namely numerical or operational flexibility, job or functional flexibility, financial flexibility and structural flexibility. Numerical or operational flexibility deals with the number of employees, the number of working hours and staffing of the organisation which facilitate the operational activities to meet production needs. As Olmsted and Smith (1994) argue, FWA are the means by which some employers have been seeking more operational flexibility. Job or functional flexibility involves the comprehensive use of skill development, and training which involves other measures to increase efficiency. Financial flexibility as the name suggests involves cost-cutting strategies and structural flexibility involves the structure and support system that allows change to take place in the organisation.

Flexible working arrangements (FWA) are alternatives to the traditional "9to-5" workday, the standard workweek, or the traditional workplace. FWA are work practices (explained by the employer in employment policies and contracts) that allow the employees a certain degree of freedom in deciding how the work will be done and how they will coordinate their schedules with those of other employees. The employer sets certain limits such as minimum and maximum number of hours of work every day, and the core time during which all employees must be present.

Flexibility enables individuals to make adjustments to changing circumstances. These alternatives can assist employees in balancing work, personal commitments and retirement planning, while meeting business needs and objectives.

There is no single definition of FWA but they encompass working arrangements which are non-standard and can be divided into three categories. Firstly, scheduling of hours worked, such as alternative work schedules that consist of flexitime and compressed workweeks and arrangements regarding shift and break 
schedules. Secondly, flexibility in the amount of hours worked, such as part-time work and job sharing; and thirdly, flexibility in the place of work, such as working at home, teleworking or at a satellite location.

Flexible working hours started in a Bolkow company of MesserschmittBolkow-Blohm at Ottobrunn, in Germany in 1967 (Allenspace, 1975). Even though many companies in Germany were using some system of flexible working time, this firm used it to a comparatively large proportion of its workforce which set the stage for lively discussion and implementation among many other German firms in the late 1960s. Allenspace (1975) noted that while there were 200 to 300 firms with flexible working hours in 1970, this figure increased ten-fold to two thousand by 1971. This working arrangement spread to many European countries and by 1975, more than 30 percent of workers in Switzerland worked under the new working system. By 1972, Hewlett Packard (HP) had established flexible working hours in the United States (Bernard, 1979).

Flexible working arrangements are low cost employee benefits which are the choice of employees and not imposed by the employer and which will improve productivity and motivate a changing workforce. According to the Bureau of Labour Statistics, by the end of this decade, 80 percent of all mothers nationwide will work outside the home during some portion of their child rearing years (Sullivan \& Lussier, 1995).

Flexitime is usually a companywide initiative where core hours remain consistent and a certain number of hours can be "flexed." The number of hours in the office remains the same but the actual time selected is left up to the employee. Many employees take advantage of the flex hours to meet the demands of elder care or childcare responsibilities (Sullivan \& Lussier, 1995). Time limits are placed on the amount of "flex" and the employee has by establishing "core hours" and a "bandwidth" (Olmsted \& Smith, 1994). Core hours are the hours during which all employees must be on the job while bandwidth is the span of time beginning at the earliest time an employee may start work and ending at the latest time an employee may stop work. 
In the mid 1970s, another form of FWA which became popular in Europe and America was regular part-time employment and there were three reasons why this work arrangement came into vogue (Olmsted \& Smith, 1994). Firstly, changes in the workforce demographics with more women joining the labour force, especially women with young children, caused a radical change in the demand for this working system. Secondly, the shift from a production-based economy to a services-based economy also led to more part-time jobs which were more client-driven and thirdly, and the most important cause, was the increasing need the workers felt for more personal time. Regular part-time employment is where an employee works less than the full ordinary weekly or monthly hours and is entitled to employment benefits on a pro-rata basis. This type of flexible working arrangement was found to very useful to retain valued employees and also cost saving to the organisation.

Telecommuting or working from home or alternate work space options saw exceptional growth from 1992 to 1994 and the main reason for the astonishing growth of this flexible work arrangement was the affordability of technology (Sullivan \& Lussier, 1995).

Job sharing is unique in that two, sometimes three, people split or share one job. This term which was coined in the mid 1960s was devised as a way to create more part-time job opportunities in career-oriented job categories in which the positions could not be reduced or split.

Compressed workweeks are prevalent in some companies as "summer hours". It refers to a workweek which is usually forty-hours long but is condensed into less than five days. However, there is a need by many employees to switch to a four-day workweek on a permanent basis. Xerox Corporation has used compressed workweeks as a business tool to reduce overhead and absenteeism (Sullivan \& Lussier, 1995).

Research on FWA date back as early as 1972 where Allenpach found that the pioneering German firm which initially adopted the system of flexible working hours was motivated by the individual psychology of encouraging staff to work full swing 
in a tight labour market. However, the emphasis moved to the importance of recognising workers' needs for respect and appreciation, and the aspiration towards self-fulfilment was only analysed later when the wide implications of the system were understood. It was also becoming more a means of relieving transit and commute problems. Shortly after, FWA began to gain adherents in Switzerland as a way to attract women with family responsibilities into the workforce.

FWA are often considered to be an essential component of 'family friendly policies' and are widely seen as an ideal means to achieve a more balanced work and home life. Research has found that FWA benefit the employees in terms of individual, family and job perspectives. Available literature clearly casts FWA as having a powerful and positive effect on employee attitudes which leads to job satisfaction (Lietchy \& Anderson, 2007; Almer \& Kaplan, 2002).

As FWA such as part-time work and flexitime give employees longer blocks of personal time and cut down on commuting time, studies show that the integration of family and work through well-designed FWA presents an opportunity to the stakeholders to improve the employee relationship and also the organisational outcomes.

\subsubsection{Benefits of FWA}

Most female employees want FWA to centre on family responsibilities and work-life balance (Liechty \& Anderson (2007). Studies in the United Kingdom (Cole, 2006) and the United States (Hotchkiss, 2006) reveal that "spending time with family" was the most popular reason why women opted for FWA. Olmsted and Smith (1994) note that most of the time companies that can attract, retain, motivate and engage the most talented within these groups have higher success rates compared to other companies. 
Employing the theory of work adjustment of Dawis, England \& Lofquist, (1968), Pierce and Newstrom's (1980) study tried to examine the relationship between FWA and quality of working life and employee productivity. The study showed the attitude difference in a FWA organisation explained in terms of stress associated with work arrivals being reduced and the possible increase in performance.

While the merits of FWA can be categorised into employee, organisational and societal benefits, the focus of this study is more on employee benefits, specifically female employees. Research also shows that employees are more satisfied with FWA compared to standard work-hour arrangement.

Studies have shown that an organisation which values its employees and recognises the importance of work-life balance stands to win in terms of staff morale and commitment (Liddicott, 2003; Nadeem \& Hendry, 2003). Employers should begin by revamping their recruitment policies to facilitate work-life balance. FWA, if used with quality practices at the workplace, can actually become the core of human resource management and lead to good work performance and higher productivity (de Menezes \& Wood, 2006; Hau \& Chew, 2006). As argued by Liechty and Anderson (2007), FWA are beneficial for both employers and employees and they also further described how highly it is valued by elderly parents, whose children work under flexible working arrangements.

Recent trend studies show that part-time work influences the ability of mothers with young children to balance work and family responsibilities (Jeffrey, et al., 2004). As Pacilli (2008) argues, mothers will be less likely to leave the labour market if more part-time jobs are available. This concept of part-time jobs and family friendly policies such as flexible working arrangements will enable more women to contribute to both work and home. With more flexible work and part-time work, literature suggests that possible benefits for these young mothers will be better monitoring of the children and more quality time with the children. 
Even though evidence pertaining to performance is mixed, (Liechty \& Anderson, 2007), empirical investigations have not documented any decrease in performance. FWA have also been proven to be useful for the employers in terms of increase in productivity, reduction in staff turnover, reduction in cost, reduction in job turnovers and improved management.

In the neighbouring country of Singapore, the Civil Service introduced flexitime as early as in 1970 with the main objective of easing traffic congestion during peak hours. But today, it is favourably received by staff as it enables better work-life balance and the scheme has helped to better attract and retain valuable talents. As a result, FWA lead to an increase in productivity, more efficient organisation of work, application of more scientific methods of management and ultimately, an increase in the productivity of the economy as a whole.

At the same time, some categories of work and job specifications cannot derive the benefits of FWA due to the nature of the job. Besides, FWA can also have somewhat unfavourable effects for workers whose brief absences from work, or "being physically not present", may have an influence on career success. Some studies have also shown that female employees are concerned about "career death" and the possibility of FWA jeopardising "their movement up the corporate ladder". As Pacilli (2008)) shows that even though job flexibility allows women to manage working time and household responsibilities, it also "reinforces conventional constructions of gender". Sometimes, FWA such as part-time work and working from the home is carried out at the expense of marginalisation of women in terms of career prospects and discrimination.

The question of whether workers "choose" and prefer FWA to standard employment has been widely explored in the western countries (Blank, 1990; Blossfeld \& Hakim, 1996) but less is known about whether FWA are a solution to work-family demands in Malaysia. From the feminist lens, FWA will help the women, however the dual burden becomes a bigger issue. 


\subsubsection{Disadvantages of FWA}

Research shows that although FWA have many advantages and benefit the women employees, this working system can be negatively perceived in terms of career progression, relationship with colleagues and work performance (Kapler \& Almer, 2000). There seems to be a trade-off between potential negative repercussions and work-life balance which means that not necessarily all women employees will take up the offer of FWA. Ng and Mitter (2005) discuss how ICT can empower women within families, workplaces, communities and cultures. Even though teleworking, could enhance women's participation in the paid labour especially in e-commerce due to its flexibility of place and time ( $\mathrm{Ng} \&$ Mitter, 2005), surveys in India and Malaysia indicate there are some reservations. Some feel that teleworking may lead to loss of career prospects, and loss of dignity of work status. In home-based work, women are more interested in flexible working arrangements such as working from the home or teleworking especially in a particular phase of their life cycle, and when there are inadequate childcare facilities. The provision of childcare still remains a key issue in retaining women in the workforce in the "New Economy as it was in the Old Economy” (Mitter, 2005, p. 49).

\subsubsection{FWA and Women's Well-Being}

With FWA, women have a better work-life balance but they still need to cope with juggling two roles. Hall (1972) identified three methods of coping with workfamily conflict from sixteen coping strategies; named Type I, Type II and Type III. Type I coping strategy or structural role redefinition is an active way which involves redefining the expectations held by other people so that fewer conflicting demands are placed upon the person. Type II coping strategy refers to personal role redefinition which involves changing the person's perceptions of his or her role demands rather than attempting to change the environment, and Type III coping strategy refers to reactive role behaviour which involves attempts to meet all of the role demands experienced. 
FWA help women to juggle work and home by allowing more time for the family and household chores. It also aids to break the social constructs on one hand. but it tends to perpetuate social constructs on the other hand. As women are sometimes expected to do more since they have more time due to their flexibility, this in turn increases their double burden.

However, women who want financial empowerment still want to work and as such FWA might be a solution for some. Whether FWA will have an effect on women's participation in paid labour and how they may affect some of the indicators of well-being are examined in this study.

\subsection{Some Global Examples of FWA and How They Work for Women}

One good example of FWA in the financial sector in the United Kingdom is the Barclays Bank which provides a flexible "Career Break Scheme" that has been introduced to enable qualifying staff to combine family and career responsibilities, which include fathers and those who are adopting kids. The Bank also provides an extended Maternity Break Scheme which provides six months' or one year's Maternity Leave for staff who qualify. An Adoption Break of 41 weeks is also available for adoptive parents. Parental Leave allows fathers to take a period of up to 12 weeks unpaid leave at any time during the year following the birth of their child.

Another example in the United Kingdom is the giant telecommunication company British Telecom which has a flexible work system called "BT Work style" which provides the largest flexible work scheme in Europe, involving more than 70,000 staff, with 10,000 of them working from the home.

In Asia, IBM in China has introduced FWA in the form of working from the home, part-time work, mobile work, leave of absence and individualised work schedule programme. About two-third of IBM's 9000 employees in China have joined the program, which has managed to eliminate restrictions of commuting, location and time problems that come together with conventional job. IBM hopes to encourage its employees to find a schedule and atmosphere that best fits the nature of 
their work and personal needs, thus increasing their productivity and earning their loyalty.

There seems to be a trade-off between potential negative repercussions and work-life balance which means that not necessarily all women employees will take up the offer of FWA. The question of whether women are interested in FWA was examined by studies such as Cohen \& Single (2001), who show that female assurance services professionals are negatively perceived in terms of career success and anticipated turnover.

In a study by Almer et al. (2003) on individual factors and organisational factors, it was found that gender, marital status and perceived advantages had an influence on employee's uptake of FWA at the workplace. As FWA can be negatively perceived because of career progression, relationships with colleagues and work performance, a trade-off between potential negative repercussions and work-life balance might discourage some employees from taking up FWA (Cohen \& Single, 2001).

Hence, in the first stage of this study, it will be interesting to identify who are the women who are interested in FWA. The major categories of factors which might influence women's uptake of FWA at the workplace were divided into four broad categories, namely demographic factors, socio-economic factors, family responsibilities and perceived advantages and disadvantages of FWA. As flexitime, permanent part-time and working from the home are three feasible types of FWA in the Malaysian context, this study will concentrate only on these three modes of FWA.

\subsection{Development Theories, Women and FWA - How they are Related}

The Question we ask is: How might we understand FWA better if we apply the insights from WID, WAD and GAD?

FWA was conceptualised in theory as WID. But the problems and challenges faced by these women were suggested by WAD in terms of increased 
burden. Hence the poorer women do not participate as easily as the richer and more educated women who are well off and have more choices in terms of work and home. WAD tried to explain how women were not incorporated into the working environment and that could be a reason why they were marginalised. The New International Development of Labour increased workload as they had to juggle work and home.

However, by adopting the GAD approach, it is possible to understand FWA better. But does FWA come in to break these social constructs or do they perpetuate further the social constructs, because it allows women to carry out two roles (sometimes three) and so it actually increases the double burden.

\subsection{Summary}

The theoretical debate in the area of gender and development tries to answer the question of women's roles in the economy and the development process.

Some issues which emerge are:-

Early development theories have always given importance to economic indicators to measure development and growth. GDP and GNI are not necessarily a sufficient measure of well-being and in fact labour force participation of women is another measure. However, all these measures have neglected women's reproductive role and their "second role" in the home. As Sen (1999) asserts that development is "a process expanding freedom" and hence "the well-being of human-beings should be at centre stage as both the goal and the means for development". The relationship between the different dimensions of women's freedom and women's participation in paid labour enhances the social standing of a woman in the household and also society and is noted as a very crucial aspect of development.

Women in Malaysia have been working unevenly both in the private sphere or the public sphere in certain low skill, low pay and monotonous jobs. With improved educational attainment and increased health status, women do have better lives and live longer. However, there is not enough enabling support for some educated 
women to work in paid labour. With FWA, there may be a way to address many key issues such as work-life balance, empowerment and improve quality of lifestyles.

FWA have always been used by women as part-time employment way back in the rural sector, in the fields and the farms. FWA can be used to address issues such as labour shortage, labour costs and discrimination. Does the promise of the new high skilled tertiary sector change the personality of the women in the labour force or does it see the women being segregated in the same occupation?

The review has established that women's position in the lower segments were constructed by certain attitudes and norms, social attitudes and constructs expecting women to be raising children and doing all the caring work and housework. It also shows women at the workplace being over-represented doing menial, repetitive and unskilled jobs. The theoretical debates and gaps that set the thesis have been identified to find some answers to address the gaps in the literature on development, women and working in paid labour. 


\section{Chapter 3}

\section{Overview of Industrialisation in the Labour Market in Malaysia}

\subsection{Introduction}

Malaysia was very much an agricultural economy, heavily dependent on tin and rubber, when it achieved independence in 1957. With the introduction of a development policy, i.e., the New Economic Policy (NEP) ${ }^{13}$ in the 1970s and the export-led industrialisation policies, young, single, local Malay women migrated from the rural areas to the urban areas and this resulted in an increase in female labour force participation. A large proportion migrated to work in urban factories as production operators (Jamilah, 1980) ${ }^{14}$.

This chapter traces how the nation's structural economic policy implemented soon after independence, resulted in a socio-economic transformation from an agrarian economy to a manufacturing based economy and eventually, to a service oriented economy. It begins with an overview of the industrialisation policies and stages of economic development from the 1950s to the present time, set in the context of the change in work structure and women's increasing role in the tertiary sector. Next, economic policies which had an impact on women and their participation in paid labour are discussed by examining the trends and patterns of FLFP rates. Malaysian women's position in the economy is viewed from the socioeconomic and cultural view points. Finally, to address how FWA may impact women's low participation in paid labour and women's well-being, the regulatory framework and some relevant government policies are discussed.

13 Explained in Section 3.2.2

14 McGee (1980, p. 15) claims strongly that the growing number of rural women into urban factories is of major importance in the Malaysian industrialisation policy because the most significant increase in the ethnic mix of the labour force was the growth of Malay female workers. 


\subsection{Industrialisation and Development in Malaysia - A Historical Overview of the Colonial Policy}

The late eighteenth century saw the beginning of the colonisation of the Malay Peninsula by the British, through the founding of Penang by Sir Francis Light in 1786. In the late nineteenth century, with the introduction of large scale-rubber planting and tin-mining, more employment opportunities were created. The British encouraged large scale immigration of Chinese and Indians from their respective countries which resulted in modern Malaysia being a multiracial country. While the Chinese immigrants concentrated mostly in the urban areas and were engaged in tin mining and service activities, the Indian immigrants were employed mainly in the rubber plantations, and the locals (Malays) were concentrated in the rural areas and were involved in their traditional farming activities (Fong, 1986). The liberal immigration policy was eventually terminated in the 1940s, and population growth since then has been mainly due to natural increase and high birth rates.

A gender division of labour was very evident in every economic activity ranging from paddy farming, tin mining and fishing to the production of handicrafts (Kaur, 1999). In the paddy fields, women were given less heavy tasks such as transplanting seedlings, weeding and reaping, while men concentrated on heavier tasks such as tilling the fields and also sowing and threshing of rice. In the fishing sector, women played a more secondary role by mending the nets and processing the catch while the men brought home the fish. The women also played a major role in marketing the produce.

In the traditional tin mining sector, men and women mainly of Chinese origin, panned for tin using flat, wooden trays and sometimes worked as 'corvee labour" in bigger mining operations. In the East Coast states of Malaysia, where fishing and handicrafts were the mainstay of economic activity, it was the women who produced the handwoven textiles and handicraft for sale both locally and in neighbouring countries. Women had been involved in sales for many years since the colonial times. Besides being an important source of secondary income, traditionally, 
women also ran the household and were important in the domestic sphere, carrying out all domestic chores.

Kaur (1999) observed three major changes precipitated by British colonial rule in Malaysia: firstly, the formation of a global market which had a high demand for agricultural commodities; secondly, the opening of new transport routes which facilitated trade to Europe and the United States; and thirdly, the creation of a new state with a new style of governance. This major development had an impact on labour relations with a prominent change for Malaysia in the international division of labour as a producer and exporter of primary products and at the same time, as an importer of manufactured goods.

Labour was differentiated along racial lines and studies show that this was a deliberate measure (Kaur, 1999) by the colonial rulers to play off one racial group against another as a strategy to control labour supply. This meant that the local Malays were only concentrated in the traditional agricultural sector, the Chinese dominated tin mines and Southern Indians who were "considered docile and suited to the dependent relationship between management and employee" (Kaur, 1999, p.6) were employed in the rubber plantations.

It was during this process of colonialism when capitalist economic relations in Malaysia became more embedded and labour became a marketable commodity. Kaur (1999) noted that there emerged three important consequences for Malaysia which were very important as "the divide and rule" policy of the colonial rule is still evident in certain aspects until present times (Kaur, 1999, p. 8). Firstly, an ethnic division of labour emerged, where local Malays were involved in the traditional agricultural sector and immigrant labour concentrated in capitalist production; secondly, policies were implemented to bring Malay peasants into closer contact with the market economy; and thirdly and most relevant to this study, was the allocation of tasks by gender which became more institutionalised.

The labour process was thus separated into two, where the men were mainly doing commodity production, while the women were expected to concentrate on 
domestic labour. The delineation between the public sphere and the private sphere was quite distinct, where women's reproductive role, the rearing of children and domestic chores were not recognised as primary income activities. There were Chinese and Indian women who participated in paid labour but being treated as secondary earners, they were paid less than men performing the same job. There was observed gender segregation together with ethnic segregation according to jobs performed. This basic governance framework which the Malaysian economy continues to function around presently, is very much shaped by the British colonialism. As Jomo \& Gomez (2000, p. 278 ) reiterated, "the relationship between economic transformation and governance has been quite dialectical”.

Colonial policies divided the ethnic groups in Malaya and involved a deliberate policy regarding Malays which aimed at preserving tradition, society and culture. It kept the Malay peasantry in rural areas under traditional leadership, thus not posing a direct challenge to British rule. By the late $19^{\text {th }}$ century, it was noted that the colonial authorities' divide and rule policies had not only subdued the Malays but also kept them tied to the land and their agricultural plots. This was a politically conservative strategy that aimed to prevent opposition colonial rule but it deeply divided the ethnic groups within the country (Jomo, 1990-1991).

\subsubsection{From Colonialism to the New International Division of Labour}

Before gaining independence in 1957, the Malaysian economy ${ }^{15}$ demonstrated a dualistic trade oriented economy due to British colonial interests. The modern production export sector concentrated on the twin pillars of the economy, namely tin and rubber, while farming and fishing products were produced only at a subsistence level. In the 1950s and 1960s, Malaysia, like most developing countries, adopted an industrialisation strategy that was based on import-substitution. The vulnerability of the trade sector which depended predominantly on income from tin and rubber exports to pay for imports of foodstuff and manufactured products

\footnotetext{
${ }^{15}$ Before independence in 1957, Malaysia comprised of separate colonial jurisdictions: the Federated States of Malaya on the Peninsular (including Singapore which later split from Malaysia) and Sarawak and North Borneo.
} 
was evident, with exports constituting 48 percent of GDP in 1970 (Mahani, 1992). Agriculture was the mainstay of the economy with processing confined to only small scale family enterprises with less than 20 workers, producing manufactured products contributing 15 percent of the Gross National Product (GNP) while the leading agricultural sector was contributing 55 percent of GNP (Lim, 1973).

Malaya, emerged as the world's largest exporter of tin and rubber which saw migrant Chinese and Indian labour playing a major role in the production of these commodities. The Chinese dominated the mining labour force, while the Indians were consistent with the development of the rubber plantation sector. There was very little specialisation and the economic unit centred on the family and subsistence agriculture in which rice and foodstuffs such as coconuts, sugarcane, tapioca and fruits were the main produce. Women played an integral role in the village economy and society as producers of children and the main producers of rice. They played a significant role in the preparation, processing and marketing of food and were a major component in the agricultural force, constituting an estimated 33.5 percent of the agricultural labour force (Kaur, 2006).

By the middle of the 1970s, industrialisation in Malaysia had taken an export- oriented approach and the development plans gave priority to export-oriented industries. In addition to incentives in the form of free trade zones and tax incentives, the industrialisation strategy also depended very much on the ability to tap sources of cheap labour so as to derive international competitive advantage (Jamilah, 1992). The government's industrial promotion was aggressive and its attractiveness was encouraging in terms of political stability and good infrastructure, followed by a productive and cost-effective labour force. Jomo and Gomez (2000) highlighted some of the export-oriented industrialisation (EOI) strategies taken by the government in the second half of the 1960s such as the Industrial Incentives Act (1968) and amendment of the labour laws which eventually led to creating more industries seeking cheap labour. This EOI strategy attracted direct foreign investment and Malaysia saw a growth in industries like electronics, food processing, textiles and garments. The production methods which were labour absorbing at a low level of technology (such as textiles and apparel), followed by 
partly labour absorbing at higher level of technology (such as electronics assembly), generated labour opportunities in the early 1970s in the Asian economy (Dowling \& Valenzuela, 2004).

These industries absorbed a new group of labour into the workforce which comprised young, relatively educated females and set the pace for women's incorporation into the labour force in Malaysia. Hence, both the multinational corporations and the government contributed significantly to the increasing female labour force participation in Malaysia in the early phase of industrialisation (Lim, 1980). This source of labour doing repetitive menial work was cheap and saw the emergence of young, single, Malay girls migrating from the rural, agricultural sector to the towns and cities (Jamilah, 2000). The setting up of multinationals and the internal migration led to rapid urbanisation in most towns and cities in Malaysia. According to Jomo et al.(1990-1991), the openness of the Malaysian economy became very highly export led and noted it was due to the structural transformation following the British colonial period .

After the early phase of industrialisation, however, other countries (such as Indonesia, China and India) were able to use even cheaper sources of labour and the rapid industrialisation of Malaysia soon created a tighter labour market which resulted in rising wages. In response to this structural change, industries moved to higher skilled and higher paid operations. Their demand for labour continued to grow but it had increasingly moved away from low skilled workers doing menial and repetitive tasks to higher educated workers using more capital intensive methods. Malaysian workers have been able to adapt to this change, and the country's generally good education system has helped. This has created a labour market where low skilled work has been performed more and more by expatriate labour (for example, in construction and domestic work).

A few observations that explain the current economic status of women in the industrialised nations may also explain women's work and working conditions in Malaysia. 
Firstly, in the early industrialisation era, there was an increase in labour force participation in non-agricultural sectors with a significant increase in the manufacturing sector, especially in the assembly line. As early as 1970, women in Malaysia accounted for 40 percent of the plantation workers who in turn, made up 16 percent of the agricultural labour force (Boserup, 1970). Agriculture continued to be the mainstay of the economy until the introduction of the New Economic Policy (NEP) in 1970. The spillover effect of demand side factors such as more job opportunities as well as supply factors such as increasing educational achievement (Siti Rohani Yahya, 2009) and change in attitude (Jamilah, 2009), resulted in an increase in women's participation in the labour force. Early studies of women in Malaysia by Hirschman and Aghajanian (1980), Jamilah (1982) and Jones (1984), highlighted women in the manufacturing sector doing assembly line jobs which were repetitive and monotonous, required low skills and paid poorly. This pattern of the new international division of labour has continued and is prevalent until present times.

Secondly, even though international production incorporated women into the global workforce, capitalist and patriarchal institutions continued to reinforce gender subordination. Hartmann (1976) argued that women's position in the labour market, earning a lower pay and segregated into "female" jobs was due to the actions and attitudes of men as capitalists.

This general pattern of male dominance and women's subordinate position in the paid workforce, together with women doing almost all the household and caring work, still prevails in most Malaysian families.

\subsubsection{Post Colonial Policy}

After Malaysia gained independence in 1957, the economy diversified from the twin pillars of the British colonial economy, which relied heavily on rubber and tin, to palm oil and tropical hardwoods. Primary commodities continued to dominate the economy in the early years after independence and by the mid 1970s, petroleum, 
gas and cocoa became increasingly significant contributors to the economic growth of the country. Although the Malaysian economy changed significantly after independence, remnants from the uneven development in the crucial formative decades under colonial rule, stayed on to shape Malaysia's economic structure.

Government policies from the late 1950s favoured import substitution industrialisation (ISI) and intervention by the government was mainly to encourage foreign investors and was in the form of tariff protection, infrastructure facilities and tax exemptions. Government strategies such as the establishment of new free trade zones with credit facilities and direct and indirect subsidies from the government also proved successful in promoting import substituting industries to set up production, assembly and packaging plants in Malaysia. However, as the technology used was typically imported from the foreign parent company, employment creation was low in the receiving country. ISI saw the manufacturing output grow at a slow pace from 9 percent of total Gross Domestic Product (GDP) in 1960 to 13 percent in 1970.

After 1957, the government policy was aimed at integrating the traditional sector with the modern sector through the increased use of modern technological input and capital in the traditional agricultural sector. This resulted in a major transformation in the agricultural sector and one of the striking consequences of mechanisation was an immediate effect on the labour market. With mechanisation, the productivity of male tasks increased, while paddy cutting operations such as transplanting and cutting operations which were traditionally accomplished by teams of women were being displaced by machines. The resistance from the farming communities came in a number of forms and the most affected were the female labour groups (Rodolpe, 1981). Mechanised tasks resulted in higher productivity and also higher remuneration in comparison to manual tasks done by females in the agricultural sector. The traditional position of women was eroded in terms of land ownership and inheritance. As a result, a number of them, especially among the poorer households, became potential workers in manufacturing industries,. This was one of the push factors which forced Malay women to look elsewhere for opportunities. 
The process of proletarianisation ${ }^{16}$ of young Malay girls was explained by McGee (1983) as due to "the recruitment system, the work and payment system, job security and occupational mobility as well as the factory socio-cultural system" (McGee, 1983, p. 16). Firstly, labour intensive firms had a preference for rural labour which was more pliable and allowed relocation; secondly, the multinational corporations (MNCs) preferred female workers because they could pay lower wages to females compared to males; thirdly, females were found to be more dexterous at assembly operations and finally, the young girls from the rural sector could be easily trained or dismissed (McGee, 1983, p. 16).

On the other hand, Chinese women served as contract labour and worked in the mining pools, where a disparity was beginning to form. Male workers could obtain a share in the mining profits through work sharing arrangements while females who were doing menial tasks of panning or "dulang washing" and with no childcare facilities, ended up going to work with the babies strapped to their backs in "baby slings" (Kaur, 1999, p. 21). Indian women were employed as contract or free labour in commercial crop cultivation, especially rubber, and their rate of participation was notably higher than that of Malay women or Chinese women. One main reason for this was they needed to supplement their partner's low earnings which were insufficient for a household. An important facilitating factor was that the plantations provided childcare facilities which allowed this trend for women to work. This trend among the three main ethnic female groups continued until the introduction of the Export Oriented Industrialisation (EOI) policy by the government in 1970.

\subsubsection{The Economic Transition $(1970-2000)$}

The government policy promoting Export Oriented Industrialisation (EOI) had started in the late 1960s but did not take off until the early 1970s with a favourable investment climate, generous fiscal incentives and a literate labour force.

\footnotetext{
${ }^{16}$ Proletarianisation refers to the social process whereby people move from being either an employer, unemployed or self-employed, to being employed as wage labour by an employer and become landless in the process.
} 
This paved the way for high technology growth for the country with the emergence of a new international division of labour, where multinational corporations were relocating their assembly, production and testing plants to countries with lower wages and production costs.

According to Jomo et al. (1997, p. 98), "many observers associated the export-oriented industrialisation policy with the NEP " but the authors thought it was just co-incidental. The NEP was launched in 1971 and was to operate for 20 years until 1990. Its main objective was to create national unity through its two pronged approach of eradication of poverty and restructuring of society through a more equitable distribution of wealth. This paved the way for the emergence of a new labour force drawing on workers, especially young, unmarried Malay women moving from rural areas to the cities. Increasing demand for labour from the labour intensive multinationals, especially the electrical and electronics industries, saw an increase in female labour force participation rate from a mere 30 percent in 1970 to 47.8 percent by 1990 .

Structural change and the government's policy led to economic growth which saw an increase in workers, especially evident in women workers. Figure 1 below shows that Malaysia went through economic crises downturns in 1985, 1997/1998 and 2001, and yet managed to attain a high rate of growth of GDP at an average of 5.5 percent between the years 1985 and 2008. This came from the expansion in the manufacturing sector and mainly due to the EOI policy (Ishak Shari \& Ragayah, 1997).

This period which was during the $\mathrm{NEP}^{17}$ had implications for employment opportunities, especially female labour where employment increased from 3.3 million in 1970 to 4.8 million in 1980 and to a further 6.7 million in 1990 at an

\footnotetext{
${ }^{17}$ The New Economic Policy (NEP) or First Outline Perspective Plan (OPP1) is a socio-economic policy, which was designed to achieve national unity through the two-pronged objectives of eradicating poverty irrespective of race and restructuring society to eliminate the identification of race with economic function. The NEP was conceived as an agenda that stretched over 20 years beginning 1970 until 1990.The redistributive approach of the NEP in Malaysia has influenced the manufacturing structure of the country (Malaysia, Third Malaysia Plan, 1976).
} 
average of 2.5 percent growth per annum. The labour market became tight at the end of the NEP resulting in some subsectors of the economy experiencing a shortage of labour and also marked the beginning of immigrant labour.

Figure 3.1 - Growth Rates of GDP

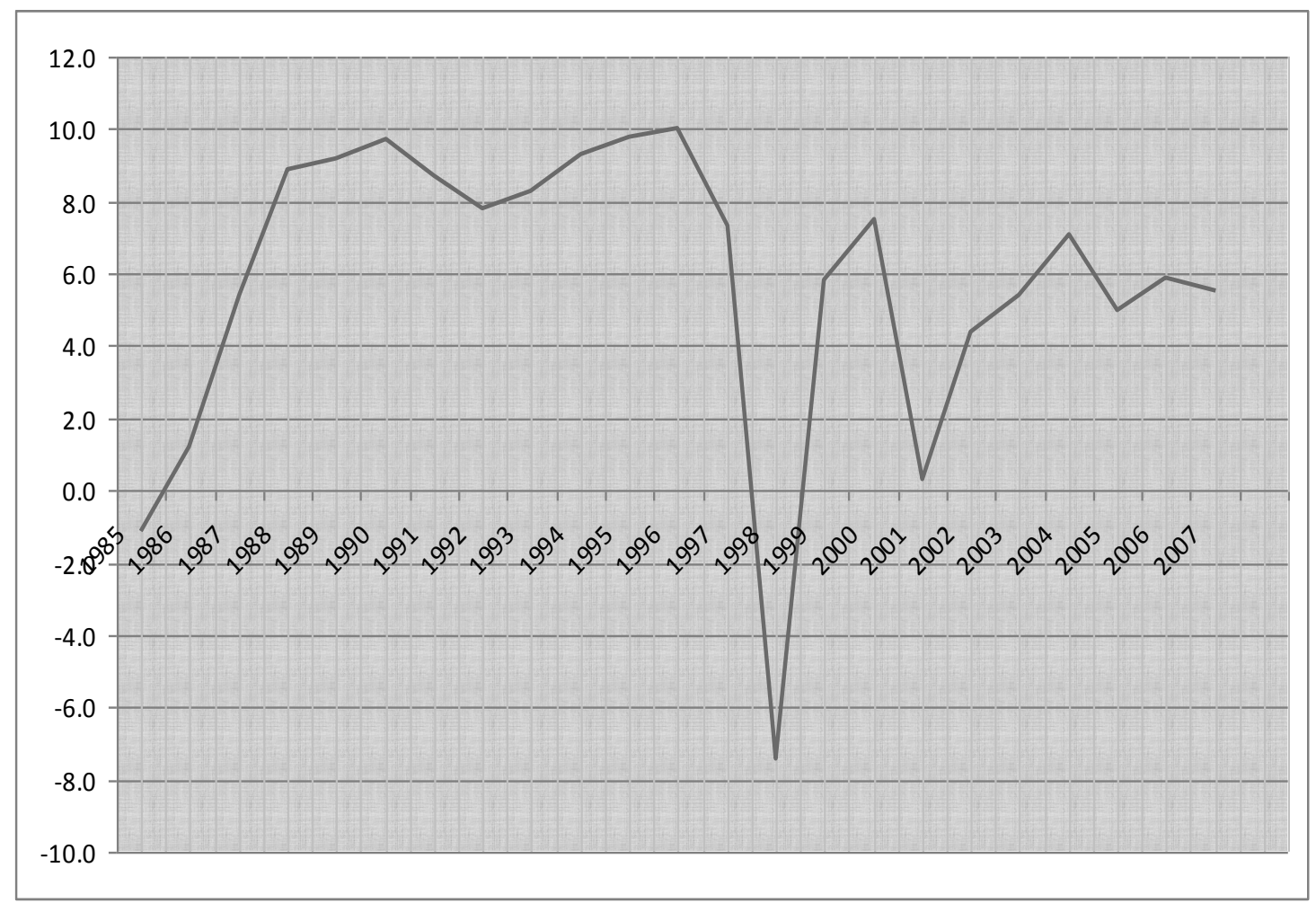

Source - Economic Reports, 1985 - 2007.

Women's participation in education and employment increased at this stage also. However, in the second half of 1997, the country again entered a new and painful crisis where the worst hit sectors were manufacturing and construction. The external shocks had an immediate effect on women working in factories and resulted in a significant decline in employment growth and loss of jobs (HAWA, ${ }^{18}$ as cited in Ahmad, 1998). However, with the government's interventionist fiscal policy, the economy recovered in 1999.

\footnotetext{
${ }^{18}$ See Paper prepared by HAWA for the APEC HRD Task Force on the Social Impact of the Financial and Economic Crisis entitled "Economic Crisis and its Impact on Women in Malaysia, Measures Taken and Future Strategies”, June 1998.HAWA is the Secretariat for Women's affairs located in the Prime Minister's Department. The objectives of HAWA are to promote the participation of women in the development process and to ensure that national development plans take into consideration the integration of women through the provision of equal opportunities and adequate facilities.
} 
In the 1970s, GDP grew at an average rate of 6 percent per year, but there was a decline from 1980 and by 1985, Malaysia experienced recession. A more liberal trade policy with attractive foreign direct investment measures and implementation of the privatisation policy allowed the economic performance to improve within two years. From 1987 to mid 1990s, economic growth was 8.5 percent per year. In 1998, the Malaysian economy experienced its deepest recession when GDP declined by 7.8 percent. However, rapid recovery was experienced due to a good fiscal stimulus which increased liquidity, stabilised the currency, restructured the financial and corporate sectors and improved corporate governance (Jomo, 2007).

Between 1990 and 2000, the primary sector's contribution to GDP declined from 32 percent to 9 percent while the manufacturing sector's contribution increased from 12 percent to 33 percent and the services sector's contribution increased from 56 percent to 58 percent (Malaysia, 1976; Table 4-4; Malaysia, 2001; Table 2-6). GNP per capita increased from RM2,414 in 1970 to RM13,464 in 2000. In terms of employment, the agricultural sector experienced a fall in employment share from 21 percent in 1990 to 15 percent, the manufacturing sector was stable at 30 percent and the services sector recorded a 5 percentage point increase from 49 percent in 1990 to 54 percent in 2000 .

In a multi-ethnic nation like Malaysia, policy objectives were always centred on achieving national unity and poverty eradication. The direction of the first national policy, the New Economic Policy (NEP) (1970-1990) was to attain economic growth with social engineering, followed by the National Development Policy ${ }^{19}$ (NDP) (1991-2000), which aimed at economic growth with equity and the present National Vision Policy $2020^{20}$ (NVP) (2001-2020) focussing on sustainable growth with resilience. The overriding objective of the NEP, i.e., to preserve national unity by eradicating poverty irrespective of race and by restructuring society to reduce identification of race with economic and social function, was maintained in the subsequent two policies - NDP and NVP.

\footnotetext{
${ }^{19}$ The National Development Policy (NDP) or Second Outline Perspective Plan (OPP2) with a target average growth rate of seven percent was for the period 1991 until 2000. The main objective of the 
The services sector was identified as the main catalyst of growth and some of the selected industries include education, tourism, finance, health, transport, and ICT related manufacturing services which were particularly promoted (DOS, Malaysia, 2003). In 1970, 53 percent of the workforce concentrated in the agricultural sector, with 11 percent in the manufacturing sector and the balance 27 percent in the services sector. Within a time span of thirty years, the labour force structure experienced a transformation with the structural economic shift. By 2000, the agricultural sector employed only 16 percent of the workforce, while the manufacturing sector employed 30 percent and the services sector employed the majority of 54 percent of the workforce (DOS, Malaysia, 2003).

In terms of occupational status, in 1970, 49 percent of the workforce comprised agricultural workers, 33 percent clerical, sales and service workers, 13 percent production workers and 5 percent professional, technical and administrative workers. In 2000, only 18 percent of the workforce comprised agricultural workers, 34 percent were from clerical, sales and service works, 33 percent production workers and 19 percent professional, technical and administrative workers (DOS, Malaysia, 2003).

Malaysia can be considered a successful example of development in the third world. The dramatic degree and pace of economic growth and industrialisation that Malaysia has experienced in the last three decades sets the country in the category of developing nations. The average annual GNP growth rate between 1960 and 1980 was seven percent. During the same period, middle income countries in Asia, Africa, and Latin America achieved only 3.8 percent annual growth, according to the World Bank figures (World Bank, 1982).

NDP was "to attain a balanced development in order to establish a more united and just society" and to "strike an optimum balance between the goals of economic growth and equity" (See Malaysia, Sixth Malaysia Plan,1991.

${ }^{20}$ The National Vision Policy aims to establish a united, progressive and prosperous Malaysia. It endeavours to build a resilient and competitive nation, and equitable society with the overriding objective of National Unity. It has seven critical thrusts and is operationalised through the Third Outline Perspective Plan (Malaysia, OPP3). 
The first stage of rapid economic growth during the 1970s was characterised by light, labour-intensive export industries. The export processing zones were located in major cities in Malaysia, and the state of Selangor served as the central locus of productive activities and administration. A large rural out-migration to Kuala Lumpur and the export processing zones from the rural sector expanded the supply of cheap labour for the MNCs. The state of Selangor was like a magnet of employment opportunities: its population grew by 113 percent between 1960 and 1970, reaching 17.6 percent of the total population in 1970 .

\subsubsection{Post NEP and Labour Industrialisation (2000 - 2011)}

With the government's emphasis on the production of high-tech industries such as electronic components, computers and capital goods as well as resourcebased industries, the manufacturing sector is headed towards the so-called “knowledge economy” which requires skilled and semi-skilled manpower.

A skilled and trained labour force is essential to a country that is experiencing rapid expansion in its manufacturing, construction and services sectors. The government's high value policy of promoting high value added and heavy industries and its intention to de-emphasise labour-intensive industries, clearly indicate that both skilled and semi-skilled labour will be in great demand in the years to come.

Studies as far back as in the 1960s, have shown that female work patterns and participation rates change in the course of economic development (Boserup, 1970; Durand, 1973). Industrial development led to an increase in employment opportunities in the manufacturing sector, especially for female job seekers. The FLFP rate saw an increase from 37 percent in 1970 to 46.5 percent by 1990 . However, they have been at a constant rate of 46-47 percent since 1985 with a slight fall to 46.4 percent in 2010 from 46.7 percent in 2000 (Labour Force Survey Report, Malaysia, 2010). This is considered low in sharp contrast to the neighbouring South East Asian countries of Thailand, Brunei Darussalam, Singapore, Indonesia and 
Philippines where the corresponding figures were $66 \%, 60 \%, 56 \%, 52 \%$ and $49 \%$, respectively ${ }^{21}$.

\subsection{Women's Position in Malaysia}

Over the years, the position of women in Malaysia has changed considerably in tandem with the demographic, social and cultural changes and this has an impact on women's role as producer and reproducer. Among those who are working, the highest (19\%) five yearly group are in the age group of 25 years to 29 years. The majority of working women i.e., 57 percent are married, while 37 percent are never married and the balance six percent are separated or divorced.

The latest statistics (Labour Force Survey Report, Malaysia, 2010) show that the majority of the working women $(52 \%)$ have at least secondary school certificate, which means 11 years of schooling and this is a government examination which is equivalent to "O" levels. The female literacy rate has increased from 85.4 percent in 2000 to 89.5 percent in 2008. Female students' enrolment in government assisted schools show that while for primary and secondary levels percentage of males and female enrolment is approximately equal, the difference is quite outstanding at college and tertiary level. In 2009, female students constituted 60 percent of the entire public and private university intake (Ministry of Women, Family and Community Development, 2010).

In terms of occupational status, gender gaps exist where most of the women are still working in low-rung lower income jobs, for example, 20 percent of the employed women work as services and sales workers and a good 19 percent are clerical staff. The next most important job category where women are gaining more employment is technicians and associate professionals and production operators in the manufacturing sector. It is noted that the percentage of women employed as professionals $(7 \%)$ is proportionately more than men $(5 \%)$ and this could be mainly

\footnotetext{
${ }^{21}$ Just for comparison, the top seven countries with the highest FLFP rates are Denmark (77\%), Sweden (76\%), New Zealand (72\%,) Germany (70\%), United Kingdom (70\%), Australia (70\%), USA (69\%) (OECD Employment Outlook, 2009).
} 
due to the size of the health and education sector which women dominate. However, at the management level, there are proportionately fewer women (5\%) compared to men $(8 \%)$. With the services sector becoming a more important economic sector, it is evident that more and more women are gaining employment in these service oriented occupations. However, they are still concentrated in the less technical, professional and management occupations.

Sector distribution shows that most women employed in the tertiary sector $(69 \%)$ are clustered in traditionally female occupations which are low skill and lowwage jobs. Most of them are heavily concentrated in the wholesale and retail trade (16\%), followed by hotels and restaurants (10\%) and the education sector (11\%). The government sector is still the single largest employer of women (3\%) but the under representation of women in the higher and middle echelons of government service is still an area of concern. Most of the women (79\%) work as employees and less than two percent are employers.

The mean age at first marriage has increased from 23 years in the 1980s to 25.3 years in 2009 (DOS, Social Statistics Bulletin, 2010). The increase in age at first marriage means postponement in giving birth to the first child among the younger age group of 20-24 years and an increase in births among women of the older age group of 25-29 years. Latest statistics also show that the average family size in Malaysia has decreased from six in the 1980s to 4.5 in 2008 (Malaysia, Ministry of Women, Family and Community Development, 2010). The percentage of nuclear family households has been steadily increasing from 55 percent in the 1980s to 68 percent in 2008, with the number of extended families decreasing slightly from seven percent to six percent during the same time period. This means childcare responsibilities which were earlier shared by grandparents and extended family, is now an issue for new mothers and this has a bearing on women's participation in paid labour.

Women's increasing participation in the services sector is a worldwide phenomenon when there is a transition from a manufacturing based economy to a service-based economy. Shahadan and Berma (1994) acknowledge that Malaysian 
women overwhelmingly work in the service sector where a high degree of occupational segregation still persists. In the course of development, women can be easily used as a "flexible and absorbing force" moving from agriculture to manufacturing and then to services sector.

Women have moved into the public sphere in many domains of paid labour, from the traditional agricultural sector to the manufacturing sector and eventually the services sector. They have contributed a lot to the economic development of the nation both as producers and reproducers in spite of being concentrated in low paying, low skilled jobs. However, a big challenge which needs immediate attention is gender division of labour at home and gendered norms in the reproduction sphere (Jamilah, 2009) which calls for a better support system for working mothers.

In terms of occupational structure, even though the percentage of women in professional occupations like dentists, lawyers and accountants have increased, many women are unable to climb out from lower level positions and lower income-paying jobs like clerks, services and sales workers. Furthermore, women often face a narrower range of job opportunities with employment heavily concentrated in "female occupations" like teaching and nursing.

The gender empowerment measures from the United Nations Development Programme's Human Resource Development Report 2005 revealed that Malaysian women remained largely under-represented at decision-making levels and political participation. As a percentage of the total, female legislators, senior officials and managers accounted for only 23 percent, while seats in parliament held by women were even lower at 13.1 percent.

Turning to gender wage gap, women in Malaysia are generally paid lower wages than their male counterparts. As observed from the gender related development index from the same report, the estimated income earned by Malaysian women in terms of purchasing power parity was only US\$6,075 in 2003 , while men earned US\$12,869. This meant that women were on average, earning less than half $(47.2 \%)$ of men's income. The gender wage gap in Malaysia is relatively large when compared with neighbouring countries like Thailand (61.2\%) and Singapore 
(51.4\%). The next section will outline the female labour trends from 1970 until 2010 in more detail.

Women in Malaysia have always played a significant role beyond the domestic domain as far back as pre-colonial times which saw peasant women in subsistence agriculture. As noted by Kaur (1999), the earliest available statistics reveal that women formed 50.9 percent of the workforce in 1960 and were predominantly engaged in paddy cultivation and contributed significantly to the village economy. Joekes (1987) also noted that from the late 1980s, employment in the industrial and services sector grew faster than the employment in the agricultural sector. Malaysian employers continue to employ women not only because of their distinct perceived characteristics such as being malleable, obedient, disciplined and conscientious (Lim, 1978; Jamilah, 1978) which were evident in the 1970s, but also because they were readily available and have the required skills. Some employers are beginning to explore ways to attract more women into employment.

For example, using the Malaysian Family Life Survey (MLFS-2) by RAND and the National Population Family Development Board of Malaysia which was fielded in Malaysia in 1988-1989, Fernandez (1997) investigated the demographic and socio-economic factors which influence women's participation in the labour market. Demographic variables such as age, marital status, ethnicity, childcare responsibility and availability of childcare help and socio-economic variable such as income, opportunity wage and educational level were examined. The logit regression analysis revealed that marital status and childcare responsibility had an influence on women's participation in the labour market. FLFP rates were higher among single women and women with less caring responsibilities.

So, a popular debate among Malaysian women's interest groups is: how did the distinctive "female" occupation form and how did the inequality get more reinforced? The answer could possibly be due to the colonial policy and practice in terms of the education system which emphasised women's nurturing and domestic roles. Also, the western influence in the history of the colonisation indirectly brought 
through formal education, further reinforced and institutionalised these values which already existed in the Malaysian society (Jamilah, 1981).

\subsection{Women and Work in Malaysia - Patterns and Trends from the 1970s}

The labour force participation rate is the percentage of the labour force (which includes those who are unemployed and actively seeking work) to the total working age population. Various factors contribute to the change in the labour force participation rates such as the rise in working age population, economic growth, improvement in educational levels, increased independence among women, decline in fertility rates and delayed age of first marriage.

Over 40 percent of women in the 15-64 years age group are full time housewives and a closer analysis reveals the existence of an inverted " $\mathrm{U}$ " or "M" shape for FLFP rates which show a decline in participation rates after the age of 34. The labour force participation rate of women aged 20-29 years was above 60 percent in 2009 , indicating that younger women are more likely to be economically active. With a shift away from traditional occupations, the proportion of women who worked as unpaid family workers has been falling, from about 40 percent in 1970 to 10 percent in 2000. More than 75 percent of the women workers are now working as employees. Statistics also show that 42 percent of females outside the labour force have worked previously whereas 58 percent of the country's working women are married and hold dual roles (Labour Force Survey Report, Malaysia, 2010). 
This increasing trend of women's participation, particularly in the modern sector of the economy has various implications for women, most of whom also have roles in the family relating to childcare. Many women in their 30s, who have a minimum of 11 years of schooling and are married, are leaving the labour market due to caring responsibilities and to become home-makers and being replaced by foreign labour.

Table 3.1- Female Labour Force Participation Rates by Age Group for Malaysia, 1970-2010

\begin{tabular}{lllllllll}
\hline Age Group & $\mathbf{1 9 7 0}$ & $\mathbf{1 9 8 0}$ & $\mathbf{1 9 8 5}$ & $\mathbf{1 9 9 0}$ & $\mathbf{1 9 9 5}$ & $\mathbf{2 0 0 0}$ & $\mathbf{2 0 0 5}$ & $\mathbf{2 0 1 0}$ \\
\hline $15-19$ & 33.0 & 33.5 & 28.2 & 25.3 & 19.1 & 19.8 & 16.4 & 12.2 \\
\hline $20-24$ & 41.9 & 54.0 & 56.2 & 63.4 & 60.4 & 63.6 & 56.2 & 51.6 \\
\hline $25-29$ & 38.4 & 44.6 & 49.4 & 54.3 & 58.3 & 63.1 & 64.3 & 66.0 \\
\hline $30-34$ & 39.0 & 40.5 & 46.1 & 49.8 & 51.0 & 54.4 & 57.5 & 61.0 \\
\hline $35-39$ & 40.0 & 42.7 & 48.0 & 49.3 & 51.1 & 52.1 & 52.7 & 57.7 \\
\hline $40-44$ & 40.0 & 43.8 & 47.8 & 46.4 & 50.2 & 52.5 & 51.4 & 53.2 \\
\hline $45-49$ & 40.7 & 41.4 & 48.8 & 42.7 & 45.9 & 49.0 & 49.3 & 51.1 \\
\hline $50-54$ & 36.6 & 36.5 & 41.6 & 34.0 & 37.6 & 38.3 & 39.9 & 42.5 \\
\hline $55-59$ & 29.2 & 30.8 & 31.2 & 24.6 & 26.3 & 25.8 & 28.5 & 27.9 \\
\hline $60-64$ & 23.7 & 25.0 & 24.9 & 17.3 & 16.2 & 19.0 & 19.3 & 17.6 \\
\hline & & & & & & & & \\
\hline $15-64$ & 36.3 & 39.3 & 43.9 & 44.4 & 44.4 & 46.7 & 45.9 & 46.1 \\
\hline Source: & & & & & & & &
\end{tabular}

Source: Labour Force Survey Report various years, (1970-2010)

Table 3.1 shows that since 1985 , the female labour force participation rate has only increased two percentage points. Another interesting point is that, there has been a consistent reduction in the women in the 15-19 years age group, showing that there are more women furthering their studies. 
Figure 3.2 - Female Labour Force Participation Rate by Age Group for Malaysia

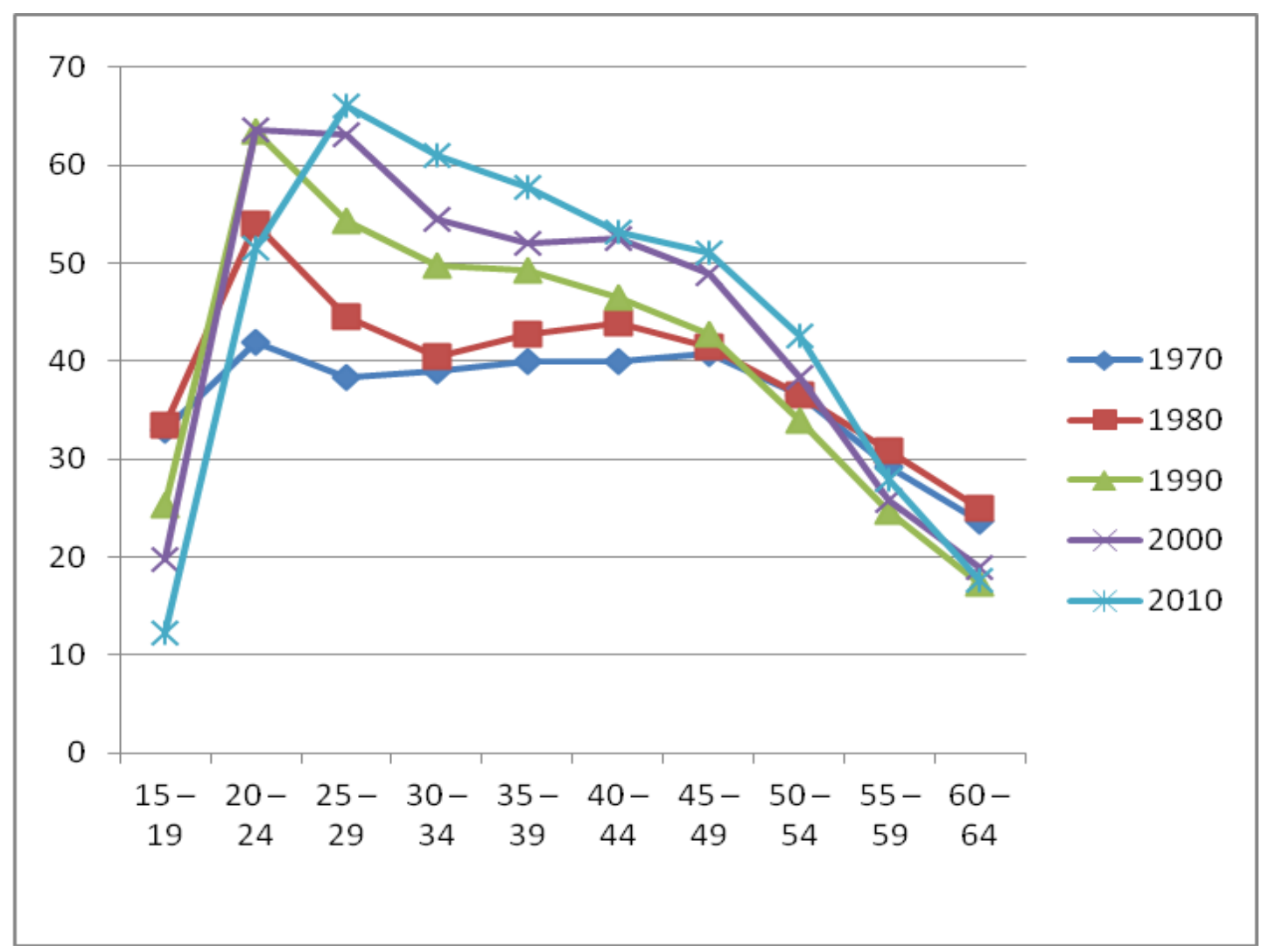

Source: Labour Force Survey Report various years, (1970 - 2010)

Figure 3.2 shows the trend of female labour force participation (FLFP) rates in various age groups as categorised by the Malaysian Labour Force Survey Report. The FLFP rate shows an M-shape (bimodal) consisting of two peaks throughout the age groups from 1970 until 1985. The first peak of the increase is noted at ages 20 to 24 years and could possibly be explained by the huge migration of young, single women from the agricultural sector to the manufacturing sector in urban areas (Siti Rohani, 2009). This trend was more visible in the first phase of industrialisation with the EOI policy and the influx of MNCs. The second peak at the age of 35 to 39 years, though small, was formed mainly due to the re-entry of married women into the service business (Maimunah \& Rusinah, 1999). However, after 1985, as the nation went into the second phase of heavy industrialisation, it is strikingly noted that the FLFP rate became a single peak, with a downward trend after the age of 30 years. 
The phenomenon of women's exit from the labour force and subsequent reentry into the labour force is prevalent in the rural sector in Malaysia where traditionally they are self-employed or work in the informal agricultural sector. The FLFP rate in the rural sector shows a "M" shape (or inverted "U" shape) where the FLFP rate increased from the 15-34 years age group, dropped slightly in the 35-39 age group, and later increased again in the 35-39 age group before showing a steady decline. This caused a twin peak FLFP rate for women until the late 1980s. However, after 1985, the FLFP rate shows an inverted U shape, meaning that women leave the labour force in increasing numbers from the 35-39 years age group.

In the case of males, the labour force participation went through the distinct three stages, showing an upward movement of male workers in the age groups of 1519 years and reaching the peak at 30-34 years and declining at the age group of 5559 years, as the retirement age was 55 years until 2008. Male labour force participation rates are higher than the females' in each age group, but since the 1970s, the FLFP rates have been increasing.

Regardless of ethnicity, the three main ethnic groups of Malays, Chinese and Indians also reveal the same pattern of twin peaks at the age group of 20-24 years and 40-44 years in the rural sector but a single peak in the urban sector. This means that women exit the labour force in large numbers from the 30-34 years age group and increase from the 35-39 years age group reaching the second peak at 40-44 years age group. As a result, the total FLFP rate shows a single peak where the women exit the labour force in the 30-34 years age group and the rate continually decreases. A micro level study by Subramaniam et al. (2010c) revealed that childbirth followed by childcare is the main reason cited for this phenomenon, which is more prevalent in the urban, formal sector.

Improved educational standard generally is a major factor for nations to progress and primary means of gaining employment especially in the manufacturing and services sectors. In the case of female labour in Malaysia, increased educational attainment has played a crucial role in increasing their participation in paid labour, both in the formal and informal sectors, slowly eliminating the perception of women 
as home-makers. With increased tertiary education, more women have participated in paid labour. Labour force participation rates were higher for upper middle class women who have had access to secondary and tertiary education (Shamsulbariah, 1994).

The 1980 Population and Housing Census showed that the employment structure for most economic sectors changed significantly over the period of 1970-80 (DOS, Malaysia, Population and Housing Census, 1981). The greatest employment growth was experienced in the construction sector, which experienced an annual growth rate of 19.9 percent, followed by the manufacturing and services sector.

Rapid industrialisation and increase in income levels resulted in a significant increase in employment opportunities in the services sector in the 1990s (Fong, 1986). Maimunah and Aminah (1999) highlighted how the labour intensive MNCs employed women to produce consumer goods by tapping on young, single, migrant women because of their perceived characteristics of patience and possessing nimble fingers. Since most of the MNCs set in the 1970s have not relocated except for a few firms which have become more capital intensive, women are still employed in large numbers as production operators in these MNCs.

Table 3.2 shows that the manufacturing and services sectors are dominated by females and the participation of women in the services sector is increasing. The percentage of women in the services sector has increased in the last decade from 23 percent in 1970 to 69 percent in 2010 and hence, the working environment in the services sector needs to be re-examined. 
Table 3.2 - Percentage Distribution of Female Labour Force by Sector, $1970-2010$.

\begin{tabular}{lrrrrrr}
\hline Sector & $\mathbf{1 9 7 0}$ & $\mathbf{1 9 8 0}$ & $\mathbf{1 9 9 0}$ & $\mathbf{2 0 0 0}$ & $\mathbf{2 0 0 5}$ & $\mathbf{2 0 1 0}$ \\
\hline Manufacturing & 8.1 & 16.3 & 24.3 & 31.5 & 31.7 & 17.9 \\
\hline $\begin{array}{l}\text { Agriculture, Forestry } \\
\text { and Life stock }\end{array}$ & 67.9 & 49.3 & 28.2 & 11.9 & 9.0 & 8.5 \\
\hline Mining and Quarrying & 0.7 & 0.3 & 0.2 & 0.2 & 0.1 & 0.2 \\
\hline Construction & 0.5 & 1.0 & 0.7 & 1.5 & 0.4 & 2.3 \\
Services & 22.8 & 33.1 & 46.6 & 54.9 & 58.8 & 71.1 \\
\hline Total & 100.0 & 100.0 & 100.0 & 100.0 & 100.0 & 100.0 \\
\hline
\end{tabular}

Source: Sixth, Seventh, Eighth, Ninth and Tenth Malaysia Plan, Government Printers, Kuala Lumpur, various years from 1970 to 2010.

Figure 3.3 - Percentage Distribution of Female Labour Force by Sector, $(1970-2010)$

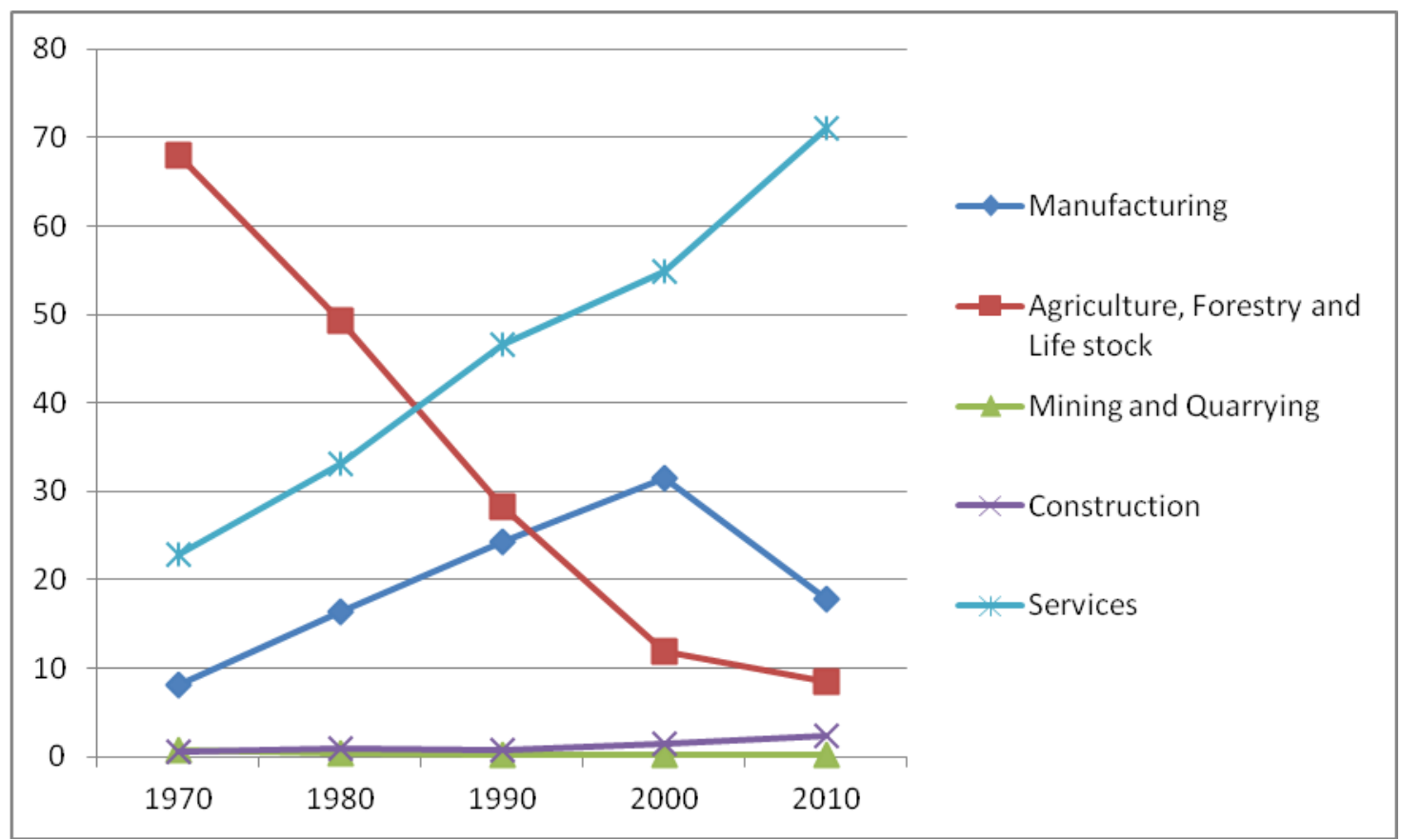

Source: Sixth, Seventh, Eighth, Ninth and Tenth Malaysia Plan, Government Printers, Kuala Lumpur

Table 3.3 shows a comparison of employment distribution of males and females by sectors from 1970 till 2010 to illustrate significant differences in the pattern of male and female employment in economic sectors and the changes which have taken place in the last 40 years. 
In the early years after independence, agriculture was the mainstay of the economy and women contributed 68 percent of the labour force in this sector which faced a sharp shrinkage from the 1970s. This trend coincided with the government's EOI strategy and the growth in the secondary and tertiary sectors. In the early years of industrialisation, the manufacturing sector became the leading sector that formed the highest share of employment expanding from 16 percent in 1980 to 31.7 percent in 2005. This has been mainly due to the outstanding growth in the manufacturing sector and its large contribution to the GDP. This time period also noted that over 50 percent of the jobs created came from the manufacturing sector. Increases in job opportunities occurred in the electrical and electronics industries, along with other industries such as garment, textiles and food processing which were often labelled as "industrial feminisation" and the real sector that encouraged more women to participate in the labour-intensive industrial sector. However, during the economic crisis in 1998/99, the economic contraction caused a lot of firms to retrench their employees. Eighty-six percent of these firms were primarily involved in urban-based activities (UN, 1998) and Jomo (1999), shows that majority of the retrenched workers were female workers.

The services sector which was the second highest contributor to total employment in the early years of EOI demonstrated positive growth and became more important in its second phase (1990s). This drew in more female workers in many areas of the services sector, especially in the wholesale, retail trade, restaurants and hotels category, which saw an increase of 20 percent and the community, social and personal services category, which increased 14 percent between 1970 and 2008 . This clearly suggests that both services are deemed suitable for women due to their domesticity and so called feminine nature. However, there were also more female workers than male workers in the finance and business category which has been a male dominant area for many years. Figure 3.4 shows that most of the females are concentrated as production operators in the manufacturing sector or as sales and service workers in the wholesale, retail trade, restaurants and hotels. 
Table 3.3- Employment Distribution by Sector and Gender (\%), Malaysia, $1970-2010$.

\begin{tabular}{|c|c|c|c|c|c|c|c|c|c|c|}
\hline Sector & $\begin{array}{l}1970 \\
F\end{array}$ & $\begin{array}{l}1970 \\
-M\end{array}$ & $\begin{array}{l}1980 \\
-F\end{array}$ & $\begin{array}{l}1980 \\
M\end{array}$ & $\begin{array}{l}1990 \\
F\end{array}$ & $\begin{array}{l}1990 \\
\text { M }\end{array}$ & $\begin{array}{l}2000 \\
F\end{array}$ & $\begin{array}{l}2000 \\
M\end{array}$ & $\begin{array}{l}2010 \\
\text { F }\end{array}$ & $\begin{array}{l}2010 \\
M\end{array}$ \\
\hline $\begin{array}{l}\text { Agriculture, } \\
\text { hunting, } \\
\text { forestry \& } \\
\text { fishing }\end{array}$ & 67.9 & 49.6 & 43.8 & 33.9 & 25.3 & 26.4 & 11.9 & 17.3 & 8.5 & 16.0 \\
\hline $\begin{array}{l}\text { Mining and } \\
\text { Quarrying } \\
\text { Manufacturing }\end{array}$ & $\begin{array}{l}0.7 \\
8.1\end{array}$ & $\begin{array}{l}2.3 \\
9.3\end{array}$ & $\begin{array}{c}0.4 \\
18.4\end{array}$ & $\begin{array}{c}1.3 \\
14.9\end{array}$ & $\begin{array}{c}0.2 \\
26.8\end{array}$ & $\begin{array}{c}0.8 \\
16.2\end{array}$ & $\begin{array}{c}0.2 \\
33.5\end{array}$ & $\begin{array}{c}0.6 \\
24.5\end{array}$ & $\begin{array}{c}0.2 \\
17.9\end{array}$ & $\begin{array}{c}0.6 \\
16.3\end{array}$ \\
\hline $\begin{array}{l}\text { Electricity, Gas } \\
\text { and Water } \\
\text { Construction }\end{array}$ & $\begin{array}{l}0.1 \\
0.5\end{array}$ & $\begin{array}{l}1.0 \\
3.1\end{array}$ & $\begin{array}{l}0.2 \\
1.0\end{array}$ & $\begin{array}{l}1.9 \\
8.1\end{array}$ & $\begin{array}{l}0.2 \\
0.8\end{array}$ & $\begin{array}{l}1.0 \\
9.4\end{array}$ & $\begin{array}{l}0.2 \\
1.5\end{array}$ & $\begin{array}{c}1.1 \\
11.8\end{array}$ & $\begin{array}{l}0.3 \\
2.3\end{array}$ & $\begin{array}{c}0.6 \\
13.0\end{array}$ \\
\hline $\begin{array}{l}\text { Wholesale, } \\
\text { retail trade, } \\
\text { restaurants and } \\
\text { hotels }\end{array}$ & 5.8 & 11.6 & 12.0 & 15.7 & 19.2 & 17.7 & 19.0 & 16.0 & 16.2 & 16.2 \\
\hline $\begin{array}{l}\text { Transport, } \\
\text { storage and } \\
\text { communication }\end{array}$ & 0.5 & 5.0 & 1.0 & 6.1 & 1.5 & 6.2 & 1.8 & 6.7 & 2.5 & 7.1 \\
\hline $\begin{array}{l}\text { Financing, } \\
\text { insurance, real } \\
\text { estate \& } \\
\text { business } \\
\text { services }\end{array}$ & - & - & - & - & 4.0 & 4.3 & 6.1 & 5.0 & 9.2 & 7.0 \\
\hline $\begin{array}{l}\text { Community, } \\
\text { social and } \\
\text { personal } \\
\text { services } \\
\text { Total }\end{array}$ & $\frac{16.4}{1000}$ & $\frac{18.1}{1000}$ & $\frac{23.2}{1000}$ & $\frac{18.2}{1000}$ & $\frac{22.1}{1000}$ & $\frac{18.4}{1000}$ & $\frac{25.8}{1000}$ & $\frac{17.0}{1000}$ & $\frac{30.4}{1000}$ & $\frac{14.9}{1000}$ \\
\hline
\end{tabular}

Source: Labour Force Survey Report various years, (1970 - 2010) 
Figure 3.4- Employment Distribution by Sector and Gender (\%), Malaysia, 2010

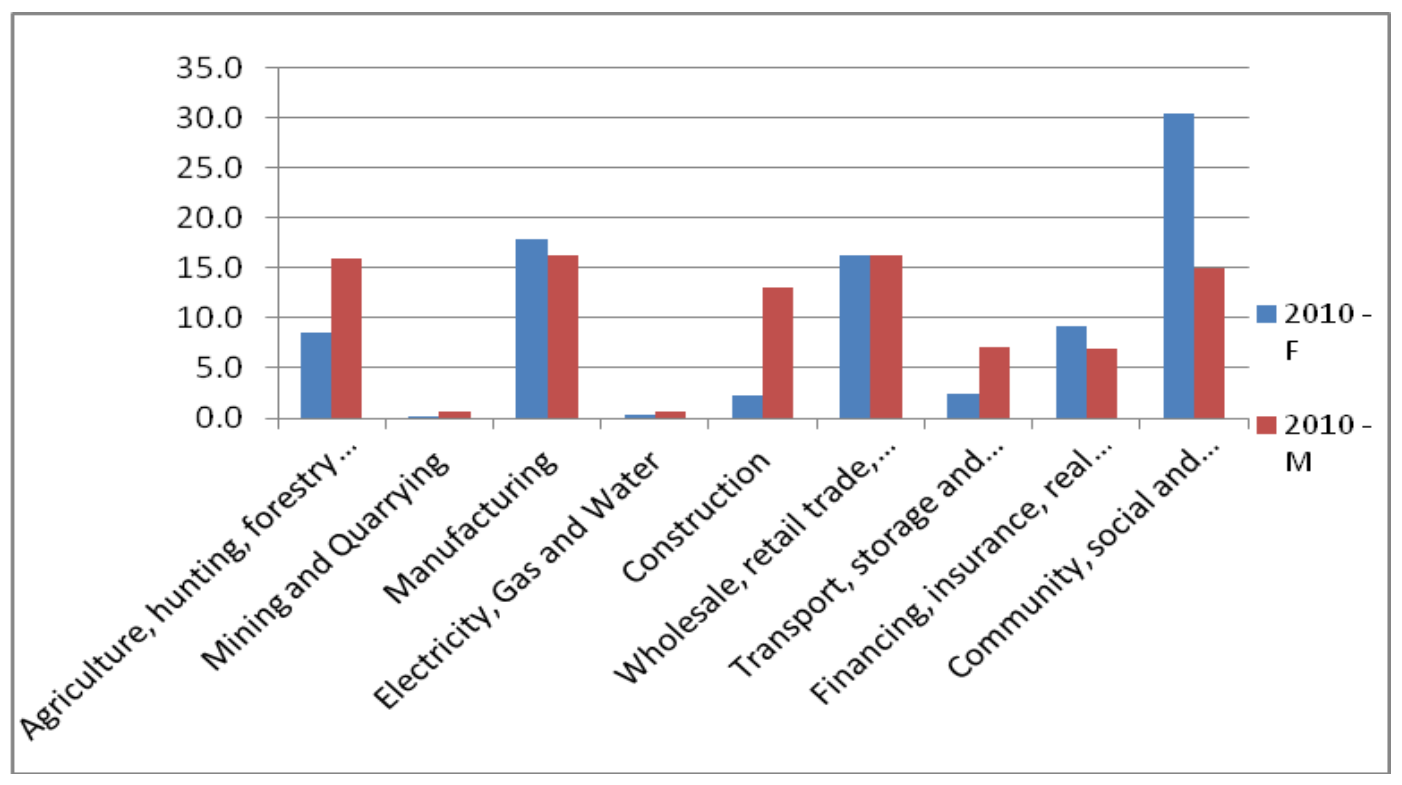

Source: Labour Force Survey Report various years, (1970 - 2010)

With an increase in educational attainment and changes in attitude, the nation saw more professionally and technically qualified women resulting in a 15 percent increase from 1980 to 2008. While female employment in the production category increased from 3.1 million in 1980 to 5.4 million in 2005, the agricultural sector saw a dip in both female and male employment.

By 2010, female workers in Malaysia were employed in various occupational fields, such as production, sales, clerical, professional and technical, which is in contrast to male employees who were more dominant in production and agriculture. Male employment saw higher growth rates in administrative and managerial positions in comparison to female employment. These figures reveal that even though more women were entering the paid labour force, they were being employed in low status and low paid occupations, which were highly regarded as "feminine" in nature (Hing, 1984; Siti Rohani, 1994).

Other than the agricultural sector, females have higher growth rates with 5 percent or more in all fields. The only other field where females outnumbered males 
is the clerical field where the females share increased from 43 percent in 1980 to 58 percent in 2005. Table 3.4 also shows a very steep increase in the professional and technical occupations from 7.7 percent in 1980 to 23 percent in 2010 which can be due to the over-representation of females in the teaching and nursing profession (Siti Rohani, 1994). It is also evident that a large gap persists between men and women in the administration and managerial position indicating that men still monopolise these jobs.

Table 3.4 - Employment Distribution by Occupational Level and Gender (\%), Malaysia, $1980-2010$.

\begin{tabular}{|c|c|c|c|c|c|c|c|c|}
\hline Occupation & $\begin{array}{l}1980 \\
-F\end{array}$ & $\begin{array}{l}1980 \\
-M\end{array}$ & $\begin{array}{l}1990 \\
-F\end{array}$ & $\begin{array}{l}1990 \\
-M\end{array}$ & $\begin{array}{l}2000 \\
-F\end{array}$ & $\begin{array}{l}2000 \\
-M\end{array}$ & $\begin{array}{l}2010 \\
-F\end{array}$ & $\begin{array}{l}2010 \\
-M\end{array}$ \\
\hline $\begin{array}{l}\text { Professional, } \\
\text { technical \& } \\
\text { related } \\
\text { workers }\end{array}$ & 7.7 & 6.2 & 10.2 & 6.4 & 13.5 & 8.9 & 23 & 18 \\
\hline $\begin{array}{l}\text { Administration } \\
\& \text { managerial } \\
\text { workers }\end{array}$ & 0.3 & 2.6 & 0.7 & 3.0 & 2.2 & 4.7 & 4.8 & 8.3 \\
\hline $\begin{array}{l}\text { Clerical \& } \\
\text { related } \\
\text { workers }\end{array}$ & 10.7 & 7.1 & 14.2 & 7.4 & 17.5 & 7.1 & 19.3 & 4.7 \\
\hline $\begin{array}{l}\text { Service and } \\
\text { sales workers }\end{array}$ & 19.5 & 18.5 & 24.8 & 21.7 & 19.5 & 18.1 & 20.1 & 14.7 \\
\hline $\begin{array}{l}\text { Agriculture, } \\
\text { animal } \\
\text { husbandry \& } \\
\text { forestry }\end{array}$ & 42.0 & 32.4 & 25.1 & 26.8 & 14.8 & 20.4 & 8.2 & 14.0 \\
\hline $\begin{array}{l}\text { Production \& } \\
\text { related } \\
\text { Workers, } \\
\text { transport etc }\end{array}$ & 19.3 & 33.2 & 25.1 & 34.7 & 22.6 & 38.4 & 24.6 & 40.3 \\
\hline Total & 100.0 & 100.0 & 100.0 & 100.0 & 100.0 & 100.0 & 100.0 & 100.0 \\
\hline
\end{tabular}

Source: Labour Force Survey Report various years, (1970 - 2010) 
In terms of employment status, the Malaysian data categorises into four groups, namely employers, employees, own account workers and unpaid workers. Table 3.5 shows that more than 80 percent of the employers are males and this trend is evident until current times with 85 percent of employers being males in 2010 . The increasing number of women in paid labour is shown with an increase in the percentage of employees from 32 percent in 1980 to 38 percent in 2010, with female workers still making up 67 percent of unpaid workers category in 2010. Women have constantly been engaged in low status employment. Women constituted 22 percent of the self-employed population, involved in formal urban based business, especially in service-oriented businesses.

Table 3.5: Percentage Distribution of Economically Active Population by Employment Status and Gender, Malaysia, 1970 - 2010.

\begin{tabular}{|c|c|c|c|c|c|}
\hline \multirow[t]{4}{*}{ Year } & \multirow[t]{4}{*}{ Gender } & & \multicolumn{3}{|c|}{ Employment Status } \\
\hline & & \multirow[b]{3}{*}{ Employer } & \multirow[b]{3}{*}{ Employee } & Own & Unpaid \\
\hline & & & & Account & Worker \\
\hline & & & & Worker & \\
\hline \multirow[t]{3}{*}{1980} & Female $(\%)$ & 15.6 & 32.7 & 26.9 & 62.8 \\
\hline & Male (\%) & 84.4 & 67.3 & 73.1 & 37.2 \\
\hline & Total ('000) & 104 & $2,601.50$ & 863 & 448.2 \\
\hline \multirow[t]{3}{*}{1990} & Female $(\%)$ & 8.6 & 34.8 & 26.8 & 64.8 \\
\hline & Male $(\%)$ & 91.4 & 65.2 & 73.2 & 35.2 \\
\hline & Total ('000) & 194.6 & $4,412.40$ & $1,383.90$ & 694 \\
\hline \multirow[t]{3}{*}{2000} & Female $(\%)$ & 11.8 & 34.2 & 24 & 64.5 \\
\hline & Male $(\%)$ & 88.2 & 65.8 & 76 & 35.5 \\
\hline & Total ('000) & 202.3 & $6,602.50$ & $1,489.10$ & 543.9 \\
\hline \multirow[t]{3}{*}{2010} & Female $(\%)$ & 15.4 & 37.9 & 21.7 & 67.4 \\
\hline & Male $(\%)$ & 84.6 & 62.1 & 78.3 & 32.6 \\
\hline & Total ('000) & 371.4 & $7,951.10$ & $1,851.10$ & 486.0 \\
\hline
\end{tabular}

Source: Calculated from Labour Force Survey Reports, various issues $1980-2010$.

Thus it is evident that as the Malaysian economy expanded, it saw more women participating in the labour force, particularly in paid work. 


\subsection{Women and work - the regulatory framework}

The main laws governing employment and industrial relations in Malaysia are the Employment Act 1955, the Industrial Relations Act 1967 and the Trade Unions Act 1959. While the Employment Act provides minimum terms and conditions to certain categories of employees, the Industrial Relations Act provides ways for settlement of trade disputes between employers and employees. Meanwhile, the Trade Unions Act regulates trade union registration and the uses of trade union funds.

The Employment Act 1955 applies to all employees in Peninsular Malaysia and the Federal Territory of Labuan. The categories of employees included in the Employment Act are any employees whose monthly wage is less than RM1,500; any employee employed in manual work regardless of his/her monthly wage including an artisan, apprentice, transport operator, supervisor or overseer of manual workers, a person employed in any capacity in vessels registered in Malaysia and even a domestic servant.

Basically, The Employment Act governs private sector employees by regulating the relationship between employer and employee and by legislating the basic terms and conditions of employment including contract of service, payment of wages, employment of women, maternity protection, hours or work, overtime, rest days, annual and sick leave, public holidays, termination benefits and so on. This is the major legislation which regulates all labour relations, and certain parts apply equally to men and women, such as contracts of service, wages, rest hours, hours of work, holidays, annual leave, sick leave, maternity benefits and termination and layoff benefits.

There is no separate law or legislation for equal pay and one major aspect which could be detrimental to women workers includes the absence of mention of equal pay for equal work in The Employment Act 1955. Women in the private sector are still subject to wage discrimination as compared to their male counterparts and they do not at present have any legal redress against wage discrimination (Ahmad, 
1998). As it is difficult to address without legislation, there is discrimination. However, it is more fair and just in the public sector where women get equal pay for equal work.

Currently, minimum wages apply only to certain types ${ }^{22}$ of employees and industry, so workers in an industry who believe they need the protection of a minimum wage may request that the Ministry of Human Resources establish a wage council.

In spite of non-governmental organisations (NGOs) and women groups pushing for it, they have not been successful in implementing any anti discrimination law on the basis of gender or ethnicity in Malaysia.

Malaysia has actually signed and ratified the International Labour Organisation (ILO), and Committee on the Elimination of Discrimination against Women (CEDAW) with some reservations, but it is more an unwritten rule how salary and wages are decided. Studies show that wages are lower for females than males at the management level, not so much at the officer and executive level (Fernandez, 2000). It is more an individual case to case issue which is brought up at the Industrial court if they can prove that there has been an element of discrimination.

The provisions of the Industrial Relations Act 1967 are carried out by the Department of Industrial Relations with the general direction, control, and supervision of all matters relating to industrial relations. This Act specifies ways in resolving differences or disputes between employer and employee or employees and their trade union and identifies techniques and agencies involved in solving the grievances between them ${ }^{23}$. The four main principles are based on trade unionism, union recognition, collective bargaining and dispute resolution.

\footnotetext{
${ }^{22}$ For example, employees in hotel and catering services, shop assistants, cinema workers, stevedores and cargo handlers and just recently security workers.

${ }^{23}$ For example, employees in hotel and catering services, shop assistants, cinema workers, stevedores and cargo handlers and just recently, security workers.
} 
Collective bargaining is a process used by representatives of the employers and the trade union to negotiate issues relating to wage agreements, conditions of works and other terms of employment. The other Act that regulates trade unions is the Trade Unions Act 1959 which regulates union activities including registration, membership and the use of trade union funds. The Director General of Trade Unions has the general supervision, direction and control of all matters relating to trade unions throughout the country. Malaysia has actually signed and ratified the ILO covenant on CEDAW but it is more an unwritten rule how salary and wages are decided, especially in the private sector.

These laws apply to employees in the private sector, and to all types of employees - casual, temporary and part-time employees, trainees, full time local employees or foreign employees. The Industrial Relations Act 1967 applies throughout the country (West Malaysia and East Malaysia) while the Employment Act applies to only Peninsular Malaysia and the Federal Territory of Labuan, with similar laws in East Malaysia. Both the departments are under the purview of the Ministry of Human Resources. Trade Unions come under the purview of the Malaysian Trade Union Congress.

The concept of "part-time employee" was added in the Employment Act in 1998. Even though the Act protects "part-time employees", employers most of the time argue on the issue of providing benefits for part-time employees resulting in pro-rated benefits or exclusion of benefits and this is one of the reasons which has lead to non acceptance of part-time employment in the country.

The "Work Regulations for Part-time Workers" came into effect on 1 October 2010 and this is a positive move towards increasing the latent labour force of some 6.8 million latent workforce comprising housewives, including single mothers, university students, and retirees. "Part-time employees" under the amendment are defined as employees who work between 30 percent - 70 percent of the normal working hours of a full-time employee in the same company carrying out the same work. This regulation allows flexibility in the number of hours put in by each employee for each day. Employers can choose to allow part-time employees to 
work eight hours in one day but put less hours another day and wages can be calculated on hourly, daily, weekly or monthly basis. However, the purview is on the employers to approve this policy and is not based on employees' needs.

In Malaysia, the average number of working hours per week is 48 hours, which is the maximum provided in the Employment Act 1955, with daily working hours not exceeding eight hours. However, in practice, many employees work more than 48 hours a week particularly in the private sector and 45 hours a week in the government sector. It was noted that generally males work longer hours compared to female workers. Among the age groups, younger workers were also observed to work longer hours in comparison to older workers (DOS, Labour Force Survey Report, 2010).

The Employment Act 1955 defines the work week as 48 hours, with a maximum of eight working hours per day and six working days per week. But as a policy to encourage time spent with family, the government implemented a five day working week for all government agencies in 2005. This move was quickly followed by the private sector and all multinational corporations. In 2007, the government in its move to increase flexibility at the workplace and to reduce traffic congestion implemented staggered working hours. Normal business hours in the private sector in Malaysia are 9 a.m. to 5 p.m. Mondays to Fridays, while all government offices are open five days a week, working staggered hours between 7.30 a.m. to 5.30 p.m. In all states except the states of Kedah, Kelantan and Terengganu, offices are open from Mondays to Fridays. Saturdays and Sundays are considered weekends and hence, the offices are closed during these days.

There has been no legislation about FWA in Malaysia, other than proposals from government with respect to part-time employment and small office home office For more employers to implement FWA such as flexi work, permanent part-time and working from the home, the regulatory framework is being addressed step by step but it has to be implemented more urgently so as to benefit the potential workers. There is a need to offer greater flexibility of work for full time employees in terms of flexibility of work location and flexibility of work hours. The provisions and benefits 
of part-time employment and other non-standard working arrangements should be spelt out clearly so that more employers will be encouraged to offer this at their workplace. A few of the common FWA in Malaysia are discussed in the next section.

\subsection{Flexible Working Arrangements in Malaysia}

Despite the lack of legislation, progress has been made in recent years in workplace and government policies that benefit dual career families. Some of the more common FWA implemented in Malaysia include flexible working time, staggered working time, working from home, telecommuting, small office home office (SOHO) and part-time work.

In terms of flexible working time, staggered working hours were introduced in all government offices from June 2007 as mentioned above where civil servants are required to clock in for work at three different times from 7.30 a.m. until 4.30 p.m., from 8 a.m. till 5 p.m. and from 8.30 a.m. till 5.30 p.m. The government decided to implement the system nationwide after it found that staggered working hours had contributed to higher productivity among civil servants.

Another initiative taken by the government was "working from the home pioneer programme" which was being pilot tested by the Public Services Department, Works Ministry in January 2010. Thirty-nine civil service employees who were highly experienced and who did not need much supervision were identified to participate in this programme where close monitoring was done by the supervisors as the staff had to turn on their computers to "clock in" in the mornings and "clock out" in the evenings. This pilot project of "Work from the Home", a majority of who participated were women, and proved to be a success among the employees, with a productivity increase of 90 percent to 100 percent and a cost reduction of RM8, 000 for a three-month period for the Government (New Straits Times, February 2011). 
Another reason for implementing FWA in Malaysia was to reduce traffic congestion on the roads especially in the Klang Valley, which has one of the highest concentration of roadway and tolled highways in the world. Despite the good basic infrastructure in the country, massive traffic jams still exist especially in the Klang Valley, and extend the working day due to lack of connectivity of public transportation. A study done by MITRANS ${ }^{24}$ in 2011 shows that only 17 percent or approximately 1.24 million trips per day are completed using public transport while the remaining of 83 percent, or 6 million trips, were made using private transport, which are mostly single occupancy vehicles. Comparing this situation to Singapore, Hong Kong and London where the share of public transport trips is $64 \%, 74 \%$ and 90\% respectively, the huge traffic jams and constant gridlock though the Klang Valley are expected. One of the main reasons cited by this study is the lack of coordinated planning by a single agency that takes ownership of the responsibility of looking at public transport as a network instead of piecemeal 'projects'. As a result, there is a lack of connectivity and networking in the public transport system.

Malaysia has a very good home working network for individual females who would like to work from the home called e-homeworking. E-homeworking is another endeavour which was started by an individual but has managed to get the support of many NGOs and the Ministry of Women, Family and Community Development. Ehomeworking promotes working from home, teleworking and the running of SOHO (small office home office) businesses through the use of information and communications technology ${ }^{25}$. The e-community promotes self-help, business partnerships and entrepreneurship development for those who want to balance work and home life. The main profit oriented activity of this organisation is producing and selling eco-baskets (which are made from recycled paper and magazines) to empower women to embark on social-economic self-reliance.

\footnotetext{
${ }^{24}$ The Klang Valley also has 3.2 million cars and this number is growing at an exceedingly fast rate at an average of 30,000 cars per month. This was reported in a media release on 11 May 2011 with reference to a study On Klang Valley MRT: Advancing Policies And Public Transport by MITRANS@UITM.

25 For further details about their various contributions to women, please refer to http://www.ehomemakers.net
} 
There are very few companies in the private sector which implement staggered working hours. Some larger companies do implement some form of FWA like flexitime and working from the home policies. For example, many multinational companies such as Shell, Cisco, IBM, Agile, HSBC and DHL have very good FWA policies implemented world-wide and also in Malaysia. Although advances in information technology have made it possible to work remotely from a central office while staying in touch with colleagues, thus lowering costs and increasing efficiency, many Malaysian employers are not looking at this option very seriously. Even if they do, flexibility is either chosen by the supervisor or rostered and can be stopped by the employer at his/her discretion.

With respect to family friendly policies, a micro level study in the Klang Valley in 2009 showed that only 16 percent of the organisations surveyed were truly family friendly with a majority 57 percent building strengths towards family friendly policies $^{26}$ (Subramaniam \& Selvaratnam, 2010a). This study showed that while most of the women were interested in FWA such as flexitime, career break, teleworking and permanent part-time employment, the common modes of family friendly policies offered were leave entitlements. As part of an effort to improve the benefits to female employees in the civil service and retain them, a 60-day paid maternity leave was introduced in 1998 and this was superseded by a 90-day maternity leave beginning early 2011. Another policy that allows mothers to take up unpaid leave for up to five years (for the first five children) was introduced in 2009. This policy is sometimes criticised as discriminatory because women employees who have more than five children are not eligible for unpaid leave. As for female employees in the private sector, they are entitled to 60 consecutive days of maternity leave with pay.

Recent investment in support services by the government has helped many working families particularly in the areas of "after school childcare" services and early childhood education services. Improvements to the availability and affordability of childcare services will be essential if more flexible work practices

\footnotetext{
26 Based on Sullivan \& Mainiero's 20 items of evaluation on the common modes of family friendly policies such as different types of leave, career breaks, nursing facilities etc, an organisation's score determined whether it can be categorised as "truly family friendly", "building strengths towards family friendly" and "needs to improve its score by utilising true family friendly benefits".
} 
are to be adopted as a major part of the response to the recession. They provide enriched environments for child development and serve as back up for childcare while parents are at work, retraining or job seeking

\subsection{Other Related Policies and Initiatives}

The government acknowledges that the FLFP rate in Malaysia is very low in comparison to other counties in the region and hence has introduced more affirmative action to encourage women to participate in paid labour.

The National Policy for Women (NPW) was formulated in 1989 to ensure equitable sharing in the acquisition of resources, information and access to opportunities and benefits for the development of both men and women, and this marked an important milestone for women. It also spearheaded the chapter on "Women and Development" in the Sixth Malaysia Plan (6MP) (1991-1995). The 6MP sealed the Government's commitment to address issues relating to female participation in economic activities and to ensure more gender sensitive policies. It saw the beginning of succeeding national development plans to promote greater female participation in the labour force under the various strategic thrusts.

Government policies and good corporate social responsibility practices include achieving an ideal work-life balance. At policy level, the Malaysian government is officially committed to gender equality as articulated in the National Government five- year plans, especially the present one, which is the Tenth Malaysia Plan (2010 -2015), which aims to increase women's participation in the labour force from 46 percent to 55 percent by 2015 .

The government agencies provided an example to the private sector by implementing flexi work time by staggering the start and end periods into three periods in 2006. Government employees can choose to start work at 7.30 a.m. and finish at 4.30 p.m. or 8 a.m. and finish at 5 p.m. or 8.30 a.m. and finish at 5.30 p.m. 
The Ministry of Women, Family and Community Development has embarked on many projects to encourage women's participation in the labour force. For example, for childcare - the government encouraged the setting up of crèches at the workplace by giving grants and encouraged the setting up of community childcare centres for children below four years, especially for the low income families. The Ministry also provides subsidies for parents with young children who earn a monthly income below RM3,000.

In terms of childcare in Malaysia, there are some formal childcare centres which are registered and informal childcare centres being run by housewives as a source of income. The Ministry of Women, Family and Community Development has classified childcare centres into four categories namely: a home-based childcare centre which is a centre which receives less than ten children into the home of a person; institution-based childcare centre which receives ten or more children; a work-place based childcare centre which is at the workplace which receives ten or more children, and a community-based childcare centre which receives ten or more children and receives aid from the government. In spite of all these measures taken by the government to institutionalise childcare, there is still an issue of reliability as public media highlights all the ill happenings and the unreliable nature of small incidents at government-run childcare centres. As this reduces the trust factor, some parents still do not send their children to these state run centres.

The enactment of the Childcare Act $1984^{27}$ was a very positive step by the government to show its seriousness in this issue. The Ministry also set up many crèches and childcare centres throughout the country in its endeavour to enable more working women to have more peace while at work ${ }^{28}$ and also to encourage more women to work in paid labour.

Another policy towards ensuring gender equality is the setting up of "Gender Focal Point" which is headed by the deputy secretary-general of each ministry. The

\footnotetext{
${ }^{27}$ The three main provisions in the Child Care Act 1984 are :-1. Ensure that every childcare centre is registered; 2. Conduct inspection and monitor control and 3. Ensure utmost importance is placed on the welfare, well-being, safety and total development of children.

${ }^{28}$ The setting up of workplace based childcare centre was mainly for this purpose.
} 
objective of the Gender Focal Point is to ensure gender equality in all policies and administration.

One of the most crucial workplace policies which might encourage women to remain in the labour force is paid maternity benefit. Employees in the public sector are eligible for 90 days maternity leave with full leave benefits provided by the government. However, in the private sector, most firms provide 60 days paid maternity leave with all benefits provided by the employers. However, unpaid leave or extension of maternity leave is not a very common entitlement in the private sector but can be applied for by the employees in the government sector. The full cost is borne by the employers and this could be one reason why employers discriminate against employing women.

There is no anti-discrimination legislation in Malaysia to guarantee equal opportunities in recruitment, career development, social security and working conditions, regardless of race, religion or gender. However, The Federal Constitution provides for equality of persons under Article 8, Clause 1, which states, "All persons are equal before the law and entitled to equal protection of the law". Clause 2 states, "Except as expressly authorised by this Constitution, there shall be no discrimination against citizens on the ground of religion, race, descent or place of birth in any law or in the appointment to any office or employment under a public authority or in the administration of any law relating to the acquisition, holding, or disposition of any property or the establishing or carrying on of any trade, business, profession, vocation or employment" ${ }^{29}$ (Jomo, 2007).

Trade unionism has not been encouraged in Malaysia from early 1970s as a measure to attract foreign investment. In 1971, amendments to the Industrial Relations Act of 1967 further limited the right to strike by designating various issues "non-strikeable". This strengthened the power of management by no longer requiring employers to state reasons for dismissal, bolstered "responsible" unions and

\footnotetext{
${ }^{29}$ Jomo, in his paper for ILO (2007) entitled "Policy Coherence Initiative on Growth, Investment and Employment The Case of Malaysia - Development Policies, Macroeconomic Regime and Employment in Malaysia.
} 
fragmented labour unity. Under provisions of the Employment Ordinance, officers of the Labour Department are empowered to decide on matters relating to conditions of employment and wage advances; their decisions can only be reversed by the High Court ${ }^{30}$ (Jomo, 2007).

However, by the 1980s, further limits were imposed on union rights where "management functions" pertaining to recruitment, job assignments, transfers, promotions and redundancies were not subject to collective bargaining. Besides, federation of unions could only be formed if it consists of unions whose membership is confined to a particular trade or industry while Japanese-style in-house unions were encouraged. Trade unions were not allowed in electronic industries before 1989, and even then, only in-house unions were allowed. As wages covered by collective agreements rose in the tight labour market in the 1990s (e.g., 10 percent in 1995), the government announced its support for productivity-linked wages (Jomo, 2007).

According to the Human Resource Minster, at the $5^{\text {th }}$ Human APEC Human Resource Development Ministerial meeting in Beijing, China (The Star, 17 Sept 2010), more robust measures are in the pipeline to transform the country's educational and training system so as to position the Malaysian labour force to meet the needs of the global economy. Improving skills, increasing income and reducing dependency on foreign labour are three of the utmost concerns of government towards a more progressive and high income economy.

In the recent Malaysian Budget 2011, announced by the Prime Minister, the government was very serious in two policy measures to encourage more women to participate in the labour force. Firstly is the Work Regulations (Part-Time Workers) 2010, which was enforced from 1 October 2010 and secondly, is the 1 Malaysia Training Programme to enhance skills in various technical fields such as languages, IT skills and technical courses. It was acknowledged that a better-trained and paid workforce comprising more women can take the country further on the road to success than a dependence on natural resources.

\footnotetext{
${ }^{30}$ For further explanation on how management functions are not subject to collective bargaining and how in-house unions were formed, please see Jomo, 2007.
} 
Many employers acknowledge the benefits of FWA to employers and employees $^{31}$ but are still slow to implement FWA at the workplace as they have cheaper sources of labour from the neighbouring countries and also outsource work to neighbouring countries.

\subsection{Conclusion}

Malaysia has internationalised due to rapid economic development in the industrial sector and as the nation's economic development enters a new era, the services sector contributes 57 percent of the GDP, and this has been accompanied by a significant increase in women's participation in the services sector.

Employment patterns show that women are still heavily concentrated in labour intensive occupations such as clerical workers, production operators and the types of lower level service workers which require little pre-employment training and technical skill acquisition. This leaves women at a disadvantage as the country moves towards a more high-technology and knowledge based economy, moving away from labour intensive industries to capital and skill intensive industries.

The support by the Malaysian Prime Minister to review the Employment Act 1955 to include flexible work hours for the female labour force is testimony that Malaysia accepts that the concept of the workplace now is different from what it was in 1955. Besides, he argues that bringing more women into the workplace has become not a choice but a necessity for both economic development and global competitiveness.

\footnotetext{
${ }^{31}$ Many employers expressed this during the Women's Summit organised annually by the Ministry of Women, Family and Community Development. Most of the employers were large multinational organisations but there were few professional firms implementing FWA because of high rental cost in the city.
} 
This study aims to provide a better understanding of how working arrangements such as FWA in Malaysia may address three big issues namely: worklife balance, empowerment and quality lifestyles and hence, may affect FLFP as well as women's life satisfaction. The methodology and methods used in the study are dealt with in the next chapter. 


\section{Chapter 4}

\section{Research Methodology and Methods}

\subsection{Introduction}

This chapter first describes the methodology and then the methods used in the study. It begins by identifying the epistemological approach to the research before re-examining the problem and objectives of this study. It then explains the unit of analysis, data collection procedures, steps taken in collecting data, development of instruments, and validation of the instruments and analysis of the data procedures. To achieve the objective of examining whether flexible working arrangements at the workplace will be able to bring in more women to participate in the labour force and whether it will benefit Malaysian women, a mixed method approach was utilised for this study. The quantitative method of data collection will be discussed first followed by the qualitative method.

\subsection{Epistemological Approach to the research}

The term 'method' refers to the tools of data collection such as questionnaires and interviews while methodology is based on the philosophical approach or paradigm that underpins the research (Creswell, 2009). Babbie defines epistemology as "the science of knowing systems of knowledge", methodology is defined as "the science of finding out or procedures for scientific investigation" (Babbie, 2010, p.4). Hence the methodology chosen is influenced by the objective of study.

The philosophical schools of thought are associated with two different types of research: positivist with quantitative and phenomenological with qualitative. While quantitative research methods were developed in the natural sciences to study natural phenomenon, qualitative methods were developed in the social sciences to study social and cultural phenomenon (Creswell, 2007). Two major theoretical 
paradigms generally used in social science research are the positivist and phenomenological or interpretive approaches (Creswell, 2009).

\subsubsection{The Positivist Approach}

As Creswell (2009) asserts, the positivist tradition which comes from $19^{\text {th }}$ century writers such as Comte, Mill and Durkheim, challenge the view that one cannot be positive about claims of knowledge especially when studying human behaviour and attitudes $(2009$, p. 7). The positivist approach (also recently known as post positivist) focusses on identifying and assessing the causes that might influence outcomes..

While positivists focus on the facts at their disposal, the world is viewed as external to them and they are assumed to act independently and objectively from social reality. Comte's suggestion that society can be studied rationally and objectively merely assumes that rationality is in the centre stage of making decisions among all individuals and all households (Creswell, 2009). However, positivism asserts that "we can understand and predict even non-rational behaviour" (Babbie, 2010, p. 41).

Even though "evidence established in research is always imperfect and fallible" (Creswell, 2009, p.7), positivism, assumes objectivity as an essential aspect of inquiry, where the scientific method of inquiry begins with a theory, then data is collected which either supports or refutes a theory, and finally necessary revisions are made, before the findings are interpreted. Thus, quantitative methods are used by positivists who look to large samples for the collection of data and provide findings. This study seeks to collect data, evidence and considerations from women employees based on the survey questionnaires. This information will be useful to explain the possible reasons regarding women's low participation in the labour force. 


\subsubsection{The Phenomenological Approach}

In contrast to the positivist school of philosophy, the phenomenological approach views the world as subjective with the researcher being part of what is being researched. Phenomenology argues that science is driven by human interests and it seeks to understand the human experience holistically and inductively (Patton, 2002). As humans are not objects, they are subject to many influences on behaviours, feelings, perceptions and attitudes. A phenomenological approach takes a person's perception of the meaning of an event and it also attempts to understand people's perceptions, perspectives and understandings of a particular, typical, normal situation. This might not be typical of the population but it seeks to get a better understanding of underlying behaviours rather than representation or normative behaviour. By carrying out in-depth interviews, it aids in the understanding of behaviour of values and also allows to make some generalisations of "what something is like" from the respondent's perspective (Leedy \& Omrod, 2010, p.141). Diversity in terms of demographic differences such as age, ethnicity, occupational status and family responsibilities can be better investigated through in-depth interviews.

While the positive approach seeks normative behaviour based on quantitative data, the phenomenological approach which is based on qualitative data attempts to understand people's perceptions, perspectives and understandings of a particular situation (Leedy \& Omrod, 2010, p. 141) This phenomenological part of the study explores the first-person account of women employees in various identified organisations, perceptions of their double burden and relates to their participation in paid labour. It aims to gain a comprehensive understanding of whether workplace reforms such as FWA will be able to encourage more women to work in paid labour. This involves investigating areas such as the demographic background of female employees, their socio-economic background, their family responsibilities and how they juggle work and home. This research aims to gain an in-depth insight into the experiences of the female employees by sharing their experiences of carrying out daily activities to participate in the productive role and the non-productive role. 
In accordance with the nature of the research, a mixed method is used to capture the normative behaviour through questionnaire survey and behaviour and perception from face-to-face interviews.

\subsubsection{The Feminist Lens}

If we look at the research from a feminist paradigm, attention is especially given to aspects of social life which are not revealed by other paradigms. Feminist theory and research focuses on gender differences and how they relate to the rest of the social organisation. Feminist paradigms have an epistemological stand that society is perceived differently by men and women and hence understood in a different way (Babbie, 2010).

Gender differences exist between working men and women which result from socially constructed norms and this is clearly represented in their division of labour at home, the distribution of power and the responsibilities and rights exercised by men and women in managing the home and the career. Feminist paradigms actually reflect a concern for the inequality women face but however they "have an epistemological recognition that men and women perceive and understand society differently" (Babbie, 2010, p. 40). Even though cultural and social values relating to the relations between men and women are found in the construction of gender relations, it varies with culture and normally can change with time.

It is appropriate to use feminist methodology which is seeking attitudes and voices of a group of working women which will be different from men's views.

The focus of this research is to examine female employees' interest towards the uptake of FWA and whether the implementation of FWA may have an effect on their participation in paid labour. In a more detailed sense, it also means to research how division of labour in the home has an effect on women's ability to juggle work and home and to make a choice to work or not to work. 
This study uses a mixed method approach which recognises value of both positivism and phenomenological insights, looking from the feminist methodology which views women differently from men.

\subsection{The Objectives of Study}

The three objectives of the study were examined using a mixed method of qualitative methods and quantitative methods in order to explore whether there exists a convergence or divergence in the perception of female employees in FWA and non-FWA organisations.

To study the first objective of investigating the factors which influence the desire to take up FWA by women employees, a quantitative approach was taken using a survey questionnaire. The factors were grouped into six categories consisting of demographic factors, socio-economic factors, family responsibilities, 'perceived advantages', 'perceived disadvantages' and types of working arrangements. The factors were identified based on the literature and constructs were added based on focus group discussions with groups which consisted of employers, women employees and non-governmental organisations.

To study the second objective, i.e., to assess whether the availability of FWA might contribute to the decision among women workers to participate in the labour force, the same sample as above was used and the same questionnaire had two questions to capture the answers. Perceptions of female employees in organisations which have implemented FWA were compared with female employees in the same type of organisations which have non-FWA. As this was a perception question, the Likert scale was used. There were two aspects for this construct. In the first part, the female employees were required to answer a Yes/No question about their interest and choice in continuing to work in the paid sector. The second part had a perception question. The Likert scale question investigated the perception of these female employees about women and their decision to participate in the labour force. 
To study the third objective of whether flexible working arrangements may have an impact on selected indicators of women's well-being, a mixed method was used. While the quantitative approach used the same questionnaire as above, the qualitative approach used face-to-face interviews. The in-depth interviews were more important than the quantitative analysis to understand the behaviours and attitudes of women employees in FWA and non-FWA. Women's well-being was examined from three selected indicators covering work-life balance, lifestyles and empowerment. These indicators were identified based on the focus group discussion which highlighted some of the apparent reasons why many women exit the labour market in Malaysia. These three main constructs were further subdivided. The constructs and the subdivisions will be dealt with later in this chapter.

\subsection{Research Methods}

In this sequential mixed method strategy (Creswell, 2009), the study begins with a quantitative method adapted from a model by Almer, Cohen \& Single (2003). This is followed by a qualitative method involving detailed interviews with 30 identified participants. According to this pragmatic inquiry, the broad survey in the first phase provides a framework to generalise results to a population and in the second phase, open-ended interviews focusses on collecting detailed views from the respondents.

As quantification makes observations more explicit, it becomes easier to measure in terms of comparison and summarising measures. Qualitative data are able to bring out the richness in meaning compared to quantified data (Babbie, 2010, p. 24). A mixed method approach was thus chosen because of the type of information sought in this study which was both perceptions which are observable and quantifiable, while understanding the behaviour and social construct required indepth interviews. The main methods of data collection were the administration of a questionnaire and intensive, structured interviews. 
The synergistic effect whereby results from the quantitative method assisted in shaping the interview questions for the qualitative method, was useful in this research. Even though Babbie (2010) viewed quantitative research as confirmatory and deductive in nature and qualitative research as exploratory and inductive in nature, in this mixed method approach, the qualitative research actually complements the quantitative research to achieve the objectives. As Creswell and Plano Clark (2007) claim, the overall strength of a mixed method study is greater than either qualitative or quantitative study as it combines the approaches of testing relationships among variables (as in a quantitative study) as well as exploring and understanding a social or human problem (as in a qualitative study) (cited in Creswell, 2009, p. 4).

A good research design should have a clearly defined purpose and evidence of consistency between the research questions and the research method (Kumar, 2005; Sekaran, 2004). So, the mixed method approach used in this study obtained initial results through the questionnaire study and the triangulation process of data collection was done by using interview results. A preliminary study of secondary data further provided the contextual background.

The social values, highest educational level attained, cultural norms and economic freedom of the women vary and have an influence on the respondents' choices. The main research methodology adopted involved several stages namely:

1. Identification of the variables and their operationalising of the definition

2. Determining methods of data collection

3. Sampling

4. Questionnaire design

5. Interviewing

6. Data analysis 


\subsection{Definitions of Variables}

Variables which were directly related to the objectives of the study to answer the research questions were identified through the use of a questionnaire. The variables are explained in detail below.

Almer et al. (2003) showed that demographic factors, socio-economic factors, family responsibilities and perceived advantages and disadvantages influenced employees' interest in taking up FWA at the workplace.

The demographic factors, socio-economic factors and family responsibilities are categorical questions and respondents were required to choose one answer only for each item. As for the 'perceived advantages and disadvantages' questions, which were also categorical, respondents were asked to rate 16 possible statements to test 'perceived advantages' and 12 possible statements to test 'perceived disadvantages' using a 5-point Likert scale.

The demographic factors in this study are sub-divided into three categories namely age, marital status and ethnicity. The age group in this study has been categorised into four groups, beginning with the minimum age women can work. Marital status is an important determinant in women's decision to work in paid labour mainly because of family responsibilities. Malaysia's diverse culture is influenced by the three main ethnicities of Malay, Chinese and Indians, whereby culture plays an important role among some Malaysian women in determining their role at home or in the economy.

Socio-economic status in this study is measured using occupational status as the base line, followed by personal income and educational status. It was noted that generally, respondents in this study were reluctant to disclose their income related information.

Education is an important component in analysing the background characteristics of the respondents as it highly determines the socio-economic status of the respondent. In Malaysia, the educational system comprises three levels: 
primary, secondary and tertiary (diploma and degree). Primary education comprises six years of schooling which begins at the age of six years, while secondary education is for five years. In line with the government's policy of basic education for 11 years, all students have to sit for the Sijil Pelajaran Malaysia examination which is equivalent to " $\mathrm{O}$ " levels. Following this, students have a choice. They either pursue further studies such as Form Six and attain the Sijil Tinggi Pelajaran Malaysia (STPM) certificate which is equivalent to "A" levels, or they pursue a diploma, degree or professional courses in the local colleges and local universities or join foreign twinning programmes offered by most of the private colleges. Generally, a larger proportion of the students attend formal education in public universities while others opt to study in private colleges or foreign universities. As for basic word processing skills, computer classes have been thought formally in all schools since mid 1990's, and the majority of the present generation have acquired these basic skills. By 2009, most students in Malaysia have had a basic 11 years of education, with literacy rate at 94 percent for males and 90 percent for females (Ministry of Women, Family and Community Development, 2010). Hence, the educational attainment in this study is categorised into six sections, with SPM or "O" levels as the basic level. As the respondents in this study have a minimum 11 years of education, they can be termed as "educated".

The occupational level of four groups was identified based on the categories of working population in the country and the different educational and income levels of the respondents. One additional group of lecturers was separated from the "professional" group because their working characteristics were very distinct from the professional or management group.

Family responsibilities were measured in regards to having young children and taking care of elderly parents or relatives. 


\subsection{Sampling Design}

A sampling design suitable to study the objectives and research questions was designed based on past research and input from focus group discussion.

\subsubsection{Sampling Technique}

Based on the statistics from the Labour Force Survey Report, (Malaysia, 2010) six sub-groups in the services sector which had a substantial number of working women were identified. The six subgroups were: Finance, Logistics, Petroleum Shared Services, Telecommunication, Educational Institutions and Professional companies. Then, a list of companies which have FWA was prepared based on the input from the Malaysian Employers Federation (MEF). After discussions with experts in FWA and using the Malaysian country data, this list was further updated and amended. The incorporated list was used to select companies in the services sector in the Klang Valley. However, there were cases when an identified company declined to give permission for the study and hence the next company in the same sub-group was chosen at random. Two companies which were considered examples of best practices of FWA in Malaysia in the services sector were also selected to get an insight into how the women employees in these companies perceived their working arrangements.

Even though the educational sector was not listed on the MEF list, it was chosen because the official statistics show that women are highly concentrated in the educational services. In 2010, 13 percent of all employed females were concentrated in this sub-sector compared to only 4 percent of males (DOS, Labour Force Survey Report, 2010). In terms of lecturers in institutions of higher learning, more than 50 percent are females ${ }^{32}$ (DOS, Social Statistics Bulletin, 2010). Hence, the sub-sector of education was further included in this study to make a better generalisation of women's perception and views on FWA. As the working environment in each

\footnotetext{
32 In 2009, 51.4 percent of lecturers in private universities and 51.2 percent of lecturers in public universities consisted of female lecturers. Computed from Social Statistics Bulletin, 2010.
} 
service sector is quite distinct with its own working conditions and work policies, the sub-groups were carefully selected to provide a better generalisation.

In Malaysia, the majority of female employees (30.5\%) are concentrated in the community, social and personal services sub-sector which consists of government service, education and also health services (DOS, Labour Force Survey Report, 2010). In this sub-sector, government employees have fixed working hours and standard policies which are followed throughout the country ${ }^{33}$. As such, this sub-sector was not chosen. As for the health services, government doctors and nurses work according to shifts while private practitioners are quite flexible with the working arrangements. The second sub-sector which employs many females is the wholesale, retail trade, restaurants and hotels which generally consists of jobs which are considered more versatile and flexible in nature. Hence, these two sub sectors were not chosen in this study as the nature of the employment in these sectors are quite flexible.

Using the purposing sampling technique, a total of seven organisations in the Klang Valley which have implemented FWA were identified from the MEF's list of FWA organisations. Using the comparative method approach (Lijphart, 1971), the corresponding seven organisations which have conventional working arrangements were identified at random.

To reduce selection bias, random sampling was done within each organisation and the women employees were selected at random by the Human Resource Manager or the Manager. From the 14 selected companies, the Human Resource Managers were very cooperative and employees were selected at random by the employer in seven organisations. As for the balance seven organisations, the snow ball technique was used and purposive sampling was done so as to make it as representative as possible in terms of race, age and occupational status.

\footnotetext{
33 All government offices have implemented FWA in the form of staggered working hours. Please see Chapter Three for further explanation.
} 
In Malaysia, the percentage of women in the services sector has shown an upward trend in the last decade and the working environment in the services sector needs to be re-examined. As this study intends to examine whether workplace flexibility may have an impact on women's participation in the labour force, the scope was thus limited to the services sector.

In the first stage, quantitative data was collected in mid 2009 where questionnaires were distributed to the Human Resource Managers of seven companies but the response rate at the initial round was quite low and not satisfactory. Therefore, in the second round, the Human Resource Managers/personnel were briefed and a meeting or focus group session with the females in the companies and the objective of the survey were explained clearly. This resulted in a higher response rate in about ten companies but the balance four companies still had a low response rate.

This study found that only if the respondents were clear about the objectives and trusted the person distributing the questionnaires, the response rate was high and more reliable conclusions could be drawn from the respondents' answers.

In the second stage, interviews were conducted in early 2010 which took three months, where the respondents from the 14 organisations were identified by the human resource personnel. In cases where there were no human resource personnel, the respondents voluntarily agreed to be interviewed and contacted the researcher via email which was mentioned in the questionnaires. There were some limitations to the method employed in the study due to non-cooperativeness from employers in carrying out the field work. This was mainly because of their lack of trust in confidentiality issues and due to time constraint. 


\subsubsection{Scope}

The area of research is the services sector and focussed on organisations located in the Klang Valley. The Klang Valley in Malaysia is an area comprising Kuala Lumpur and its suburbs, and adjoining cities and towns in the state of Selangor. This is where the central business region of the country and the capital of Putrajaya are located. This conurbation had a total population of over 7 million people as of January 2010 and is the heartland of Malaysia's industry and commerce. The Klang Valley is home to a large number of migrants from other states within Malaysia and foreign workers largely from neighbouring Asian countries. To be more specific, most of the respondents for this study originated from major cities and towns namely Putrajaya and various parts of Kuala Lumpur, Petaling Jaya and Shah Alam, including major towns such as Subang Jaya, Port Klang and Klang.

\subsubsection{Sample Size}

The initial plan was to obtain a sample of 500 respondents, which are 250 female employees from FWA organisations and 250 from non-FWA organisations. To avoid errors in inquiry of generalisation, a sufficiently large sample size of 500 respondents was thought to be necessary (Sekaran, 2004, p. 295).

For this survey, 500 questionnaires were distributed, 250 to FWA organisations and 250 to non-FWA organisations. The response rate was slightly lower for the non-FWA compared to the response rate from FWA. The total sample size was 396, which consisted of 57 percent from FWA and 43 percent from nonFWA.

For the qualitative study, 30 respondents from the 14 selected organisations were interviewed and each interview lasted for 40 to 45 minutes. While 50 percent of them volunteered, the balance 50 percent was identified by the human resource personnel of the organisations. 


\subsection{Quantitative Method}

\subsubsection{Instrument}

Careful attention was given in the preparation of the questionnaire which was done in two stages. First, based on literature, questions that might capture the element of the study were identified. This was further tested by holding roundtable discussions with employees in FWA and non-FWA organisations. Two focus group discussions were also conducted with employees and the human resource personnel of two organisations.

According to Malhotra and Birks (2000), it is vital to pre-test the research instrument as it allows the researcher to get feedback, to check the effectiveness of the interview schedule, and to evaluate the practicality of the analysis to be employed. A pilot test was conducted on 50 respondents and the questionnaire was amended before it was carried out on the respondents from the 14 organisations.

Part A consisted of three items on the demographic profile of the respondents; Part B consisted of three items on the socio-economic factors; Part C consisted of two items on family responsibilities; Part D consisted of 16 questions to assess the perceived advantages of FWA to the employees. Part E contained 12 questions to assess the perceived disadvantages. There was a slight variation in the questionnaire for FWA and non-FWA in terms of questions Numbers 26, 27, 28 and 29 (Please refer to Appendix 4.1 and 4.2).

All the variables were identified based on a pilot study and focus group discussion. The questionnaire consisted of four parts. The demographic, socioeconomic factors and family responsibilities parts were generic in nature and the respondents were required to answer Parts $\mathrm{A}$ and $\mathrm{B}$ by ticking the boxes with the most appropriate answer. Part $\mathrm{C}$ which was on family responsibilities was answered by writing the correct answer in the blank space. There were two sub-sections in Part D and Part E, where the first section was on 'perceived advantages' which had 16 items, and the second section was on 'perceived disadvantages' which had 12 items 
in a five-point Likert scale section. The items were based on the model by Almer et al. (2003).

Items measuring the variables in this study were derived from an extensive review of the literature on flexible work arrangements, general work environment support, job insecurity, social support and household attributes. Wherever possible, scales that operationalised constructs were adapted from past research where psychometric properties were already established (Saunders et al., 2007).

The demographic and socio-economic information of the respondents were categorical and answers were obtained by the respondents ticking the relevant boxes at the end of the question. For the demographic factors, respondents had to indicate their age, marital status and ethnic group with which they were identified. As for socio-economic factors, the respondents had to tick the job characteristics, income earned and highest educational level achieved.

\subsubsection{Questionnaire Administration}

After completing sample selection, a pilot test was done among 30 employees, where 15 were from FWA organisations and another 15 from non-FWA organisations. The questionnaire was drafted on the basis of the objectives and theoretical framework. After the pilot test, a few of the questions were modified so as to capture the variables to be tested.

\subsubsection{Statistical Analysis}

Data were cleaned first to remove incomplete questionnaires and to rectify typing errors. To achieve the first objective, logistic regression analysis within blocks, i.e., between independent variables and dependent variable was done. Within each block, stepwise regression was done. Logistic regression must be used when the dependent variable is a discrete variable with a dichotomous Yes/No response (Hair, et al., 2006). As there were four categorical independent variables 
and two continuous variables, factor analysis had to be done on the continuous variable to ensure that the constructs were measuring the factor examined. To achieve the second objective, cross tabulation and independent t-tests were done. The details are explained in Chapter Five.

\subsubsection{Hypothesis Testing}

Although various researchers have attempted to classify reasons for the uptake of FWA according to social, economic and cultural factors, this study follows the framework categorised into three general dimensions for evaluation. Many factors hold explanatory potential in an analysis. In this study, five main groups of independent variables were utilised and the selection was based on various considerations.

As the main objective of the study is to examine whether FWA at the workplace will be able to encourage more women into the labour force and whether there is any impact on women's well-being, the hypotheses tested were:

$\mathrm{H}_{1}$ : Demographic factors have an effect on women's desire to take up FWA at the workplace.

$\mathrm{H}_{2}$ : Socio-economic factors have an effect on women's desire to take up FWA at the workplace.

$\mathrm{H}_{3}$ : Family responsibilities factor has an effect on women's desire to take up FWA at the workplace.

$\mathrm{H}_{4}$ : Perceived Advantages have an effect on women's desire to take up FWA at the workplace.

$\mathrm{H}_{5}$ : Perceived Disadvantages have an effect on women's desire to take up FWA at the workplace.

$\mathrm{H}_{6:}$ Working Arrangements have an effect on on women's desire to take up FWA at the workplace.

$\mathrm{H}_{7}$ : There is a significant association between FWA and women's decision to continue working.

$\mathrm{H}_{8}$ : There is a significant association between FWA and women's decision to participate in the labour force. 
$\mathrm{H}_{9}$ : FWA has an effect on working women's work-life balance.

$\mathrm{H}_{10}$ : FWA has an effect on working women's empowerment.

$\mathrm{H}_{11}$ : FWA has an effect on working women's lifestyles.

\subsection{Qualitative Method}

\subsubsection{Introduction}

This thesis is an exploratory study seeking to get a deeper insight into female workers' experience of their daily activities (Sekaran, 2003).

Qualitative research is all about exploring issues, understanding phenomena and answering questions and it uses unstructured information like field notes, transcripts and audio recordings, instead of numbers to arrive at conclusions. How female employees feel about participating in paid labour and managing work and life based on daily routine was better captured in face-to-face interviews. In this part of the phenomenological research, it was important that the researcher set her own experiences aside so that the participants' experiences and information would be as accurate as possible.

\subsubsection{Instrument}

Semi-structured interviews were the main instrument used for gathering qualitative data. These usually consist of a combination of open-ended and closed questions and are suitable when both factual and attitudinal information need to be collected (Saunders et al., 2007). This was relevant to the current study where factual information such as the respondent's background, family responsibilities, husband's role at home and juggling work and family needed to be collected in addition to information in the questionnaire. Denscombe (2005) asserted that semi-structured interviews allow for flexibility within the interview process, that the interviews can follow a non-standardised format allowing for deviation from the schedule where necessary. 
Even though quantitative, it characterised "objective, representative and was specified in numbers," (Overton \& van Dierman, 2003, p. 38) and it is the openended questions that brings out more value "because they illuminate more about the issues and problems (Scheyvens \& Storey, 2003, p. 7). As such, the questions in this study were open-ended but probing, trying to follow a guideline in this current research. Questions addressed in the interview concentrated on issues which needed an in-depth exploration and addressed areas such as perceptions, attitudes and experiences that may have an impact on female labour and working conditions.

\subsubsection{Participants}

Interviews were conducted with 30 women from 14 organisations which comprised 50 percent Malays, 30 percent Chinese and 20 percent Indians. The sample ranged in age from 25 to 55 years old. A total of 23 respondents (77\%) were married and the balance was single. The sample was urbanised and Malaysia's main multiethnic society was well represented with Malays, Chinese and Indians. They were all Malaysian born and represented the multicultural and the socio-economic diversity of the country.

There were 30 respondents who were interviewed with 15 female employees from FWA organisations, while the others were from non-FWA organisations. Creswell (2009) mentions that a typical sample size of 5-25 individuals who have direct experience with the phenomenon study will be able to reveal rich information if the researcher and the respondents work together in order to arrive at the core of the matter (Creswell, 2009). By listening carefully and organising the data, the analysis can be organised thematically to highlight issues and concerns of the working women.

In order to ensure reliability, an interview schedule that followed a structure was designed which allowed for repeatability and consistency. As Creswell (2009), informs us, validity refers to the extent to which the research method measures what it claims to measure. 
Information was elicited from the participants through a questionnaire as well as a structured interview session. A structured interview style questionnaire was developed to ascertain certain elements such as socio-economic background, demographic background and family responsibilities (Please refer to Appendix 4.3 and 4.4). Once the respondents filled up these details, they were asked to narrate a routine day in their life from the time they wake up until they go to sleep. The questions in all the three sections were formulated by taking into account the related literature, which focussed on juggling work and home.

\subsubsection{Method of Analysis}

As suggested by Rosenblatt and Fischer (1993), the early stages of qualitative data analysis involve "intense analysis", the "creation of typologies", and "some sort of formal coding and counting" (p.172). A qualitative approach may enable researchers to address and understand decisions the way women themselves conceptualize them. By taking each woman's information through a systematic process of analysis, valuable information about what the women do as a routine every day, how they juggle work and home, how they perceive their well-being and any statements they made concerning work-life balance, empowerment and wellbeing were noted.

The content analysis served to identify some issues relating to work-life balance and this analysis provided an insight into how women viewed themselves in their role as juggling work and home. The qualitative part was based on the grounded theory framework to formulate the codes, concepts and the categories with regards to how the working women juggle work and home.

\subsubsection{Procedure}

The questionnaire was pilot tested on two participants, one from a FWA organisation and one from a non-FWA organisation. The participants gave their verbal consent to participate in the study. They first completed the demographic form 
before being interviewed. Additionally, the aim of the pilot study was to assess the participant's understanding of the way the questions were asked and to assess the time taken in the interviews. The participants were interviewed individually by the researcher. The interview generally took 40 to 45 minutes to complete.

Once the pilot study was done, the dates were set for the interview with each organisation. The participants were randomly chosen by the Human Resource personnel of each organisation. Prior approval was obtained from the authority concerned and meetings were arranged for the interviews. The researcher arranged the interview times according to the convenience of the participants and the organisations. Information regarding the research project was provided to each participant verbally by the researcher and the participants were informed of their right to withdraw from the interview at any time, that there were no right or wrong answers, and that they could pass on any questions they could not or did not want to answer.

\subsection{Ethical Considerations}

Prior to carrying out the study, the researcher had to obtain approval from the Victoria University of Wellington Human Ethics Committee for the primary survey. An ethical approval for the two sets of questionnaires was obtained before the study commenced. Generally, main issues in relation to ethical consideration, which should be observed carefully, are consent, confidentiality and anonymity.

Consent is best obtained by informing the respondents clearly about the aim and objectives of study. Questionnaires contained a participant information statement on the front page, as per University ethics guidelines (Please refer Appendix 4-5). The best way to observe confidentiality is by ensuring that a given person's response is not used or quoted publicly (Babbie, 2010). Anonymity was further guaranteed as the respondent's name was not mentioned anywhere in the questionnaire and as such, one cannot identify a given response with a given respondent. All information that was derived from the questionnaire was stored in the SPSS 18 software using code numbers. As for interview information, the data was stored as taped interviews 
in a password protected soft version. The publication of all results was carefully deidentified.

The data used in this research comes from two main sources, primary sources where survey and interviews were carried out, and secondary data that were obtained from the Department of Statistics, Malaysia (DOS). Although the secondary data collected involved human subjects, the data provided by DOS did not evoke any ethical issues as only variables needed for this research were released and all the personal information was withheld and identification of respondents was totally impossible. Confidentiality and anonymity was hence observed throughout the study.

The same confidentiality was also observed in the questionnaire survey on employers and employees. The interviews required no names and all the information collected was kept confidential and strictly used for this research only. Furthermore, the information collected was coded and prior to carrying out the survey, consent was secured from the respondents before proceeding with the interviews. Respondents were informed at the start of the interviews that participation in the survey was totally voluntary and that they were allowed to pull out at any point of time (Please refer to Appendix 4.6).

As for anonymity, both survey and interview respondents were assured of anonymity and were given consent form to fill in. Individual respondents who filled in the questionnaire also read and signed the consent forms and submitted them to their human resource personnel. But for others who filled and submitted the forms via email, they read the consent forms but did not sign as they submitted their questionnaire through email. As the participants felt assured of anonymity they participated in the survey voluntarily. Either way, confidentiality was the main aim and the respondents were assured of it.

As for the qualitative interviews, each respondent filled up the consent form and allowed their interviews to be recorded. Besides, they were very interested to know the findings of the study but none of them requested for a copy of the findings. 
It was noted that as long as the respondents were confident about anonymity and confidentiality, they consented to be part of the survey and the response rate was high and usable. Completed forms were also high. Only in cases where the Human Resource (HR) personnel were not cooperative and consent from the HR personnel was difficult, the response rate was low.

\subsection{Summary}

In this mixed method approach, the quantitative method tested the hypotheses on who the women who are interested in the uptake of FWA are and whether FWA will have an effect on women's participation in the labour force. On the other hand, the qualitative in-depth interviews provided direct experiences to better understand the social and cultural contexts within which the women act. The results which come from both quantitative data and qualitative data will be presented and discussed in detail in the next two chapters. 


\section{Chapter 5}

\section{Flexible Working Arrangements and Female Labour Force -A Quantitative Analysis}

\subsection{Introduction}

The main research question this chapter seeks to identify is the characteristics of women who have the desire to take up FWA if it was offered at the workplace. It further provides a scope of the occupational sector of the labour market which could best offer such arrangements suitable for female employees. A perception analysis was also used to examine if FWA could possibly interest women who are currently not in the labour force to participate in paid labour. In order to obtain a better understanding of the demographics and socio-economic status of the respondents, this chapter provides descriptive statistics which present survey data in a tabular form, as a comparison to available population data. Using a logistic regression analysis, this chapter analyses whether demographic, socio-economic and cultural factors influence women's interest in taking up FWA. 'Perceived advantages' and 'perceived disadvantages' of FWA were analysed to ascertain what the more important costs and benefits of FWA were for women. Finally independent t-tests and cross tabulations were done to examine whether FWA will possibly bring more women to participate in paid labour.

\subsection{Characteristics of Respondents}

Of the 396 respondents who participated in this study, a high proportion of the women were in the youngest age group of (20-29 years), were married, were of Malay ethnicity and originated from the urban areas (Please refer to Chapter Four for 
details on survey sampling method). The educational level shows that all of them had a minimum of eleven years of schooling and the majority of them (72\%) possess a bachelor's degree. The majority earned an income below RM3,000 ${ }^{34}$ per month (NZD1,162). The tables below summarise the findings based on a field survey carried out in mid June 2010. However, some tables show figures less than 396 due to missing values, particularly regarding information on income.

The demographics of the respondents, such as age, marital status and culture are important determinants which influence the employees' desire to take up different types of working arrangements. Table 5.1 shows the age profile of the respondents in the study. A large proportion (42\%) of the respondents was in the age group of 20-29 years, while nearly 40 percent were women in the 30-39 years age group. The age group portrayed in this sample size reflects the trend of the female labour force participation in Malaysia. Further analysis showed that the majority of the women in the 20-29 years age group were single women. The mandatory retirement age in Malaysia is 56 years in the public sector, with an option of 58 years but most private organisations allow employees to retire at 60 years. As such, there were only 3 respondents in the 60 and above age group and hence, they were regrouped into the last category.

Table 5.1-Age Profile of Sample in Comparison to Labour Force Population

\begin{tabular}{lcc}
\hline Age & $\begin{array}{c}\text { Sample }^{*} \\
\text { Percent }\end{array}$ & $\begin{array}{c}\text { Population }^{* * *} \\
\text { Percent }\end{array}$ \\
\hline $20-29$ & 42 & 36 \\
$30-39$ & 39 & 29 \\
$40-49$ & 13 & 22 \\
50 and above & 6 & 13 \\
\hline Total & 100 & 100 \\
\hline Source: & *Field Survey & \\
& $*$ & \\
& &
\end{tabular}

\footnotetext{
${ }^{34}$ The average conversion rate in August 2011 between Malaysian Ringgit (RM) and New Zealand Dollar is NZD $1=$ RM2.58
} 
In Malaysia, just like most Asian cultures, marriage is an institution which binds a male and a female for legal and ethical relationship, before they have children. Living together before marriage or having babies out of marriage are legally unaccepted. Table 5.2 shows that 63 percent of the respondents were married women. As the objective was to test whether marital status has an effect on women's uptake of FWA, women who were single parents, separated and divorced were regrouped as married. As shown in Table 5.1, the majority of the respondents (58\%) are in the "above 30 years" category and this explains the marital status of the respondents who are mostly married. Out of the 250 married respondents, there were only two single mothers. A further cross tabulation showed that 38 percent of the married women have children while 17 percent are in the 20-29 years age group and do not have children.

Table 5.2-Marital Status of Survey Sample in Comparison to Population

\begin{tabular}{lcc}
\hline Marital Status & $\begin{array}{c}\text { Sample } \\
\text { Percent }\end{array}$ & $\begin{array}{c}\text { Population } \\
\text { Percent }\end{array}$ \\
\hline Married & 63 & 68 \\
Single & 37 & 32 \\
\hline Total & 100 & 100 \\
\hline \multirow{2}{*}{ Source: ${ }^{*}$ Field Survey } & \\
& ${ }^{* *}$ Department of Statistics, Malaysia, (2010b)
\end{tabular}

In addition, Malaysia is a country where culture plays an important role in family and society. In terms of ethnicity, there are three major groups, the Malays who comprise 67 percent of the population, followed by the Chinese $(25 \%)$ and the Indians $(7 \%)$. There is a small minority $(1 \%)$ of other communities comprising Sri Lankans, Eurasians, Indonesians and other foreigners (Department of Statistics, 2010b). The sample generally reflects the population distribution of the country, with more than 50 percent comprising Malays, followed by 23 percent Chinese and 20 percent Indians representing the three main ethnic groups of the country. There were a few foreigners $(3 \%)$ who were employed by the multinationals and also spouses of Malaysians who do not have residency status. Table 5.3 shows the survey sample, in comparison to the working population sample in 2010. As can be seen from the table, ten percent of the working population comprise non-Malaysians. This is a 
result of shortage of labour in certain sectors such as manufacturing, plantation, construction and some services sector, which is a great concern in terms of foreign currency outflow and other socio-economic issues ${ }^{35}$.

Table 5.3-Ethnicity of Survey Sample in Comparison to Working Population Sample

\begin{tabular}{lcc}
\hline Ethnicity & $\begin{array}{c}\text { Sample } \\
\text { Percent }\end{array}$ & $\begin{array}{c}\text { Working } \\
\text { Population } \\
\text { Percent }\end{array}$ \\
\hline Malay & 54 & 57 \\
Chinese & 23 & 25 \\
Indian & 20 & 7 \\
Others & 3 & 1 \\
Non Malaysians & - & 10 \\
\hline Total ${ }^{*}$ Field Survey & 100 & 100 \\
\hline & ${ }^{* *}$ Malaysia, Department of Statistics, 2010
\end{tabular}

More than 90 percent of the respondents originated from the urban sector and are also currently residing in the urban sector. Whether the respondents originated from the urban sector or the rural sector plays an important role in determining the behaviour and attitude of the respondents. Literature shows that culture and place of origin plays an important role in work attitude (Almer et al., 2003, Jamilah, 2009). For example, women in the eastern states of Malaysia are more traditional in their outlook. But in this sample, as the majority of the respondents are from the urban strata, there is no significant difference in place of birth and work behaviour but ethnicity does have an influence.

\footnotetext{
${ }^{35}$ For example, between 1990 and 2005, foreign labour contributed more than a third of the increase in total labour supply, and over $98 \%$ were low-skilled contract migrant workers (National Economic Advisory Council (NEAC) (2010).
} 
Table 5.4 - Place of Birth of Respondents

\begin{tabular}{lc}
\hline Place of Birth & $\begin{array}{c}\text { Sample } \\
\text { Percent }\end{array}$ \\
\hline Urban & 90 \\
Rural & 8 \\
Others & 2 \\
\hline Total & 100 \\
\hline
\end{tabular}

Table 5.5 shows that all the respondents have a minimum of eleven years of schooling and all of them have acquired a certificate from formal education after sitting for a public examination. More notable is that nearly half (49\%) of the respondents in the study possess a basic bachelor's degree. This is well explained by student enrolment trends in public higher institutions in Malaysia, which constitute 63 percent females at first degree level, 74 percent at diploma level, 54 percent at masters level and 39 percent at post-graduate studies. (Ministry of Women, Community \& Family Development, 2010).

Table 5.5 - Highest Educational Level Achieved by Respondents

\begin{tabular}{|c|c|}
\hline Highest Educational Level & Sample \\
\hline Achieved & Percent \\
\hline SPM / “O” Levels $\left(11^{\text {th }}\right.$ year $)$ & 22 \\
\hline STPM/"A" Levels (13 ${ }^{\text {th }}$ year $)$ & 6 \\
\hline Diploma & 24 \\
\hline Degree & 42 \\
\hline Post graduate & 7 \\
\hline Total & 100 \\
\hline
\end{tabular}

Table 5.6, shows that nearly half (46\%) of the respondents in this study are at officers/executives level. Employees from universities and professional organisations were involved and this constituted 12 percent of the management and professional level. As the sample was randomly selected, it shows that women are interested to work and shoulder responsibilities at the workplace, if given the chance. Initially there were six categories in the occupational level, but as there were only three 
respondents at the senior management level, hence senior management and management were incorporated into one category. Having only three at senior management level could be an issue of sampling method because the questionnaires were distributed randomly by the management.

Table 5.6 - Occupational Level of Respondents

\begin{tabular}{lc}
\hline Occupational Level & Sample \\
& Percent \\
\hline Clerical level & 23 \\
Technicians/Assistants & 5 \\
Officers/Executives & 46 \\
Lecturers & 14 \\
Management/Professionals & 12 \\
\hline Total & 100 \\
\hline
\end{tabular}

As can be seen from table 5.7, even though the majority $(61 \%)$ of the respondents were in the officers/executives level, their earning capacity was below RM3,000 per month. This compares favourably with Malaysian wages level ${ }^{36}$ and is probably due to the age of the respondents who are relatively from a younger age group. However, it is encouraging to note that about 17 percent are earning more than RM4,000 and among this category, a good 11 percent earn a very high income above RM7,000.

Table 5.7- Personal Monthly Income of Respondents

\begin{tabular}{cc}
\hline $\begin{array}{cc}\text { Personal Income } \\
\text { Per month(RM) }\end{array}$ & $\begin{array}{c}\text { Sample } \\
\text { Percent }\end{array}$ \\
\hline RM 1000 - RM2000 & 37 \\
RM 2001 - RM3000 & 24 \\
RM 3001- RM 4000 & 11 \\
RM 4001- RM 7000 & 17 \\
Above RM 7000 & 11 \\
\hline Total & 100 \\
1NZD is equivalent to RM 2.58 & \\
1USD is equivalent to RM 3.00
\end{tabular}

36 This conforms to findings by NEAC (2010) which show that 40 percent of the Malaysian population earn below RM1,500 per month. 
In most cultures, family responsibilities in terms of taking care of young children or taking care of the elderly are shouldered by women. Table 5.8 shows that 46 percent of the married women had children. Whether women work or not, studies in Malaysia have shown that women's time spent on family work is significantly affected by the size of household, having young children below three years and the number of children they have (Jamilah, 2010, Chiu, 1999).

Table 5.8-Number of Married Respondents with Young Children

\begin{tabular}{|c|c|c|}
\hline $\begin{array}{l}\text { Number of Married } \\
\text { Respondents } \\
\text { (children below } 6 \text { years) }\end{array}$ & Frequency & Percent \\
\hline Yes & 115 & 46 \\
\hline No & 135 & 54 \\
\hline Total & 250 & 100 \\
\hline
\end{tabular}

As Table 5.9 shows, more than 70 percent of the married respondents who had young children had only one young child below the age of six years whereas Table 5.10 shows that 53 percent of the married women had at least two children. None of the single respondents had children or had to take care of children.

Table 5.9- Married Respondents with Number of Young Children

\begin{tabular}{ccc}
\hline $\begin{array}{c}\text { Number of Young Children } \\
\text { (children below 6 years) }\end{array}$ & Frequency & Percent \\
\hline 1 & 82 & 71 \\
2 and above & 33 & 29 \\
\hline Total & 115 & 100 \\
\hline
\end{tabular}


Table 5.10 - Married Respondents with Total Number of Children

\begin{tabular}{ccc}
\hline Number of Children & Frequency & Percent \\
\hline 0 & 58 & 23 \\
1 & 60 & 24 \\
2 & 63 & 25 \\
$3-4$ & 56 & 22 \\
$5-6$ & 11 & 5 \\
$7-8$ & 2 & 1 \\
\hline Total & 250 & 100 \\
\hline
\end{tabular}

In terms of caring responsibilities, childcare is a greater concern compared to elderly care among the respondents. As shown in Table 5.11, only 44 percent of the respondents took care of elderly parents. Some of them took care of their parents or their elders financially but most of them took care of them physically, meaning they lived in the same house. In the Malaysian culture, it is the son and daughter-in-law who are expected to take care of his parents and this is more prominent among the Chinese and the Indian ethnicity (Jamilah, 2009).

Table 5.11 - Respondents who Take Care of Elderly Parents

\begin{tabular}{cc}
\hline $\begin{array}{l}\text { Take care of Elderly } \\
\text { Parents }\end{array}$ & Percent \\
\hline Yes & 44 \\
No & 56 \\
\hline Total & 100 \\
\hline
\end{tabular}

Transport to work has become a critical issue in the urban cities in the Klang Valley due to the high cost of fuel and traffic congestion. Public transport is available in the form of buses, taxis and electric trains. However, connectivity from public transport stations to the workplace is not very efficient and is very time consuming. Hence, most people choose to drive to work or get dropped off by their spouses. Car pooling among employees is still not popular as many find it inconvenient. Table 5.12 shows that a high proportion (79\%) of the respondents travelled to work by car with a very small percentage commuting by bus and trains. 
Table 5.12 - Mode of Transport to Commute to Work

\begin{tabular}{lc}
\hline Mode of Transport & Percent \\
\hline Car (private vehicle) & 79 \\
Public transport & 11 \\
Motorcycle & 5 \\
Company transport & 5 \\
\hline Total & 100 \\
\hline
\end{tabular}

The main objective of this study was to find out whether women are interested in FWA and whether this mode of working arrangement may have an effect on female labour force participation. Women employees from organisations with FWA and non-FWA were asked a simple question: "Are you interested in flexible working arrangements at your workplace?" As flexible working arrangements are still a relatively new concept in the country, the definition of FWA and some common types of FWA were mentioned explicitly in the questionnaire.

As Table 5.13 shows, 86 percent of the respondents were interested in FWA at their workplace and only a small percentage of 14 percent were not interested. Further cross tabulation showed that workplace type has an effect on respondents' interest in the uptake of FWA (Please refer to Appendix 5.1).

Table 5.13-Interested in Flexible Working Arrangements (FWA)

\begin{tabular}{cc}
\hline $\begin{array}{c}\text { Interested in } \\
\text { FWA }\end{array}$ & Percent \\
\hline Yes & 86 \\
No & 14 \\
\hline Total & 100 \\
\hline
\end{tabular}

Table 5.14 shows the fourteen survey organisations from where the respondents were sourced from. The organisations from the services sector were selected, with one having FWA and the corresponding type of organisation from the same service sector with non-FWA. Among the banks, the one which had FWA was an international bank while the non-FWA was the second largest local bank in 
Malaysia. The logistics company which had FWA was an international company while the non-FWA was a local logistics company which is the largest in Malaysia. The petroleum shared services which had FWA is a multinational company which is very well known for FWA best practices and has been acclaimed as a role model for practising FWA in Malaysia, while the non-FWA company is also an international company. The telecommunication company which has FWA is a multinational organisation which has FWA, while the non-FWA is the largest local telecommunication company in the country. As for the educational institutions, all public universities in Malaysia practise some form of FWA, which basically expects lecturers to be present during lectures, meetings and when necessary. However, private universities and colleges which offer twinning degree programmes are still quite strict and fixed with the working hours. Hence, respondents from a public and a private university were randomly selected. All the four professional organisations are locally owned, two by males and two by females. Both the medium sized professional organisations employ about 25-30 members of staff. The organisation which practises FWA is a lawyer's firm managed by a male and the non-FWA is an organisation which provides fire-fighting services managed by a female. The small professional firms employ around 10-12 staff, the FWA owned by a female is an architect's firm and the non-FWA which is owned by a male is an engineering firm.

Out of the seven FWA organisations which were identified, FWA were offered to all the employees only in five organisations, irrespective of their occupational status or department. In these five organisations, excluding the bank and logistics organisation, the common mode of FWA were flexible working time, while the petroleum shared services and telecommunication organisations had flexible working place also, whereby the employees were allowed to work from the home a few days a week. In all these five organisations, it was the right of the employee to opt to work flexible time or location but in most cases they had to either inform or report to their immediate supervisors regarding their work arrangements. The employees from the professional firms and educational institutions used FWA according to their discretion and there was no sign of abuse. Only in the bank and logistics organisations, FWA was offered for certain operations and departments and not offered across the board. However, to make it representative, the sample for this 
study only consisted of bank and logistics organisation employees who were offered FWA.

Even though 500 questionnaires were equally distributed, with 250 to FWA organisations and 250 to non-FWA organisations, 57 percent of the returned questionnaires were from FWA while the balance 43 percent were from non-FWA organisations as shown in Table 5.14.

Table 5.14-Type of Working Arrangements

\begin{tabular}{lcc}
\hline Type of Working Arrangements & Frequency & Percent \\
\hline & & \\
FWA & 225 & 57 \\
Non-FWA & 171 & 43 \\
\hline Total & 396 & 100 \\
\hline
\end{tabular}


Table 5.15 - Organisation Type where Respondents Work

\begin{tabular}{lcc}
\hline Types of Organisations & Frequency & Percent \\
\hline Banks & 79 & 20 \\
FWA & 45 & 11 \\
Non-FWA & & \\
\hline & 27 & 7 \\
Logistics Organisation & 67 & 17 \\
FWA & & \\
Non-FWA & 70 & 18 \\
\hline & 10 & 3 \\
Petroleum Shared Services & & \\
FWA & & \\
Non-FWA & 7 & 2 \\
\hline Telecommunication Organisation & 7 & 2 \\
FWA & & \\
Non-FWA & & 7 \\
\hline & & \\
Tertiary Institutes /Educational & 27 & 2 \\
Institutions & 15 & 5 \\
FWA & & \\
Non-FWA & 9 & \\
\hline & 21 & \\
Professional Organisation (medium) & & \\
NWA & & \\
\hline
\end{tabular}

Professional Organisation (small)

\begin{tabular}{lrc} 
FWA & 6 & 1 \\
Non-FWA & 6 & 1 \\
\hline Total & 396 & 100 \\
\hline
\end{tabular}

Based on the descriptive analysis, the demographic, socio-economic and cultural factors well represent the Malaysian case in terms of age, marital status, ethnicity, and highest educational level attained. Most of the respondents were either at officer level or executive level, with a few at management and professional levels and more than 50 percent earned less than RM3000 per month. A good 46 percent of them had young children and less than 50 percent took care of the elderly. The data 
above also shows that more than 85 percent of the women are interested in FWA at the workplace.

Further cross tabulations were done to examine details in the demographic factors, socio-economic factors, family responsibilities and working arrangements towards women's uptake of FWA. Table 5.16 shows the summary of the cross tabulations and the significance at 10 percent. In terms of demographic profile, FWA were preferred among the Chinese ethnicity, women who were in the 30-39 years age group and among married women. However, none of these demographic factors were statistically significant. In terms of socio-economic factors, it was found that women who were at the management level, earning an income above RM7000 and having a university degree were more interested in FWA at the workplace. The next section provides statistical analysis which answers various hypotheses postulated in this study. 
Table 5.16 - Summary of Cross Tabulation of Selected Socio-economic Factors

\begin{tabular}{|c|c|c|c|c|}
\hline \multirow[t]{2}{*}{ Variable } & \multirow[t]{2}{*}{ Sub Group } & \multicolumn{2}{|c|}{ Interested in FWA } & \multirow[t]{2}{*}{$\mathrm{p}$-value } \\
\hline & & $\mathrm{n} / \mathrm{N}$ & Percent & \\
\hline \multirow[t]{3}{*}{ Ethnicity } & Malays & $183 / 215$ & 85 & 0.744 \\
\hline & Chinese & $82 / 92$ & 89 & \\
\hline & Indians & $66 / 78$ & 85 & \\
\hline \multirow[t]{4}{*}{ Age } & $20-29$ & $143 / 167$ & 86 & 0.846 \\
\hline & $30-39$ & $136 / 155$ & 87 & \\
\hline & $40-49$ & $44 / 52$ & 85 & \\
\hline & 50 and above & $18 / 22$ & 82 & \\
\hline \multirow[t]{2}{*}{ Marital Status } & Married & $216 / 250$ & 86 & 0.470 \\
\hline & Single & $125 / 146$ & 85 & \\
\hline \multirow{5}{*}{$\begin{array}{l}\text { Occupational } \\
\text { Status } \\
\end{array}$} & Clerical Level & $64 / 92$ & 70 & $0.000 *$ \\
\hline & Technicians & $17 / 18$ & 94 & \\
\hline & Officers/Executives & $163 / 182$ & 90 & \\
\hline & Lecturers & $49 / 55$ & 89 & \\
\hline & Management Level & $46 / 47$ & 98 & \\
\hline \multirow[t]{6}{*}{ Personal Income } & RM1000-RM2000 & $112 / 141$ & 79 & $0.012 *$ \\
\hline & RM2001-RM3000 & $77 / 91$ & 85 & \\
\hline & RM3000-RM4000 & $36 / 42$ & 86 & \\
\hline & RM4000-RM5000 & $19 / 20$ & 95 & \\
\hline & RM5000-RM7000 & $43 / 45$ & 96 & \\
\hline & Above RM7000 & $41 / 42$ & 98 & \\
\hline \multirow[t]{5}{*}{ Educational Level } & SPM/ "O" Levels & $60 / 81$ & 74 & $0.000 *$ \\
\hline & STPM/ "A" Levels & $20 / 24$ & 83 & \\
\hline & Diploma & $71 / 89$ & 80 & \\
\hline & Degree & $145 / 153$ & 95 & \\
\hline & Post-Graduate & $45 / 49$ & 92 & \\
\hline
\end{tabular}

* statistically significant at 10 percent level.

Source - Calculated from Survey Sample. 


\subsection{The Uptake of FWA by female employees in Malaysia}

This section sets to answer the first objective of the study which is to investigate the factors which influence the desire to take up flexible working arrangements by women employees at the workplace. It provides answers for the first five hypotheses as outlined below:-

$\mathrm{H}_{1}$ : Demographic factors have an effect on women's desire to take up FWA at the workplace.

$\mathrm{H}_{2}$ : Socio-economic factors have an effect on women's desire to take up FWA at the workplace.

$\mathrm{H}_{3}$ : Family responsibilities factor have an effect on women's desire to take up FWA at the workplace.

$\mathrm{H}_{4}$ : Perceived Advantages have an effect on women's desire to take up FWA at the workplace.

$\mathrm{H}_{5}$ : Perceived Disadvantages have an effect on women's desire to take up FWA at the workplace.

To test these five hypotheses, logistic regression analysis was used which is discussed in detail below. 


\subsubsection{Logistic Regression Theory}

Logistic regression is used to predict discrete dependent variables from a group of independent variables that may be discrete, continuous, or a mix of both. Basically, logistic regression is used to predict the outcome category for each case (Hair et al., 2010). As logistic regression is a non-linear model, the equations used to describe the regression are complex. The dependent variable, $\mathrm{Y}$, is the probability of the event of interest, in this case the probability of the interest in the uptake of FWA having one outcome or another based on the best linear combination of independent variables:

$$
\mathrm{Y}_{i}=\frac{\exp (\mathrm{Z})}{1+\exp (\mathrm{Z})}
$$

Where:

$Y_{i}$ is the estimated probability that the ${ }_{i}$ th case $\left({ }_{i}=1, \ldots, n\right)$ is in one of the categories and $Z$ is the linear regression equation:

$$
Z=\beta_{0}+\beta_{1} X_{1}+\beta_{2} X_{2}+\ldots+\beta_{k} X_{k}
$$

with constant $\beta_{0}$ coefficients $\beta_{j}$, and independent variables $\mathrm{X}_{j}$ for $k$ independent variables $(j=1,2, \ldots, k)$.

Coefficients are estimated by converging on values that maximise the likelihood of obtaining observed frequencies (Hair et al., 2006).

The goodness of fit for a logistic regression is determined by the chi-squared statistic $\left(\chi^{2}\right)$. A big value implies ill fit while a small value implies a good fit. There are many types of logistic regressions, including direct, hierarchical and stepwise. 
In this study, the stepwise logistic regression is used where in the statistical programme, the variables are entered one at a time. The first variable entered is the one which is most closely associated with the outcome of the event of interest. The second variable entered is the one which is most closely associated, given that the first variable is already in the predictive equation. Variables are added until no further variables are significantly associated with the outcome. In a stepwise logistic regression, inclusion and exclusion of independent variables are based on statistical tests. The user has no input as to which independent variables are included, and in what order they are included (Hair et al., 2010).

\subsubsection{Logistic Regression Model}

In this study, the event of interest is the probability of the uptake of FWA, and there are eleven independent variables which are classified into six groups. The nine categorical variables are age, marital status, cultural factor (Demographic Factor), job characteristics, income level, educational level (Socio-economic Factors) having young children, taking care of elderly (Family Responsibilities) and FWA, non-FWA (Working Arrangements). 'perceived advantages' and 'perceived disadvantages' were used as continuous variables taking the values 1 through 5 . Literature on research theory states a logistic regression must be used when the dependent variable is a discrete variable with a dichotomous Yes/No response (Hair et al., 2010).

The independent variables were entered into the regression using forward stepwise regression method in two different blocks. This allowed for a determination of the unique effect by each group of independent variables on the variance in the dependent variable, taking into consideration the variance accounted for by the previously entered groups of independent variables. In a stepwise logistic regression, inclusion and exclusion of independent variables are based on statistical tests. The results of each logistic regression were looked at overall and then by the individual variable. First, the overall significance ('p' value) was checked to see if the variables entered were significant. Next, the chi-squared value $\left(\chi^{2}\right)$ was examined to determine goodness-of-fit. For individual variables, the significance ('p' value) was checked to 
see if the individual variable was significant within the step. Finally, the Wald statistics (z) and odds ratios were then compared to determine the strength of the relationship between the variable and the probability of the event of interest.

The statistical package used to perform the logistic regressions in this study is SPSS version 18. The specific regression used from SPSS is binary logistic, which can be found under the analyse/ regression menu.

\subsubsection{Results for Logistic Regression}

The key dependent variable in this study is whether or not a female employee is interested in taking up FWA in the workplace. The four groups of categorical variables and the two groups of continuous variables were entered into the regression model in two blocks.

For the first continuous variable, 'perceived advantage' an exploratory factor analysis ${ }^{37}$ was done using a varimax rotation to reduce dimensionality (Hair et al., 2010). Next, looking at the eigenvalues, which are the proportion of explained over unexplained variation, three factors with values more than 1 were retained. Values more than 1 means more variation is explained than unexplained. Out of the 16 statements, only one statement had cross loading that is "Productivity will improve" and as a consequence, this question was eliminated from the factor analysis. In factor analysis, the Kaiser Meyer Olkin (KMO) value is used to assess the adequacy of dimension reduction. According to Hair et al., (2010), values between 0.6 and 0.7 are the acceptable norm. Values between 0.7 and 0.8 are considered to be good, while values above 0.8 are considered to excellent. The KMO (Kaiser Meyer Olkin) of 0.9

\footnotetext{
${ }^{37}$ Factor analysis is a statistical approach that can be used to analyse interrelationships among a large number of variables and to explain these variables in terms of their common underlying dimensions (factors). It is a commonly used as a tool for data reduction. When a factor analysis was run, it was found that the sixteen original items actually were represented by three factors. This analysis uses correlations among the items and items that show the highest correlation among each other is generally grouped together. Note that a single original variable can have more than one factor explaining that variable and it is called communality. Prior to running a factor analysis, literature review was done to get the items for the research. As not many studies of this nature have been done in Malaysia in the services sector, a focus group discussion was done for the initial items. A 5 point or Likert scale was used. (Hair, et al.,2010.)
} 
shows that the items stated explain the factors well and gave three factors which explain more than 68 percent of the variability in the data. The fifteen statements were grouped into three factors namely Job Satisfaction, Time Management and Family Relationship.

The first factor, job satisfaction and work quality (grouped as Job Satisfaction) captures the possible change in job commitment, job satisfaction and work quality associated with the uptake of FWA. The second factor, autonomy and time-related (grouped as Time Management) captures the possible change associated with autonomy, commuting time and productive time. This includes having autonomy on workplace location, working at the most productive time and saving on commuting time. The third factor, Positive Impact on Family Relationship (grouped as Family Relationship) captures the effect of FWA on family relationships, which includes siblings, children, spouse and parents. The factors, items and factor loadings for 'Perceived Advantages' are as shown in Table 5.17. The factor scores are then saved and used for further analysis. 
Table 5.17 - Items, Factors and Factor Loadings for 'Perceived Advantages'

\begin{tabular}{lccc}
\hline Items & Factor Loadings \\
\hline & F1 & F2 & F3 \\
\hline My loyalty and job commitment will increase. & .973 & \\
My job satisfaction will increase. & .947 & \\
My quality of work will improve. & .877 & \\
My morale will improve because I feel treated as a responsible & .783 & \\
professional. & .630 & \\
My stress level will be reduced. & & .811 \\
I can save on commuting time. & & .760 \\
I can avoid interruptions at the office and get work done later. & & .751 \\
I have autonomy over my own time schedule. & & .706 \\
I can work during hours when I am most productive. & & \\
It will allow more time for networking. & & .651 \\
It will allow more time for family. & & .578 \\
It will have a favourable effect on relations with my siblings. & & & .877 \\
It will have a favourable effect on relations with my parents. & & & .869 \\
It will have a favourable effect on relations with my spouse. & & & \\
It will have a favourable effect on relations with my children. & & & .857 \\
\hline
\end{tabular}

Where,

F1 refers to Job Satisfaction

F2 refers to Time Management

F3 refers to Family Relationship

As for 'perceived disadvantages', the same procedure was done and the KMO was 0.9 which shows that the items stated explain the factors well and gave two factors which explain more than 67 percent of the variability in the data. All the 12 statements were chosen and were grouped into two factors namely Challenges and Career Progress. The first factor 'problems of working away from office' (grouped as Challenges) captured problems which might occur because the employee 
is not physically present at the workplace and also the problems of working from the home. The second factor, 'likely effects on career' (grouped as Career Progress) included statements to capture negative effects on career promotion and also interaction with other staff.

The factors, items and factor loadings for 'perceived disadvantages' are as shown in Table 5.18. The factor scores are then saved and used for further analysis.

Table 5.18-Items, Factors and Factor Loadings for Perceived Disadvantages

\begin{tabular}{lll}
\hline Items & \multicolumn{2}{l}{ Factor } \\
& Loadings \\
\hline & F1 & F2 \\
\hline
\end{tabular}

Distraction at home will be harder to handle than those in the office.

It is stressful to work and look after my children simultaneously.

My supervisor will lose his/her control over me.

I will have difficulty separating work and home activities.

My office workspace will be reduced.

People at my workplace may react negatively to people using FWA.

Some of my work might be reassigned to my peer.

My career level might be negatively affected due to not physically being present in the workplace.

I will miss out on discussions and meetings.

I will likely be passed over at promotion time because my supervisor does not see me often enough.

My interaction with business contacts will be reduced.

Social interaction with other employees will be affected

Where,

F1 refers to Challenges

F2 refers to Career Progress 
When the stepwise logistics regression was done with the factors as covariates, only three variables had a significant influence on women's uptake of FWA. They are Educational level, Career Progress which is a sub-factor in 'perceived disadvantages' and Family Relationships which is a sub-factor in 'perceived advantages'. Table 5.19 shows that out of the eleven independent variables, only three variables had a statistically significant effect on the dependent variable which is shown with a p value below 0.05 .

Table 5.19 - Parameter Estimates from Stepwise Logistic Regression Analysis

\begin{tabular}{|c|c|c|c|c|c|c|c|c|}
\hline \multirow[b]{2}{*}{$\begin{array}{l}\text { Interested in } \\
\text { FWA }\end{array}$} & \multirow[b]{2}{*}{ B } & \multirow[b]{2}{*}{$\begin{array}{l}\text { Std. } \\
\text { Error }\end{array}$} & \multirow[b]{2}{*}{ Wald } & \multirow[b]{2}{*}{ df } & \multirow[b]{2}{*}{ Sig. } & \multirow[b]{2}{*}{$\operatorname{Exp}(B)$} & \multicolumn{2}{|c|}{$\begin{array}{c}95 \% \text { Confidence } \\
\text { Interval for } \\
\operatorname{Exp}(B)\end{array}$} \\
\hline & & & & & & & $\begin{array}{l}\text { Lower } \\
\text { Bound }\end{array}$ & $\begin{array}{l}\text { Upper } \\
\text { Bound }\end{array}$ \\
\hline Intercept & 1.297 & .277 & 21.960 & 1 & .000 & & & \\
\hline $\begin{array}{l}\text { Career } \\
\text { Progress }\end{array}$ & -.337 & .173 & 3.786 & 1 & .052 & .714 & .508 & 1.002 \\
\hline $\begin{array}{l}\text { Family } \\
\text { Relationship }\end{array}$ & .548 & .164 & 11.210 & 1 & .001 & 1.730 & 1.255 & 2.384 \\
\hline STPM & .797 & .687 & 1.345 & 1 & .246 & 2.219 & .577 & 8.538 \\
\hline DIPLOMA & .402 & .389 & 1.066 & 1 & .302 & 1.494 & .697 & 3.204 \\
\hline DEGREE & 1.533 & .457 & 11.259 & 1 & .001 & 4.632 & 1.892 & 11.341 \\
\hline POST GRAD & 1.333 & .617 & 4.661 & 1 & .031 & 3.791 & 1.131 & 12.713 \\
\hline SPM & $0^{\mathrm{b}}$ & & & 0 & & & & \\
\hline
\end{tabular}

$* \mathrm{~b}$ is the reference category 
The Logistic Regression equation for uptake of FWA is given by:

$\mathrm{Z}=1.297-0.337$ (Career Progress) +0.548 (Family Relationship) +0.797 $(\mathrm{STPM})+0.402($ Diploma $)+1.533($ Degree $)+1.333($ Post graduate $)$.

The estimated probability of uptake of FWA can be obtained by the following equation:

$$
\mathrm{P}(\mathrm{Uptake} \text { of FWA })=\frac{\operatorname{Exp}(\mathrm{Z})}{1+\operatorname{Exp}(\mathrm{Z})}
$$

Where, STPM, Diploma, Degree and Post graduate are dummy variables.

The results show that women employees who are more educated are more likely to be interested in FWA compared to SPM (equivalent to ' $\mathrm{O}$ ' levels) which is a minimum school certificate most workers in Malaysia possess. Those who possess a degree are 4.63 times more likely to be interested in FWA, while those with a post graduate degree are 3.79 times more likely to be interested in FWA and those with a STPM certificate are 2.2 times more likely to be interested in FWA compared to female employees who hold a SPM certificate only. The respondents who perceive that FWA will affect their Likely Effects on Career will less likely to be interested to take up FWA. The respondents who perceive that their Positive Impact of Relationship with the family will be better will be more interested to take up FWA.

As logistic regression is appropriate for non-parametric data, there was no necessity to test for normality. The forward stepwise regression was used to control for multicollinearity. Firstly, all variables were allowed to enter but only three variables entered and one had five groups. The ' $p$ ' value $(<0.05)$ was significant for these three variables.

Based on the parameter estimates shown in Table 5.19, Career Progress shows a value of 0.052 , which is border line significance. However, the negative coefficient $(\mathrm{B}=-.337)$ explains the correlation between how the female employees 
perceive career progress and the uptake of FWA. It shows the likelihood that female employees will have less desire to take up FWA if they perceive that their career progress will be affected by their uptake of FWA.

The 'family relationship' factor shows a 'p' value which is statistically significant. The $\mathrm{B}$ value which is positive $(\mathrm{B}=.548)$ indicates that female employees perceive that with the uptake of FWA, they will have a better relationship with spouse, family and children. The next statistically significant factor is education, which is subdivided into five different groups. It shows a positive coefficient.

The ' $p$ ' values for each educational level were compared to the baseline that is, SPM qualification which is equivalent to ' $O$ ' levels. Women who have postgraduate and degree qualifications are significantly more interested in the uptake of FWA compared to women who possess SPM qualification ( $\mathrm{p}=0.01$ and 0.03 respectively). However, women who have STPM ('A' Levels) and Diploma qualification are not statistically different from women with SPM qualification in that regards. With literacy rate increasing, this could probably be the case because most women in Malaysia choose either to stop their studies after SPM or join the labour force, or if they choose to pursue their studies, they go to university to get degrees. Generally, very few of them actually stop at STPM and join the labour force.

Two groups of variables did not enter the logistics regression model, meaning that they did not have significant influence on women's interest in the uptake of FWA. Demographic variables such as age, ethnicity and marital status and family responsibilities possibly did not have a significant effect on the uptake of FWA compared to educational achievement and its compounding effects of occupational status and income. Women who had higher qualification were generally earning higher income and were in better positions in the organisation and hence, were more aware of FWA and its benefits. (Please refer to Appendix 5.2) 


\subsubsection{Perceived Advantages and Disadvantages to Respondents}

Respondents were asked to indicate their opinions regarding the 'Perceived Advantages and Disadvantages' which could possibly be achieved as a result of using FWA at the workplace. The importance of advantages was rated on a fivepoint-scale ranging from (1) strongly disagree to (5) strongly agree. If the mean value is higher, it suggests greater 'Perceived Advantages'.

Table 5.20 shows the respondents' 'Perceived Advantages' such as more time for family, save time on commuting, increase in job satisfaction and having autonomy over own time schedule. The mean ranges from 3.788 to 4.321 . Though the highest mean and the lowest mean have to do with family relationships, the respondents found that time factor is more important than relationships factor as denoted by the mean value. They perceive that flexibility will allow more time which is an issue of scarcity. These rankings are almost equivalent to studies done by Lim et al. (2000) whose study was based on ranking of factors which motivate workers to telework, which is another form of FWA. This is an indication that FWA offers female employees time flexibility, less commuting stress, more autonomy and better job satisfaction.

In the same score, respondents were asked to rate 'perceived disadvantages' associated with FWA. The importance of disadvantages was rated on a five-pointscale ranging from (1) strongly disagree to (5) strongly agree. A higher mean value suggests greater perceived disadvantage and the ranking is summarised in Table 5.21. The results show that the respondents are more concerned with issues pertaining to reduced interactions with other employees and career advancement 
Table 5.20 - Perceived Advantages of the Respondents

\begin{tabular}{clcc}
\hline Rank & Items & Mean & $\begin{array}{l}\text { Std. } \\
\text { Dev. }\end{array}$ \\
\hline 1 & It will allow more time for family. & 4.321 & 2.17 \\
2 & I can save on commuting time. & 4.113 & 0.86 \\
3 & My job satisfaction will increase & 4.098 & 2.69 \\
4 & I have autonomy over my own time schedule. & 4.081 & 0.82 \\
5 & I can work during hours when I am most productive. & 4.081 & 0.83 \\
6 & My stress level will be reduced & 3.984 & 0.88 \\
7 & My morale will improve because I feel treated as a & 3.977 & 0.88 \\
& responsible professional. & 3.957 & 0.79 \\
8 & My productivity will improve & 3.931 & 0.81 \\
9 & My quality of work will improve & 3.929 & 0.82 \\
10 & My loyalty and job commitment will increase & 3.926 & 0.97 \\
11 & It will have a favorable effect on relations with my children. \\
12 & It will have a favourable effect on relations with my parents. & 3.884 & 0.92 \\
13 & I can avoid interruptions at the office and get work done & 3.876 & 0.91 \\
& later. & & \\
14 & It will have a favourable effect on relations with my spouse. & 3.866 & 0.95 \\
15 & It will allow more time for networking. & 3.836 & 0.87 \\
16 & It will have a favourable effect on relations with my siblings. & 3.788 & 0.90 \\
& & & \\
\hline
\end{tabular}

Basically, the respondents are more concerned that they will miss out on social and peer interaction which might have an impact on career development. These findings are consistent with previous studies such as Lim et al. (2000), which show that reduced physical presence might adversely affect their career advancement opportunities.

The mean of the advantages (Table 5.20) seem to be higher than the mean of the disadvantages (Table 5.21) which shows that the respondents perceive the advantages to be very much higher than the 'perceived disadvantages'. Even though there are employees who perceive that career progression and social interaction will be affected by FWA, their individual means are very much lower than the mean of the 'Perceived Advantages'. 
Table 5.21 - Perceived Disadvantages of Respondents

\begin{tabular}{|c|c|c|c|}
\hline Rank & Items & Mean & $\begin{array}{l}\text { Std. } \\
\text { Dev. }\end{array}$ \\
\hline 1 & Social interaction with other employees will be affected & 3.290 & 1.02 \\
\hline 2 & I will miss discussions and meetings. & 3.265 & 1.10 \\
\hline 3 & $\begin{array}{l}\text { My career level might be negatively affected due to not } \\
\text { physically being present in the workplace. }\end{array}$ & 3.200 & 1.03 \\
\hline 4 & My interaction with business contacts will be reduced. & 3.162 & 1.08 \\
\hline 5 & $\begin{array}{l}\text { I will likely be passed over at promotion time because } \\
\text { my supervisor does not see me often enough. }\end{array}$ & 3.156 & 1.08 \\
\hline 6 & Some of my work might be reassigned to my peer. & 3.141 & 1.03 \\
\hline 7 & My office workspace will be reduced. & 3.073 & 0.99 \\
\hline 8 & $\begin{array}{l}\text { It is stressful to work and look after my children } \\
\text { simultaneously }\end{array}$ & 3.058 & 1.02 \\
\hline 9 & $\begin{array}{l}\text { Distraction at home will be harder to handle than those } \\
\text { in the office. }\end{array}$ & 3.048 & 1.04 \\
\hline 10 & $\begin{array}{l}\text { People at my workplace may react negatively to people } \\
\text { using FWA. }\end{array}$ & 3.048 & 1.03 \\
\hline 11 & $\begin{array}{l}\text { I will have difficulty separating work and home } \\
\text { activities. }\end{array}$ & 2.964 & 1.08 \\
\hline 12 & My supervisor will lose his/her control over me. & 2.833 & 1.09 \\
\hline
\end{tabular}

\subsection{Do Working Arrangements Affect Women's Desire to Work?}

This section sets to answer the second objective of study which is to assess whether the availability of flexible working arrangements might contribute to the decision among women workers to participate in the labour force. It provides answers for the following two hypotheses of this study as outlined below:-

$\mathrm{H}_{6}$ : There is a significant association between FWA and women's decision to continue working.

$\mathrm{H}_{7}$ : There is a significant association between FWA and women's decision to participate in the labour force

To test the first hypothesis, analysis was done using cross tabulation. As the study was conducted among working women in FWA and non-FWA, two main questions were asked in the questionnaire to achieve this objective. The first question captures the respondent's choice regarding continuity in work which read "Do you 
have intentions of stopping work before retirement age?". As Table 5.22 shows, 58 percent of the respondents did not have any intentions of stopping work before retirement age.

Table 5.22 - Intentions of Stopping Work before Retirement Age

\begin{tabular}{lc}
\hline Variable & Percent \\
\hline Continue Work & 58 \\
Stop Work & 42 \\
\hline Total & 100 \\
\hline
\end{tabular}

A further analysis was done using cross tabulation to assess whether workplace flexibility will have an effect on women who are currently working and their choice to continue working until retirement age. The results show that workplace flexibility was not statistically significant for women in FWA organisations and non-FWA organisations, meaning that there is no significant association between FWA and women's decision to continue working (Please refer to Appendix 5.3). Though it was not statistically significant, this could be due to other factors which were not tested in this study.

The second question captures the respondents' perception about how they associated FWA and more women participating in the labour force. The respondents were asked to rate their perceived opinion and the possibilities were rated on a fivepoint-scale ranging from (1) strongly disagree to (5) strongly agree. Table 5.23 shows that the majority (70\%) of the working women perceived that FWA will have an effect on the decision for more women to go out to work.

Table 5.23 - Flexible Working Arrangements and More Women Going Out to Work.

\begin{tabular}{ccc}
\hline Agree & Uncertain & Disagree \\
\hline $72 \%$ & $22 \%$ & $6 \%$ \\
\hline
\end{tabular}

Further analysis was done using an independent t-test to see whether working arrangements will have an effect on the decision for women to go out to work (Please refer to Appendix 5.4). The results were statistically significant, meaning that 
flexible working arrangements have an effect on women's choice to go out to work. As mentioned earlier, the majority of the women were interested in the uptake of FWA at the workplace and this was statistically significant (Please refer Table 5.13). This analysis shows that there is a strong association between FWA and women's decision to go and work in the labour force.

\subsection{Summary}

The majority of the respondents $(86 \%)$ in this study are interested in FWA at the workplace. The results indicate that socio-economic status affects female employees desire to take up FWA at the workplace. Women holding a degree, earning an income above RM7,000 and in the higher occupational status were the ones who were more interested in FWA.

The most commonly stated 'perceived advantages' of FWA were having more family time and the reduction in commuting cost. Achieving job satisfaction was also noted as a very highly perceived advantage among the respondents besides having autonomy on work schedule. On the other hand, the female employees are also concerned about FWA and its possible effect on career advancement.

In brief, these findings suggest that FWA may bring more advantages for women employees in terms of economic and social well-being.

Based on the descriptive analysis, more than 86 percent of the women are interested in FWA at the workplace. Further cross tabulations showed that in terms of demographic profile, FWA was preferred among the Chinese ethnicity, married women, and those who were in the 30-39 years age group. However, the demographic factors were not statistically significant. As for the socio-economic factors, women who were in the management level, earning income 'above RM 7,000' category and holding a bachelor's degree were the most interested in FWA. These results were statistically significant. More than 58 percent of the women quizzed were also interested in continuing working until retirement age. Further analysis using cross tabulation showed that the majority of these women worked in 
FWA organisations. While 72 percent agreed that FWA will have an effect on the decision for more women to go out and work, this result was also statistically significant among the two groups.

This chapter has shown factors which have an effect on women's uptake of FWA and how FWA has an effect on bringing more women into the labour force. How FWA affects women's well-being will be discussed in the next chapter. 


\section{Chapter 6}

\section{The Impact of FWA on Women's Well-being - A Qualitative Analysis}

\subsection{Introduction}

Findings from the previous chapter reveal that flexible working arrangements (FWA) at the workplace are a matter of interest especially among the more educated respondents, those holding a higher occupational status and earning a higher income. This chapter aims to address the following research questions: How do women perceive the benefits they may achieve if they were offered FWA at the workplace? How do women use flexible work to juggle their other demands? The discussion centres on the expected benefits of FWA and their impact on women's well-being focussing on three main aspects, namely work-life balance, empowerment and lifestyles. This discussion is framed around both the quantitative data analysis and qualitative information. The first section analyses data which was gathered from the questionnaire on women's well-being which is measured by the three aspects mentioned above. The second section is based on in-depth information gathered from interviews from a working woman's perspective of a daily routine and some issues on how they juggle work, home and other demands. Issues of working women in different working arrangements are highlighted as they try to juggle paid work and unpaid work. This part of the chapter expands the conclusions of the quantitative data analysed in the earlier section by establishing the link between working arrangements and women's participation in paid labour.

\subsection{Method}

Data triangulation was used in this chapter through the use of survey questionnaires and interview analysis. As explained in Chapter Four, there were 415 questionnaires which were completed by women employees in 14 organisations and out of which 396 were usable for the analysis. As for the face-to face interviews, 30 
respondents voluntarily participated in the study which gave a lot of insight into their work and home experiences. Out of the 14 organisations, seven were FWA and seven were non-FWA. All the women in the seven FWA organisations were doing FWA.

Of the 396 respondents who participated in the survey, a high proportion of the women were in the youngest age group, were married, were Malays and originated from urban areas. The educational level shows that all had a minimum of eleven years of schooling and the majority of them (72\%) possess a bachelor's degree. Most earn an income below RM3,000 per month. The hypothesis tested was to see whether FWA will have any effect on women's well-being measured in terms of work-life balance, empowerment and lifestyles.

\subsection{Quantitative Analysis - MANOVA analysis}

Based on focus group discussion with women's groups, and women employees, items which measure these three indicators of well-being, namely worklife balance, empowerment and lifestyles were included in the questionnaire (Please see Appendix 4.1, Questions 37, 38, 39 and 41). There were four items for work-life balance, seven items for empowerment, and three items for lifestyles. Respondents indicated on a scale of 1 (Strongly disagree) to 5 (Strongly Agree) their perception on statements with regards to the three selected indicators.

In this study, the independent variable 'Working Arrangement' was being tested against the three dependent variables; work-life balance, empowerment and lifestyles, to determine whether FWA have an effect on the three aspects of women's lives. As there are three dependent variables, a MANOVA or Multivariate Analysis of variance was carried out.

For the first concept, "Work-Life Balance", an exploratory factor analysis, a dimension reduction technique, was performed using a varimax rotation (Hair, et al., 
2010). Based on the eigenvalues ${ }^{38}$, only one factor with value more than 1 was retained in each of the three constructs namely, work-life balance (WLB), Empowerment (Emp) and Lifestyles. In this analysis, the KMO value for WLB was 0.6, which is considered to be acceptable. A single factor was extracted that explained more than 63 percent of the variability in the data. The norm is that at least 50 percent of the total variance must be explained by the factor (Hair, et al., 2006.) The factor loading, KMO values and explained variation for the three constructs are shown in Table 6.1 .

Table 6.1- Summary Results From Factor Analysis

\begin{tabular}{|l|c|c|c|}
\hline Construct & No of Items & KMO & $\begin{array}{l}\text { Explained } \\
\text { Variation }\end{array}$ \\
\hline WLB & 4 & 0.6 & $63 \%$ \\
\hline Empowerment & 7 & 0.8 & $78 \%$ \\
\hline Lifestyles & 3 & 0.7 & $82 \%$ \\
\hline
\end{tabular}

The same procedure was done for empowerment and the KMO value was 0.8 , which shows that the items which were expected to measure empowerment explains the factors well and gave a factor which explains more than 78 percent of the variability in the data. As for lifestyles, the KMO was 0.7 and gave a factor which explains more than 82 percent of the variability of the data.

Using MANOVA test, it was found that the mean for work-life balance was $p$ $=0.025$, and for empowerment the mean was $\mathrm{p}=0.035$, which shows significant difference between women in the FWA organisations and non-FWA organisations. However, the mean for lifestyles was 0.34 , which means there was no significant difference in the lifestyles of women working in FWA or non-FWA organisations. The MANOVA test showed that working arrangements had an effect on women's well-being in terms of work-life balance and empowerment but not lifestyles as shown in Table 6.2 .

\footnotetext{
${ }^{38}$ Eigenvalues are the proportion of explained over unexplained variation, only one factor with values more than 1 was retained. Values more than one means more variation is explained than unexplained.
} 
Table 6.2- MANOVA Table Showing Significance Values for Working Arrangements and the Effect on Women's Well-being

\begin{tabular}{|c|c|c|c|c|c|c|}
\hline Source & $\begin{array}{l}\text { Dependent } \\
\text { Variable }\end{array}$ & $\begin{array}{c}\text { Type } \\
\text { III Sum } \\
\text { of } \\
\text { Squares }\end{array}$ & df & $\begin{array}{l}\text { Mean } \\
\text { Square }\end{array}$ & $\mathrm{F}$ & Sig. \\
\hline \multirow[t]{3}{*}{ Work Type } & WLB & 5.041 & 1 & 5.041 & 5.096 & .025 \\
\hline & EMP & 4.401 & 1 & 4.401 & 4.501 & .035 \\
\hline & LIFE & .913 & 1 & .913 & .917 & .339 \\
\hline
\end{tabular}

This quantitative analysis was further tested using in-depth interviews and it was found that women working in FWA had a better work-life balance and more empowerment compared to women in non-FWA organisations. The content analysis below will discuss the in-depth interview findings in detail.

\subsection{Qualitative Analysis - Content Analysis}

In this section, the main aim was to investigate how women employees manage work and home. This qualitative analysis revealed aspects of women's views about managing work and home. In the course of analysis, some underlying behaviours of how working women cope with work and family and possible reasons why women do not take up paid work were revealed. The cost and benefits of FWA were discussed by respondents working in FWA organisations while respondents in non-FWA stated the potential usefulness to the respondents who were working in non-FWA.

The research question to be answered was: How do women use flexible working arrangements (FWA) to juggle work and other demands and how beneficial are they to working women? Most of the women were very excited to reveal their stories about their daily routine and were happy to describe a day in their life with no 
reservations. The analysis provided an insight into how women viewed themselves in their role juggling work and home. Some common themes emerged, which are described below.

Interviews were conducted with 30 women, which constituted 15 women from FWA organisations and 15 women from non-FWA organisations. These women were from 14 organisations in the services sector and their ages ranged from 26 to 52 years with a mean age of 35 years. A total of 23 respondents (77\%) were married and the balance was single. Of the 23 married respondents, only 20 had children, while two were newly married couples and one was a widow.

Among the respondents who had children, eleven (55\%) had at least one child six years old or below, and ten (50\%) had at least one school going child. There were six respondents with college going or working adults. Please refer to Table 6.3.

Table 6.3 - Summary of Respondents with Children in FWA and Non-FWA

\begin{tabular}{|c|c|c|c|c|c|}
\hline $\begin{array}{l}\text { Working } \\
\text { Arrangements }\end{array}$ & Number & & Children & & $\begin{array}{c}\text { Total } \\
\text { Respondents } \\
\text { With } \\
\text { Children }\end{array}$ \\
\hline & & $\begin{array}{l}\text { Below } \\
6 \text { years }\end{array}$ & $\begin{array}{r}6-18 \\
\text { years }\end{array}$ & $\begin{array}{l}\text { Above } \\
\text { 18years }\end{array}$ & \\
\hline FWA & 15 & 5 & 7 & 4 & 12 \\
\hline Non-FWA & 15 & 6 & 2 & 1 & 8 \\
\hline
\end{tabular}

The sample was urbanised and Malaysia's main multiethnic society was well represented with thirteen Malays, seven Chinese and ten Indians. They were all Malaysian born and represented the multicultural and socio-economic diversity of the country. Some of the main features of the respondents are shown in Table 6.4. 
Table 6.4 - Main Features of the Respondents

\begin{tabular}{|c|c|c|c|c|c|c|}
\hline $\begin{array}{l}\text { Participant } \\
\text { (code) }\end{array}$ & $\begin{array}{l}\text { Age } \\
\text { (years) }\end{array}$ & Ethnicity & $\begin{array}{l}\text { Marital } \\
\text { Status }\end{array}$ & $\begin{array}{l}\text { Educational } \\
\text { Level }\end{array}$ & $\begin{array}{l}\text { Occupational } \\
\text { Level }\end{array}$ & Children \\
\hline F1 & 35 & Malay & Married & Degree & HR Manager & 3 children \\
\hline $\mathrm{F} 2$ & 38 & Chinese & Married & Degree & Executive Level & 2 children \\
\hline F3 & 42 & Malay & Married & $\begin{array}{l}\text { SPM } \\
\text { (O levels) }\end{array}$ & Supervisor & 2 children \\
\hline $\mathrm{F} 4$ & 28 & Indian & Single & Diploma & Administrator & - \\
\hline F5 & 28 & Malay & Single & Degree & $\begin{array}{l}\text { Transport } \\
\text { Coordinator }\end{array}$ & - \\
\hline F6 & 33 & Chinese & Married & Degree & $\begin{array}{l}\text { Marketing } \\
\text { Adviser }\end{array}$ & - \\
\hline F7 & 49 & Malay & Married & $\begin{array}{l}\text { Post } \\
\text { graduate } \\
\text { (Masters) }\end{array}$ & Training Head & 3 children \\
\hline$\overline{F 8}$ & 53 & Indian & Married & SPM & Coordinator & 2 children \\
\hline F9 & 44 & Indian & Married & $\begin{array}{l}\text { Post } \\
\text { graduate }\end{array}$ & Team Head & 1 child \\
\hline F10 & 50 & Malay & Married & Diploma & Admin Exec & 4 children \\
\hline F11 & 38 & Malay & Married & SPM & $\begin{array}{l}\text { Asst } \\
\text { Administrator }\end{array}$ & 3 children \\
\hline F12 & 52 & Chinese & Married & $\begin{array}{l}\text { Post } \\
\text { graduate }\end{array}$ & Senior Lecturer & 3 children \\
\hline F13 & 49 & Malay & Married & $\begin{array}{l}\text { Post } \\
\text { graduate }\end{array}$ & Professor & 4 children \\
\hline F14 & 41 & Indian & Married & $\begin{array}{l}\text { Post } \\
\text { graduate }\end{array}$ & Senior Lecturer & 1child \\
\hline F15 & 40 & Indian & Married & Masters & HR Manager & 1 child \\
\hline N16 & 27 & Malay & Married & $\begin{array}{l}\text { SPM } \\
\text { (O Levels) }\end{array}$ & Clerk & 1 child \\
\hline N17 & 52 & Indian & Married & $\begin{array}{l}\text { SPM } \\
\text { (O Levels) }\end{array}$ & HR Assistant & 3 children \\
\hline N18 & 32 & Chinese & Single & $\begin{array}{l}\text { SPM } \\
\text { (O Levels) }\end{array}$ & Clerk & - \\
\hline N19 & 32 & Malay & Married & Degree & $\begin{array}{l}\text { Senior } \\
\text { administrator. }\end{array}$ & 1 children \\
\hline $\mathrm{N} 20$ & 25 & Indian & Married & Diploma & $\begin{array}{l}\text { Junior } \\
\text { Administration } \\
\text { Assistant }\end{array}$ & - \\
\hline N21 & 26 & Malay & Married & SPM & Administration & 2 children \\
\hline
\end{tabular}




\begin{tabular}{|c|c|c|c|c|c|c|}
\hline & & & & (O Levels) & Assistant & \\
\hline $\mathrm{N} 22$ & 34 & Indian & Married & $\begin{array}{l}\text { SPM } \\
\text { (O Levels) }\end{array}$ & $\begin{array}{l}\text { Administration } \\
\text { Supervisor }\end{array}$ & 3 children \\
\hline $\mathrm{N} 23$ & 27 & Malay & Married & Diploma & $\begin{array}{l}\text { Administration } \\
\text { Assistant }\end{array}$ & 1 child \\
\hline $\mathrm{N} 24$ & 26 & Malay & Married & $\begin{array}{l}\text { SPM } \\
\text { (O Levels) }\end{array}$ & Coordinator & - \\
\hline N25 & 32 & Malay & Married & $\begin{array}{l}\text { SPM } \\
\text { (O Levels) }\end{array}$ & Clerk & 2 children \\
\hline $\mathrm{N} 26$ & 28 & Chinese & Single & Diploma & HR Assistant & - \\
\hline N27 & 38 & Chinese & Single & Degree & Designer & - \\
\hline N28 & 38 & Indian & Married & $\begin{array}{l}\text { P Post } \\
\text { graduate }\end{array}$ & Lawyer & 2children \\
\hline $\mathrm{N} 29$ & 32 & Indian & Single & $\begin{array}{l}\text { Post } \\
\text { graduate }\end{array}$ & Lecturer & - \\
\hline N30 & 38 yrs & Chinese & Single & Degree & $\begin{array}{l}\text { Marketing } \\
\text { Manager }\end{array}$ & - \\
\hline
\end{tabular}

The respondents related a wide array of experiences which revealed their daily routine and the many challenges faced by women who chose to continue work after starting a family. These challenges were more evident among women who had young children aged five or below. Generally, there were some consistent themes which emerged such as caring responsibilities, workplace cultures and practices, economic independence and commuting time. One focus was to assess how the travelling time differs for the respondents using FWA and non-FWA and how this had an impact on their time allocation at home. A wide range of related issues also emerged such as patriarchal ideologies, gendered division of labour, coping strategies and male dominance in the home front. The key concept in this section was flexible working arrangements and its link to how women juggle work and home. The study focuses on three main themes which encapsulate the three main issues, i.e., work-life balance, empowerment and lifestyles of these women who were working in organisations with two different working arrangements. 


\subsubsection{Theme One - Work-Life Balance}

How women manage work and home was explored by discussing the respondents' daily routine from the time they wake up until the time they retire to bed. Both the domains of work and home and the use of FWA were discussed using the theme of work-life balance. In terms of family, the daily activities were discussed in terms of time management, how they managed household chores and caring responsibilities and the availability of family time, while work-life was discussed focussing on work stress and commuting time. The focus was to ascertain how travelling time differs for women using FWA and non-FWA. The aim was to examine whether FWA may have any impact on work-life balance.

The respondents had a range of perspectives on what work-life balance meant to them, some of the obstacles on their path to achieving it, and also ways to improve their work-life balance. While most people see work-life balance as a woman's issue, many of the respondents thought that individuals, families, communities, employers and the government could help towards achieving better work-life balance.

\subsubsection{Managing Time at Home}

One characteristic which was prevalent among all the respondents was long days, where most of them had an early wake, at least by 6 a.m. and did not retire to bed before 11.30 p.m. But it was more of a choice for the single respondents who had no caring responsibilities and chose to wake up early to either to go for a walk or to attend to personal needs. A large proportion of the married respondents woke up early, regardless of the nature of their working environment. Most of them had to bear the brunt of working both outside and at home. Time management is a great concern with most of the respondents who eventually learn how to manage household chores, family and work. However, while one of the respondents was tired by 9 p.m. and retired to bed by 10 p.m., the majority of them did not go to sleep until 11.30 p.m. 
N22, an Administrative Supervisor who is married with three young children, starts her day as early as 5 a.m. as she needs to cook breakfast and lunch for her family before leaving for work with her husband by 8.15 a.m. In her case, the assistance of her extended family proves to be very useful as her father helps to babysit her three young children. While her nine-year-old and her eleven-year-old go to school, her five-year- old is being cared for by her father.

"Having to wake up early and getting two meals ready for six of us and then going to work makes me very tired. My husband and my two young ones help me but I still get very tired by 9.00 p.m. Sometimes I wish I could quit my job and stay at home. At least one consolation is that earlier I used to send my children to a baby-sitter but from last year, my father volunteered to help us with the children. It's such a relief for my husband and me to go to work with peace of mind as we are confident that our children are in good hands."

For N22 and a few others working in non-FWA organisations, time management is a very challenging issue. This problem is aggravated if they have young children.

N25, a clerk who has two young children below five years, also does not get to sleep before 1 a.m. during the weekdays because of household chores. She however manages to "watch television for at least half an hour before going to bed".

As for the young, single respondents, all of them also wake up by 6.30 a.m. but the difference is they do not have to rush to get things ready in the morning. While most of the single respondents like F4, F5, N18, N29 say that they "take their own sweet time and have breakfast and get ready for work" without the normal morning stress, this was not echoed by the other two single respondents who have to leave home early to beat the morning traffic jam. Both N27 and N30 leave home early to avoid the peak time jam but they have a "good breakfast near their workplace".

Respondents in FWA organisations generally wake up before 6.30 a.m., have a lot more flexibility in terms of juggling household chores and work, and show 
better control over time management. One notable feature is they have more time in the mornings either for themselves or their family. This is evidenced by the following:

\begin{abstract}
As F8 quoted,
"I wake up early every morning by 6.45 a.m., but I have enough time to go for a walk, return home to make breakfast, eat with my husband and son...before I get ready to go to work. As I work in a FWA organisation which allows me to adjust my time, I start work only at 9.00 a.m. ".
\end{abstract}

F7 goes for an hour's walk every morning before having breakfast with her husband and then takes off to work. Similarly, F12, F13 and F15 who are also in FWA organisations, generally have enough time every morning to have breakfast with their husbands and children, drop their children at school and then proceed to work. However for F14, who is also working in a FWA organisation, it is quite a different experience. She still finds that getting her seven year old daughter ready and sending her to school before going to work "tires her in the morning and causes undue stress".

There was a marked difference in time management among respondents who work in non-FWA organisations compared to those who worked in FWA organisations. For example, the respondents in non-FWA organisations have to plan well ahead, wake up early to prepare meals and hardly have much breathing space for themselves. The researcher detected an underlying tone of strain in some of their voices as they revealed a life that is rushed, especially among those respondents who have to get breakfast ready as well as prepare and send the children to school.

N16 and N28 who have school-going children lament about "how mornings are so stressful because they have not only to prepare meals, but also get the children ready for school and then drive them to school before going to work". As for N19, whose husband has shift duty and has a three-year-old child, "there is not much time to rest during weekdays with the mundane 'cook, eat and clean' routine". 
Based on the different experiences of the respondents, working arrangements seem to have a great bearing on time management and how much time the respondent has for her family. This is discussed further in the next section.

\subsubsection{Managing Family Time}

On weekdays, dinner time was the most common hour where respondents spent time with their families as noted in both groups. Most of the respondents working in FWA organisations highlighted the amount of time spent with their spouse and children, both in the mornings and at night. On the other hand, most respondents in non-FWA organisations were found to spend dinner time and also had more time with their families during the weekends.

F13, who works in an academic institution which has FWA, commented that the nature of her job, gives her ample time to be with her family:

"I feel very lucky working in this kind of an organisation and this kind of job because it gives me the opportunity to spend more time with my family. I spend at least an hour every day after dinner checking on my youngest son's school work before I do my own reading. In fact, I have the luxury of having breakfast with my husband every morning and dinner with at least one of my two working children. Sometimes my daughter works late, so we get to have breakfast together".

This kind of sentiment was also expressed by F15 who has a six-year-old daughter and works flexible time. She feels that time with the family is important and one has to make a concerted effort to make the time and get priorities right. According to F15,

"As I start work only at 9.00 or 9.30 a.m., I have enough time to have breakfast with my six-year-old daughter, send her to school, go for a walk, and then get ready for work. Every night, I make sure that 7.00 p.m. to 8.00 p.m. is my time with my girl, before I have dinner with my husband". 
According to F10 who works in a small professional organisation, which has FWA, "family comes first". Her husband who is 65 , recently retired from work and is at home, while she goes to work. She adds,

"I sometimes feel that my work time is taking me out from my family time. It is typical of Asian culture to spend a lot of time with the family. But as I work in a FWA organisation, I am able to manage my time and make sure I spend breakfasts and dinners together, and of course the weekends".

It was more obvious among respondents from non-FWA to comment on "no time syndrome for family" during the weekdays. However, all the respondents made it up by spending the weekends with their families or their parents and their parentsin-law.

Said N20, who is newly married:

"Even though my husband and I work in the same office, our work times differ. I work from 8.45 a.m. to 5.15 p.m. but he works on shift, such as 2 p.m. to 10.00 p.m. or 10.00 p.m. to 6.00 p.m. As a result, we spend time together only during the weekends and not really during the weekdays. As I live with my parents-in-law, I do not feel lonely but spend time with them and help my mother-in-law with housework".

This sentiment was echoed by many respondents who had young children and school going children as they found that they hardly had enough time.

N21, a mother of a three-year-old and a five-month-old baby, had the following to say:

"Soon after feeding the children, I have to make them sleep by 9.00 p.m. and then it's time for dinner. My husband is quite helpful with washing up and handling the baby. However, by the time, we finish all the work, we are so tired and it is time to go to sleep. We spend time together, watching television or going out during the weekends only".

This was also the case for three of the seven single respondents, who only have time with their families during the weekends as their working parents work in 
non-FWA organisations. Even though F5 has a lot of free time, her mother works in a non-FWA organisation and they spend "quality time only during the weekends".

N27, a single professional, who works in a non-FWA, and lives with her mother, says:

"My mom has a more colourful life than me. By the time I reach home at 8.00 p.m., she is still at her friends' place or most of the time she goes overseas. We only spend weekends together".

The respondents in the FWA organisations, especially those working from the home, feel that if they plan their work and work with a set target, they have more time for themselves and their families. It depends on how one manages and prioritises time for the family. Most respondents in non-FWA organisations allocate their weekends for family time. Housework and caring responsibilities are other aspects which also take up the respondents' time.

\subsubsection{Balancing the Demand of Work and Household Chores}

Women continue to perform most of the household chores and caring responsibilities even when they enter paid labour, combining raising a family as well as full time employment as the norm of the day. Spending eight hours or more at the workplace and coming home to handle household chores is a contributory factor to stress. Most of the household chores like cooking, washing, cleaning and ironing are still a woman's domain as far as Malaysian culture is concerned and this conditioning still prevails today.

Most of the respondents had to make sure that there was food at the table, whatever time they returned from work. It was a more challenging task for respondents with young children to prepare food and also attend to the young children as soon as they returned from work, compared to unmarried respondents and those who have domestic helpers. 
There was an obvious feeling that patriarchal views still exist among many of the spouses' of the respondents, regardless of the working arrangements. It was found that there are high expectations from the spouses with regards to family, especially among the Malays and also the Indians, as in many cases, the women are expected "to take care of home and the man is supposed to bring in the income". Some of the cases below depict how the respondents have to take care of household chores with no help or minimal help from the spouses.

F3, a Malay supervisor, says:

"As soon as I get home, I go straight to the kitchen to prepare dinner. I have two adult children from my husband's first marriage but they do not help me at all. My husband used to help earlier but after he retired and went into business, he has no time to help me. Sometimes if the need arises, I work overtime on Saturdays and Sundays and that is when he becomes angry with me not attending to household needs. My husband is a very nice man but when it comes to housework, it is my domain and it is worse because he also does not encourage my two grown-ups to help me".

Similarly, F8, an Indian training coordinator who is home by 4.30 p.m., says:

"I reach home by 4.30 p.m. most days and work from the home the other days. As soon as I am home, I get the housework done and get the dinner ready. All work is completed by 7.00 p.m. I log on to the computer at 7.00 p.m. and do teleconferencing with clients from 9 p.m. to 10 p.m. My husband is very supportive of my working but he does not help me with any housework".

A group of the respondents, i.e., F3, F6, F8, F10 and F11 are able to cope with household chores and paid work without any help from their spouses or children because they work in FWA. While F3 and F11 have flexible working time, F6 and F8 work from the home two or three times a week.

However, the domestic pressures are more marked among respondents in non-FWA organisations. Respondents entrenched in household structures that allow male dominance are exposed to more stress but "eventually learn how to cope and manage time". Gendered division of labour was apparent where the respondents had 
to carry out many household chores such as cooking, cleaning and washing all by themselves with little or no help from their spouses. Sometimes there is little help from the husband and there was no sign of men meeting women half way in the case of most married women.

N16, a Malay mother of an eleven-month-old baby, explains:

"On my way back from work, I pick up my baby from my mother-inlaw's house. As soon as I get home, I have to prepare dinner and do all the housework. My husband is supportive of my working at the bank but he comes home late from work everyday. Therefore, I have to do all the housework with no help. He sometimes helps to take care of the baby while I get the washing and cleaning done".

N28, a, Indian mother of two young children who are eight and five years old respectively, relates her daily routine:

"I pick up my children from my mother's house on the way home from work. I am grateful that my mom gives me dinner too. So, when I go home I have to get moving with the household chores, cleaning, washing, ironing etc. My husband is a very good man and very supportive of my working but he does not help me with any housework. As he runs his own business, he sometimes brings work home. Well, I have learnt to cope with this life".

This mindset is due to cultural differences and social obligations and is found to be quite apparent among the Malay and the Indian ethnicities. However, a change is beginning to take place and this is more notable among some married couples who have children, where some husbands participate in household work.

For F1, who is 35 years old and has three young children,

"My mother does the cooking during the weekdays but my husband helps with cleaning and washing". 
F12, a 52 year old with three adult children explains,

"While I do the cooking and washing, my husband helps me with the cleaning. My sons who are in college also do their share of housework by washing and ironing their clothes and cleaning their rooms. Therefore, our work is done quite fast. We do not need a domestic helper".

By the same token, F14, 41 years, who has a school-going child, says,

"My husband shares in all the housework. So, I really am not very stressed with housework".

N21, a 26-year old who has two young children and N23, a 27-year old who has an eight-month old baby, are cases of young Malay couples where their husbands are very supportive of their working and share in all the household chores.

While variations in household size and structure are important determinants of domestic responsibilities, married women with young children were noted to get more support from their spouses. However, all respondents expressed a feeling of gendered division of labour showing that patriarchal views are still alive.

For example, out of the 23 married respondents, only seven (30\%) claimed that their spouses were very helpful at home. Even then it was mostly helping to take care of the children and doing the washing up after meals. As for the others, most (9) of them had to do all the housework by themselves, while another five of them have domestic helpers and two were assisted by their extended families.

It was noted that all the respondents who employed domestic helpers had young children and worked in FWA. The domestic helpers were all foreigners of Indonesian origin. They did all the household chores and also childcare. The respondents who had domestic helpers generally led a very stress-free life, had more time for themselves, more time for the family and could concentrate on their jobs. These respondents were also in the higher occupational status and therefore, could afford a domestic helper. 
F9 works in a FWA organisation which has been cited for FWA best practices in Malaysia. She is a single mother who employs a part-time domestic helper who stays with her dyslexic son until she gets back from work. This is her experience:

"I have been working in this organisation for about four years and I find it more challenging than my previous job. However, as I have a dyslexic son who needs more attention, I decided to remain in this job. My part-time helper is very useful as she is at home when my child comes back from school, gives him his lunch and tea and waits until I come back. As I work in a FWA organisation, I sometimes go to work at 9.30 a.m. and come back around 6.30 p.m. or go to work at 10.00 a.m. and return at 7.00 p.m. With the domestic helper and FWA, I am able to cope with work and home. In fact my organisation is very understanding, and allows me to take my son on my official trips overseas".

F15, who also works for a FWA organisation has a six-year-old whom she leaves very confidently with her domestic helper when she goes to work.

"I have a helper who does all the work, including cooking and taking care of my daughter. I still wake up at 6.00 a.m., send my daughter to school at 7.00 a.m. and then go for a morning walk before I go to work at 10.00 a.m. As I go to work only at 10.00 a.m., I come back only at 7.00 p.m. The housework is done by my helper and my husband does not help in any way. I am able to concentrate well on my job as my helper has been trained to take care of my daughter and also prepare meals accordingly. I spend at least an hour and a half with my daughter every night and have a lot of time for my husband. I normally sleep by 10.00 p.m. during the weekdays."

Like F15, most of the respondents who have domestic helpers do not get any help from their husbands or their children. As the household tasks are taken care of, the respondents are able to spend more time for their family. They are also able to have more time for their recreational walks and gymnasium activities. This enriched lifestyle is further enhanced when they have FWA.

Extended families have always been a distinct feature in the Asian culture with some dual career families leaving the children with the grandparents while they 
are at work. However, this trend has been changing in recent times where most of the grandmothers themselves are working. Some of the respondents had extended families to help them take care of the children. F1 has her mother and N22 her father to help take care of their children while they are at work. N20, who is newly married, has her mother-in law to take care of the household chores.

The single women had more time for themselves as they did not have much responsibility of helping their mothers who end up doing all the housework. As such, caring responsibilities were not a major issue for single women or married women who had domestic helpers but more a challenge for working women with young children.

\subsubsection{Managing Work and Caring Responsibilities}

Two-earner couples are a common phenomenon and trying to combine work and caring responsibilities is a challenge especially among married respondents with young children.

Most of the married respondents $(87 \%)$ had children, except for two newly married couples and one widow. From the 20 respondents who had children, only two had adult children, while the balance of 18 had at least one school going child or young child and $11(55 \%)$ respondents have young children aged six years or below. However, it was noted that out of the eleven respondents with young children aged six years or below, only three had domestic helpers and two others had parents or extended families to stay with them and help with childcare. The balance of six sent their children to either baby sitters or relatives to take care of the children while they were at work.

Among the 15 respondents working in FWA organisations, three had young children below six years and all of them had domestic helpers. Two of them believed that the domestic helpers were well trained and were taking care of their children well so much so that "they are able to work peacefully, without worries at their job". 
But, one respondent who had a bad experience with the previous domestic helper sends her two young children, aged 3 and 5 years, with her domestic helper to her relative's house every morning. Besides having a helper, all these respondents have time to organise their children and their needs in the morning before going to work late.

Among the seven respondents in the non-FWA organisations who had young children, six of them send their children to their relatives and only one sends her child to a baby sitter. The extended families played an important role for these respondents. In spite of the children being in "good hands", the issue of guilt was raised and expressed by some respondents concerning working long hours and leaving the child with the "caretaker". The respondents working in the non-FWA organisations expressed this feeling of guilt more.

Says N16, a young clerk at a bank,

"Every morning I send my 11-month-old baby to my mother-in-law's house at 7.45 a.m. before going to work. Officially, bank working hours are from 8.45 a.m. to 5.45 p.m. But, I never get to leave the bank before 7.00 p.m. Sometimes, I need to stay even later to finish up work and I feel so guilty picking my baby up after 7.00 p.m. If only I can leave the bank at 5.45 p.m., I would not have this feeling of guilt, but whatever it is, I still prefer to work than stay at home".

Even though N17, who has adult children and N18, a single respondent, do not have caring responsibilities, they also voiced their dissatisfaction with the bank's long working hours and how it takes a toll on their family time. The long working hours culture is very obvious among certain sectors and the banking industry is certainly one sector, which employs many women and most of them have an issue managing work and home life.

The respondents in the non-FWA logistics organisation seem to be a happier group in terms of working hours and managing work and caring responsibilities. 
N19, who has a three year old daughter, is an example of a respondent who has learnt how to cope with work and life in her present organisation.

N19 is a 32-year old senior administrator in a non-FWA logistics organisation for the past five years. She is married and has a three-year-old daughter, whom she just started sending to a nursery near her home. Prior to this, she was taken care of by a babysitter. She sends her daughter every morning at 8.15 a.m. to the nursery, on her way to work which starts at 8.45 a.m. She finishes work at 5.15 p.m. and by 5.40 p.m., she picks her daughter up and is home by 6 p.m. At home, she has to do all the housework and caring responsibilities by herself. As her husband works on shift or by rotation, he hardly helps with any housework or caring of the child.

N19 says, "I am fine with this way of life at the present moment, but if I have a second child, I might have to think about other options. Whatever it is I would like to work as long as my husband allows me to work. I want the economic independence. We can't rely on men these days".

She does not seem to mind the fixed working hours as long as she can leave the office by 5.15 p.m.

For many women like N19, who is working in a non-FWA organisation which is near her house and easily accessible, the fixed working hours are not a problem as long as they are able to go home after eight hours of work. Taking care of the child does not seem a difficult task for this respondent and this same view was initially expressed by her colleague, N22, whose father helps to babysit her children in her house. But in the last part of her interview, she revealed that "if only I can do some part-time work or part-time business, I will be able to cope better with work and family".

Other than those with young children aged five and below, there were eleven respondents who had young school going children who also needed care while the 
parents were at work. While some were looked after by the domestic helpers, most of them were taken care of by the extended families or the elder siblings.

One classic example where FWA was really useful was in the case of F14. She works in a FWA academic institution and has an eight-year-old daughter who goes to primary school. F14 sends her to school every morning at 6.45 a.m. and goes to work by 7.45 a.m. even though she works flexitime. School finishes at 1.10 p.m. F14 picks her daughter up, gets her some lunch and brings her to her workplace. As F14 has her own room, her daughter stays in her room and does her homework until F14 finishes her lectures. Most days, she goes home by 3 p.m. Some days, she has classes until 5.00 p.m. and so her daughter stays with her until 5.00 p.m. Her daughter is very happy with this arrangement where she gets to complete her homework, play on the computer and also have a nap. She sometimes takes her daughter to the lecture hall where the daughter sits at the back of the class. When F14 goes home, she gets dinner ready and her husband is very helpful with housework.

This is just one case where respondents can bring their children to their workplace and are able to do their jobs with peace of mind. Most workplaces do not allow this as it will interfere with work practices. Among the married respondents who had extended families or domestic helpers to take care of their children, the lack of a good support system for childcare was voiced by many of them. More than half of the respondents were of the opinion that a formal and reliable childcare facility should be arranged near the office place. This childcare facility can be organised with the cooperation of a few companies who agree to set up a nursery or childcare centre near the work area. This will facilitate a good working environment for the mothers/parents to work with peace of mind.

As N21, a mother of two young children said:

"If only there is a reliable childcare centre in my working area, I do not have to undergo stress every morning sending my two kids who are 3-years- old and 5-months-old to a baby sitter at 7.00 a.m. before going to work. Besides, I can check on them during my lunch break too”. 
This statement also highlights the importance of childcare facilities to married women who have young children and need nursing facilities. Traditionally, most women stop nursing their babies when their maternity leave of sixty days is over. However, with the increasing awareness of the advantages of nursing babies until six months, many mothers try their best to fulfill that but most of the time, working conditions do not permit this.

However, eight respondents who work in large organisations felt that the childcare centre should be located at the office building itself and this was more strongly voiced by two respondents who were nursing their babies. They do not think that childcare centres in the office premise will be a nuisance to their work or productivity. Instead, they feel that it will "enable them to work with peace of mind as they know that the children are reachable at all times".

The availability of affordable and reliable childcare centres near the workplace was widely accepted as crucial to allowing married women to work in paid labour. However, five respondents differed in their opinions and felt that childcare centres near the home will be conducive for the working parents because "you don't need to cart the children every morning all the way to work".

Trying to combine motherhood and paid work can be very challenging at times as N22 who has three young children aged five, nine and eleven years, feels. "It's not that I really enjoy my work, but my husband feels that the family would enjoy a better standard of living if I work and that's why I have to leave my three young children with my father, while I go to work."

Most of the respondents did not have to take care of the elderly, except for F7, who occasionally sends her mother for therapy and F8 who takes care of her mother when her brother goes overseas. In both instances, FWA has been very useful to them to manage both their mothers and work. The issue of childcare came up frequently during the interviews. 
F1, a Human Resource Manager at a FWA bank had the following to say:

"Look here, if you want more women to join the labour force, you need a good support system. Foreign domestic helpers are just not reliable and childcare centres are so few and expensive sometimes. That's why some women in the lower income group end up quitting their jobs to take care of their children".

A case in point here is that nearly all the respondents were of the view that there are many Malaysian women who are educated but are not working in paid labour. Most of them (50\%) felt that caring responsibilities and an affordable support system were lacking while others felt that male dominance and patriarchal views were very strong in determining women's exit from the workforce.

Other than household chores, caring responsibilities are another important aspect in the lives of working women and it was noted that respondents who had domestic helpers and who worked in FWA had an easier task of managing work and childcare. Childcare facilities are generally considered as one of the main instruments that enable parents to combine family responsibilities and work.

\subsubsection{Managing Commuting to the Workplace}

Even though paid work and unpaid work are separated, it is important to know how the respondents managed their routine workday. All the respondents travelled to work by car. Most of them had their own cars, while one respondent carpooled and a few were driven to work by their spouses.

Generally, respondents in FWA start work only after 9.00 a.m., while a few start at 10.00 a.m. and many of them work from the home. The best part of working in FWA according to a respondent is that they are able to avoid the traffic jam and hence, are not so tired when they reach home. 
F15 who works in a FWA telecommunication company claims that:

"I go to work around 9.00 a.m. every day and leave office at 7.00 p.m., but I am not so tired when I reach home because it's a non-peak commuting period. I sometimes work from the home".

Commuting to and from work has always been a great issue of discussion in terms of mode of transport and commuting time. Most of the respondents spend at least half an hour to travel one way to their workplace There were two respondents who travelled an hour everyday to work while another respondent mentioned that if she did not leave her home before 6.45 a.m., it would take her $1 \frac{1 / 2}{2}$ hours to reach her workplace.

F9, a post-graduate, holding a senior management position is of a strong opinion that "the way work is done should depend entirely on the employee". Thus one should be objective and "management by objective is more productive than management by observation". In her large organisation, FWA is supposedly available for all departments across all jobs, but her superior "is very strict, the type who does not encourage flexible work, is more traditional in his outlook and comes from more of an army background". She says:

"As far as I am concerned, we save so much time in terms of commuting time which could be put to better use and flexible work actually does not have any negative effect on productivity. One actually works longer hours if she works from the home".

Most of the respondents working in FWA organisations save a lot of time due to flexible hours as they are able to plan their commuting time during non-peak periods. As for those in the petroleum shared services organisation and telecommunication organisation, they have the option of working from the home which saves a lot of time and money. Whether the respondents are married or single, all of them felt that "commuting time can be saved and it's less tiring" with FWA. 
Commuting time played a more important role to assess how tired these respondents were when they reached home after work, compared to the commuting mode. Public transport is generally good but connectivity from one mode to another is still lacking in most parts of the country. Out of the fourteen organisations chosen, half of them were in the city centre while the others were not so easily accessible via public transport.

F10, who works in a professional FWA organisation says:

"Since I do not drive during the traffic jam period, even though I go back sometimes at 8.00 p.m., I do not feel so tired because it takes me only 15 minutes to reach my house which otherwise takes me an hour to reach. In the mornings, I only go to work around 10.00 a.m. and my boss does not mind as I stay back to work late".

It is evident that commuting time plays a very crucial role in the respondents' working life. The respondents, regardless of whether single or married, are highly affected by the commuting time to and from their workplace.

For example, both F4 and F5 are single women but one notable difference between them is that F4 takes one hour to commute to and from her workplace, while F5 takes 15 minutes only. Both of them work late sometimes, possibly because they are single and career oriented, and return home around 9.00 p.m. on most days. However, F4 is "very tired, feels stressed at work and would prefer to stop work" but F5 who takes a much shorter time to travel to her workplace and being the coordinator of her department finds her job challenging and less stressful. She "sometimes feels stressed, but loves to continue working in that organisation".

Most of the respondents in non-FWA start work between 8.30 a.m. to 9.00 a.m. and there is a marked difference in their finishing time. Even though the official finish time is between 5.00 to 5.30 p.m., depending on the nature of the job, some leave by 5.15 p.m. while most leave around 6.00 p.m. and the single, unmarried respondents work late until about 7.00 p.m. However, the commuting time is one of 
the determining factors of their timing to leave office where some choose to leave later so as to avoid getting caught in the "after office" hours traffic jam.

Most of the respondents, who worked long hours, regardless of working arrangements, found that working fixed hours had a negative effect on their lives and families.

As N27, a single, professional commented,

"One of the biggest setbacks of fixed working arrangements is the time I spend on the road. Going to work in the morning takes me about 45 minutes if I leave before 6.45 a.m. and an hour and a half if I leave any time after 6.45 a.m. Though I only start work at 8.30 a.m., I have to leave early to avoid the traffic jam. In the evenings, though I finish theoretically at 5.30 p.m., I don't leave my office until 8.00 p.m.....even then I reach home at 9.00 p.m. If I leave any time earlier than 8.00 p.m., it takes me two solid hours to clear traffic. It would be good if I could work from the home on some days, but my organisation does not have this work policy".

However, it must be highlighted that the respondents from the non-FWA logistics organisation were of a different situation regarding commuting. The logistics organisation is located in the outskirts of a town in the Klang Valley which is only accessible by own transport and it generally takes about 15 minutes to travel to the workplace. The respondents working here experience no traffic jam. They all start work at 8.30 a.m. and leave work by 5.15 p.m. and are home before 6.00 p.m. They did not complain of tiredness compared to the respondents who worked in the city. They were luckier in the sense that they all did not have a long commute time. Commuting time is a very important factor for working women especially when they need to go home to continue the second part of their work.

\section{Says N22,}

"My day starts at 5.00 a.m. and ends at 9.00 p.m. That does not seem too long compared to some people who sleep at 12.00 a.m. and 1.00 a.m. but it is fully packed. It is as if I have no time to breathe. I have to plan and work according to plan. As my husband drives me to and from work, I generally take a nap in the car on my way back home; 
otherwise, it is too tiring for me. When I get home, I have the second part of my work waiting for me...So commuting time is very stress free and no traffic jam".

This was more apparent among respondents who were working from home and had flexitime. For the respondents working in FWA, their major benefit is commuting time. As they are able to leave after the peak period, they do not waste much time and energy on the road. Those respondents who work from home also get a lot of work done without any interruption and save a lot of time and energy by being at home. However, other than commuting time, various other benefits and possible disadvantages were highlighted by the respondents and these are discussed in the next section.

It can be concluded that respondents working in FWA organisations generally have a better work-life balance compared to their counterparts in non-FWA organisations. This view was clearly expressed by most respondents in terms of their ability to better manage household chores and caring responsibilities, with less stress on commuting times due to planned commuting or less commuting. On the other hand, respondents in non-FWA organisations seem to have more of a challenge balancing work and home, mainly caused by having to leave home early and coming back late due to traffic during peak hours. This scenario is further aggravated if they have no support from their spouses.

\subsubsection{Theme Two - Work, Lifestyles and Well-being}

Women sometimes find it difficult to cope with work outside the home and have time for themselves or their friends. As discussed in the previous section, managing time spent for work, family and themselves is of utmost importance to ensure a certain level of work-life balance. However, there is a notable change in attitude towards paid work and its relationship to the lifestyles of working women as quality of life is valued more by women in the present decade. 
Respondents in FWA organisations generally revealed that they have much more time for themselves, especially in the mornings where they go to the gymnasium, for walks or have a good breakfast with their family members. Fitness and health care is the norm for respondents who have time for themselves. This feature of health consciousness was more apparent among married respondents in organisations which have FWA.

F9, who is a single parent, says,

"I spend at least half an hour every morning from 6.45 a.m. until 7.15 a.m. doing work outs in the gymnasium in my condominium. I then get my son ready for school and the school van picks him up at 8.15 a.m. Most of the weekends, I spend time with my son, his games, his piano class, etc. I also make it a point to go for women's programmes organised by the Women's Institute of Management and am very active in Toastmasters Club. I am an avid reader and have a big collection of books in my study at home. I read at least an hour every day before I sleep at 11.30 p.m.".

This same interest in walking and exercising is expressed by other respondents such as F7, F8, F13 and F15 who are all married but it must be mentioned here that three of them have domestic helpers and that means household chores are taken care of. It is noted that family based commitments typically result in a reduction in the time available for leisure, for personal needs and time for friends.

The issue of having time for oneself was also demonstrated by many respondents in terms of the activities they do during their free time at night and during the weekends. There was a marked difference in the availability of time for leisure activities among respondents in FWA organisations and non-FWA organisations. Most of the respondents in FWA had time to watch television or do leisure reading. In addition to watching television, many respondents also spend time reading but this was more apparent among those working in the FWA. 
Says F1,

"Once we have finished dinner and my husband helps to wash up, I oversee my children with their homework for at least an hour. I then go to my room and do some reading. I am not really a TV person so while my husband watches TV, I prefer to read before I retire to bed by 10.30 p.m.".

All, but one respondent in FWA organisations, have time to read every night at least for 15 minutes but a few of them mentioned that they do not watch much TV on weekdays. F3, was the only respondent in a FWA organisation who has really not much time for herself, even though she has no young children.

F3 is a Malay woman who is the second wife of a business man. Her husband has two adult children, aged 25 years and 27 years. Even though she works flexitime, with two grown-ups who do not help at all and a husband who is very demanding and busy with business, she hardly has any time for herself. Initially her husband was very supportive of her working but in recent times, he has shown his dissatisfaction. She wakes up at 6.00 a.m. and does not sleep until 1.00 a.m. Most of the days, she works until 8.00 p.m. and some weekends, she works over-time at her office. She is tired most days by 10.00 p.m. but she feels she needs a career and her own money.

For respondents like F3, culture and tradition are inhibiting factors to her lifestyle. Even though she does not have caring responsibilities, male dominance is portrayed in her life with heavy household responsibilities. She has a choice of leaving paid labour but she values her economic independence and her job, so she'd rather get her house straight by doing all the chores single-handedly. There are many women whose husbands are economically well off and would prefer their wives to keep house and be good housewives, but there are a few like F3 who treasure their economic independence and are willing to sacrifice their rights. This in turn tilts the work-life balance. 
In the case of the respondents in non-FWA organisations, most of them do not have enough time for relaxation before or after work on weekdays. Of the fifteen respondents in the non-FWA organisations, only three mentioned going to the gymnasium and all were single. It is not that married respondents are uninterested in gym activities but they have no time due to caring responsibilities. Besides, it was noted that those who commute far and who have to leave early or come back late from work to continue with the household chores without any help are the ones who really have no time for themselves.

While N23 and N25 have young children, they still are able to 'spend a few minutes watching television with their husbands". As for N17 and N24, who do not have young children to worry about, as soon as the household chores are done, they "relax by watching television".

Most of the respondents however commented that they have more time for themselves during the weekends. They spend time by going shopping, going to the movies with family, going on family outings and visiting relatives. They were not very keen on voluntary work except for two respondents who felt that if they had more time "they would like to do more work for the church".

Irrespective of the working arrangements, one feature of the unmarried respondents was distinct cultural difference. While the two Malay respondents and the three Chinese respondents spend a lot of time on their career, the two Indian respondents work according to office time and prefer to spend more time at home helping their mother. They did not seem to be very career oriented but more house bound. This accords with literature as outlined in Chapter Three.

Many of the respondents however found it very difficult to fit in work, family and social life or holiday. Working arrangements do not have a great effect on the time they spend for socialising with friends and relatives. They still have the same amount of time for themselves or for friends. As for socialising with friends, it was not their main priority to spend time with their friends and this view was especially evident among the married respondents. Most of them commented that "they were 
happy if they had more time for family". Some commented that they spend enough time via emails and mobile phones. Socialising does not necessarily mean meeting face-to-face.

F6, who has no children and a lot of time for herself says,

"My family has always lived nearby and so we are always in touch with each other. It's how you make the time - as you move on to different stages of life, priorities change, more because one is married but not really the job itself. I have FWA and so I have time but most of my friends do not have FWA and have no time...so we keep in touch through the cyber world of emails, Facebook and sms. We are happy with the cyber connectivity".

On the other hand, some respondents make it a point to keep in touch with relatives and extended family when they have time.

F7 says,

"When my children were younger, time seemed to be very limited. Now the children have all grown up and we have more time for socializing. Working in a FWA organisation allows me to organise family reunions at least once a month".

Some respondents were happy to meet up with their friends and relatives during weddings or feasts but were quick to note that they have no time to visit friends. However, the seven unmarried respondents had a lot of time for friends on weekdays and also during the weekends, irrespective of where they worked. Going for dinner or movies with friends was more common among single respondents and not a priority for the married respondents.

It is a different kind of society nowadays where people are connected in the most disconnected way. Some respondents, for example F8, claimed that they "are not very sociable" and do not really feel it is important to visit friends and relatives, but they try to keep connected by meeting during weddings or functions. 
However, an exception to this view was noted by a more sociable person like N19, who has a three-year old child. She explains thus:

"Though I keep in touch with my relatives using the online network, but I still make it a point to meet up with them at least once a month or alternate months during get together dinners. Social interaction for me is a real face-to-face chat over some meal, especially with close family members and their children".

Most of the respondents who are in their 30 s were very quick to comment about socialising using the social networks such as Facebook, LinkedIn, Twitter and also short messaging systems (sms) and mobile phones.

F2, who is busy with two young children, explains that:

"In this cyber age, it is not really necessary to visit someone physically but I keep in touch with my good friends via the cyber space and online chatting. Social networking is very simple these days, thanks to our mobile phones and online facilities".

Respondents in FWA and also non-FWA organisations feel that health is not affected much by the nature of their working arrangements because some of the organisations provide family friendly policies. Good family friendly policies (FFP) provide a working environment which helps increase the morale and job satisfaction of the employees. For example, all the organisations had good FFP such as their own pantry, medical benefits, annual retreats and dinners, annual leave, and 60 days paid maternity leave. One FWA organisation had their own gymnasium facilities, inhouse medical services, free annual medical check-up, nursing room, and resting room while two of the FWA organisations had a TV room and children's room for the employees' children to work or play while the parents work. 
However, the issue of maternity leave did arise among some of the respondents. Most of the organisations in this sample had a minimum 60 days paid maternity leave. One of the respondents did voice out her concern on maternity leave saying:

"Is the woman ready to work soon after 60 days of childbirth? Would she have recovered well? Would she be fit?".

Many respondents experience stress due to their dual roles in the workplace and at home. Two married respondents feel the stress to the extent that it affects their health with frequent migraine attacks and high blood pressure. The respondent who works in a non-FWA organisation feels so tired working long hours that she hardly has any time for her social life and feels tired by 9.00 p.m.

Most of the respondents do not bring work home, except for those working in educational institutions. In the banking industry which is considered quite stressful, the respondents learn how to separate social life from work-life by not taking work home. Much of the stress for the respondents from non-FWA was due to family responsibilities in comparison to workplace stress. Trying to get the children ready for childcare centres or school and then driving to work on time creates stress. Health wise, many of the respondents had either a backache due to long hours of sitting at the desk or stress due to driving in a traffic jam and this was more common among respondents from non-FWA.

Women who report high levels of well-being are those who felt satisfied with the conditions of their lives as measured in terms of being happy with work and family. For this, the respondents were asked two simple questions: "Are you happy with your working arrangement? Does it allow you to be a satisfied worker and also get all the home responsibilities done?"

Out of the fifteen FWA respondents, fourteen of them were very happy with their working arrangements. They basically were happy because they were able to manage work and home responsibilities to a large extent. To them "work life balance 
is achieved" in their own sense. They have a career, a family and their life. Only one respondent, F6, who works once a week from home, is newly married and has no children commented that "sometimes working from the home can be equally stressful, if you do not know where to draw the line and stop work. As a result we end up working more than ten hours sometimes". For respondents like F6 who is young and very career oriented, drawing the line between work and home is difficult as she has less caring responsibilities.

As for the 15 non-FWA respondents, from the eight respondents who had children below ten years and more than one child were not very happy with their working arrangements. They explicitly claimed that "if given a chance, I would like to work half a day or part-time at least until my child is school going". Only one respondent was quick to say that she is so used to working fixed hours, so FWA does not really matter to her, what is more important is good planning.

As the respondents all have a minimum of eleven years of education and are economically independent, all of them, irrespective of their working arrangements, are very clear with their goals and have control over their lives and this will be described further in the next section.

\subsubsection{Theme Three - Household, Economic and Social Empowerment}

Women's empowerment is the essence of greater freedom and control over important decisions that affect their lives. Empowerment outcomes for women can be defined in terms of their role in economic empowerment, household empowerment and social empowerment. Decision making within the household for household matters and personal matters were revealed by some respondents on their own, while others had to be asked specifically about their autonomy on this issue. As for economic empowerment, the respondents were explicitly asked the question "Who makes the decisions regarding finance, purchase and ownership of assets in your family?". Social empowerment was captured in this study based on the 
respondents' stories of their mode of travel to work, owning a vehicle and visits to friends and relatives' houses.

In the course of the interview, the respondents' level of empowerment was mainly measured based on household empowerment and their autonomy and capability of making decisions which might have an effect on their work-life balance. One measure of empowerment in the context of power relation within the household shows that women's varied working arrangements help to elevate them from stressful lives and both directly and indirectly influence their well-being. Household empowerment sometimes measured in a narrow sense is seen as the ability to juggle better with FWA and is important for women to experience it. In this study, empowerment is measured, in terms of economic empowerment, social empowerment as well as household empowerment.

Even though there was not much difference in economic empowerment and social empowerment among respondents in FWA and non-FWA organisations, there was a difference in household empowerment. Household empowerment, measured in a narrow sense basically referred to the ability of the respondents to juggle work and home better as they had more flexibility in carrying out their chores. Respondents in FWA organisations were able to organise themselves better in terms of managing work and home. They had more control over domestic matters and also their personal lives. Some of them showed how independently they made choices with regards to managing the school going children and work.

For instance, F14 could send her daughter to school at 7.00 a.m. in the morning on the way to work. Even though she worked in an academic institution which has FWA, she made the choice of going early to work, so that "time and money will be saved this way, instead of driving back and forth". In this way, "I start early and I also finish early most days, unless I have a late lecture, where I need to stay back".

In a similar vein, F2 also sends her young children to extended families on the way to work and does not "mind starting work early so as to finish early as well". 
As for F10, her workplace, children's school and her home are all nearby. So, she is able to pick up her children when school is over at 1.30 p.m., send them home, have lunch and go back to work, a little bit after 2.30 p.m. This is "thanks to my boss who practises FWA and based on trust, as she knows I do not abuse the system".

F12, who does not have caring responsibilities, is able to manage all household chores by "planning her flexible time and organising it in such a way that she can have food for the family, get the housework done and also get her spouse to help".

These are instances where access to resources in terms of flexible time and location has assisted the respondents in their challenge to balance work and home. With FWA, life is simpler because they get to carry out the entire household work and able to do it better. In fact, some respondents also felt that it has further increased their subordination and accentuated their primary role in the domestic sphere. Out of the thirteen married respondents working in FWA organisations, eight respondents $(72 \%)$ revealed that their spouses never help with the household chores and they manage because of domestic helpers or because of FWA.

Says F8, who works flexitime and sometimes works from home,

"With FWA, there are some costs and some benefits. I am able to manage my household and family better since I can organise more time for my children and the household chores. But as time passes, I notice that my husband does not take any interest in household chores at all".

It was not an issue of ability but more an issue of resources. As for the respondents in the non-FWA organisations who did not have access to FWA, they had to manage work and home within the available resources. They had to identify the situation and plan to make it work so that they can carry out home responsibilities and also participate in paid labour. Out of the ten married respondents, only four respondents (40\%) revealed that their husbands never assisted them in any way, either due to shift work or because of the presence of domestic helpers. 
There seems to be a clear pattern whereby among the FWA group, it is the older men who help with household chores and in the non-FWA group, it's among the younger couples, and the husbands help with the caring responsibilities of the babies who are below one year old. It is notable that the young ones have changed in terms of childcare responsibilities but that is because in both cases, there was no other assistance from domestic helpers or extended family. While the three older men were helping their wives with household chores such as cleaning, ironing and washing, the younger couples were helping out by taking care of the babies only. There seems to be a slight mindset change from doing nothing to at least some caring responsibilities.

All the married respondents, irrespective of the working arrangements, have a great amount of influence with regard to decisions in money matters in the household. In terms of economic empowerment, other than groceries purchase, decisions relating to purchase of property and assets and consumer goods were all discussed jointly between the spouses before a final decision was made. Matters regarding children's school, nursery, childcare arrangements and also holiday arrangements were also jointly discussed before coming to a decision. In some cases, the respondents exclaimed "that they have the final say in the matter", while in other cases, the respondents "highly influenced the decision".

This change in mindset of men as the only decision makers to make decision making is more apparent among the younger generation of respondents.

F13, a 49 -year-old university professor, relates thus:

"My husband makes it a point to discuss all purchases with me, but somehow I find that I highly influence the final decision."

Another similar view was expressed by N17, a 52-year-old Human Resource Assistant:

"Though we discuss all money matters and other purchases before we buy something, it always ends up that I have the final say. My husband knows for sure that I am very careful with money and more often than not, accepts my decision." 
However, a different trend was noted among the younger married couples, like F2, F6, N20 and N21 who are newly married, whereby all their decisions are discussed jointly and sometimes their husband has the final say. As for the single respondents, decisions are made entirely by them even though they discuss generally with their parents. They have "the freedom to spend on themselves" but they also "make sure they contribute to the family expenditure". The trend is now for the younger husbands to help with childcare.

Out of the thirty respondents, only seven of them felt that they would prefer to stay at home. Four were from FWA organisations and three were from non-FWA organisations. It was surprising to note that while three of the respondents wanted to stop work "to spend more time with the children", two single, unmarried respondents wanted to stop work because they "could not cope with a stressful life, particularly due to the traffic jam". The other two respondents felt that "age was getting to them and as they were already in their fifties, they were waiting to take a break". One common feature noted among these respondents was that even if they quit their jobs, they would still want to do some small business from the home or start their own business to obtain some income for themselves and their family. Two of them have plans to continue working until they start their own business. However in all the cases, the respondents made their own decision to continue working, without compulsion.

Another aspect of economic empowerment was revealed by many respondents with regards to their reasons for working. While all the respondents had a minimum of eleven years of schooling, with a large proportion holding degrees and two with postgraduate qualifications, they revealed a strong view of the decision making ability.

Most of the respondents (57\%) feel that they wanted to work in order to have "economic freedom" and "economic independence". It was noted that a majority $(60 \%)$ of respondents in the FWA organisation have other reasons to work such as "personal development", "avoid boredom", "avenue to socialise" and "intellectual 
development" compared to "economic independence". In fact, working in FWA organisations gave them ideas of "starting a business and they already had business plans for future".

But among those in non-FWA organisations, sixty percent of them want to work due to economic independence. On the whole, all the respondents, except for one, had full support from their husbands or their parents to work in paid labour. They all indirectly revealed that they were able to exercise freedom in their choice of workplace and the nature of their job status. The respondents revealed that economic empowerment can be achieved best through working in paid labour.

The story of F3 demonstrates that a woman's traditional position within a household remains largely unchanged despite her access to education and employment. This is the only instance where the respondent's access to independent sources of income fails to elevate the position within the household from their subordinate position... Her gendered notion is very closely associated to her primary role that is linked to domesticity. Despite her education and eleven years of employment, marriage has brought her to a subordinate position. However, as she feels "that career is important", working in a FWA organisation has assisted her in being able to manage work and home.

In terms of social empowerment, the respondent's role in influencing the decision making process within a household is captured with regards to visits to her family and friends' residences. Those who have more spare time make more visits. There was no strain in any of the respondents" views regarding "forced visits" but more so "since we have more time during the weekend, we visit family and relatives".

FWA did improve the respondents' household empowerment by giving them access to work flexitime and flexi location which led to a better control over their own lives and their household. The respondents also had more time for themselves for recreational activities and for relaxing. However, there was no distinct difference 
in terms of working arrangements and economic empowerment and social empowerment.

\subsection{Costs and Benefits of FWA}

One of the main objectives of the interview was to find out the benefits and disadvantages, if any, of FWA at the workplace. The respondents in FWA organisations were asked to comment on any benefits they are experiencing due to FWA policies at their workplace or any possible disadvantages they are facing at their workplace due to FWA. The respondents in the non-FWA organisations, were first given a brief explanation on what FWA means before they were asked about the possible advantages and disadvantages of working in a FWA organisation. They were further asked, if given a choice, would they like to work in an organisation with FWA.

Working flexible time and working from home were the two types of FWA mentioned by most of the respondents employed in FWA organisations, while many non-FWA respondents mentioned the potential benefits of permanent part-time work. However, most of the respondents working in non-FWA organisations were more interested in working from home and permanent part-time work. Some examples of how respondents expressed their views on the benefits and possible costs of FWA are described below.

A big difference was noted in terms of working hours and family responsibilities. All the respondents who work in FWA organisations, irrespective of marital status, strongly concur that "FWA means more time for their family responsibilities" while many say "they have more time to eat meals with their family members and spend time with the family". For those in non-FWA organisations who have an issue of "no time for family", a majority were of the similar opinion, except for two respondents who felt that "flexible working arrangements do not necessarily mean more time for family". 
Employees who have caring responsibilities describe FWA positively and state that it also makes people happier as they are "able to manage housework even without any helper". Whether it is caring for children, the elderly or the sick, FWA is very helpful to manage work and caring responsibilities.

A single mother of a dyslexic son explained that "FWA has worked very positively for her in the last five years, and she does not think she will ever leave this job unless she needs to follow her son for his studies overseas in ten years time". The two married respondents who occasionally took care of their mothers, sometimes worked from home, allowing them to care for their mothers whenever the need arose. "I could take care of my ailing mother and also get my office work done without any disruption," said one respondent.

Some respondents with a single child feel that "they can still cope with fixed hours, but if they have more children, they would need to rethink the way of juggling work and home". In other words, they are aware of the benefits of FWA and they also feel that "if given a choice, they would prefer FWA" even though they are happy with their current organisation.

FWA generally allows more time for oneself. A few respondents working in non-FWA were very quick to respond that given a choice, they would like to quit their present job to start a small business which will give them flexibility and more time for themselves. Many of the FWA respondents who work from home feel that if they plan their work and work with a set target, they are able to achieve the target and have more time for themselves and also their families.

Women who are not able to balance work and family sometimes exit the labour force. Many of the respondents (50\%) feel that FWA will help women juggle work and home and encourage them to work in paid labour. Two respondents in the banking industry claimed that "FWA such as part-time work will definitely encourage more women to participate in the labour force because they can take care of their children and also work". They were also of the strong opinion that "women who really need the income would not mind earning less based on the number of 
hours worked as long as they can balance work and caring responsibilities". For instance, according to F7, "there was a period when my husband was pressuring me to leave my job to take care of the baby...but after I found this job with a lot of "working from home" chances, it has been very smooth sailing for me. My husband and my children are very happy that I am around for them when needed".

FWA certainly will contribute to a better a quality of life because there will be less stress in commuting time to and from work and in the possibility of avoiding rush hour traffic. It was surprising to note that all respondents who needed to commute more than 30 minutes to work felt that FWA will "definitely reduce stress". This will also be beneficial for the older generation and senior citizens who opt to work after 60 years and will encourage more women to work in paid labour. As F15 commented "I'm not tired in this organisation, even though I come home only at 7.00 p.m. unlike my previous organisation where I worked 9 to 5 , because I can avoid driving during peak hours. It's motivating and I can see the difference in myself'.

The benefits of FWA in terms of personal satisfaction were also highlighted by many respondents in FWA organisations who continued to elaborate that "if you are a satisfied employee, you will have job satisfaction and this will certainly lead to higher staff morale".

The importance of flexibility was highlighted by many respondents in nonFWA. The respondents from non-FWA have always worked fixed working hours and some of them commented on how difficult it is to achieve their desired combination of work and family time. But some of them who have young children felt that "working permanent part-time would be really conducive for them to juggle work and home during the few years when the family needs them, and to go back to full time work when the children start going to school". This feeling, for example, was voiced by N19 and N21, who had children below six years old.

In some organisations, FWA may not be implemented across the board in all departments or available to all employees. For example, in the banking sector, FWA 
will be cumbersome to be implemented in certain departments or certain operations. This is especially so with jobs dealing directly with customer service which will be more systematic only if done by the same person and within a certain time period. Confidentiality is another reason why certain jobs and certain departments do not allow work to be done at home such as the technical department of the petroleum shared services and the telecommunication organisations. In both these cases, permanent part-time or working from home are not suitable work policies. However, some respondents in the non-FWA organisations feel that these issues should be dealt with case by case and can be implemented by tailoring it to the employee's needs. For instance, in the banking industry, it would be more suitable to implement FWA in the loans or credit card departments but not so easy to implement in operations or customer service departments.

The respondents also feel that FWA can be implemented by any organisation without fear or favour but the key word is "trust". Planning is crucial and discipline has to be maintained. The employees might need close supervision but only at the initial stage. For example, one respondent from a FWA organisation comments that "my supervisor prefers the employees to work fixed hours and be physically present. Some of my colleagues from my department feel very frustrated when they compare themselves with their colleagues in other departments. They release their pent up feelings of being left out and in fact feel that they have less time to do things at home and less time for the family".

Just as many respondents revealed the benefits of FWA, views on the possible negative effects of FWA also emerged. Abuse was the main possible negative implication which most respondents highlighted which can be very bad for the organisation. FWA is open to abuse just like all other systems which are not monitored closely and it may have ripple effects on the productivity and morale of other staff. A respondent from a small professional FWA organisation which employs 12 employees says that her boss "runs motivation and religious talks every month to remind employees not to abuse the facilities and privileges given to them". Employers have to monitor and supervise the staff closely at least initially when the system is implemented. In her organisation, there are no time sheets or punch cards 
or sign-in forms and the whole system operates on trust basis. There are very good family friendly policies in her organisation. If architect plans or survey research results are needed on a certain date, employees are requested to work over the weekends, and they are allowed to bring their children to work. In addition to that, the employees are rewarded by getting time off during the weekdays.

Even though career progression and promotion aspects are generally based on performance, some employees fear that there is less opportunity to advance because people cannot see you work at the table. A respondent from a FWA organisation comments that "in my organisation, management looks at output and not the physical attendance. As such, I am very happy to work here and with this mode of working arrangement, I can take care of the home responsibilities and it also allows me to do my best for the organisation". Another FWA organisation respondent claims that "I do not think my career prospects are affected as working from home and flexible time are work policies offered to all the departments except the technical department".

Respondents from non-FWA organisations also feel that abuse might be the biggest setback of FWA organisations in this country as "there is still a lack of necessary mindset for that nature of work". Said a non-FWA professional, "Nowadays, a young employee comes to work for three days and you do not see him after that. Work ethics is slacking among some".

However, another notable feature among the respondents which needs to be highlighted is the mindset of the respondents. While the higher educated and the higher income earners, regardless of the working arrangements, gave priority to work-life balance and FWA, it was different among the less educated and the lower rung of the occupational status respondents. About four respondents, who had a basic "O" Levels educational background and are either administrative assistants or clerks, are of the opinion that "if we want to work, we must know how to manage time. It does not matter whether there is FWA or not". These four married respondents were in the mid 20s, with two having young children. 


\subsection{FWA and Women's Well-Being - Summary of Findings}

Based on the quantitative analysis, respondents who have access to FWA have better work-life balance and more household empowerment.

The qualitative study supports the quantitative study and further identified that there are a range of issues which can lead to the well-being of working women. Generally, most of the respondents want to work and be economically independent but they also want to achieve a good work-life balance. While some respondents are more successful in juggling work and home, some are still trying to cope with whatever they are doing, hoping to achieve it one day.

Broadly speaking, the present analysis shows that work-life balance is achieved with a more encouraging tone from those respondents who practice FWA. Those who are working in FWA organisations are able to manage work and household chores and caring responsibilities better. These findings reveal that respondents in FWA organisations are able to spend more time for family.

Juggling household chores without any help is really a major problem for working women and if they are in non-FWA organisations, commuting and traffic jam aggravate their problem and add to stress. A significant finding of this study is that commuting time and traffic jams are stress contributors and have a major effect on a working woman's quality of life. Commuting time regardless of workplace arrangements was an important predictor of women's well-being.

Another pertinent difference was that even though the majority of the respondents were in favour of FWA, this was not felt by a small group of respondents in the lower rung holding clerical positions. They were happy to work, irrespective of the working arrangements, where working hours they were engaged in was more important.

The availability of affordable and reliable childcare centres near the workplace was widely accepted as very crucial to allowing married women to work 
in paid labour. Even though there are many informal childcare centres and government-aided childcare centres in housing areas throughout the country, many of the respondents feel strongly that reliability has to be improved for more parents to send their children to the centres.

Some of the respondents gave some valuable insights into the values and attitudes of Malaysians and their changing mindset. However, FWA does seem to accentuate the notion of gendered division of labour and in some cases force women to do "more work". Elsewhere, the interviews showed that the respondents who had domestic helpers lead a very balanced life, regardless of the working arrangements.

Working flexible time, working from home and permanent part-time appear to be the favourite choice of most of the respondents. Working arrangements do not have a great effect on the time they spend for socialising but it did not seem to matter to them as in this cyber world, social networking is very convenient and affordable.

\subsection{Concluding Remarks}

There is diversity in the opinions, but still, many commonalities emerged among the respondents' views on the costs and benefits of FWA. While many of the respondents experienced work-life balance barriers, some common threads and themes revealed that FWA will be a good option towards achieving work-life balance.

Both quantitative data and qualitative data identified that FWA have a positive effect on women's well-being in terms of work-life balance and household empowerment. 


\section{Chapter 7}

\section{Conclusions}

\subsection{Introduction}

Historically, Malaysian women have worked in the agricultural field, where both paid and unpaid work was quite flexible but poorly recognised and remunerated (Kaur, 1990). However, working in the paid labour force in the formal service sectors has become a major challenge for women trying to juggle work and home responsibilities as revealed in this study.

The findings of this thesis suggest several conclusions with regard to whether FWA could be an option to bring more women into paid labour in Malaysia. Female labour force participation is currently only at 46.4 percent and due to caring responsibilities and family pressure, many women exit permanently from paid labour. This chapter first highlights key findings which supports previous studies and refute others. It then summarises the findings from the study by addressing the key research questions investigated via the quantitative and qualitative empirical studies. This is followed by a theoretical discussion of the issues which emerge from these findings that could improve the socio-economic status of Malaysian women and the society at large. The discussion further brings out FWA in the context of the three theoretical models of women and development, i.e., WID, WAD and GAD. It then suggests some policy recommendations which may assist to increase women's participation in paid labour in Malaysia finally presents directions for future research.

\subsection{Summary}

The first chapter of this study presented a broad picture of the phenomenon of low female labour force participation rates in Malaysia. It explained how changes in the world market and the new international division of labour influenced 
employment patterns worldwide, moving from the traditional agricultural sector to the modern secondary and tertiary sectors. It concluded by describing how the development process led to export-oriented industrialisation and urbanisation, which brought women into the labour force in Malaysia. It is argued that the low female labour force participation could be due to rigid working hours and the lack of an enabling environment. The main concern is the issue of women juggling work and home, given that women are expected to do all housework and caring responsibilities. Hence, it is believed that one possible way to manage both roles will be to work in organisations which have FWA. This situation raised the following questions which were the main objectives of the study: Firstly, who are the women who are really interested in FWA? Secondly, will FWA influence women's decision to participate in paid labour? Finally, how will FWA have an impact on women's well-being?

Chapter Two reviewed the literature and traced the dynamic change in the definition of development from economic growth to include the well-being of the people. The review highlighted how FWA are placed within the framework of women and development models and this informs the current research.

Chapter Three highlighted the industrialisation process and women's participation in the labour force in Malaysia, tracing the trend of women's participation from the 1970s until present times.

Methods of data collection and data analysis were described in Chapter Four. The study used primary and secondary data as well as qualitative interviews. The quantitative method used survey questionnaires, while the qualitative method used structured questionnaires. The field survey was conducted in fourteen identified organisations in the Klang Valley, which is the central business hub of Malaysia and also where the capital of Malaysia, Kuala Lumpur, is located.

Chapter Five analysed the quantitative data of 396 women working in fourteen organisations in the field survey. A majority (86\%) of women working in the identified organisations in the services sector highlighted their interest in the 
uptake of FWA at their workplace and revealed that FWA create a work-life balance and have positive implications in their lives. Even though this is more evident in terms of family responsibilities and commuting time, there are two major issues of concern with regards to participation in paid labour. The implications of the empirical findings are:

Firstly, FWA do not affect all women in the same way. Evidence from this study shows that women who are well educated and in the middle and higher income groups are more interested in FWA. So, implementation of FWA as a standalone work policy might not reach the desired outcome of increasing the female labour force participation rate in the country. Instead, this might create other socioeconomic disparities.

Secondly, FWA at the workplace need to be accompanied by other matters which need to be addressed in the social, economic and cultural context. In terms of gender, the patriarchal views and gender division of labour mindset needs to undergo a transformation towards a more open and equitable perspective. Even though attitudinal shift is a long term concept, there needs to be a change for the whole system to work effectively so that eventually it will benefit the women and the households. A policy measure which provides an enabling environment which supports caring responsibilities with more family friendly policies, will enhance work-life balance and allow more women to participate in paid labour.

Chapter Six analysed findings derived from interviews conducted with 30 identified women. In order to get an in-depth understanding of how women carry out their productive and reproductive roles, interviews were conducted with these women. Findings suggest that FWA have a positive effect on women's well-being. There is diversity in the opinions, but still many commonalities emerged among the respondents' views on the costs and benefits of FWA. While many of the respondents experienced work-life balance barriers, some common threads and themes revealed that FWA will be a good option towards achieving work-life balance. 
Chapter Seven highlighted the emerging issues of the study where the major concern centres on gender issues. Policies and programmes to encourage more women to participate in labour force should focus on a more enabling environment, the need for attitudinal changes and policy reforms to encourage women to work in the labour force.

\subsection{FWA and Working Women in Malaysia - Findings}

The main aim of this thesis was to investigate whether flexible working arrangements may contribute to an increase in women's labour force participation in the context of the development of the Malaysian economy. The three specific objectives were:

- to investigate the factors which influence the desire to take up flexible working arrangements by women employees at the workplace.

- to assess whether the availability of flexible working arrangements might contribute to the decision among women employees to participate in the labour force.

- to examine whether flexible working arrangements may have an impact on selected indicators of women's well-being such as work-life balance, lifestyles and empowerment.

To achieve the above mentioned objectives, the study answered six research questions:

- What are the factors which affect the extent to which women employees will be interested in the uptake of flexible working arrangements?

- What are the characteristics of women who are most interested in exploiting flexible working arrangements and what sectors of the labour market are best able to offer such arrangements?

- How do women use flexible working arrangements to juggle their other demands? 
- How do flexible working arrangements operate in Malaysia and how well are they working for women employees?

- How is flexible work for women linked to other parts of the labour market, especially the demand for paid domestic work?

- How do women perceive the benefits they might achieve in their well-being in terms of work-life balance, empowerment and lifestyles?

The findings and discussion presented in this section reflect several important issues identified in this study which may give public policy makers and organisational stakeholders a better understanding of how FWA may be useful for working women in Malaysia. Hence, it may contribute strategies to address the low female labour force participation rates among married women with children in Malaysia. This section highlights the main findings which are presented to answer the three objectives above and the six research questions which the study sets to answer.

\subsubsection{Who are the Women Interested in FWA in Malaysia?}

The first two research questions in the study with regard to the factors which influence women's uptake of FWA were answered using a logistics regression analysis as explained in Chapter Five.

The first research question was: What are the factors which affect the extent to which women employees in a few selected organisations will be interested in the uptake of FWA?

Firstly, socio-economic factors have an effect on women's uptake of FWA in the workplace. Higher educated women who are holding university degrees, and earning a higher income with higher occupational status are more interested in FWA at the workplace compared to women who do not possess higher education. In a knowledge economy, human capital is given paramount importance as the 
knowledge worker's competencies are a key component of value in realising organisational goals. Women are perceived to be potentially well placed to prosper in the knowledge economy due to their educational and relational skills (Mincer, 1996). This in turn relates to the impending issue of women leaving their careers to care for their families as a serious economic issue, as these women are mostly young and educated women in their mid thirties.

In Malaysia, this might be hazardous to the economy of the family and the country at large as these women may become fully dependent on their husband's income to support their children and themselves. This is more critical with the increase in divorce rates in the country which is more so in the case of Muslim women as compared to non-Muslim women ${ }^{39}$. Islamic law allows Muslim men to take as many as four wives, provided they can support all wives financially and agree to treat them fairly. Even though under the Islamic law (Syariah law) a man as the head of the family is responsible for the provision of maintenance for the wife and his family, Maznah (2010) explains, that in a Muslim marriage "male privilege inordinately representing the face of authority and female good behaviour the image of religious submission" has resulted in "new Muslim masculinity and femininity reinforced and reproduced" 40 (Maznah, 2010, p. 21).

Secondly, findings show that women perceive that the best benefit of FWA is a better relationship among family, children and siblings. This arises from the better work-life balance achieved among women who use FWA. Further analysis on the rankings of the 'Perceived Advantages' show details which determine that more time for family and saving time on commuting are ranked highest among 16 items. This model which was adapted from Almer, Cohen \& Single (2003), initially had 16 items which through factor analysis were reduced to three major factors consisting of "family relationships", "job satisfaction and performance", and "autonomy and

39 The number of Muslim divorces increased from 13,536 in 2000 to 27,116 in 2009 compared to non-Muslim divorces which increased from 1,613 to 2,938 during the same period (Ministry of Women, Family and Community Development, 2010).

40 Maznah (2010) in her paper entitled "Malaysian Sharia Reforms in Flux: The Changeable National Character Of Islamic Marriage" critically expresses how the Malaysian laws for the Muslims changed from Early Family Sharia (with its plural tradition) to becoming a Transitional one (embodying female progressivism) and culminating the consolidation of a New Family Sharia (supported by the trope of male entitlement and female obedience) (Maznah, 2010, p. 21). 
commuting time”. Studies on teleworkers in Singapore by Lim et al. (1995) also found that more family time and less commuting time were the main reasons women prefer flexible time and flexibility in location. This is an indication that FWA offer female employees time flexibility, less commuting stress, more autonomy and better job satisfaction.

Thirdly, findings show that women perceive that the biggest disadvantage of FWA is that their career progression might be at stake. Women are making it very clear that they do not want to choose between succeeding at home and succeeding at work. In general, they are more concerned about succeeding in life which brings them to a stalemate as they are trying to consider options which are in reality, not options but rather, circumstances forced onto them.

The second research question asked was: What are the characteristics of women who are most interested in exploiting FWA and what sectors of the labour market are best able to offer such arrangements?

Demographically, the majority of the women in the quantitative study who were interested in FWA were in the 30-39 years age group and of Chinese ethnic origin. Most of them had more than two children and were at the management and professional level. Irrespective of the children's age, managing caring responsibilities and paid work becomes more difficult with more children. This finding conforms with Chiu's (1999) study which shows that women's time spent on family work is significantly affected by the size of household, having young children and the number of children. More than 85 percent of the women perceived that FWA may help to mitigate the exit of women from paid labour and encourage nonworking women to join the labour market (Please refer to Table 5.22).

The next two research questions were answered based on the qualitative studies explained in Chapter Six where the major findings centred around indicators of well-being such as work-life balance, empowerment and lifestyles. 


\subsubsection{How Helpful is FWA to Working Women in Malaysia?}

The third research question was: How do women use FWA to juggle their other demands?

Firstly, women working in FWA organisations found that they are able to have a better work-life balance as managing work and the home becomes more organised. The challenges faced by women who choose to continue working after starting a family, including caring for the family, household chores and career advancement, show that they all have their own coping strategies. Most women try to cope with the demands of the work and family by adopting Type III coping strategy (Hall, 1972). Although Type III strategy imposes more stress on the women, they try to adapt to the dual demands by expanding their roles, instead of changing other people's expectations (Type I) or changing their expectations (Type II).

Secondly, it was clear that the age-old patriarchal views have not died and traditional expectations of women's roles still exist among most of the respondents. Culture and tradition did show an influence on gender division of labour, among the Malay women, and the newly married women were found to be virtually doing all the household work. In spite of technological innovation in the household, it has failed to ease or eliminate household tasks but has rather increased expectations of the housewife's roles and further reinforced traditional gender division of labour (Cowan, 1979). For women working flexible time and working from home, they revealed how they managed time well and juggled work and home amidst expectations of family and society. On the other hand, women in non-FWA, who had help from extended families and domestic helpers, generally were able to cope with caring responsibilities and had a better work-life balance. However, women in nonFWA organisations, with no help from domestic helpers and extended families, led a stressful life trying to cope with work and home. Hence, FWA created a real impact on work-life balance for these working women.

Next, women in FWA organisations also had more time for themselves for recreational activities or for hobbies such as watching television or reading as well as 
to pursue other interests. Most of them could indulge in a morning walk or a few minutes of television every night. However, this was not the case for women in the non-FWA organisations. It is increasingly becoming a phenomenon even among young adults spending more time on paid work and childcare, sacrificing their leisure time and recreational activities. In general, it appears that even young adults are sacrificing leisure time for housework, and in large parts, traditional gender roles prevail in the split between housework, childcare, and paid employment, although the gap has narrowed somewhat. For example, Gauthier \& Furstenber (2004), analysed 23 different time-use surveys carried out since the 1970s in 11 countries and found that women devote less time to paid work than their male counterparts and spend more time than men on housework, and less time on leisure than men in all subgroups.

Finally, even though the women have the autonomy of choosing the jobs they want to do, it is expected that their choice be linked to domesticity as revealed by some women in non-FWA organisations. Proximity to the current workplace was a central factor for the choice to work among some of the young married women who had young children, the reason being the ease of sending the child to childcare centres or to extended families.

The fourth research question was: How do women perceive the benefits they might achieve in their well-being in terms of work-life balance, empowerment and lifestyles?

In terms of work-life balance, other than working arrangements which are flexible, commuting time was the other factor which showed up as an important criteria on the ability to balance work and home.

Secondly, in terms of empowerment, there was a significant difference in household empowerment between women in FWA organisations and women in nonFWA organisations. Though all the women, irrespective of their working arrangements, had economic empowerment in joint decision making regarding finances and social empowerment in terms of visiting friends and relatives, women in FWA organisations revealed a distinct household empowerment. It was interesting 
to note that most of them had freedom in the choice of their jobs, mode of transport to work and working times. The majority of them wanted to work for economic independence, while some work for personal advancement. These findings were also revealed in a study by Subramaniam, Iyer \& Maniam (2010b), where 60 percent of the women who exit the labour force wanted to return to work after the children were above five years old. The study conducted in the Klang Valley also showed that the balance 40 percent of the women wanted to do some form of business or "work which is more flexible" in order to be economically independent. This shows that Malaysian women who still look at domestic responsibilities as a woman's main role (Jamilah, 2009, Aminah, 1999) feel more empowered if they have their own source of income. For example, Bennets (2007) in her book The Feminine Mistake: Are We Giving Up Too Much?, says very aptly that if women become financially dependent on their husbands, they will eventually end up in a vulnerable position, especially under the present conditions of rising divorce rates and longer life expectancy rates for women ${ }^{41}$. Even though economic empowerment is necessary, household empowerment also played a significant role on women working in FWA or nonFWA organisations.

Thirdly, in terms of lifestyle, health and well-being, women in FWA organisations did not show much difference in their daily routines compared to their counterparts in non-FWA organisations. They all had to wake up early, get meals ready, take charge of caring responsibilities and do cleaning chores. But in terms of health and well-being measured by job satisfaction and happiness, women in FWA seem to be able to cope better with dual roles and are happier with their lives. The findings also reveal the perception that women with independent sources of income have a louder voice in decision-making within a household and that was perceived to improve their well-being.

\footnotetext{
${ }^{41}$ In this book, Bennets expresses her findings based around interviews with women, either stay-athome women or professional advisors of various sorts. Her respondents were interviewed on marriage, motherhood and work. She moves from some negative stories of women who were left bankrupt with three children and a few thousand dollars a year while their husbands moved on to ever more flourishing careers to some positive stories of women. Basically, she propagates that women should work and discusses what are the benefits, aside from the obvious one of a little extra money, for women who continue to work.
} 


\subsubsection{How do FWA Work in Malaysia?}

The fifth research question: How do FWA operate in Malaysia and how well are they working for women employees?

The types of FWA implemented in Malaysia include flexible working time, staggered working time, working from home, telecommuting, small office home office (SOHO) and part-time work. The government's implementation of staggered working hours in 2007 was one of the measures towards encouraging more women to work in paid labour. At policy level, there are many plans and policies to encourage FWA at the workplace ${ }^{42}$. However, many employers in the private sector have not implemented FWA with flexibility rostered and can be stopped by the employer at his/her discretion. It is only the larger companies and multinational companies that have various types of FWA such as flexitime, working from the home and teleworking.

Based on the qualitative analysis, women in FWA were found to have better work-life balance and more empowerment, and FWA worked well for working women, regardless of the number of children or the age of their children. Women in FWA claim that they are able to have a better work-life balance because they are able to manage work and household chores and caring responsibilities better. As for those women in non-FWA, juggling household chores without much help and further aggravated with traffic jams have a major effect on a working woman's quality of life. Commuting time regardless of workplace arrangements was an important predictor of women's well-being. Even though informal childcare centres and government-aided childcare centres are available in housing areas in many parts of the country, reliability has to be improved for more parents to send their children to the centres.

\footnotetext{
${ }^{42}$ The Ninth Malaysia Plan includes measures that provide necessary support facilities such as family friendly workplaces, retraining programmes and community childcare centres. Also included are flexible working hours, the concepts of home-offices and measures to protect woman in the informal sector (Malaysia, 2006)
} 
Women who have domestic helpers, regardless of the working arrangements, were found to lead a very balanced life. Working arrangements do not have a great effect on the time they spend for socialising but it did not seem to matter to them as in this cyber world, social networking is very convenient and affordable.

\subsubsection{FWA and Linkage with Other Sectors in Malaysia}

The sixth research question was: How is flexible work for women linked to other parts of the labour market, especially the demand for paid domestic work?

Domestic help is employed by many households, especially among the higher income earners which solves the dilemma of getting household chores done and taking care of childcare responsibilities, but this comes with its own set of economic and social issues. The reliability issues with childcare, ill treatment and abuse of the children, and other related social issues have been discussed in the press and women NGOs in recent times.

If domestic help is not affordable, or not available, women still go to work by relying on extended family that help with childcare. Even though it is argued that the 'extended family does not disappear with 'modernisation' and 'urbanisation'," (Moser, 1993, p. 17), in Malaysia, the reduced reliance on extended family is fast becoming a norm as more of the older women are either working or having a good social life themselves and they are not too keen to take care of the children. Reliance on extended family is more prevalent among Malay families, which have strong kinship ties and some of them send their children to their parents or in-laws in the village to be cared for.

If there are no domestic helpers or extended family, many women continue working by sending their young children to informal babysitters, who are normally their neighbours or live in the same neighbourhood. In these cases, the caretaker may not be trained or may have no knowledge about babysitting other than her own experience, which is also questionable at times. 
Compared to employing an expensive foreign domestic helper, sending the children to an extended family member or working in a FWA, the majority of the women were happy to choose FWA i.e., flexibility at location as an option for childcare. And most of the women opted for permanent part-time job or working from the home as the preferred type of FWA. As for career minded women who need to commute more than 30 minutes daily to and from the place of work, flexibility of time was a popular vote. For women who are in the lower rung and who have less options of childcare, FWA will definitely help them juggle work and caring responsibilities. However, how these issues were resolved by a working woman every day was outlined in the preceding chapter.

The findings demonstrate that a woman's subordinate position within a household is changing rather slowly despite her access to education and employment. They reveal that a woman's earning status has elevated her from a totally subordinate status within a household but conferred on her a 'double role' which is that of home-maker and earner. Such a positioning of woman within a household is reinforced by complex processes of cultural and traditional values with a mindset that continues allowing patriarchal views. These findings lead to some socio-economic issues which should be discussed within a framework of women's labour force participation.

\subsection{FWA and the Emerging Issues}

Women's contribution is critical to both the household and the economy. However, women's entry into the labour force is seen by the policy makers as an economic issue of her contribution towards the economy while her views and satisfaction, her interests, the impact on her health and her second role at home are neglected. In discussing FWA as an option to encourage women's participation in paid labour, some pertinent issues emerge. These issues which are dealt from the economic and social perspective in the next section show that a woman's role has an equal bearing on women, society and the nation. 


\subsubsection{Choice and Discrimination}

Gender roles in Malaysia are perhaps more socially and culturally constructed compared to many other countries and this results in discrimination against women even prior to entry into the labour market and causes inequality within the family.

Hence, there are gender differences in the labour market further perpetuated by women's employment patterns, job characteristics and cultural norms which require women to work and also take care and bring up children, in addition to managing household tasks. In cases of employer discrimination, women still face inequality at the workplace with respect to selection, training, opportunities for promotion and other employment practices. While the economy suffers from inefficiency and underutilisation of women's labour, women themselves suffer from impediments combining paid work and unpaid work.

The second issue in question is the great unevenness in the terms of income and educational status. FWA do not seem to be very much in favour among those in the lower income group but appear to be more popular among the women in the higher income group. Those who are in the lower income category are posed with a question of either working in paid labour or not working in paid labour. The most important thing for them is working and earning an income. The type of working arrangements is a secondary issue. The gender implication with regards to their socio-economic status concerns issues of choices that the women face, namely the choice of work, and whether to work or not to work. However, in the Malaysian scenario, the majority of the women are constantly making a choice of whether to work or not to work in paid labour.

As FWA for the lower income group are not the norm, they are not able to make a choice of work type because these women are not given the choice of whether to work in FWA or non-FWA organisations, but rather whether to work in paid labour or to stay at home. Women's choice of a particular occupation is very much conditioned by the social context where a woman's primary role is aligned to 
domesticity, especially among the lower income category. Their options are severely constrained when incomes are low and hence, the only option is to accept work which is usually in non-FWA organisations. On the other hand, women who are better off and more educated have more options and can exploit FWA better.

Working arrangements, types of job, and even levels of earnings are not as crucial to lower income group women as much as their ability to have an income. In this case, FWA might be useful in enticing the more educated women as well as the women in the higher occupational level into the labour force. This is a pertinent issue as Malaysia aims to achieve a developed nation status by 2020 and as such, accumulating the critical mass of highly educated and highly skilled graduates will help the country to achieve this goal ${ }^{43}$. This has social and economic consequences in terms of equity and employability of women.

\subsubsection{Patriarchal Views}

In terms of societal changes, there has been a tremendous shift in the social attitude among Malaysian men towards married women working outside the house. Most of the married women confirmed support from their spouses to participate in paid labour but support in household tasks was confined to families who had young children and did not have any domestic helpers. There was very little involvement from men in household tasks. Gendered division of labour was clear and very much alive with strong patriarchal views noted by most women.

In this case, the main constraint is the matter of culture, tradition and values. Loh-Ludher (2010, p. 309) cites that in Malaysia, "women comprise the 'reserve army of labour' as postulated by the Marxist theory", and claims that Malaysian cultural norms and values are the main reasons which inhibit women's emancipation.

\footnotetext{
${ }^{43}$ Vision 2020 is a national development policy with the objective of Malaysia achieving a fully developed status by the year 2020. There are nine central objectives listed in this policy and the sixth objective is the challenge of establishing a scientific and progressive society, a society that is innovative and forward-looking, and one that is not only a consumer of technology but also a contributor to the scientific and technological civilisation of the future.
} 
This leads us to another important issue which is the need for change in mindset. Although the men of today want women to work and participate in paid labour and help with the household finance, in dual career families, child caring responsibilities and household chores still remain a woman's domain. One can begin to see the mindset change among the younger, educated generation, but a lot more needs to be done to achieve a balance at home.

\subsubsection{Enabling Environment}

Firstly, from the micro perspective, the need for a good childcare support system which is affordable and reliable and near the workplace was widely accepted as very crucial to enable married women and single mothers to work in paid labour. While foreign domestic helpers can be useful in caring responsibilities and managing all household chores, it is not an affordable option for those in the lower income group and in recent times there has been a shortage of domestic helpers from certain countries $^{44}$. It is also increasingly difficult for many women to get assistance from their extended families as family size itself is becoming smaller and the extended family system is slowly fading out with an increase in nuclear families.

From the individual level, women appear to be better off, more economically independent and more empowered when they go to work but there is somewhat of a trade off against the problems of juggling work and time for themselves. The first and most dominating issue is the enabling environment of the support system, especially for caring responsibilities.

With FWA, women who have to take care of babies and young children are able to manage work and home in a better way. FWA in the form of permanent part-

\footnotetext{
44 The mid 1980s saw an inflow of foreign maids where some 4,000 work permits were issued and this number increased to 311,000 by 2006 (refer to Table $2.1 . .2$ ). The majority of these maids are from Indonesia because of geographical and cultural proximity. Moreover, Indonesian maids are the lowest paid maids compared to maids from other countries (Chin, 2005). Indonesian maids are only paid about USD105 compared to Filipino maids who are paid at least USD400 per month (The Star, 2010). However, in the last one year due to abuses by a small minority of employers, there has been a ban on maids from Indonesia for the last two years which should be lifted by the first week of September 2011(Raya maid ban lift, 2011).
} 
time and working from home allow women to work and take care of young children. It is evident that there are tradeoffs for these women who have to cope with the responsibilities and their career. Family friendly policies such as FWA are the real solution for some of these women.

One of the main issues contributing to women's stagnated participation rate at 47 percent in Malaysia is the "lack of an alternative childcare system which allows women to fulfil their double and triple burden of responsibilities - at home and outside the home". In order to bring the women in the 30-39 years age group into the labour force, an enabling environment of a good, reliable and affordable support system for caring responsibilities is pertinent.

\subsubsection{Demographic Issues vs. Economic Issues}

From the economic viewpoint, there is a need to increase female labour force participation. In a developing country like Malaysia which has an educated labour force, the economic contention is that women might become better off by participating in paid labour. The issues of concern in this matter are some gender based obstacles which are induced by culture which needs a change in the traditional mindset of both men and women.

With continuing development, these demographic changes are expected to occur just like in most western countries which see a drop in fertility rate, increase in life expectancy and an increase in dependency rate. These demographic changes are similar to what happened in Western Europe. Malaysia is beginning to see the changes which had taken place in the west and is undergoing the transformation now.

Major structural changes in the economy in the last 40 years (1970-2010) has successfully shifted the economy from an agrarian country to a manufacturing based country and now it has become a service led country. This trend is very crucial in explaining the FLFP rate in Malaysia as women's increasing participation in paid labour is in line with the structural economic development of the nation. The FisherClark's theory of structural change suggests that as the economy grows, it moves 
from the primary sector to the secondary sector and finally to the tertiary sector. Malaysia seems to be following the Clark-Fisher model moving from the primary sector to the secondary sector and is currently in the post-industrial stage where most people are employed in the tertiary or services sector. There has been an increase in women's labour force participation rates ${ }^{45}$ but the FLFP rates are not increasing as expected. There has been no increase in female labour force participation, which is a phenomenon which happens with development. Extended families are decreasing, yet fewer women are working in paid labour. This leads to the question, "Why are many Malaysian women not participating in the labour force as expected?".

From the mid 1990s, the nation has seen some demographic changes which are not encouraging for the growth of a population and labour force in Malaysia. The drop in fertility, increase in divorce rates, increase in single mothers and single career women have all become issues of concern to policy makers ${ }^{46}$ (Malaysia, Ministry of Women, Family \& Community Development, 2010). If no proactive action is taken by the government, the fundamental decision to have children, may be inevitably affected by how it would impact women's ability to manage their work and family. The issue of smaller family size and having the first marriage at a later age is also a related concern. With an aging labour force, the increase of the average retirement age and the workforce becoming increasingly multi-generational, it will become an increasing challenge for women to find a balance between paid work and unpaid work.

\subsubsection{FWA and Other Linkages}

The final point of concern related to economic issues centres on foreign skilled labour, outsourcing and the brain drain. In 2010, there were two million registered foreign workers in the country, out of which two percent were skilled expatriates and the majority of them were working in the services sector. This shows

\footnotetext{
45 Please See Chapter Three for detailed discussion.

46 As highlighted by United Nations Resident Coordinator for Malaysia in conjunction with the International Women's Day 2011, (Sunday Star, 6 March 2011, p. 26).
} 
that there is an issue of shortage of skilled and semi-skilled labour. Along the same lines, Malaysia has been undergoing a serious brain drain, where currently more than 700,000 skilled Malaysians are working in other countries. These economic issues are closely related to tapping our own potential resources and the issue of using Malaysian women to work in paid labour. In short, public policies, particularly programmes aimed directly or indirectly at the female labour force, may entice women to participate in paid labour.

\subsubsection{FWA - In Retrospect}

Based on the data analysis, three major issues with regards to the low female participation rates need to be highlighted.

Firstly, women are not participating in the labour force due to strong patriarchal views which still persist.

Secondly, there is an uneven distribution in terms of women who opt for FWA. Women who are well off are working and participating in paid labour, while women who are not so well off are also working but are constrained by their choices.

Finally, there is a lack of an enabling environment, particularly in childcare and flexibility at the workplace.

Considering all the emerging issues, FWA do have a positive role at macro level. They can help more women to enter the labour force but the work policy itself will not solve all the problems. FWA work well for middle and upper class and more educated women and not for the lower income and less educated women.

To be able to encourage the lower income women to join the labour force, FWA need to be followed with cultural and attitudinal changes. FWA can be used as an option, where they are offered as a work strategy for women who need this option. 
There needs to be a greater awareness among employees, employers and the government with regards to FWA in terms of their benefits, implementation and monitoring.

From the employer's perspective, reduction in cost of production, in terms of office space and utilities and happier staff are some of the bigger advantages of allowing FWA at the workplace. Retaining talent and reducing training and retraining costs are also seen as a bigger advantage to the larger organisations where there is a tendency for employees to move jobs if the prospects offered elsewhere are better. However, the biggest perceived challenge for employers in Malaysia in implementing FWA is capturing trust and responsibility among the employees.

In defending their stand, some management personnel claim that even if FWA were provided, the response will not be positive or encouraging. But this type of a study has not been carried out in Malaysia and hence, it is based on anecdotal evidence only. However, based on this study, it was found that 85 percent of the women were interested in FWA, especially flexible working time, permanent parttime and working from the home. It is therefore, of utmost importance that the government takes serious action on these issues and encourage more women in paid labour to avoid a brain drain. Work-life balance is not only a matter of concern for individuals but also to organisations and to the nation. There is a relationship between achieving work-life balance and improving female labour force participation rates as well as enhancing social well-being.

From the employees' perspective, FWA benefits range from more family time, to job satisfaction, more autonomy, better work performance, a saving of commuting time and a reduction in stress. However, the most significant benefit women perceive is the ability to balance work and home and have a better work-life balance.

FWA are good but they have limitations and hence, it is necessary to work on FWA not as a comprehensive package but on a case to case issue. One major 
concern of FWA is that they are a threat to career advancement but for women who have to make a choice to work or not to work, they do not see that as a threat but more as a coping strategy.

For the nation as a whole, happier and satisfied staff means higher productivity. At macro level, it means a more environment friendly workplace with less traffic congestion and better family management.

\subsection{Policy Recommendations - How can FWA bring in more women into the Malaysian labour force?}

In this study, three types of FWA were studied, namely flexible working time, part-time and working from the home and hence, FWA should not be treated as a package but provided as an option for employees. In terms of policy implications, findings conclude that FWA have an effect on women's work-life balance, empowerment and lifestyles and further suggest that FWA may have an effect on encouraging more women to work in paid labour. However, FWA need to be seen as a complex set of work and social relationships, not a single policy option that will suit all women in all circumstances.

The results may be useful in developing specific public policies directly or indirectly, to provide guidance to policy makers to encourage women's participation in paid labour. The policies can be observed as practical initiatives which are short term measures or strategic initiatives which are more long term measures. The practical initiative constitutes creating an enabling environment and the Malaysian government should aim at these direct policy initiatives which can be implemented in three modes to benefit women.

First, an enabling environment has to be provided by the government in a more institutionalised structure in the provision of childcare centres (both social and material). This would allow women to make decisions based on possibilities, rather than limitations and encourage the corporate sector to set up childcare centres near places of work. 
To increase women's participation in the paid labour involves a concerted effort by at least three ministries to incorporate the necessary measures in their efforts to have a more successful outcome. The Ministry of Human Resources Malaysia is trying to reduce foreign labour in the country by increasing the annual fee for foreigners, increasing levy and imposing a higher insurance premium. If the Ministry of Human Resources reduces foreign labour, it might have an upward effect on increasing wages for locals.

The Ministry of Women, Family and Community Development Malaysia, in its endeavour to encourage more women to participate in the labour force is encouraging the setting up of childcare centres at the government offices, enhancing the availability of childcare in the community and the workplace and the training of skilled teachers and careers. The same Ministry is also trying to instil the value of Corporate Social Responsibility in the corporate sector to enhance family friendly policies such as setting up of childcare facilities. However, these two Ministries which are working in isolation, need to work together with the Ministry of Education and align themselves to collaborate and provide a better system for childcare, and school children care so that mothers can work in paid labour. The Ministry of Education should also improve the school system by providing good libraries so that children can stay back after school to do their homework. If these three ministries can work together to provide a good support system for childcare and after-school care, more women may participate in paid work.

At present, there are many institutionalised childcare centres and crèches in the country. However, the system has to be more reliable and affordable to meet the objectives to encourage women to leave their children in trustworthy hands. To this end, the state should play a more important role in implementing and regulating childcare and after-school care centres which provide quality care.

This leads to the second initiative which needs to look at legislation which is more gender sensitive and family-friendly, in step with changes in society, and this can be done, for example through tax incentives and rebates. A reform in the Employment Act 1955 needs to be addressed to ensure greater flexibility for full 
time employment, making clear provisions for part-time employment and considering protection for other non-standard employment such as working from home.

The third policy initiative, which may have a direct effect to encourage women to participate in paid labour, is tax incentives or rebates for women with young children. This policy has already been implemented in the government sector but not in the corporate sector. In establishing the Annual Development Budget of fine-tuning for the Tenth Malaysia $\mathrm{Plan}^{47}$, the various industries should consolidate and stream line their objectives and create a new key performance indicator (KPI) to show an increase in FWA participation, which will indirectly increase the GDP of the nation. These tax and other fiscal incentives should also be extended to the employers to improve flexibility in the workplace, for the purchase of enablers and to support family friendly work policies.

These practical policies actually reflect the WID model where the policies aim simply to increase female labour force participation (FLFP). The strategic initiative involves long term policy measures where the government needs to change mindsets to embrace a paradigm shift and this is more in line with a GAD approach. It is necessary and crucial for men to recognise women's position in the society, their multiple capabilities, resilience and also capitalise on their multifaceted talents and contribution in various fields instead of treating them as a threat. This includes changing the mindset on the traditional roles of men and women, eliminating discriminatory practices and working towards gender equality. There needs to be an emphasis that work-life balance should not be marginalised as a women's issue, but more a national issue. Although the men of today want women to work and participate in paid labour and help with the household finance, in dual career families, child caring responsibilities and household chores still remain a woman's domain.

\footnotetext{
47 One of the strategies to reform the labour market in the plan was to increase female labour force participation from 46 percent in 2010 to 55 percent by 2015. An important policy was to introduce the Part Time Work Regulations under the Employment Act 1955 in order to tap the workforce consisting housewives, retirees and disabled persons. This 'Part Time Work Regulations" has already been in place from October 2010.
} 
Public policies can address gender biases by instilling community awareness, with additional care taken by educational and training programmes towards not highlighting women's roles as wives, mothers and sisters only but also as equal partners in life. These initiatives will lead to attitudinal changes which are a long term measure to encourage men to share equally with women the household responsibility and realise that household chores and caring responsibilities are not a woman's domain anymore. Women in Malaysia are still perceived as secondary earners or supplementary earners and this idea needs to be minimised and diminished with orientation programmes initiated possibly through community service centres, places of worship and the educational system.

They can move towards not highlighting women's roles as wives, mothers and sisters only but also as equal partners in life. These initiatives will lead to attitudinal changes which is a long term measure to encourage men to share equally with women the household responsibility and realize that household chores and caring responsibilities are not a woman's domain anymore.

As for affirmative action to be implemented within the less-regulated private sector in terms of working arrangements and organisational reform at the workplace, there is a need to move away from the perception that 'work can only be done at one's desk' and that working long hours are necessary to demonstrate one's worth. This action can only be successful if complemented with tax rebates, tax incentives, and legislation giving recognition to companies that are doing their part for women.

\subsection{Theoretical Considerations}

The WID, WAD, GAD models provides a framework for understanding and analysing FWA in Malaysia.

In the WID model, women were seen more as a production factor and the focus was to integrate women in the economic system by increasing their labour force participation. As this classic development policy in the early 1970 s focussed 
more on the productive role, it ignored the reproductive role, women's welfare and well-being. Grounded in the modernisation theory, the WID model was geared towards policy measures focussed on increasing FLFP rates, with women seen as an instrument for economic development. The WID approach which was nonconfrontational, also accepted women's place and social structures and did not question subordination or oppression. The underlying social issue of patriarchy was also neglected. Hence, class, culture and race were overlooked leading to women being treated as an undifferentiated category. Even though the WID model noted that benefits of modernisation did not reach women, this did not emerge as an issue as the focus was more on minimising the disadvantages of working women and increasing their participation in paid labour.

It could be suggested that current policies are consistent with this WID approach, i.e., increasing women's participation in the labour force with the assumption that women will benefit from this phenomenon. Findings from this research show that the availability of FWA will encourage more women to participate in paid labour as desired by WID analysts. Moreover, findings also showed that the underlying issue of patriarchy still exists among most households in Malaysia but this was something which was not recognised by WID analysts.

The WAD model which spanned the second half of the 1970s based on the dependency theory, critically viewed the WID model which focussed only on the productive role of women. WAD analysts who focussed on women as being part of the development process did not see the need to further integrate women in the development process, which they felt might lead to inequality. Women were accepted as important economic indicators and the public and private domain of women's work were emphasised but they did not analyse women's oppression and subordination. It was assumed that if internal structures become more equitable, women's position will improve. However, one obvious critique of the WAD model is that it does not question the relationship between gender roles.

However, as suggested by the WAD model, if more women participate in paid labour, problems such as increased double burden and the neglect of women's 
well-being will be further accentuated. The costs and opportunity costs borne by women working in FWA as explained by the WAD critique, highlights the possibility of the research findings on why women earning lesser income are not so interested in FWA as compared to the more educated and higher income earning women who are able to exploit FWA better. By just adopting FWA at the workplace, women do not become better but they still have to bear the double burden and the WAD critique is further confirmed.

What the WAD model does for this study however, is point to the critical issue of the uneven and negative impact on women, which is increased participation in the wage labour, especially for unskilled, low paid work. It might explain low participation among the lower paid sector. Perhaps the WAD model suggests that better educated women who earn a higher income participate in FWA because they could use family members and domestic helpers to do the extra work for them.

The GAD model which became prominent in the 1980s based on the social feminist theory, gives a more holistic perspective and looks at all aspects of women's lives. By recognising women's contribution inside the house and outside the house, it does not assign specific gender roles. It basically rejects the private-public dichotomy and enters the private sphere to promote women's emancipation. Women are seen as "agents of change". GAD recognises that it is patriarchy which operates within and across classes that oppress women.

The GAD model is the core of this study because adopting the GAD perspective allows a better understanding of working women and FWA. As GAD proponents recognised patriarchy and its relations in the home and the workplace, working women face a double or triple burden in most countries. The research findings confirm that even though married women are allowed to work, most husbands' expectations of housework, cooking and caring responsibilities show that patriarchal views still exist in most homes. This is the main reason why educated women are exiting the labour force or not joining the labour force. Despite working in paid labour, there has not been much change in the fundamental relations in the 
home and the workplace. Only if the patriarchal and traditional views of society change, will women's position in society improve.

The WID, WAD, GAD model is useful in explaining women's participation in the labour force. The social dimensions to these issues also help confirm the findings that the higher income earners and better educated are able to exploit and use FWA. Being in a better economic and social position, they are able to exploit and use FWA better, whereas the less educated and poor do not have much of a choice in the matter. When these women exploit FWA, there is no effect on other women who are less educated and earning a lower income. Even though FWA may allow more women to participate in paid work, it may create social issues such as the demand for domestic helpers and unpaid family labour as well as increased reliance on extended families.

There are three major conclusions from the study which need to be highlighted:

Firstly, flexible working arrangement is not a single concept as it consists of various types of working arrangements with flexibility of place and time. Flexible working arrangements cover a range of workplace situations and work policies and hence, are certainly not a blue print one can apply in all situations and expect to get a significant and uniformed outcome. Even though FWA can be good for both employers and employees, a win-win policy has to be drawn out carefully. What FWA literature needs to do is to understand the complexity of FWA and the complexity of the social, cultural and economic situations where they are applied.

Currently in Malaysia, FWA in most organisations are rostered and not an option for the employee but more a work policy for the employer, offered at certain occupational levels. Even though FWA originated with flexibility given to the employees to make a choice on work times observing some core hours (Allenspace, 1975), the government sector's staggered working hours is rostered either monthly or periodically. As for the larger organisations, employees are more flexible to plan 
their flexitime of working from the home but it has to be either informed or preapproved by the supervisors.

Secondly, FWA do not affect all women in the same way. Findings shows that women who are already better off and are higher educated are more aware of the options and therefore able to exploit FWA favourably. The poorer and less educated do not have many options and are not in a position to embrace these opportunities. Instead, it might create other disparities and increase the double burden for women as well as lead to indirect effects and implications on family labour, extended family and domestic labour.

Hence, by just implementing FWA at the workplace, without other socioeconomic issues addressed, the desired outcome of increasing women's participation in the labour force cannot be achieved. If FWA continue to be used without attention to socio-economic issues, they may magnify the inequalities among women because of the uneven distribution of income.

Thirdly, FWA need to be accompanied by other changes in the socioeconomic and cultural aspects in which women live. By examining the triple roles of women introduced by The Moser Gender Planning Framework, it maps the activities of household members over a course of twenty-four hours (Moser, 1993). The three roles are 'productive role' which includes all work done for remuneration; 'reproductive role' which includes childbearing and rearing and also domestic tasks such as cooking and cleaning; and 'community management role' which includes work that supports collective consumption and maintenance of community resources. Moser raises the question on the existence of the gender division of labour and her answer lies in the institution called marriage - where she says marriage-based households are constructed by definition on the basis of gender, and this is the reason why housework and childcare are most influenced by the relations of marriage"(Moser, 1993, p. 31).

Hence, the ideology of patriarchy has reinforced the stereotype male breadwinner resulting in subordination within marriage. In order for FWA to bring 
more women into the labour force, there certainly needs to be an enabling environment with a good support system, attitudinal shifts in the society and policies such as tax rebates and incentives for FWA to achieve an increase in FLFP rate.

\subsection{Indication of Future Research}

This study concentrates on women employees in 14 organisations in the services sector in the Klang Valley, which is the central business hub of Malaysia.

Future research should look at different areas including women in the rural economics and more lower paid industrial work and take into consideration different cultural aspects, particularly lower income households and less educated women living in the rural areas and their relationship with FLFP. This should also be qualitative in nature so as to enable an in-depth understanding and should look at the social impact of FWA on the work-life balance of women in the lower income. As the scope of this study only analyses women's interest in FWA specifically in organisations in the services sector, a further study should look at women in the manufacturing sector to determine whether there is much difference in the interest towards FWA.

\subsection{Concluding Remarks}

FWA, if implemented in the services sector is likely to be successful among women who are in the higher income level and who are more educated and have higher skills. For FWA to encourage more women to participate in the labour force, the initiative needs to go down the scale so as to reach the lower income and lower educated women, so that there will be a broader impact with the associated changes. Secondly, there needs to be attitudinal changes among households and shifts in mindset among both men and women regarding house, work and women. Thirdly, the government policies such as an enabling environment, legislation and tax reforms may help FWA to be implemented and hence bring about more women to participate in the labour force 
"Flexible Working Arrangements" is not a simple concept and hence, should not be treated as a single, comprehensive package which might be suitable for all women. Firstly, as it refers to various types of working arrangements which range from workplace flexibility to work time flexibility, and it should be implemented as an option for all staff and not just as a cost-cutting means for employers. Secondly, as the work policy involves social relationships and works differently for women of different socio-economic levels, a lot of organisational planning needs to be done before it is implemented.

Flexible Working Arrangements are necessary to achieve the desired outcome of increasing female labour force participation in Malaysia. However, they cannot work without being supported by an enabling environment. FWA may encourage more women to work in paid labour but many underlying socio-economic and cultural issues need to be addressed to make flexible working arrangement a successful initiative. This requires an enabling environment in the form of family friendly policies, especially more reliable and available childcare facilities. For FWA to benefit women and society, the underlying issues of patriarchy at home and at the workplace have to be resolved.

Currently, FWA and women's participation are both politically and policy wise seen as women's issue. For it to be successful, it has to be seen as a national development policy and embraced through a shift in attitude across the whole society. 


\section{REFERENCES}

Adams, F. G. (2006). East Asia, Globalisation and the New Economy. New York: Routledge.

Aghion, P,E. Caroli \& C. García-Peñalosa (1999). Inequality and economic growth: The perspective of the new growth theories. Journal of Economic Literature, 37, 1615-1660.

Aminah Ahmad (1995). Role conflict and coping behaviour of married working women. Pertanika Journal of Social Science \& Humanities, 3(2), 97-104.

Aminah Ahmad (1998). Women in Malaysia - Country Briefing Paper. Paper prepared for Programmes Department East and Office of Environment and Social Development, Asian Development Bank.

Aminah Ahmad (1999). Participation of Malaysian women in employment: A gender stratification analysis. In Maimunah Ismail \& Aminah Ahmad (Eds.), Women and Work: Challenges in Industrialising Nations (pp.8-30). London: Asean Academic Press.

Akbulut, R. (2011). Sectoral changes and the increase in women's labor force participation. Macroeconomic Dynamics, 15 (2), 240-264.

Alastair, G., Hulme, D., \& Turner, M. (2007). Challenging Global Inequality Development Theory and Practice in the 21st Century: Palgrave Macmillan.

Aldaba, R. M., \& Pasadilla, G. O. (2010). The ASEAN Services Sector and the Growth Rebalancing Model: Asian Development Bank Institute.

Allenspach, H. (1975). Flexible Working Hours. Geneva: International Labour Office.

Almer, E. D., Cohen, J. R., \& Single, L. E. S. (2003). Factors affecting the choice to participate in flexible work arrangements. Auditing, 22(1), 69-92.

Almer, E. D., \& Kaplan, S. E. K. (2000). Myths and realities of flexible work arrangements. The CPA Journal, 70(4), 14-21.

Almer, E. D., \& Kaplan, S., E. K. (2002). The effects of flexible work arrangements on stressors, burnout, and behavioral job outcomes in public accounting. Behavioral Research in Accounting, 14, 1-35.

Altman, M., \& Golden L. (2007). The economics of flexible work scheduling: Theoretical advances and contemporary paradoxes. Sociology of Work, 17, 313-341. 
Amla Salleh M, Zuria Mahmud \& Nila Inangda (2007). A study on coping strategies employed by successful women in Malaysia: Women in paid employment. International Journal of Diversity in Organisations, Communities \& Nations, 7(4), 135-146.

APEC Human Resource Development Working Group (1999). Time for Work: Linkages Between Paid and Unpaid Work in Human Resource Policy. Hong Kong, China.: APEC.

Babbie, E. (2010). The Practice of Social Research (12 ${ }^{\text {th }}$ ed.). USA: Wadsworth, Cencage Learning.

Bacik, I., \& Drew, E. (2006). Struggling with juggling: Gender and work/life balance in the legal professions. Women's Studies International Forum, 29(2), 136-146.

Baird, M., \& Williamson, S. (2009). Women, work and industrial relations in 2008. Journal of Industrial Relations, 51(3), 331-346.

Bandrage, A. (1984). Women in development: Liberalism, Marxism and Marxist feminism. Development and Change, XV, 495 -515.

Beneria, L., \& Sen, G. (2000). Accumulation, reproduction and women's role in economic development: Boserup Revisited. In N. Visvanathan, et al., (Eds.). The Women, Gender \& Development Reader (pp. 42-50). London: Zed Books Ltd..

Bennets, L. (2007). The Feminine Mistake: Are We Giving Up Too Much? eBook Edition April 2007. Retrieved from http://www.amazon.com/FeminineMistake-Are-Giving-Much/dp/1401303064

Berecki-Gisolf, J., Lucke, J., Hockey, R., \& Dobson, A. (2008). Transitions into informal caregiving and out of paid employment of women in their 50s. Social Science \& Medicine, 67(1), 122-127.

Bernasek, A., \& Gallaway, J. H. (1997). Who gets maternity leave?: the case of Malaysia. Contemporary Economic Policy, 15 (n2).

Blomström, M., \& Hettne, B. (1984). Development Theory in Transition: The Dependency Debate and Beyond; Third World Responses. London: Zed Press.

Boje, T. P. (1996). Gender, work time and flexible employment - The case of Denmark. Time \& Society, 5(3), 341-361.

Boserup, E. (1970). Women's Role in Economic Development. New York: St. Martin's Press.

Brooks, A. (2006). Gendered Work in Asian Cities - The New Economy and Changing Labour Markets. Hampshire: Ashgate Publishing Limited. 
Boulding, E. (1977). Women in the Twentieth Century World. New York: Sage Publications

Bryman, A., \& Bell, E. (2007). Business Research Methods $\left(2^{\text {nd }}\right.$ ed). Oxford: Oxford University Press.

Burgess, J., French, E. L., \& Strachan, G. (2010). The diversity management approach to equal employment opportunity in Australian organisations. The Economic and Labour Relations Review, 20(1), 77-92.

Charlton, S. E. (2000). Development as History and Process. In N. Visvanathan, et al., (Eds.). The Women, Gender \& Development Reader (pp. 30-41). London: Zed Books Ltd.

Chin, C. B. N. (2005). Neither at work nor at home: Asian transnational domestic workers in Malaysia. In S. Huang, B. S. A. Yeoh \& Noor Abdul Rahman (Eds.), Asian Women As Transnational Domestic Workers (pp. 262-287). Singapore: Marshall Cavendish.

Chiu, K. K. L. (1999). The hidden side of Taiwan's economic miracle: Women's decision to work and their lives in Taiwan. Department: School of Social Work. Unpublished PhD Thesis. Columbia University.

Cole, G. A. (2006). Flexibility and the workplace: the battle to control working time. Managerial Law, 48(6), 536-540.

Costa, G., \& Sartori, S. (2005). Flexible work hours, ageing and well-being. International Congress Series, 1280, 23 -28.

Creswell, J. W. (2009). Research Design: Qualitative, Quantitative and Mixed Methods Approaches (3rd ed.). Los Angeles, CA: Sage Publications.

Creswell, J. W., \& Plano Cark, V. L. (2006). Designing and Conducting Mixed Methods Research. Thousand Oaks, CA: Sage Publications.

Department of Statistics, Malaysia (1981). General Report of The Population and Housing Census. Putrajaya: Department of Statistics, Malaysia.

Department of Statistics, Malaysia (2010). Vital Statistics, Malaysia. Putrajaya:

Department of Statistics, Malaysia.

Department of Statistics, Malaysia. (DOS)(2003). Labour Force Survey Report: Department of Statistics, Malaysia.

Department of Statistics, Malaysia. (DOS)(2010). Labour Force Survey Report: Department of Statistics, Malaysia.

Department of Statistics, Malaysia. (DOS)(2010). Population and Housing Census of Malaysia, Department of Statistics, Malaysia. 
Department of Statistics, Malaysia. (DOS)(2010). Social Statistics Bulletin, 2010, Malaysia.

Dowling, J.M., \& Valenzuela, M.R. (2004). Economic Development in Asia. Singapore: Thomson.

Durand, J. D. (1975). The Labor Force in Economic Development - A Comparison of International Census, 1946-1966. Princeton: Princeton University Press.

Economic Planning Unit, Malaysia (2000). Eight Malaysia Plan (2000 - 2005), Putrajaya: Economic Planning Unit.

Economic Planning Unit, Malaysia (2006). Ninth Malaysia Plan (2006 - 2010), Putrajaya: Economic Planning Unit.

Economic Planning Unit, Malaysia (2010). Tenth Malaysia Plan (2010 - 2015), Putrajaya: Economic Planning Unit.

Elias, J. (2009). Gendering liberalisation and labour reform in Malaysia: fostering competitiveness in the productive and reproductive economies. Third World Quarterly, 30(3), $469-483$.

ESCAP. (1986). Status of women in Asia and the Pacific region series 2 (Working Series). Bangkok: ESCAP.

Esteva, G. (1992). Development. In W. Sachs. (Ed.), The Development Dictionary: A Guide to Knowledge as Power. (pp. 6-20). London: Zed Books.

Faturochman, Hull, T., \& Dwiyanto A.(1998). Validity and reliability of family welfare measures: An experiment in Central and East Java. Journal of Population. 4, 33-5.

Faridah Karim.(2009). Women in education in Malaysia. In Jamilah Ariffin (Ed.), Readings on Women and Development in Malaysia - A Sequel. Tracing Four Decades of Change. (pp. 159-178). Petaling Jaya: MPH Group Publishing.

Faridah Shahadan \& Berma, M., (1994). Economic development trends and women's participation in the services sector. In Jamilah Ariffin (Eds.), Readings on Women in Development (pp.174-204). Kuala Lumpur: Population Studies Unit, University Malaya.

Fatimah Kari \& G. Sumitha (1994). "Economic Planning and its Impact on Integration of Women in Development". Paper presented at the Bengkel Wanita Malaysia:Sepanjang Dua Dekad Pembangunan. (Workshop on Women in Malaysia: Two Decades of Development) 
Fernandez, L. J. (1997). Labour force participation of urban women in Peninsular Malaysia. In B.N. Ghosh, Lai Yew Wah \& S. Narayanan. (Eds) Industrialisation In Malaysia: Some Contemporary Issues. Kuala Lumpur: Utusan Publication \& Distributors Sdn. Bhd.

Fong Chan Onn (1986). New Economic Dynamo-Structures and Investment Opportunities in the Malaysian Economy. Australia: Allen \& Unwin.

Froebel, F. (1980). The New International Division of Labour. Cambridge: Cambridge University Press.

Gauthier, A.H., \& Furstenberg F.F. Jr., (2004). On the Frontier to Adulthood:

Theory, Research, and Public Policy. Settersten, R.A., Furstenberg F.F. Jr., \& Rumbaut, R.G., (eds)Retrieved from

http://www.transad.pop.upenn.edu/restricted/frontier/ch5gauthier\%20and\%2 Ofurstenberg(05-03).htm

Ghosh, N. (2008). The road from economic growth to sustainable development: How was it traversed? SSRN Working Paper, retrieved from http://ssrn.com/abstract=1082686.

Gillis, M., Perkins, D., H., Roemer, M., \& Snodgrass, D., R. (1996). Economics of Development. New York: W.W. Norton \& Company, Inc.

Grice, M.M., McGovern, P.M., \& Alexander, B.H. (2008). Flexible work arrangements and work-family conflict after childbirth. Occupational Medicine, 58(7), 468- 474.

Hall, D. T. (1972). A model of coping with role conflict: the role behavior of college educated women. Administrative Science Quarterly, 17(4), 471-486.

Hair, J. F., Black, W.C., Babin, B.J., \& Anderson. R. E. (2010). Multivariate Data Analysis A Global Perspective ( $7^{\text {th }}$ ed). New Jersey, USA: Pearson Prentice Hall.

Hariati Azizan (2011, March 6). Still Far From Equal. Sunday Star. Retrieved from http://thestar.com.my/news/story.asp?file=/2011/3/6/nation/8199413\&sec $=$ n ation.

Hartmann, H. (1976). Capitalism, patriarchy and job segregation by sex, in $M$. Blaxall \& B. Reagan (Eds), Women and the Workplace. USA: University of Chicago Press.

Hau I.S.C., \& Chew I.K.H. (2006). The effect of alternative work schedules on employee performance. International Journal of Employment Studies. 14(1), $105-129$.

HAWA (1990). Dasar Wanita Negara, (National Women's Policy) Kuala Lumpur, Urusetia Hal Ehwal Wanita (Women's Secretariat). 
Heyzer, N. (1986). Working Women in South-East Asia: Development, Subordination and Emancipation. Philadelphia, Pennsylvania: Open University Press.

Heyzer, N. (ed) (1988). Daughters in Industry: Work, Skills and Consciousness of Women Workers in Asia. Kuala Lumpur: Asian and Pacific Development Centre.

Hing, A. Y. (1984). Women and Work in West Malaysia. In A.Y. Hing et al.,(Eds) Women in Malaysia, Petaling Jaya: Pelanduk Publications.

Hill, E.J., Martinson, V. K., Ferris, M., \& Baker, R.Z., (2004). Beyond the mommy track: The influence of new concept part time work for professional women on work and family. Journal of Family and Economic Issues, 25 (1), 121136.

Hirschman, C. \& Aghajanian, A. (1980). Women's labour force participation and socioeconomic development: The case of Peninsular Malaysia, 1957-1979, Journal of Southeast Asian Studies, 11, 30 -49.

Hotchkiss J.L. (2006). Changes in behavioral and characteristic determination of female labor force participation 1975-2005. Economic Review, 17(1), 106-138.

Husna Sulaiman (1994). Rural women in rice based farming system: Trends and implications in Jamilah Ariffin (Ed), Readings on Women and Development in Malaysia - A Sequel. Tracing Four Decades of Change. Petaling Jaya: MPH Group Publishing.

Hyman, P. (1994). Women and Economics - A New Zealand Feminist Perspective. Wellington: Bridget Williams Books Ltd.

Ishak Shari \& Ragayah Mat Zin (1997). Southeast Asia on the growth path. In A. Mahdzan (Ed.), Economic Growth and Equity in Malaysia: Performance and Prospects. Kuala Lumpur: Aslita Sdn. Bhd.

Jamilah Ariffin (1980). Female Labour Migration to Urban-Based Factories in Malaysia and Malay Women's Participation in the Labor Force - An Analysis of the Changing Trends and Patterns. Paper presented at the Eleventh Summer Seminar Workshop on 'Analysis of Female Migration' East- West Center, Honolulu.

Jamilah Ariffin (1992) Women and Development in Malaysia, Petaling Jaya: Malaysia, Pelanduk Publications.

Jamilah Ariffin (Ed.). (1994a). Women, Development and Poverty : Globalised Issues and Empirical Findings Relevant to Studying Poor Women in Malaysia. Petaling Jaya: Pelanduk Publications. 
Jamilah Ariffin. (1994b). From Kampung to Urban Factories: Findings from The HAWA Study. Kuala Lumpur: University of Malaya Press.

Jamilah Ariffin (Ed). (2009). Readings on Women and Development in Malaysia - A Sequel. Tracing Four Decades of Change. Petaling Jaya: MPH Group Publishing.

Jaquette, J. S. (1982). Women and Modernization Theory, World Politics 34(2), $267-$ 273. Retrieved from business.reachinformation.com.cws8.my-hostingpanel.com/Modernization theory.aspx.

Joekes, S. (1987) Women in the World Economy, ILO/INSTRAW Study, New York: Oxford University Press.

Johnson, E. N., Lowe, D. J., \& Reckers Philip M.J. (2008). Alternative work arrangements and perceived career success: Current evidence from the big four Firms in the US. Accounting, Organizations and Society, 33, 48-72.

Jomo K. S. (1990-1991). Whither Malaysia's New Economic Policy? Pacific Affairs, University of British Columbia Stable, 63(4 ), 469-499.

Jomo K. S, \& Hui, W. C. (n.d) Policy coherence initiative on growth, investment and employment the case of Malaysia development policies, macroeconomic regime and employment in Malaysia Retrieved January 15, 2011, from www.ilo.org/wcmsp5/groups/public/---asia/---ro.../wcms_101733.pdf

Jomo K.S, Chen Y.C., Brian C.F., Irfan ul-Haque, Pasuk Phongpaichit, Batara Simatupang, et al. (1997). Southeast Asia's Misunderstood Miracle. Colorado: Westview Press.

Jomo K.S., \& Kanapathy, V. (1999). Economic Liberalisation and Labour in Malaysia: Efficiency and Equity. Geneva: ILO.

Jomo K.S, \& Gomez E.T. (2000). Rents, Rent Seeking and Economic Development Theory and Evidence in Asia. In H.Mushtaq, Khan \& K. S. Jomo (Eds.), The Malaysian Development Dilemma. Cambridge: Cambridge University Press.

Jomo, K.S \& Wee C.H. (2007). Paper for ILO entitled Policy coherence initiative on growth, investment and employment the case of Malaysia - Development policies, macroeconomic regime and employment in Malaysia. Bangkok.

Jones, G.W. (1984). Women in the Urban and Industrial Workforce, Southeast and East Asia. USA: University of Hawaii Press.

Kahneman, D., \& B. Krueger, A. (2006). Developments in the measurement of subjective well-being. Journal of Economic Perspectives, 20(1), 3-24. 
Kaplan, E., \& Granrose C. S. (1993). Factors influencing women's decision to leave an organization following childbirth. Employee Responsibilities and Rights Journal, 6(1), 45-54.

Kaufman, G. (2005). Gender role attitudes and college students' work and family expectations. Gender Issues, Spring, 58-71.

Kaur, A. (1986). Women at work in Malaysia. In A.Y.Hing \& Rokiah Talib (Eds.), Women and Employment. Kuala Lumpur: Department of Anthropology and Sociology, University of Malaysia (Women's Association): Asian and Pacific Development Center.

Kaur, A. (1999). Women's Work: Gender and Labour Relations in Malaysia. Working papers on Asian Labour, Armidale University of New England, Australia.

Kaur, A. (2004). Women Workers In Industrialising Asia: Costed Not Valued. New York: Palgrave Macmillan.

Kumar, R. (2005). Research Methodology A Step by Step for Beginners (2 ${ }^{\text {nd }}$ ed.). London: Sage Publications.

Lall, S. (1979). Multinationals and market structure in an open developing economy: the case of Malaysia. Weltwirtschaftliches Archive, 115 (2) 325 - 350

Lee, K. H., Quek, A. H., \& Chew, S. B. (2001). Education and Work - The State of Transition. Kuala Lumpur: University Malaya Press.

Leedy, P.D \& Ormrod, J. E. (2010). Practical Research $\left(9^{\text {th }}\right.$ ed.). New Jersey: Pearson Education International.

Loh-Ludher, L. L. (2010). From factories to telecenters: Journey of women in the Malaysian labour force In Jamilah Ariffin (Ed.).Readings on Women and Development in Malaysia - A Sequel Tracing Four Decades of Change (pp. 223- 244). Petaling Jaya: MPH Group Publishing.

Liddicoat, L. (2003). Stakeholder perceptions of family-friendly workplaces: An examination of six New Zealand Organisations. Asia Pacific Journal of Human Resources, 41, 354- 370

Liechty, J. M., \& Anderson, E. A. (2007). Flexible workplace policies: Lessons from the Federal Alternative Work Schedules Act. Family Relations, (56), 304317.

Lightbody, M. (2009). Turnover decisions of women accountants: using personal histories to understand the relative influence of domestic obligations. Accounting History, 14(1/2), 55-78. 
Lijphart, A., (1971). Comparative Politics and the Comparative Method. American Political Science Review, 65 (3)

Lim, Linda Y.C. (1980). Women Workers in Multinational Corporations: The Case of Electronics Industry in Malaysia and Singapore. Michigan Occasional Paper in Women's Studies, IX, 1978; $2^{\text {nd }}$ print.

Lim, D. (1983). Further Readings on Malaysian Economic Development. Kuala Lumpur: Oxford University Press.

Lim, V.K.G., Teo, T.S.H., \& See, S.K.B. (2000). Perceived job image among police officers in Singapore: factorial dimensions and differential effects. The Journal of Social Psychology, 140 (6), 740 - 750.

Lyn P. (2005). The Agency of Women in Asia. Singapore: Marshall Cavendish International.

Madeline, B., \& Faridah Shahadan (2009). Women's Participation in the Services Sector in Malaysia: Trends and Issues. In Jamilah Ariffin (Ed.), Readings on Women and Development in Malaysia - A Sequel. Tracing Four Decades of Change, (pp. 201 -222), Petaling Jaya: MPH Group Publishing.

Maimunah Ismail and Aminah Ahmad (Eds.). (1999). Women and Work Challenges in Industrializing Nations. Kuala Lumpur: ASEAN Academic Press, London.

Maimunah Ismail and Rusinah Joned (1999). The Profile and Value System of Women Entrepreneurs"in Maimunah Ismail and Aminah Ahmad (eds.) Women and Work - Challenges in industrializing Nations. Kuala Lumpur: ASEAN Academic Press, London.

Oakley and Marsden (1984). Approaches to Participation in Rural Development. Geneva: ILO.

Osman-Rani,H.(1983). Structural changes and employment expansion in the manufacturing industry of Peninsular Malaysia 1963-78. Kajian Ekonomi Malaysia, 20(2), 127-141.

Maznah Mohamad (2010). Malaysian sharia reforms in flux: The changeable national character of Islamic marriage. International Journal of Law, Policy and the Family. 1- 25. doi:10.1093/lawfam/ebq016

Maxwell, C.(2000). The future of work - understanding the role of technology. BT Technology Journal, 18(1), 55-56.

Malhotra, N. K. \& Birks, D. F. (2000). Marketing Research: An Applied Approach. England: Pearson Education Ltd. 
McGee, T.G. (Ed.) (1986). Industrialisation and Labour Force Processes - A Case Study of Peninsular Malaysia. Canberra: Australian National University.

McGee. T.G. (1983). Prolerarianization, industrialization and urbanization in Asia: A case study of Malaysia. AKADEMIKA - Journal of Humanities and Social Sciences, 23, 3-20.

McMichael, P. (2000). Development and Social Change - a Global Perspective $\left(^{\text {nd }}\right.$ ed.). California: Pine Forge Press.

Mincer, J. (1996). Economic development, growth of human capital, and the dynamics of the wage structure. Journal of Economic Growth, Vol. 1(1), 2948.

Ministry of Women, Community \& Family Development, (2010). Statistics on Women, Family and Community Development, Kuala Lumpur.

Mitter, S. (2005). Globalization, ICTs and economic empowerment : A feminist critique. In C. Ng \& S. Mitter (Eds.), Gender and the Digital Economy Perspectives from the Developing World. New Delhi: Sage Publications.

Mitter, S., \& Ng, C. (Eds.). (2005). Gender and Empowerment in the Information Economy: An Introduction. New Delhi: Sage Publications.

Morrison, R. (2007). Gender differences in the relationship between workplace friendships and organisational outcome. Research Paper Series, Faculty of Business, Auckland University of Technology.

Moser, C. O. N. (1993). Gender Planning and Development: Theory, Practice, and Training. Retrieved from Ebrary database.

Murray, W. E. (2006). Geographies of Globalization New York: Routledge.

Murray, W. E., \& Overton, J. D. (2003). Designing development research In R. Scheyvens \& D. Storey (Eds.), Development Fieldwork: A Practical Guide (pp.17-35). London: Sage Publications.

Nadeem, S.,\& Hendry, C. (2003). Power dynamics in the long term development of employee-friendly flexible working, Women in Management Review, 18(1/2), $32-49$.

Nafziger, E. W. (2006). From Seers to Sen - The Meaning of Economic Development. Helsinki, Finland: World Institute for Development Economics Research (WIDER), United Nations University (UNU).

Nagaraj, S., Goh K.L., Tey N.P., \& Rohana Jani. (2009). Human capital formation and Labour market dynamics: A gendered perspective. Unpublished FEA Working Paper no. 2009-1, Faculty of Economics and Administration, University Malaya. 
Nagaraj, S., \& Siti Rohani Yahaya (1998). Women and Development in Malaysia. In L. Y. Soon, and S.Nagaraj (Eds.). The Seventh Malaysia Plan: Productivity for Sustainable Development. Kuala Lumpur: University of Malaya Press.

National Economic Advisory Council (NEAC) (2010). New Economic Model For Malaysia Part I: Strategic Policy Directions, Government Printers, Kuala Lumpur.

New Straits Times (2011). February 2011

New Zealand, Department of Labour, 2006

Ng, C., \& Leng, C. H. (1999). Women in Malaysia: Present Struggles and Future Direction. In C. Ng (Ed.), Positioning Women in Malaysia. Hampshire: Macmillan Press Ltd.

Olmstead, B., \& Smith, S. (1994). Creating A Flexible Workplace - How To Select \& Manage Alternative Work Options. New York: American Management Association.

Osman-Rani, H. (1983). "Structural changes and employment expansion in the manufacturing industry of Peninsular Malaysia 1963-78", Kajian Ekonomi Malaysia, 20(2): 127-141.

Overton, J., \& van Dierman P., (2003) Using quantitative techniques In R. Scheyvens \& D. Storey (Eds.), Development Fieldwork Using Quantitative Techniques. London, SAGE Publications Ltd. Retrieved from http://books.google.com.my

Papalexandris, N., \& Kramar, R. (1997). Flexible working patterns: towards reconciliation of family and work. Employee Relations, 19(6), 581-595.

Patton, M. Q. (2002). Qualitative Research and Evaluation Methods (3 ${ }^{\text {rd }}$ ed.). California: Thousand Oaks, Sage.

Perrons, D. (2000). Flexible working and equal opportunities in the United Kingdom: A case study from retail. Environment and Planning, 32(10), 1719-1734.

Petra, D. (1999). Conformity or Resistance? Women Workers in the Garment Factories in Bangladesh. Bielefeld Universität Bielefeld, Sociology of Development.

Philippe, A., Eve, C., \& Cecilia, G.P. (1999). Inequality and Economic Growth: The Perspective of the New Growth Theories. Journal of Economic Literature, 37(4), 1615-1660. 
Pierce, J. L., \& Newstrom, J. W. (1980). Toward a conceptual clarification of employee responses to flexible working hours: A work adjustment approach. Journal of Management, 6(2), 117- 134.

Pini, B., \& McDonald, P. (2008). Men, masculinities and flexible work in local government. Gender in Management, 23(8), 598-612.

Rathgeber, E.M., \& Vainio-Mattila, A. (2005). Whither GAD? new directions in gender and development, Gender and Development, Canadian Journal of Development Studies, 26(sup1), 569-571.

Rathgeber, E. M. (1990). WID, WAD, GAD: Trends in research and practice. Journal of Developing Areas, 24, 489-502.

Ravenswood, K. (2008). The role of the state in family-friendly policy: An analysis of Labour-led government policy. New Zealand Journal of Employment Relations (Online), 33(3), 34.

Reyes G. E (2001). Four Main Theories of Development: Modernization, Dependency, Word-System and Globalization.

Retrieved from http://www.ucm.es/info/nomadas/4/gereyes1.htm.

Robbins, S. P., Chatterjee, P., \& Canda, E.R. (1998). Contemporary Human Behavior Theory. Boston: Allyn \& Bacon.

Rodan, G., Hewison, K., \& Robison, R. (Eds.). (2001). The Political Economy of Southeast Asia: Conflict, Crises and Change ( $2^{\text {nd }}$ ed.). Oxford: Oxford University Press.

Rodolphe De K. (1981). Of Rice, Men, Women and Machines in Malaysia. In Osman Rani, K. S. Jomo \& Ishak Shaari (Eds.), Development in the Eighties with Emphasis on Malaysia. Kuala Lumpur: Universiti Kebangsaan Malaysia.

Sagayam, A. (2011, August 19) Raya maid ban lift - Announcement soon to end freeze on Indonesian domestic help to Malaysia. The Malay Mail..

Saunders, M., Lewis, P.,\& Thornhill, A. (2007). Research methods for business Students $\left(4^{\text {th }}\right.$ ed). London: Prentice Hall.

Scheyvens, R., \& Storey, D. (Eds.) (2003). Development Fieldwork Using Quantitative Techniques. London, SAGE Publications Ltd. Retrieved from SAGE Research Methods Online.

Seers, D. (1969). The meaning of Development. Institute of Development Studies 1969, 44

Sekaran, U. (2004). Research Methods For Business- A Skill Building Approach (4 $^{\text {th }}$ ed). John Wiley \& Sons. 
Sen, A. (1999). Development as Freedom. Oxford: Oxford University Press.

Sha'ban Muftah Isma'il (1997). Women, Economic Growth \& Development in Malaysia. Petaling Jaya: IBS Buku Sdn.Bhd.

Shamsulbariah Ku Ahmad (1994). Stratification and Occupational Gender. Segmentation in the Labour Force in Jamilah Ariffin (ed.) Readings on Women in Development in Malaysia. Population Studies Unit, University of Malaya.

Siti Rohani, Y. (2009). The Development Process and Women's Labour Force Participation : A Macro-level Analysis of Patterns and Trends from the 1980s. In Jamilah Ariffin (Ed.), Readings on Women and Development in Malaysia - A Sequel Tracing Four Decades of Change (pp.19-56). Petaling Jaya: MPH Group Publishing.

So, A.Y. (1990). Social Change and Development: Modernization, Dependency, and World System Theories. Newbury Park: Sage.

Subramaniam,G., Ali, E., \& Overton, J. (2010a). Are Malaysian women interested in flexible working arrangements? Business Studies Journal, 2 (SI), 83-98.

Subramaniam,G., Iyer, M.G. \& Maniam,B. (2010b). Do Malaysian women who opt out of the labour market want to return? A micro level analysis. International Journal of Business Research, 10(1), 106-113.

Subramaniam,G., \& Selvaratnam, D.P. (2010c). Family friendly policies in Malaysia : Where are we?. Journal of International Business Research, 9(1), 43-55.

Subramaniam,G., Saadiah Mohamad, \& Selvaratnam D.P. (2010d). Why do some women leave the labour force - A micro perspective from Malaysia. Economic Bulletin, 11, 1-17.

Sullivan, S. \& Lussier, R.(1995). Flexible work arrangements as a management tool. Supervision, 56, 14-17.

Sullivan,S. E. \& Mainiero, L. A. (2007). Kaleidoscope Careers: The Kaleidoscope Career Company Audit. Retrieved from http://www.sciencedirect.com.

Sunday Star (2011) 6 March 2011, p. 26

The Star (2010,17 September) p. 29

The Star. (2009, 26 June). Jakarta stops export of maids immediately. The Star.

The Star. (2010, 29 May) Group: Raising maids "e pay by $80 \%$ not logical. The Star, 
Thomas, L (2001). The Race to the Top: The Real Story of Globalization.

Washington, D.C,: Cato Institute.

Todaro, M. P., \& Smith, S. C. (2009). Economic Development $\left(10^{\text {th }}\right.$ ed.). London: Pearson Education.

Tremblay, D., \& Genin, M. (2008). Permeability between work and non-work: The case of self-employed it workers. Canadian Journal of Communication, 33(4), 701- 720.

United Nations (2011). Malaysia - Achieving the Millennium Development Goals Economic Planning Unit, Prime Minister's Department, Malaysia \& United Nations Country Team Malaysia.

UNDP. (2005). Malaysia - Achieving the Millennium Development Goals Economic Planning Unit, Malaysia \& United Nations Country Team Malaysia.

UNESCAP (2007), United Nations Economic and Social Commission for Asia and the Pacific, annual report.

Verma, V. (2004). Engendering development: Limits of feminist theories and justice. Economic and Political Weekly, 39(49), 5246-5252.

Visvanathan, N., Duggan, L., Nisonoff, L., \& Nan, W. (Eds.). (2000). The Women, Gender \& Development Reader. London: Zed Books Ltd.

Voydanoff, P. (1988). Work role characteristics, family structure demands and work/family conflict. Journal of Marriage and Family, 50(3), 749-761.

Wallace, P. A. (Ed.). (1982). Women in the Workplace. Boston: Auburn House Publishing Company.

Wallace, P. A. (2009). Reasons women chartered accountants leave public accounting firms prior to achieving partnership status: A qualitative analysis. Canadian Journal of Administrative Sciences, 26(3), 179 - 189.

Waring, M. (1999). Counting for Nothing: What Men Value and What Women are Worth ( $2^{\text {nd }}$ ed.) . University of Toronto Press.

Warren, H.(2007). Using gender analysis frameworks: theoretical and practical reflections. Gender and Development, 15(2), 187-198.

World Bank (1982). World Development Annual Report 1982, Volume 1. 
APPENDICES 


\section{APPENDIX 4-1}

Questionnaire for Female Employees in FWA Organisations 


\section{Flexible Working Arrangements In Malaysia and The Participation of Women in the Labour Force}

Dear Valued Participants,

I am a PhD student in Victoria University of Wellington, New Zealand. As part of this degree, I am undertaking a research project examining flexible working arrangements in Malaysia. This study will focus on women employees working in the services sector in a few selected organisations.

As we all have commitments and responsibilities at work and outside work, it sometimes becomes a struggle to juggle work and life successfully. In spite of this, many women enjoy working and hence participate in the labour force.

Flexible working arrangements entail a partnership between women, family and the organisation. The education sector is one of the main sectors in the services industry which provides women employment with flexible working hours. These flexible work policies benefit both employees and also the organisation. In Malaysia, very few organisations have implemented flexible working arrangements and this organisation is one of the educational institutions which have flexible working arrangements.

The main aim of this study is to evaluate your perception towards how women, family and the organisation collaborate in flexible working arrangements at your workplace. The study also looks at whether these work arrangements will have an effect on the well-being of working women.

Your response to this survey is completely confidential. Thank you very much for your participation.

\section{Instructions: Please mark $(x)$ in the box which applies to you.}

\section{Section I - Job Related Characteristics}

1. Occupational level

a. Senior Management level (MD,GM)

b. Middle Management level

c. Executives/Officers

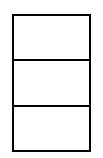

d. Clerical Level

e. Technicians/Assistants

f. Others, please state

2. Time taken to travel from home to workplace

3. Distance between home and workplace

4. Mode of transport to work

\section{Section II - Income \& Expenditure}

5. Personal Income (Monthly)

a. RM 1000 - RM 2000

d. $\quad$ RM $4001-$ RM 5000 

b. RM 2001 - RM 3000
c. RM 3001 - RM 4000

e. RM 5001 - RM 7000

f. Above RM 7000

6. Household Income (Monthly)
a. RM 1000 - RM 3000
b. RM 3001 - RM 5000
c. RM 5001 - RM 7000

\begin{tabular}{|ll}
\hline d. & RM 7001 - RM 9000 \\
e. & RM 9001 - RM 11000 \\
f. & Above RM 11000
\end{tabular}

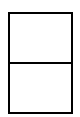

7. Average Family Expenditure (Monthly)
a. RM 1000 - RM 3000
b. RM 3001 - RM 5000
c. RM 5001 - RM 7000

\begin{tabular}{|rl}
\hline d. & RM 7001 - RM 9000 \\
e. & RM 9001- RM 11000 \\
f. & Above RM 11000
\end{tabular}

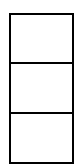

\section{$\underline{\text { Section III - Cultural factors }}$}

8. Race
a. Malay
b. Chinese

\begin{tabular}{|l}
\hline c. Indian \\
\hline d. \\
\hline
\end{tabular}

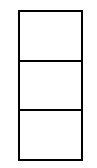

9. Place of Birth

10. Current Place of Residence

Please tick the answer which best describes the statements below with regards to support.

o- not applicable, 1- no support, 2- very little support, 3- little support, 4supportive, 5 - very supportive.

\begin{tabular}{|l|l|l|l|l|l|l|}
\hline & \multicolumn{1}{|c|}{} & 0 & 2 & 3 & 4 & 5 \\
\hline 11. & My husband is supportive towards my working outside the home. & & & & & \\
\hline 12. & $\begin{array}{l}\text { In my opinion, our society is supportive towards women working outside } \\
\text { the home. }\end{array}$ & & & & & \\
\hline
\end{tabular}

\section{$\underline{\text { Section IV - Family Responsibilities }}$}

13. How many children do you have?

14. How many children are aged 6 years and below?

15. How many children are aged between 6 years and 12 years?

16. How many children are aged between 13 years and 18 years?

17. Do you take care of elderly parents or relatives? Yes/No

18. In your opinion, what would be the most suitable type of childcare facility most women need nowadays

(Provided at workplace, At residential place, Nursery, Community Centres etc) 
19. Please tick the answer which best describes the extent of help given by family members or others with your household responsibilities and caring tasks.

0 - not applicable, 1 - no help, 2 - very little help, 3 -little help, 4 -helpful, 5-

\begin{tabular}{|c|l|c|c|c|c|c|c|}
\hline & & 0 & 1 & 2 & 3 & 4 & 5 \\
\hline a. & Husband - housework & & & & & & \\
\hline b. & Husband - childcare & & & & & & \\
\hline c. & Mother/Father - childcare & & & & & & \\
\hline d. & Paid helper, please state nationality _- & & & & & & \\
\hline e. & Others, please state & & & & & \\
\hline
\end{tabular}

very helpful

Section V - Demographic Profile

20. Age

a. $\quad 20-29$ years

b. $\quad 30-39$ years

c. $\quad 40-49$ years

d. $\quad 50-59$ years

e. 60 years and above

21. Highest Educational Level Achieved
a. $\quad \mathrm{SPM} /$ "O" Level
b. STPM / "A" Level
c. Diploma

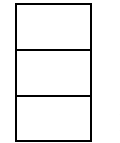
d. Degree/ Professional Course
e. Post Graduate
f. Others, please state .......

22. Marital Status
a. Married
b. Single

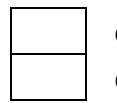

c. Single Mother

d. Others, please state .....

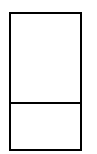

23. Type of home living presently
a. Single Storey Link
b. Double Storey Link
c. Semi detached

\begin{tabular}{|l|l} 
d. & Bungalow \\
e. & Apartments/Flats \\
f. & Others, please state .....
\end{tabular}

\section{$\underline{\text { Section VI - Flexible Working Arrangements (FWA) \& Work Policies }}$}

Flexible working arrangements can be in the form of flexi hours, part-time work, working from the home, teleworking, job sharing, compressed week etc.

24. a. Various types of FWA are offered at your workplace. Are you interested in FWA? Yes/No ...

b. Have you used any form of FWA at your workplace in the last one year? Yes/No If No, please go to Q 25.

c. Name two common types of FWA used in the last one year. 
25. Below are some of the common types of flexible working arrangements, please state how interested you are in using them at your workplace.

1-not very interested, 2-not interested, 3-uncertain, 4 - interested, 5-very interested

\begin{tabular}{|l|l|l|l|l|l|l|}
\hline & \multicolumn{1}{|l|}{} & 0 & 1 & 2 & 3 & 4 \\
\hline a. & Overall, how interested are you in FWA? & & & & & \\
\hline b. & Flexible time (starting and finishing time) & & & & & \\
\hline c & Part-time work (either morning or afternoon with a fixed income) & & & & & \\
\hline d. & Working from the home & & & & & \\
\hline e. & Working outside the office & & & & \\
\hline f. & Teleworking & & & & \\
\hline g. & $\begin{array}{l}\text { Any other } \\
\text { types }\end{array}$ & & & & \\
\hline
\end{tabular}

Please indicate the extent to which you agree with these statements by ticking (/) at the most appropriate answer.

\section{1-strongly disagree, 2- disagree, 3-neither disagree nor agree, 4-agree, 5- strongly agree}

\section{Section VII - Perceived Advantages and Disadvantages of Flexible Working}

\section{Arrangements (FWA)}

\begin{tabular}{|c|c|c|c|c|c|c|}
\hline 26. & $\begin{array}{l}\text { In my opinion, some of the advantages of flexible working } \\
\text { arrangements to me as an employee:- }\end{array}$ & 1 & 2 & 3 & 4 & 5 \\
\hline a. & My stress level will be reduced & & & & & \\
\hline b. & My morale will improve because I feel treated as a responsible professional. & & & & & \\
\hline c. & My job satisfaction will increase. & & & & & \\
\hline d. & My loyalty and job commitment will increase & & & & & \\
\hline e. & My quality of work will improve & & & & & \\
\hline f. & It will have a favourable effect on relations with my spouse. & & & & & \\
\hline g. & It will have a favourable effect on relations with my parents. & & & & & \\
\hline h. & It will have a favourable effect on relations with my children. & & & & & \\
\hline i. & It will have a favourable effect on relations with my siblings. & & & & & \\
\hline & & 1 & 2 & 3 & 4 & 5 \\
\hline $\mathrm{j}$. & It will allow more time for family. & & & & & \\
\hline $\mathrm{k}$. & It will allow more time for networking. & & & & & \\
\hline 1. & I can save on commuting time. & & & & & \\
\hline $\mathrm{m}$. & I can avoid interruptions at the office and get work done later. & & & & & \\
\hline $\mathrm{n}$. & My productivity will improve. & & & & & \\
\hline o. & I can work during hours when I am most productive. & & & & & \\
\hline p. & I have autonomy over my own time schedule. & & & & & \\
\hline
\end{tabular}

\begin{tabular}{|c|c|c|c|c|c|c|}
\hline 27. & $\begin{array}{l}\text { In my opinion some of the disadvantages of flexible working } \\
\text { arrangements to me as an employee:- }\end{array}$ & 1 & 2 & 3 & 4 & 5 \\
\hline a. & $\begin{array}{l}\text { My career level might be negatively affected due to not physically being present } \\
\text { in the workplace. }\end{array}$ & & & & & \\
\hline b. & Some of my work might be reassigned to my peer. & & & & & \\
\hline c. & I will miss out on discussions and meetings. & & & & & \\
\hline d. & My interaction with business contacts will be reduced. & & & & & \\
\hline e. & $\begin{array}{l}\text { I will likely be passed over at promotion time because my supervisor does not } \\
\text { see me often enough. }\end{array}$ & & & & & \\
\hline
\end{tabular}




\begin{tabular}{|l|l|l|l|l|l|}
\hline f. & I will have difficulty separating work and home activities. & & & & \\
\hline g. & Distraction at home will be harder to handle than those in the office. & & & & \\
\hline h. & It is stressful to work and look after my children simultaneously. & & & & \\
\hline i. & My supervisor will lose his/her control over me. & & & & \\
\hline j. & My office workspace will be reduced. & & & & \\
\hline k & People at my workplace may react negatively to people using FWA. & & & & \\
\hline m & Social interaction with other employees will be affected & & & & \\
\hline n & Others, please state & & & & \\
\hline
\end{tabular}

\begin{tabular}{|c|c|c|c|c|c|c|}
\hline 28. & $\begin{array}{l}\text { In my opinion some of the advantages of flexible working arrangements to } \\
\text { my organisation :-. }\end{array}$ & 1 & 2 & 3 & 4 & 5 \\
\hline a. & Employee's productivity will improve & & & & & \\
\hline b. & Employee's morale will improve & & & & & \\
\hline c. & $\begin{array}{l}\text { Reduction in overhead costs due to reduced need for office space, transport } \\
\text { claims, utilities bills etc. }\end{array}$ & & & & & \\
\hline d. & Employees turnover or loss of good employees will be reduced & & & & & \\
\hline e. & Sick leave will be reduced & & & & & \\
\hline
\end{tabular}

\begin{tabular}{|l|l|l|l|l|l|l|}
\hline 29. & $\begin{array}{l}\text { In my opinion some of the disadvantages of flexible working } \\
\text { arrangements to my organisation :- }\end{array}$ & 1 & 2 & 3 & 4 & 5 \\
\hline a. & Supervision and management of staff who are on FWA might be difficult. & & & & \\
\hline b. & Work performance evaluation of staff who are on FWA might be difficult & & & & \\
\hline c. & Designing a salary scheme for those on FWA will be difficult & & & & \\
\hline d. & $\begin{array}{l}\text { Public image of the organisation might be adversely affected as clients may } \\
\text { doubt that the staff are not truly working }\end{array}$ & & & & \\
\hline e. & To draw out the initial human resource policies might be difficult & & & & \\
\hline
\end{tabular}

\section{Section VIII - Organisational Issues}

\begin{tabular}{|c|c|c|c|c|c|c|}
\hline A. & Employee Outcomes & 1 & 2 & 3 & 4 & 5 \\
\hline 30. & Job Security & & & & & \\
\hline a. & I feel secure working in this organisation. & & & & & \\
\hline 31. & Job Satisfaction with Work Schedule & & & & & \\
\hline a. & I am satisfied with the ease of getting time off for family as needed & & & & & \\
\hline b. & I am satisfied with the amount of flexibility in work scheduling & & & & & \\
\hline c. & $\begin{array}{l}\text { I am satisfied with the opportunity to perform my job well and yet be able to } \\
\text { perform home related duties adequately. }\end{array}$ & & & & & \\
\hline 32 & Career Satisfaction & & & & & \\
\hline a. & I am satisfied with the success I have achieved in my career. & & & & & \\
\hline b. & $\begin{array}{l}\text { I am satisfied with the progress I have made toward meeting my goals for } \\
\text { income. }\end{array}$ & & & & & \\
\hline c. & $\begin{array}{l}\text { I am satisfied with the progress I have made toward meeting my goals for } \\
\text { advancement. }\end{array}$ & & & & & \\
\hline
\end{tabular}




\begin{tabular}{|c|c|c|c|c|c|c|}
\hline B. & Performance Outcomes & & & & & \\
\hline 33. & & & & & & \\
\hline & & & & & & \\
\hline a. & I feel like "part of the family" in my organisation. & & & & & \\
\hline b. & I am proud to be able to tell people where I work. & & & & & \\
\hline c. & $\begin{array}{l}\text { I am willing to put in a great deal of effort beyond that expected to help this } \\
\text { organisation be successful. }\end{array}$ & & & & & \\
\hline 34. & Loyalty & & & & & \\
\hline a. & I will not leave this company until I retire. & & & & & \\
\hline b. & I will not reveal confidential matters of the company to others. & & & & & \\
\hline c. & I will not leave this company unless I really have no other choice. & & & & & \\
\hline & & & & & & \\
\hline & & 1 & 2 & 3 & 4 & 5 \\
\hline 35. & Supervisor's Support & & & & & \\
\hline a. & $\begin{array}{l}\text { I can freely discuss with my supervisor/ boss on issues regarding my working } \\
\text { arrangements. }\end{array}$ & & & & & \\
\hline b. & $\begin{array}{l}\text { I can rely on my supervisor/boss to provide me with feedback about my job } \\
\text { performance with regards my working arrangements. }\end{array}$ & & & & & \\
\hline c. & $\begin{array}{l}\text { I can rely on my supervisor/boss for assistance when I encounter difficulties } \\
\text { regarding my working arrangements or working time. }\end{array}$ & & & & & \\
\hline 36. & Work Colleagues Support & & & & & \\
\hline a. & $\begin{array}{l}\text { I can rely on my work colleagues for assistance when I encounter difficulties } \\
\text { regarding my working arrangements or working time. }\end{array}$ & & & & & \\
\hline b. & $\begin{array}{l}\text { My work colleagues will generally be supportive of me regardless of my } \\
\text { working arrangement. }\end{array}$ & & & & & \\
\hline
\end{tabular}

Please indicate the extent to which you agree with these statements by ticking (/) at the most appropriate answer.

1-strongly disagree, 2- disagree, 3- neither disagree nor agree, 4-agree, 5- strongly agree

\section{Section IX - Selected Indicators}

\begin{tabular}{|c|c|c|c|c|c|c|}
\hline 37. & Economic Independence & 1 & 2 & 3 & 4 & 5 \\
\hline & Having my own income, & & & & & \\
\hline a. & I have authority on making economic decisions. & & & & & \\
\hline b. & I feel more empowered. & & & & & \\
\hline c. & I feel more self-confident. & & & & & \\
\hline d. & I feel more secure. & & & & & \\
\hline 38. & Decision Making & & & & & \\
\hline & As a working member of the family, & & & & & \\
\hline a. & $\begin{array}{l}\text { I have significant control over decisions involving finance and purchases of } \\
\text { assets. }\end{array}$ & & & & & \\
\hline b. & I have significant control over decisions involving ownership of assets. & & & & & \\
\hline c. & $\begin{array}{l}\text { I have significant influence over my personal spending for health, recreation } \\
\text { and other personal needs. }\end{array}$ & & & & & \\
\hline 39. & Lifestvles & & & & & \\
\hline
\end{tabular}




\begin{tabular}{|c|c|c|c|c|c|c|}
\hline & As a working women, I have enough time & & & & & \\
\hline a. & to socialise and spend with friends. & & & & & \\
\hline b. & to spend for my personal needs. & & & & & \\
\hline c. & to participate in recreational activities. (sports, gymnasium, etc) & & & & & \\
\hline 40. & Health & & & & & \\
\hline a. & I have enough time to spend on my personal health needs & & & & & \\
\hline b. & I feel stressed working in this organisation & & & & & \\
\hline c. & I face occupational hazards which affect my health. & & & & & \\
\hline 41. & Work-life Balance & & & & & \\
\hline a. & After work, I come home too tired to do some of the things I'd like to do. & & & & & \\
\hline b. & $\begin{array}{l}\text { On the job, I have so much to do that it takes away from my personal } \\
\text { interest. }\end{array}$ & & & & & \\
\hline c. & My personal demands are too great that it takes me away from my work. & & & & & \\
\hline \multirow[t]{2}{*}{ d. } & My office culture makes it easy to balance work and family responsibilities. & & & & & \\
\hline & & 1 & 2 & 3 & 4 & 5 \\
\hline 42. & Decision to participate in the Labour Force & & & & & \\
\hline a. & $\begin{array}{l}\text { In my opinion, flexible working arrangements may have an effect on the } \\
\text { decision for women to go out to work. }\end{array}$ & & & & & \\
\hline b. & $\begin{array}{l}\text { A good childcare system might enable more married women into the labour } \\
\text { force. }\end{array}$ & & & & & \\
\hline
\end{tabular}

43. Do you have intentions of stopping work before retirement age?
a. If Yes, please go to Q 44
b. If No, please go to Q 45

44. Please write in the box the two main reasons which might make you want to stop working before the retirement age. (1-most important \& 2-second important)
a. Pregnancy.
b. To take care of child/children.
c. To take care of elderly people.
d. To continue studies.
e. Not satisfied with working conditions.
f. Not satisfied with working hours.
g. Health reasons.
h. Financially stable household
i. Others, please state

45. Please tick two main reasons which makes you continue working.
a. Financial Independence
b. Personal Satisfaction
c. Ability to have control over financial decision making
d. Career Aspirations
e. Others, please state

\section{Section X}

Please give your opinion on why some educated women are not working 
2. Please comment on whether flexible working arrangements can be implemented in the present economic situation.

Thank you very much for your valuable time \& cooperation in participating in my study. If you would like to contribute further, please contact Geetha at 0123191363 or geethamaniam@gmail.com 
APPENDIX 4-2

Questionnaire for Female Employees in non-FWA Organisations 


\section{Code Number}

\section{Flexible Working Arrangements In Malaysia and The Participation of Women in the Labour Force}

Dear Valued Participants,

I am a PhD student in Victoria University of Wellington, New Zealand. As part of this degree, I am undertaking a research project examining flexible working arrangements in Malaysia. This study will focus on women employees working in the services sector in a few selected organisations.

As we all have commitments and responsibilities at work and outside work, it sometimes becomes a struggle to juggle work and life successfully. In spite of this, many women enjoy working and hence participate in the labour force.

Flexible working arrangements entail a partnership between women, family and the organisation. The education sector is one of the main sectors in the services industry which provides women employment with flexible working hours. These flexible work policies benefit both employees and also the organisation. In Malaysia, very few organisations have implemented flexible working arrangements and this organisation is one of the educational institutions which have flexible working arrangements.

The main aim of this study is to evaluate your perception towards how women, family and the organisation collaborate in flexible working arrangements at your workplace. The study also looks at whether these work arrangements will have an effect on the well-being of working women.

Your response to this survey is completely confidential. Thank you very much for your participation.

\section{Instructions: Please mark (x) in the box which applies to you.}

\section{Section I - Job Related Characteristics}

1. Occupational level

a. Senior Management level (MD,GM)

b. Middle Management level

c. Executives/Officers
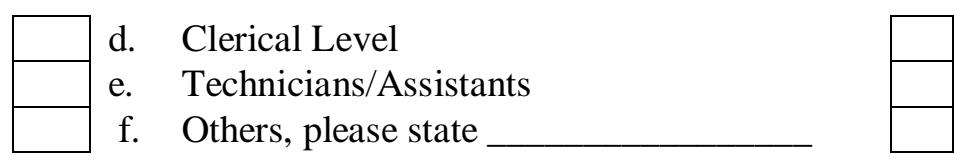

2. Time taken to travel from home to workplace

3. Distance between home and workplace

4. Mode of transport to work 


\section{Section II - Income \& Expenditure}

5. Personal Income (Monthly)
a. RM 1000 - RM 2000
b. RM 2001 - RM 3000
c. RM 3001 - RM 4000

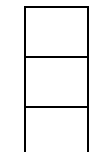
d. RM 4001 - RM 5000
e. $\mathrm{RM} 5001$ - RM 7000
f. Above RM 7000

6. Household Income (Monthly)
a. RM 1000 - RM 3000
b. RM $3001-$ RM 5000
c. RM 5001 - RM 7000

\begin{tabular}{|ll}
\hline d. & RM 7001 - RM 9000 \\
e. & RM 9001 - RM 11000 \\
f. & Above RM 11000
\end{tabular}

7. Average Family Expenditure (Monthly)
a. $\mathrm{RM} 1000$ - RM 3000
b. RM 3001 - RM 5000
c. RM 5001 - RM 7000

d. RM 7001 - RM 9000

e. RM 9001- RM 11000

f. Above RM 11000

\section{$\underline{\text { Section III - Cultural factors }}$}

8. Race
a. Malay
b. Chinese

c. Indian

d. Others, please state ....

9. Place of Birth

10. Current Place of Residence

Please tick the answer which best describes the statements below with regards to support.

0 - not applicable, 1- no support, 2- very little support, 3-little support, 4supportive, 5 - very supportive.

\begin{tabular}{|c|c|c|c|c|c|c|c|}
\hline & & 0 & 1 & 2 & 3 & 4 & 5 \\
\hline 11. & My husband is supportive towards my working outside the home. & & & & & & \\
\hline 12. & $\begin{array}{l}\text { In my opinion, our society is supportive towards women working outside } \\
\text { the home. }\end{array}$ & & & & & & \\
\hline
\end{tabular}

\section{$\underline{\text { Section IV - Family Responsibilities }}$}

13. How many children do you have?

14. How many children are aged 6 years and below?

15. How many children are aged between 6 years and 12 years?

16. How many children are aged between 13 years and 18 years?

17. Do you take care of elderly parents or relatives? Yes/No

18. In your opinion, what would be the most suitable type of childcare facility most women need nowadays. (Provided at workplace, At residential place, Nursery, Community Centres etc) 
19. Please tick the answer which best describes the extent of help given by family members or others with your household responsibilities and caring tasks.

0 - not applicable, 1 - no help, 2 - very little help, 3 - little help, 4 - helpful, 5-very helpful

\begin{tabular}{|c|c|c|c|c|c|c|c|}
\hline & & 0 & 1 & 2 & 3 & 4 & 5 \\
\hline a. & Husband - housework & & & & & & \\
\hline b. & Husband - childcare & & & & & & \\
\hline c. & Mother/Father - childcare & & & & & & \\
\hline d. & Paid helper, please state nationality & & & & & & \\
\hline e. & Others, please state & & & & & & \\
\hline
\end{tabular}

\section{$\underline{\text { Section V - Demographic Profile }}$}

20. Age
a. 20 - 29 years
b. $\quad 30-39$ years
c. $40-49$ years

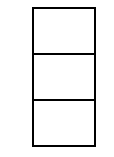

d. $50-59$ years

e. 60 years and above

21. Highest Educational Level Achieved
a. SPM / "O" Level
b. STPM / "A" Level
c. Diploma
$\square$ d. Degree/ Professional Course
e. Post Graduate
f. Others, please state

22. Marital Status
a. Married
b. Single

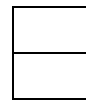
c. Single Mother
d. Others, please state .....

23. Type of home living presently
a. Single Storey Link
b. Double Storey Link
c. Semi Detached

d. Bungalow

e. Apartments/Flats

f. Others, please state

\section{Section VI - Flexible Working Arrangements (FWA) \& Work Policies}

Flexible working arrangements can be in the form of flexi hours, part-time work, working from the home, teleworking, job sharing, compressed week etc.

24. a. Various types of FWA are offered at your workplace. Are you interested in FWA? Yes/No ...

b. Have you used any form of FWA at your workplace in the last one year? Yes/No

c. Name two common types of FWA used in the last one year. 
Please indicate the extent to which you agree with these statements by ticking (/) at the most appropriate answer.

\section{1-strongly disagree, 2- disagree, 3-neither disagree nor agree, 4-agree, 5- strongly agree}

\section{Section VII - Perceived Advantages and Disadvantages of Flexible Working Arrangements (FWA)}

\begin{tabular}{|c|c|c|c|c|c|c|}
\hline 26. & $\begin{array}{l}\text { In my opinion, some of the advantages of flexible working } \\
\text { arrangements to me as an employee could result in:- }\end{array}$ & 1 & 2 & 3 & 4 & 5 \\
\hline a. & My stress level will be reduced & & & & & \\
\hline b. & My morale will improve because I feel treated as a responsible professional. & & & & & \\
\hline c. & My job satisfaction will increase. & & & & & \\
\hline d. & My loyalty and job commitment will increase & & & & & \\
\hline e. & My quality of work will improve & & & & & \\
\hline f. & It will have a favourable effect on relations with my spouse. & & & & & \\
\hline g. & It will have a favourable effect on relations with my parents. & & & & & \\
\hline h. & It will have a favourable effect on relations with my children. & & & & & \\
\hline i. & It will have a favourable effect on relations with my siblings. & & & & & \\
\hline j. & It will allow more time for family. & & & & & \\
\hline $\mathrm{k}$. & It will allow more time for networking. & & & & & \\
\hline 1. & I can save on commuting time. & & & & & \\
\hline $\mathrm{m}$. & I can avoid interruptions at the office and get work done later. & & & & & \\
\hline n. & My productivity will improve. & & & & & \\
\hline o. & I can work during hours when I am most productive. & & & & & \\
\hline $\mathrm{p}$. & I have autonomy over my own time schedule. & & & & & \\
\hline 27. & $\begin{array}{l}\text { In my opinion some of the disadvantages of flexible working } \\
\text { arrangements to me as an employee could result in:- }\end{array}$ & 1 & 2 & 3 & 4 & 5 \\
\hline a. & $\begin{array}{l}\text { My career level might be negatively affected due to not physically being present } \\
\text { in the workplace. }\end{array}$ & & & & & \\
\hline b. & Some of my work might be reassigned to my peer. & & & & & \\
\hline c. & I will miss out on discussions and meetings. & & & & & \\
\hline d. & My interaction with business contacts will be reduced. & & & & & \\
\hline e. & $\begin{array}{l}\text { I will likely be passed over at promotion time because my supervisor does not } \\
\text { see me often enough. }\end{array}$ & & & & & \\
\hline f. & I will have difficulty separating work and home activities. & & & & & \\
\hline g. & Distraction at home will be harder to handle than those in the office. & & & & & \\
\hline h. & It is stressful to work and look after my children simultaneously. & & & & & \\
\hline i. & My supervisor will lose his/her control over me. & & & & & \\
\hline $\mathrm{j}$. & My office workspace will be reduced. & & & & & \\
\hline $\mathrm{k}$ & People at my workplace may react negatively to people using FWA. & & & & & \\
\hline $\mathrm{m}$ & Social interaction with other employees will be affected & & & & & \\
\hline $\mathrm{n}$ & Others, please state & & & & & \\
\hline
\end{tabular}




\begin{tabular}{|c|c|c|c|c|c|c|}
\hline 28. & $\begin{array}{l}\text { In my opinion some of the advantages of flexible working arrangements to } \\
\text { my organisation could result in :-. }\end{array}$ & 1 & 2 & 3 & 4 & 5 \\
\hline a. & Employee's productivity will improve & & & & & \\
\hline b. & Employee's morale will improve & & & & & \\
\hline c. & $\begin{array}{l}\text { Reduction in overhead costs due to reduced need for office space, transport } \\
\text { claims, utilities bills etc. }\end{array}$ & & & & & \\
\hline d. & Employees turnover or loss of good employees will be reduced & & & & & \\
\hline e. & Sick leave will be reduced & & & & & \\
\hline
\end{tabular}

\begin{tabular}{|l|l|l|l|l|l|l|}
\hline 29. & $\begin{array}{l}\text { In my opinion some of the disadvantages of flexible working } \\
\text { arrangements to my organisation could result in:- }\end{array}$ & 1 & 2 & 3 & 4 & 5 \\
\hline a. & Supervision and management of staff who are on FWA might be difficult. & & & & & \\
\hline b. & Work performance evaluation of staff who are on FWA might be difficult & & & & \\
\hline c. & Designing a salary scheme for those on FWA will be difficult & & & & \\
\hline d. & $\begin{array}{l}\text { Public image of the organisation might be adversely affected as clients may } \\
\text { doubt that the staff are not truly working }\end{array}$ & & & & \\
\hline e. & To draw out the initial human resource policies might be difficult & & & & \\
\hline
\end{tabular}

\section{Section VIII - Organisational Issues}

Please indicate the extent to which you agree with these statements by ticking $(/)$ at the most appropriate answer.

\section{1-strongly disagree, 2- disagree, 3- neither disagree nor agree, 4-agree, 5- strongly agree}

\begin{tabular}{|c|c|c|c|c|c|c|}
\hline A. & Employee Outcomes & 1 & 2 & 3 & 4 & 5 \\
\hline 30. & Job Security & & & & & \\
\hline a. & I feel secure working in this organisation. & & & & & \\
\hline 31. & Job Satisfaction with Work Schedule & & & & & \\
\hline a. & I am satisfied with the ease of getting time off for family as needed & & & & & \\
\hline b. & I am satisfied with the amount of flexibility in work scheduling & & & & & \\
\hline c. & $\begin{array}{l}\text { I am satisfied with the opportunity to perform my job well and yet be } \\
\text { able to perform home related duties adequately. }\end{array}$ & & & & & \\
\hline 32 & Career Saticfaction & & & & & \\
\hline a. & I am satisfied with the success I have achieved in my career. & & & & & \\
\hline b. & $\begin{array}{l}\text { I am satisfied with the progress I have made toward meeting my goals for } \\
\text { income. }\end{array}$ & & & & & \\
\hline c. & $\begin{array}{l}\text { I am satisfied with the progress I have made toward meeting my goals for } \\
\text { advancement. }\end{array}$ & & & & & \\
\hline B. & Performance Outcomes & & & & & \\
\hline 33. & Organisational Commitment & & & & & \\
\hline a. & I feel like "part of the family" in my organisation. & & & & & \\
\hline b. & I am proud to be able to tell people where I work. & & & & & \\
\hline c. & $\begin{array}{l}\text { I am willing to put in a great deal of effort beyond that expected to help } \\
\text { this organisation be successful. }\end{array}$ & & & & & \\
\hline & & & & & & \\
\hline
\end{tabular}




\begin{tabular}{|c|c|c|c|c|c|c|}
\hline 34. & Lovalty & & & & & \\
\hline a. & I will not leave this company until I retire. & & & & & \\
\hline b. & I will not reveal confidential matters of the company to others. & & & & & \\
\hline c. & I will not leave this company unless I really have no other choice. & & & & & \\
\hline & & & & & & \\
\hline & & 1 & 2 & 3 & 4 & 5 \\
\hline 35. & Supervisor's Support & & & & & \\
\hline a. & $\begin{array}{l}\text { I can freely discuss with my supervisor/ boss on issues regarding my } \\
\text { working arrangements. }\end{array}$ & & & & & \\
\hline b. & $\begin{array}{l}\text { I can rely on my supervisor/boss to provide me with feedback about my } \\
\text { job performance with regards my working arrangements. }\end{array}$ & & & & & \\
\hline c. & $\begin{array}{l}\text { I can rely on my supervisor/boss for assistance when I encounter } \\
\text { difficulties regarding my working arrangements or working time. }\end{array}$ & & & & & \\
\hline 36. & Work Colleagues Support & & & & & \\
\hline a. & $\begin{array}{l}\text { I can rely on my work colleagues for assistance when I encounter } \\
\text { difficulties regarding my working arrangements or working time. }\end{array}$ & & & & & \\
\hline b. & $\begin{array}{l}\text { My work colleagues will generally be supportive of me regardless of my } \\
\text { working arrangement. }\end{array}$ & & & & & \\
\hline
\end{tabular}

\section{Section IX - Selected Indicators}

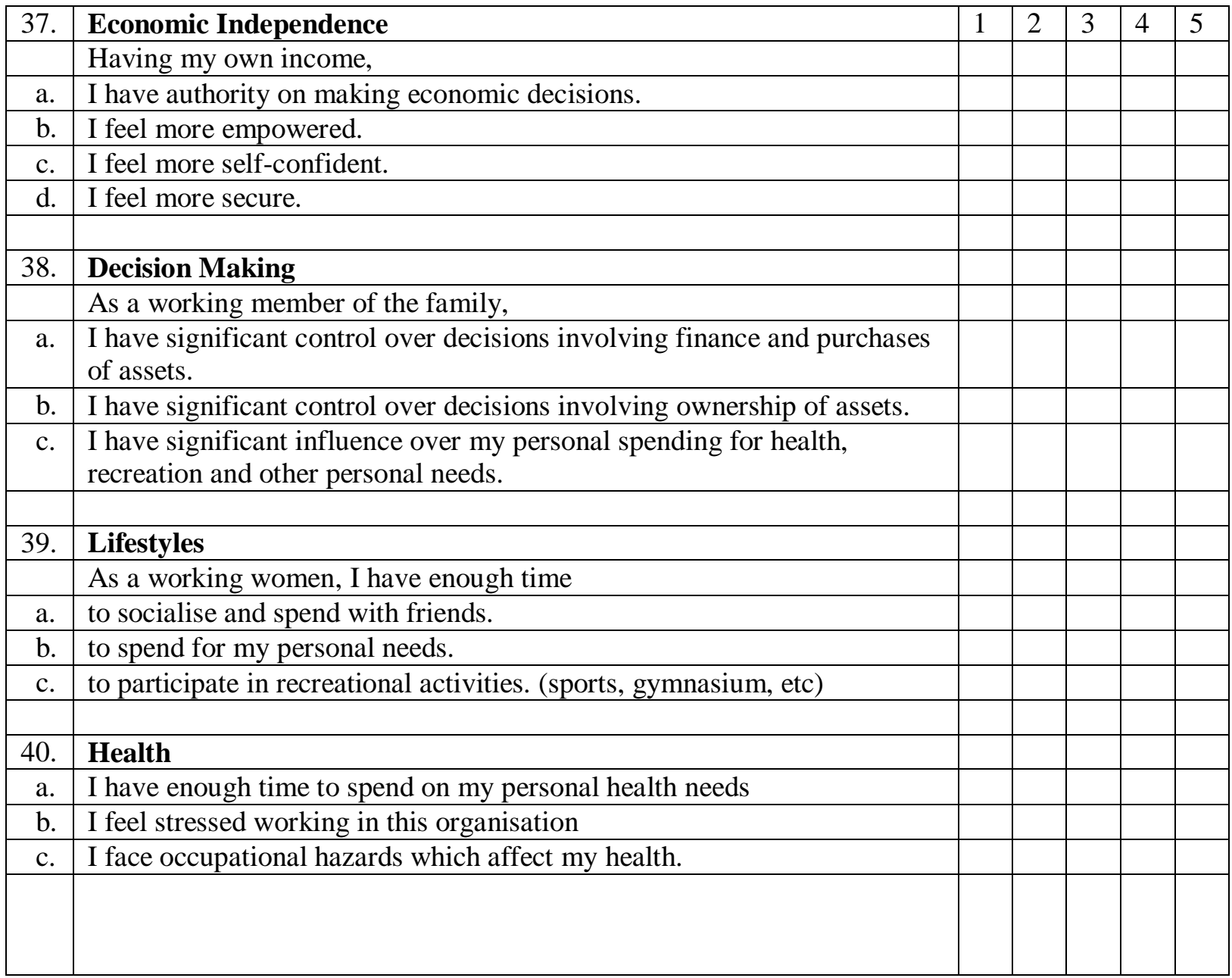




\begin{tabular}{|c|c|c|c|c|c|c|}
\hline 41. & Work-life Balance & & & & & \\
\hline a. & After work, I come home too tired to do some of the things I'd like to do. & & & & & \\
\hline b. & $\begin{array}{l}\text { On the job, I have so much to do that it takes away from my personal } \\
\text { interest. }\end{array}$ & & & & & \\
\hline c. & My personal demands are too great that it takes me away from my work. & & & & & \\
\hline d. & $\begin{array}{l}\text { My office culture makes it easy to balance work and family } \\
\text { responsibilities. }\end{array}$ & & & & & \\
\hline & & 1 & 2 & 3 & 4 & 5 \\
\hline 42. & Decision to participate in the Labour Force & & & & & \\
\hline a. & $\begin{array}{l}\text { In my opinion, flexible working arrangements may have an effect on the } \\
\text { decision for women to go out to work. }\end{array}$ & & & & & \\
\hline b. & $\begin{array}{l}\text { A good childcare system might enable more married women into the } \\
\text { labour force. }\end{array}$ & & & & & \\
\hline
\end{tabular}

43. Do you have intentions of stopping work before retirement age?

a. If Yes, please go to Q 44

b. If No, please go to $\mathrm{Q} 45$

44. Please write in the box the two main reasons which might make you want to stop working before the retirement age. (1-most important \& 2-second important)
a. Pregnancy.
b. To take care of child/children.
c. To take care of elderly people.
d. To continue studies.
e. Not satisfied with working conditions.
f. Not satisfied with working hours.
g. Health reasons.
h. Financially stable household
i. Others, please state

45. Please tick two main reasons which makes you continue working.
a. Financial Independence
b. Personal Satisfaction
c. Ability to have control over financial decision making
d. Career Aspirations
e. Others, please state

\section{Section X}

Please give your opinion on why some educated women are not working

2. Please comment on whether flexible working arrangements can be implemented in the present economic situation.

Thank you very much for your valuable time $\&$ cooperation in participating in my study. If you would like to contribute further, please contact Geetha at 0123191363 or geethamaniam@gmail.com 
APPENDIX 4-3

Structured Interview Questionnaire for Female Employees in FWA Organisations 


\section{List of Areas to Discuss - Female Employees in FWA}

\section{Flexible Working Arrangements In Malaysia and The Participation of Women in the Labour Force}

1. Introduce myself and objectives of research and show proof of documentation.

2. Get them to fill up some details about their demographic profile, socioeconomic profile and family responsibilities by giving them the survey questionnaire.

3. Basically, please give me an account of what you do in a normal day.... From the time you wake up until you go to sleep.

4. Women and Paid Labour
i) What can you say about women's participation in paid labour in Malaysia
ii) How many women staff are there in this department/company
iii) In which department are they concentrated? What's the nature of their job?

5. Conditions of Work
i) Flexible Working Arrangements (FWA)
What type of flexible working arrangements does your organisation implement? Flexitime, Teleworking, Part time work, Compressed week, Job sharing etc.
ii). What are the other types of family friendly policies that your organisation has implemented?
iii) What made your organisation implement this mode of working arrangement?

$6 \quad$ Impact on Employee
i). What's your opinion on staff morale and productivity as a result of FWA/FFP?
ii). Is there any difference after implementing FWA?
iii) What are some of the benefits/pros from FWA/FPP
iv) What are some of the disadvantages from FWA/FPP?

7. Employers/ Managers/Heads Opinion

1) What are some of the challenges you face in implementing this work policy?

8. How do you think working in paid labour has an effect on your
i.) Social life
ii) Family Life
iii) Decision Making at Home
iv) Spending Pattern 
9. How employees/ staff union are involved?

10 Government's Encouragement/ Policy

11. Any other comments in relation to FWA/FPP?

12. In your opinion, do you think that flexible working arrangements might encourage more women to work? Discuss and prompt participant.

13. Do you think that if more women work in paid labour, there will be an effect on economic development? Discuss

Express gratitude for the invaluable time and support. Mention that the suggestions, opinions and insight from employees' perspective will help me in my study. 


\section{APPENDIX 4-4}

Structured Interview Questionnaire for Female Employees in non-FWA Organisations 
List of Areas to Discuss - Female Employees in Non-FWA organisations

\section{Flexible Working Arrangements In Malaysia and The Participation of Women in the Labour Force}

1. Introduce myself and objectives of research and show proof of documentation.

2. Get them to fill up some details about their demographic profile, socioeconomic profile and family responsibilities by giving them the survey questionnaire

3. Women and Paid Labour

i) What can you say about women's participation in paid labour in Malaysia

ii) How many women staff are there in this department/company

iii) In which department are they concentrated? What's the nature of their job?

4. Basically, please give me an account of what you do in a normal day.... From the time you wake up until you go to sleep.

5. Conditions of Work

i) Fixed Working Arrangements

ii). What are the other types of family friendly policies that your organisation has implemented?

iii) Are you interested in Flexible Working Arrangements (FWA) If yes,.what type of flexible working arrangements will you be interested?

Flexitime, Teleworking, Part time work, Compressed week, Job sharing etc.

$6 \quad$ Impact on Employee

i) What are some of the benefits/pros you might expect from FWA/FPP

ii) What are some of the disadvantages you might expect from FWA/FPP?

7 Employers/ Managers/Heads Opinion

1) What are some of the challenges you face in implementing this work policy?

8 How do you think working in paid labour has an effect on your

i.) Social life

ii) Family Life

iii) Decision Making at Home 
9. How employees/ staff union are involved?

10 Government's Encouragement/ Policy

12. Any other comments in relation to FWA/FPP?

13. In your opinion, do you think that flexible working arrangements might encourage more women to work? Discuss and prompt participant.

14. Do you think that if more women work in paid labour, there will be an effect on economic development? Discuss

'Express gratitude for the invaluable time and support.

Mention that the suggestions, opinions and insight from employees'

perspective will help me in my study. 


\section{APPENDIX 4.5 - Cover Letter For Questionnaire \\ TE WHARE WĀNANGA O TE OPOKO O TE IKA A MĀUI

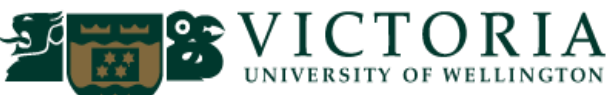

\section{FLEXIBLE WORKING ARRANGEMENTS IN MALAYSIA AND THE PARTICIPATION OF WOMEN IN THE LABOUR FORCE}

I'm a PhD student in the Development Studies Department, School of Geography, Environment and Earth Sciences, Faculty of Science at Victoria University of Wellington, New Zealand. As part of this degree I am undertaking a research project leading to a thesis. I am currently engaged in a research project to study flexible working arrangements in Malaysia.

Your participation in this study is voluntary and if you consent, please answer the questionnaire which will take approximately 20 minutes.

If you agree to participate in this study, you have the right to:

- refuse to answer any particular question and to withdraw from the study at any time,

- ask any further questions about the study,

- be given access to a summary of the findings from the study when it is completed.

I would like to assure you that your response to this questionnaire is strictly confidential

Should you require further information, please do not hesitate to contact me or my supervisor.

Thank you very much for your valuable time and cooperation.

Researcher's Name and

Contact Information

\section{GEETHA SUBRAMANIAM}

Development Studies Department,

School of Geography, Environment and

Earth Sciences

Faculty of Science

Victoria University of Wellington,

Wellington,

New Zealand

Telephone - 60123191363 (Malaysia)

Email-geethamaniam@gmail.com
Supervisor's Name and

Contact Information

PROFESSOR JOHN OVERTON

Development Studies Department,

School of Geography, Environment and Earth Sciences,

Faculty of Science

Victoria University of Wellington

Wellington,

New Zealand

Telephone : +64 44635281 (O)

Email - john.overton@vuw.ac.nz 


\title{
APPENDIX 4.6 Consent Form for Interview Participants
}

\author{
TE WHARE WĀNANGA O TE OPOKO O TE IKA A MĀUI

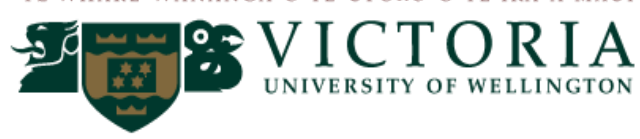 \\ FLEXIBLE WORKING ARRANGEMENTS IN MALAYSIA AND THE \\ PARTICIPATION OF WOMEN IN THE LABOUR FORCE
}

\section{Consent To Participate In Research}

I have been given and have understood an explanation of this research project. I have had an opportunity to ask questions and have them answered to my satisfaction. I understand that I may withdraw myself (or any information I have provided) from this project (before data collection and analysis is complete) without having to give reasons or without penalty of any sort.

I understand that any information I provide will be kept confidential to the researcher, the supervisor and the person who transcribes the tape recordings of our interview. I also understand that the published results will not use my name, and that no opinions will be attributed to me in any way that will identify me. I understand that the tape recording of interviews will be electronically wiped at the end of the project unless I indicate that I would like them returned to me.

I agree to take part in this research

Signed

Name of Participant

Date:

Researcher's Name and

Contact Information

\section{GEETHA SUBRAMANIAM}

Development Studies Department,

School of Geography, Environment and and

Earth Sciences

Faculty of Science

Victoria University of Wellington,

Wellington,

New Zealand

Telephone - 60123191363 (Malaysia)

Email-geethamaniam@gmail.com

\author{
Supervisor's Name and \\ Contact Information
}

PROFESSOR JOHN OVERTON

Development Studies Department,

School of Geography, Environment

Earth Sciences,

Faculty of Science

Victoria University of Wellington

Wellington,

New Zealand

Telephone : +64 44635281 (O)

Email -john.overton@vuw.ac.nz 


\section{APPENDIX 4.7 - Information Sheet for Survey Participants FLEXIBLE WORKING ARRANGEMENTS IN MALAYSIA AND THE PARTICIPATION OF WOMEN IN THE LABOUR FORCE}

\section{Researcher:}

Geetha Subramaniam, Development Studies Department, School of Geography, Environment and Earth Sciences, Faculty of Science, Victoria University of Wellington, New Zealand.

\section{Overview}

I am a PhD student in the Development Studies Department, Faculty of Science at Victoria University of Wellington, New Zealand. As part of this degree I am undertaking a research project leading to a thesis.

\section{Objectives of Study}

1. To investigate the factors which influence the uptake of flexible working arrangements by both employers and employees at the workplace.

1. To examine the impact of flexible working arrangements on the socio-economic status of women.

3. To assess the contribution of flexible working arrangements towards the aim of increasing the female labour force participation in the Malaysian economy.

As a requirement of the university, ethics approval has been obtained from the Victoria University of Wellington Ethics Committee prior to commencement of this research.

\section{What do you need to do and how long will it take?}

As part of my study, I am inviting women who are working in your company to participate in this study. Participants will be asked to complete a questionnaire. It is envisaged that the questionnaire will take about 20 minutes to complete and may be completed in your own time. I will collect the questionnaire personally from you once you have completed it.

\section{Declaration to participants}

Should any participant feel the need to withdraw from the project, they may do so without question at any time before the data is analysed. Just let me know at the time.

\section{What will happen to the information collected?}

Responses collected will form the basis of my Ph.D thesis. All material collected will be kept confidential. No other person besides me and my supervisors will see the questionnaires. No participants will be named in the research report. The thesis will be submitted for marking to the Development Studies Department, Faculty of Science, Victoria University of Wellington and deposited in the Victoria University Library, Wellington, the University Malaya Library, Universiti Teknologi MARA Library and the National Library Malaysia. It is intended that one or more articles will be submitted for publication in scholarly journals. Questionnaires will be destroyed three years after the end of the project.

If you would like to contribute further in this survey by participating in a short interview, please contact me at geethamaniam@gmail.com. This gesture will be really appreciated and it will only take 30 minutes. If you have any questions or would like to receive further information about the project, please contact me at geethamaniam@gmail.com or 6012 3191363, or my supervisor, Professor John Overton, at john.overton@vuw.ac.nz. or (04) 463-5281 at the Development Studies Department, Faculty of Science at Victoria University, P O Box 600, Wellington, 


\section{APPENDIX 5.1 - Cross Tabulation Tables for Work Type}

Frequency Table for Work Type

\begin{tabular}{|l|c|c|c|c|}
\hline & Frequency & Percent & Valid Percent & $\begin{array}{c}\text { Cumulative } \\
\text { Percent }\end{array}$ \\
\hline FWA & 225 & 56.8 & 56.8 & 56.8 \\
Non FWA & 171 & 43.2 & 43.2 & 100.0 \\
Total & 396 & 100.0 & 100.0 & \\
\hline
\end{tabular}

Mean and Std. Deviation for Work Type

\begin{tabular}{|c|c|c|c|c|}
\hline $\begin{array}{l}\text { Work } \\
\text { Type }\end{array}$ & $\mathrm{N}$ & Mean & Std. Deviation & Std. Error Mean \\
\hline FWA & 225 & 1.0933 & .29155 & .01944 \\
$\begin{array}{l}\text { Non } \\
\text { FWA }\end{array}$ & 171 & 1.1988 & .40029 & .03061 \\
\hline
\end{tabular}

Significance Level

\begin{tabular}{|c|c|c|c|c|c|}
\hline & $\mathrm{F}$ & Sig. & $\mathrm{t}$ & df & $\begin{array}{l}\text { Sig. (2- } \\
\text { tailed) }\end{array}$ \\
\hline $\begin{array}{l}\text { Interested in } \\
\text { FWA }\end{array}$ & 37.986 & .000 & -3.034 & 394 & .003 \\
\hline & & & -2.909 & 297.952 & .004 \\
\hline
\end{tabular}




\section{APPENDIX 5.2 - Logistic Regression Output}

\begin{tabular}{|c|c|c|c|}
\hline \multicolumn{4}{|c|}{ Case Processing Summary } \\
\hline & & $\mathrm{N}$ & $\begin{array}{l}\text { Marginal } \\
\text { Percentage }\end{array}$ \\
\hline \multirow[t]{2}{*}{ Interested in FWA } & yes & 325 & $86.2 \%$ \\
\hline & no & 52 & $13.8 \%$ \\
\hline \multirow[t]{4}{*}{ Race } & Malay & 205 & $54.4 \%$ \\
\hline & Chinese & 85 & $22.5 \%$ \\
\hline & Indian & 77 & $20.4 \%$ \\
\hline & Others & 10 & $2.7 \%$ \\
\hline \multirow[t]{4}{*}{ Age } & $20-29$ & 161 & $42.7 \%$ \\
\hline & $30-39$ & 145 & $38.5 \%$ \\
\hline & $40-49$ & 50 & $13.3 \%$ \\
\hline & 50 and above & 21 & $5.6 \%$ \\
\hline \multirow[t]{2}{*}{ Marital Status } & married & 234 & $62.1 \%$ \\
\hline & single & 143 & $37.9 \%$ \\
\hline \multirow{5}{*}{$\begin{array}{l}\text { Highest Educational } \\
\text { Level (Self) }\end{array}$} & STPM & 23 & $6.1 \%$ \\
\hline & Diploma & 87 & $23.1 \%$ \\
\hline & Degree & 141 & $37.4 \%$ \\
\hline & Post graduate & 47 & $12.5 \%$ \\
\hline & SPM & 79 & $21.0 \%$ \\
\hline \multirow{2}{*}{$\begin{array}{l}\text { Take care of elderly } \\
\text { parents }\end{array}$} & Yes & 165 & $43.8 \%$ \\
\hline & No & 212 & $56.2 \%$ \\
\hline \multirow[t]{4}{*}{ Mode of transport } & car & 296 & $78.5 \%$ \\
\hline & Public transport & 43 & $11.4 \%$ \\
\hline & motorcycle & 20 & $5.3 \%$ \\
\hline & company transport & 18 & $4.8 \%$ \\
\hline \multirow[t]{2}{*}{ Work Type } & FWA & 216 & $57.3 \%$ \\
\hline & Non FWA & 161 & $42.7 \%$ \\
\hline \multirow[t]{6}{*}{ Personal Income } & RM 1000- RM 2000 & 140 & $37.1 \%$ \\
\hline & $\begin{array}{l}\text { RM } 2001 \text { - RM } \\
3000\end{array}$ & 89 & $23.6 \%$ \\
\hline & RM 3001- RM 4000 & 41 & $10.9 \%$ \\
\hline & RM 4001- RM 5000 & 20 & $5.3 \%$ \\
\hline & RM 5001- RM 7000 & 45 & $11.9 \%$ \\
\hline & above RM 7000 & 42 & $11.1 \%$ \\
\hline Valid & & 377 & $100.0 \%$ \\
\hline Missing & & 19 & \\
\hline Total & & 396 & \\
\hline Subpopulation & & $377^{\mathrm{a}}$ & \\
\hline
\end{tabular}

a. The dependent variable has only one value observed in 377

(100.0\%) subpopulations. 
Step Summary

\begin{tabular}{|c|c|c|c|c|c|c|}
\hline \multirow[b]{2}{*}{ Model } & \multirow[b]{2}{*}{ Action } & \multirow[b]{2}{*}{ Effect(s) } & $\begin{array}{c}\text { Model } \\
\text { Fitting } \\
\text { Criteria }\end{array}$ & \multicolumn{3}{|c|}{ Effect Selection Tests } \\
\hline & & & $\begin{array}{c}-2 \text { Log } \\
\text { Likelih } \\
\text { ood }\end{array}$ & $\begin{array}{c}\text { Chi- } \\
\text { Square }\end{array}$ & $\mathrm{df}$ & Sig. \\
\hline 0 & Entered & Intercept & 302.497 & & & \\
\hline 1 & Entered & $\begin{array}{l}\text { Family } \\
\text { Relationship }\end{array}$ & 285.492 & 17.005 & 1 & .000 \\
\hline 2 & Entered & $\begin{array}{l}\text { Educational } \\
\text { Level }\end{array}$ & 269.994 & 15.498 & 4 & .004 \\
\hline 3 & Entered & \begin{tabular}{|l} 
Career \\
Progress
\end{tabular} & 266.088 & 3.905 & 1 & .048 \\
\hline
\end{tabular}

Stepwise Method: Forward Entry

a. The chi-square for entry is based on the likelihood ratio test.

\begin{tabular}{|c|c|c|c|c|}
\hline \multirow[b]{3}{*}{ Model } & \multicolumn{4}{|c|}{ Model Fitting Information } \\
\hline & $\begin{array}{l}\text { Model } \\
\text { Fitting } \\
\text { Criteria }\end{array}$ & Likel & d Ratio & \\
\hline & $\begin{array}{c}-2 \text { Log } \\
\text { Likelihood }\end{array}$ & Chi-Square & df & Sig. \\
\hline Intercept Only & 302.497 & & & \\
\hline Final & 266.088 & 36.409 & 6 & .000 \\
\hline
\end{tabular}


Pseudo R-Square

\begin{tabular}{|l|r|}
\hline Cox and Snell & .092 \\
Nagelkerke & .167 \\
McFadden & .120 \\
\hline
\end{tabular}

Likelihood Ratio Tests

\begin{tabular}{|c|c|c|c|c|}
\hline \multirow[b]{2}{*}{ Effect } & $\begin{array}{c}\text { Model Fitting } \\
\text { Criteria }\end{array}$ & \multicolumn{3}{|c|}{ Likelihood Ratio Tests } \\
\hline & $\begin{array}{c}-2 \text { Log } \\
\text { Likelihood of } \\
\text { Reduced } \\
\text { Model }\end{array}$ & Chi-Square & $d f$ & Sig. \\
\hline Intercept & $2.661 \mathrm{E} 2$ & .000 & 0 & \\
\hline Career Progress & 269.994 & 3.905 & 1 & .048 \\
\hline Family Relationship & 277.603 & 11.514 & 1 & .001 \\
\hline Educational Level & 281.190 & 15.102 & 4 & .004 \\
\hline
\end{tabular}

The chi-square statistic is the difference in -2 log-likelihoods between the final model and a reduced model. The reduced model is formed by omitting an effect from the final model. The null hypothesis is that all parameters of that effect are 0 .

a. This reduced model is equivalent to the final model because omitting the effect does not increase the degrees of freedom 
Parameter Estimates

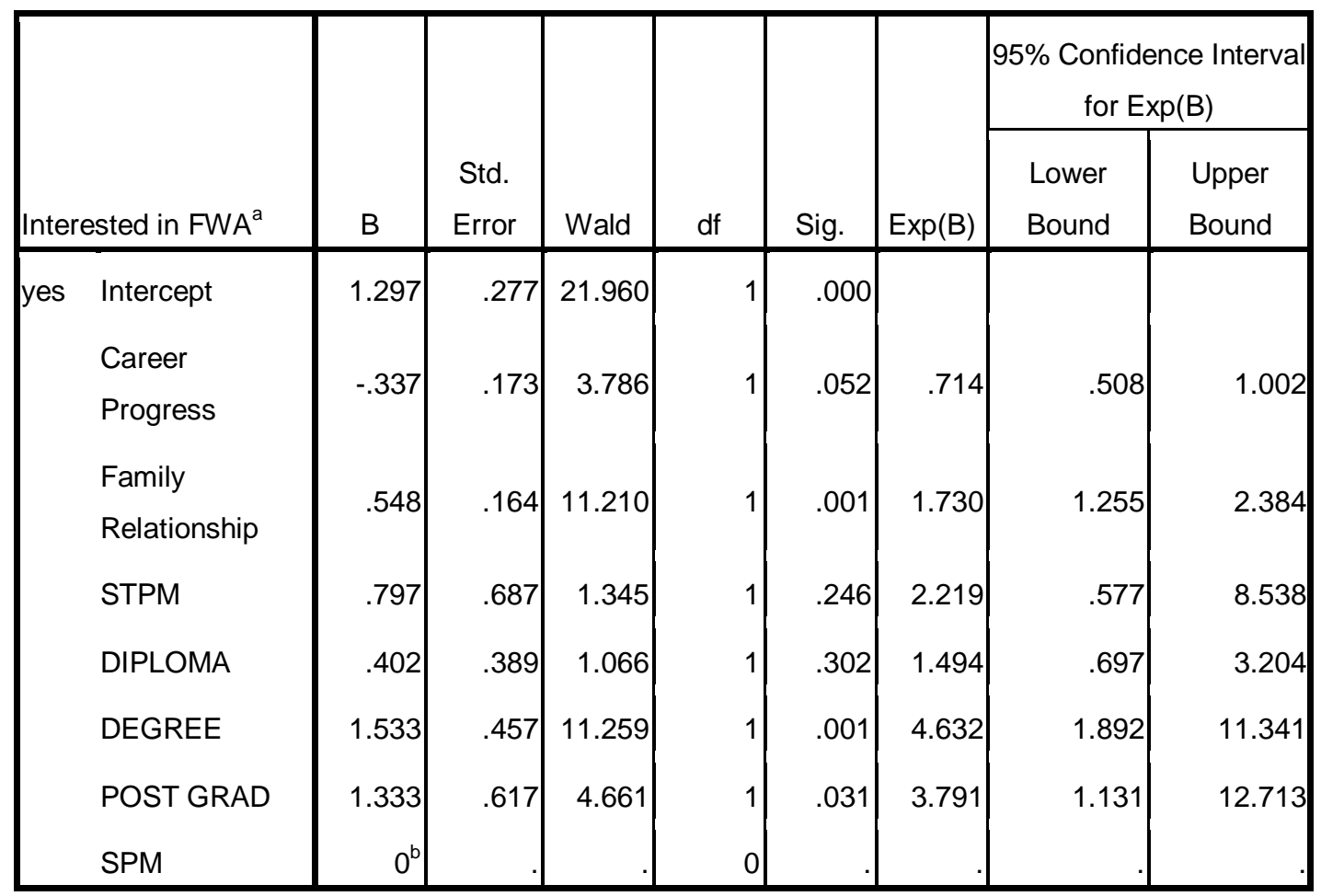

a. The reference category is:

no.

b. This parameter is set to zero because it is

redundant. 


\section{APPENDIX 5.3- Cross Tabulation Output}

\begin{tabular}{|c|c|c|c|c|c|}
\hline & & & \multicolumn{3}{|c|}{ WorkType } \\
\hline & & & FWA & Non FWA & Total \\
\hline \multirow{9}{*}{$\begin{array}{l}\text { Intentions of stopping work } \\
\text { before retirement age }\end{array}$} & yes & Count & 89 & 75 & 164 \\
\hline & & $\begin{array}{l}\% \text { within Intentions of } \\
\text { stopping work before } \\
\text { retirement age }\end{array}$ & $54.3 \%$ & $45.7 \%$ & $100.0 \%$ \\
\hline & & $\%$ within WorkType & $42.0 \%$ & $45.5 \%$ & $43.5 \%$ \\
\hline & no & Count & 123 & 90 & 213 \\
\hline & & $\begin{array}{l}\% \text { within Intentions of } \\
\text { stopping work before } \\
\text { retirement age }\end{array}$ & $57.7 \%$ & $42.3 \%$ & $100.0 \%$ \\
\hline & & $\%$ within WorkType & $58.0 \%$ & $54.5 \%$ & $56.5 \%$ \\
\hline & Total & Count & 212 & 165 & 377 \\
\hline & & $\begin{array}{l}\% \text { within Intentions of } \\
\text { stopping work before } \\
\text { retirement age }\end{array}$ & $56.2 \%$ & $43.8 \%$ & $100.0 \%$ \\
\hline & & \% within WorkType & $100.0 \%$ & $100.0 \%$ & $100.0 \%$ \\
\hline
\end{tabular}

Chi-Square Tests

\begin{tabular}{|c|c|c|c|c|c|}
\hline & Value & df & $\begin{array}{l}\text { Asymp. Sig. (2- } \\
\text { sided) }\end{array}$ & $\begin{array}{l}\text { Exact Sig. (2- } \\
\text { sided) }\end{array}$ & $\begin{array}{l}\text { Exact Sig. (1- } \\
\text { sided) }\end{array}$ \\
\hline Pearson Chi-Square & $.455^{\mathrm{a}}$ & 1 & .500 & \multirow{6}{*}{.531} & \multirow{6}{*}{.284} \\
\hline Continuity Correction ${ }^{\mathrm{b}}$ & .325 & 1 & .569 & & \\
\hline Likelihood Ratio & .455 & 1 & .500 & & \\
\hline Fisher's Exact Test & & & & & \\
\hline Linear-by-Linear Association & .454 & 1 & .500 & & \\
\hline$N$ of Valid Cases & 377 & & & & \\
\hline
\end{tabular}

a. 0 cells $(.0 \%)$ have expected count less than 5 . The minimum expected count is 71.78 . 
Chi-Square Tests

\begin{tabular}{|c|c|c|c|c|c|}
\hline & Value & df & $\begin{array}{l}\text { Asymp. Sig. (2- } \\
\text { sided) }\end{array}$ & $\begin{array}{c}\text { Exact Sig. (2- } \\
\text { sided) }\end{array}$ & $\begin{array}{l}\text { Exact Sig. (1- } \\
\text { sided) }\end{array}$ \\
\hline Pearson Chi-Square & $.455^{\mathrm{a}}$ & 1 & .500 & & \\
\hline Continuity Correction ${ }^{\mathrm{b}}$ & .325 & 1 & .569 & & \\
\hline Likelihood Ratio & .455 & 1 & .500 & & \\
\hline Fisher's Exact Test & & & & .531 & .284 \\
\hline Linear-by-Linear Association & .454 & 1 & .500 & & \\
\hline $\mathrm{N}$ of Valid Cases & 377 & & & & \\
\hline
\end{tabular}
a. 0 cells $(.0 \%)$ have expected count less than 5 . The minimum expected count is 71.78 .
b. Computed only for a $2 \times 2$ table 


\section{APPENDIX 5.4- Independent T-Test Output}

Group Statistics

\begin{tabular}{|ll|r|r|r|r|}
\hline & WorkType & $\mathrm{N}$ & Mean & Std. Deviation & Std. Error Mean \\
\hline $\begin{array}{l}\text { In my opinion, flexible } \\
\begin{array}{l}\text { working arrangements may } \\
\text { have an effect on the } \\
\text { decision for women to go out } \\
\text { to work. }\end{array}\end{array}$ & Non FWA & 167 & 3.7305 & .91565 & .06216 \\
\hline
\end{tabular}

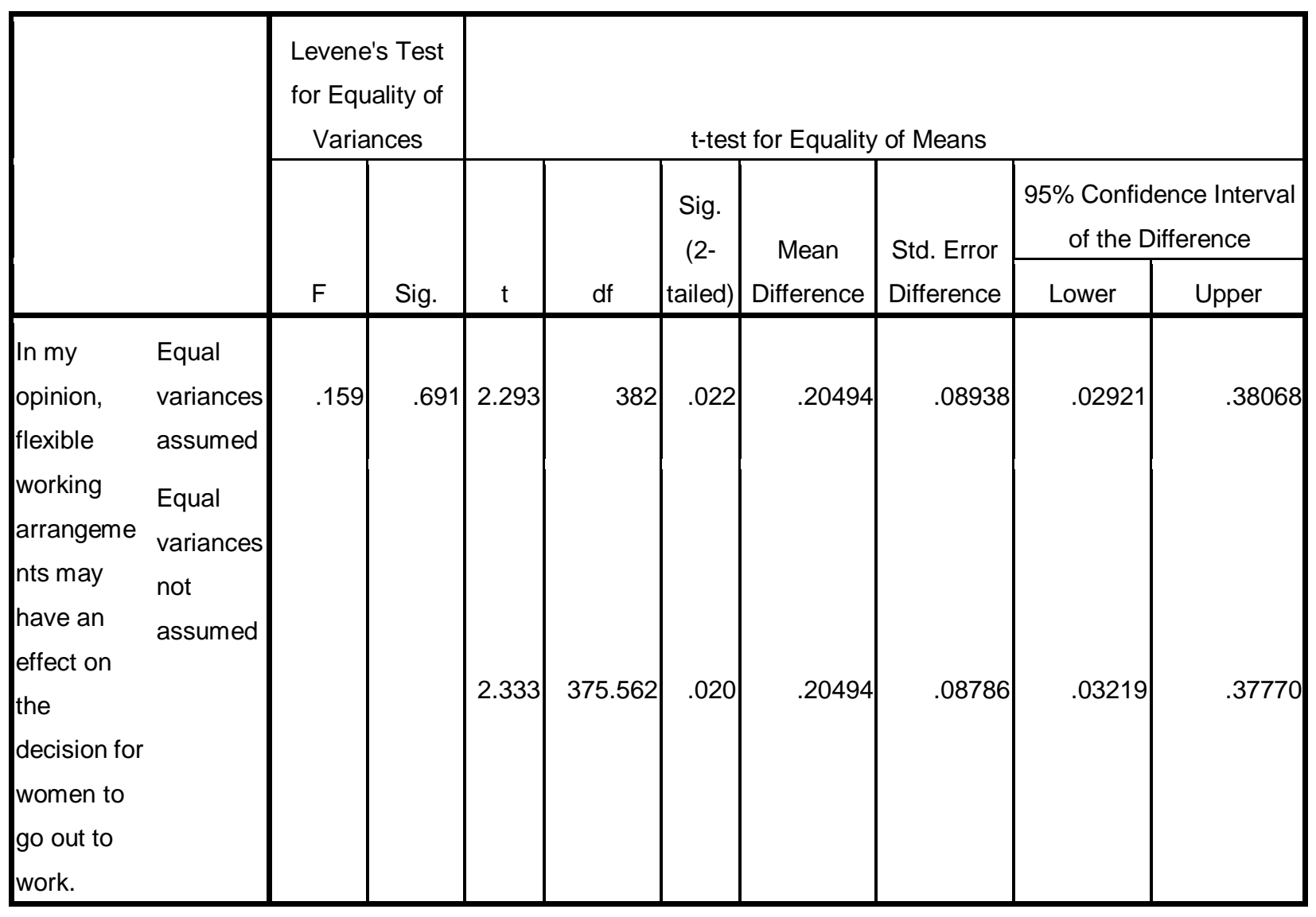




\section{APPENDIX 6.1 - Demographic Profile of Interview Respondents}

\begin{tabular}{|c|c|c|c|c|c|c|c|c|}
\hline $\begin{array}{l}\text { Participant } \\
\text { (code) }\end{array}$ & Age & Ethnicity & $\begin{array}{l}\text { Marital } \\
\text { Status }\end{array}$ & $\begin{array}{l}\text { Educational } \\
\text { Level }\end{array}$ & $\begin{array}{l}\text { Occupational } \\
\text { Level }\end{array}$ & Children & Elderly & $\begin{array}{l}\text { Organisatio } \\
\mathrm{n}\end{array}$ \\
\hline $\mathrm{F} 1$ & 35 & Malay & Married & Degree & HR Manager & $\begin{array}{l}3 \text { children } \\
\text { G- } 15 y r s \\
\text { G- } 12 y r s \\
\text { B- } 9 y r s\end{array}$ & No & Bank \\
\hline F2 & 38 & Chinese & Married & Degree & $\begin{array}{l}\text { Executive } \\
\text { Level }\end{array}$ & $\begin{array}{l}2 \text { children } \\
\mathrm{G}-5 \mathrm{yrs} \\
\text { B- } 3.5 \mathrm{yrs}\end{array}$ & & Bank \\
\hline F3 & 42 & Malay & Married & $\begin{array}{l}\text { SPM } \\
\text { (O levels) }\end{array}$ & Supervisor & $\begin{array}{l}2 \text { children } \\
\text { B- } 27 \mathrm{yrs} \\
\text { B }-25 \mathrm{yrs}\end{array}$ & No & Logistics \\
\hline $\mathrm{F} 4$ & 28 & Indian & Single & Diploma & $\begin{array}{l}\text { Administrato } \\
\mathrm{r}\end{array}$ & - & Parents & Logistics \\
\hline F5 & 28 & Malay & Single & Degree & $\begin{array}{l}\text { Transport } \\
\text { Coordinator }\end{array}$ & - & Parents & Logistics \\
\hline F6 & 33 & Chinese & Married & Degree & $\begin{array}{l}\text { Marketing } \\
\text { Adviser }\end{array}$ & 0 children & No & $\begin{array}{l}\text { Petroleum } \\
\text { Shared } \\
\text { Services }\end{array}$ \\
\hline F7 & 49 & Malay & Married & $\begin{array}{l}\text { Post grad } \\
\text { (Masters) }\end{array}$ & $\begin{array}{l}\text { Training } \\
\text { Head }\end{array}$ & $\begin{array}{l}3 \text { children } \\
\text { G-20 yrs } \\
\text { G-18 yrs } \\
\text { B- } 15 \text { yrs }\end{array}$ & No & $\begin{array}{l}\text { Petroleum } \\
\text { Shared } \\
\text { Services }\end{array}$ \\
\hline$\overline{F 8}$ & 53 & Indian & Married & SPM & Coordinator & $\begin{array}{l}2 \text { children } \\
\text { B- } 28 \text { yrs } \\
\text { G- } 26 \text { yrs, }\end{array}$ & Mother & $\begin{array}{l}\text { Petroleum } \\
\text { Shared } \\
\text { Services }\end{array}$ \\
\hline F9 & 44 & Indian & $\begin{array}{l}\text { Married } \\
\text { (Single } \\
\text { parent) } \\
\text { mother) }\end{array}$ & $\begin{array}{l}\text { Post grad } \\
(\mathrm{PhD})\end{array}$ & Team Head & $\begin{array}{l}1 \text { child } \\
\text { B- } 4 \text { yrs }\end{array}$ & No & $\begin{array}{l}\text { Petroleum } \\
\text { Shared } \\
\text { Services }\end{array}$ \\
\hline F10 & 50 & Malay & Married & Diploma & Admin Exec & $\begin{array}{l}4 \text { children } \\
\text { B-20 yrs } \\
\text { G-16 yrs } \\
\text { G-12 yrs } \\
\text { B-8 yrs }\end{array}$ & No & $\begin{array}{l}\text { Prof } \\
\text { Company }\end{array}$ \\
\hline
\end{tabular}




\begin{tabular}{|c|c|c|c|c|c|c|c|c|}
\hline F11 & 38 & Malay & Married & SPM & Asst Admin & $\begin{array}{l}3 \text { children } \\
\text { B -8 yrs } \\
\text { B-5 yrs } \\
\text { B- } 3 y r s\end{array}$ & No & $\begin{array}{l}\text { Prof } \\
\text { Company }\end{array}$ \\
\hline F12 & 52 & Chinese & Married & $\begin{array}{l}\text { Masters } \\
\text { (Postgradu } \\
\text { ate) }\end{array}$ & $\begin{array}{l}\text { Senior } \\
\text { Lecturer }\end{array}$ & $\begin{array}{l}3 \text { children } \\
\text { B-25 yrs } \\
\text { B-22 yrs } \\
\text { B-16yrs }\end{array}$ & No & University \\
\hline F13 & 49 & Malay & Married & $\begin{array}{l}\text { PhD } \\
\text { (Post } \\
\text { grad) }\end{array}$ & Professor & $\begin{array}{l}4 \text { children } \\
\text { G-26 yrs } \\
\text { G-24 yrs } \\
\text { B-22 yrs } \\
\text { B-12 yrs }\end{array}$ & No & University \\
\hline F14 & 41 & Indian & Married & $\begin{array}{l}\text { PhD } \\
\text { (Postgradu } \\
\text { ate) }\end{array}$ & $\begin{array}{l}\text { Senior } \\
\text { Lecturer }\end{array}$ & $\begin{array}{l}\text { 1child } \\
\text { G-7 yrs }\end{array}$ & No & University \\
\hline F15 & 40 & Indian & Married & Masters & HR Manager & $\begin{array}{l}1 \text { child } \\
\text { G-6 yrs }\end{array}$ & No & $\begin{array}{l}\text { Telecomm } \\
\text { unication }\end{array}$ \\
\hline N16 & 27 & Malay & Married & $\begin{array}{l}\text { SPM } \\
\text { (O Levels) }\end{array}$ & Clerk & $\begin{array}{l}1 \text { children } \\
\text { G-11 } \\
\text { mths }\end{array}$ & No & Bank \\
\hline N17 & 52 & Indian & Married & $\begin{array}{l}\text { SPM } \\
\text { (O Levels) }\end{array}$ & HR Assist & $\begin{array}{l}3 \text { children } \\
\text { G-26 yrs } \\
\text { G-25 yrs } \\
\text { B-22 yrs }\end{array}$ & No & Bank \\
\hline N18 & 32 & Chinese & Single & $\begin{array}{l}\text { SPM } \\
\text { (O Levels) }\end{array}$ & Clerk & No & Parents & Bank \\
\hline N19 & 32 & Malay & Married & Degree & $\begin{array}{l}\text { Senior } \\
\text { administrator. }\end{array}$ & $\begin{array}{l}1 \text { children } \\
\text { G- } 3 \text { yrs }\end{array}$ & No & Logistics \\
\hline $\mathrm{N} 20$ & 25 & Indian & Married & Diploma & $\begin{array}{l}\text { Junior } \\
\text { Admin asst }\end{array}$ & 0 & $\begin{array}{l}\text { Parents } \\
\text {-in-law }\end{array}$ & Logistics \\
\hline $\mathrm{N} 21$ & 26 & Malay & Married & $\begin{array}{l}\text { SPM } \\
\text { (O Levels) }\end{array}$ & Admin Asst & $\begin{array}{l}2 \text { children } \\
\text { B- } 5 \text { mths } \\
\text { G- } 3 \text { yrs }\end{array}$ & No & Logistics \\
\hline $\mathrm{N} 22$ & 34 & Indian & Married & $\begin{array}{l}\text { SPM } \\
\text { (O Levels) }\end{array}$ & $\begin{array}{l}\text { Admin } \\
\text { Supervisor }\end{array}$ & $\begin{array}{l}3 \text { children } \\
\text { G-11 yrs } \\
\text { G-9 yrs } \\
\text { B-5 yrs }\end{array}$ & $\begin{array}{l}\text { Parents } \\
\text { - } \\
\text { Finance }\end{array}$ & Logistics \\
\hline $\mathrm{N} 23$ & 27 & Malay & Married & Diploma & Admin Asst & $\begin{array}{l}1 \text { child } \\
\text { B- } 8 \text { mths }\end{array}$ & No & Logistics \\
\hline
\end{tabular}




\begin{tabular}{|c|c|c|c|c|c|c|c|c|}
\hline $\mathrm{N} 24$ & 26 & Malay & $\begin{array}{l}\text { Married } \\
\text { (Single } \\
- \\
\text { widow) }\end{array}$ & $\begin{array}{l}\text { SPM } \\
\text { (O Levels) }\end{array}$ & Coordinator & 0 & No & $\begin{array}{l}\text { Petroleum } \\
\text { Shared } \\
\text { Services }\end{array}$ \\
\hline $\mathrm{N} 25$ & 32 & Malay & Married & $\begin{array}{l}\text { SPM } \\
\text { (O Levels) }\end{array}$ & Clerk & $\begin{array}{l}2 \text { children } \\
\text { B- } 5 \text { yrs } \\
\text { G- } 3 \text { yrs }\end{array}$ & No & $\begin{array}{l}\text { Petroleum } \\
\text { Shared } \\
\text { Services }\end{array}$ \\
\hline N26 & 28 & Chinese & Single & Diploma & HR Assistant & 0 & No & $\begin{array}{l}\text { Petroleum } \\
\text { Shared } \\
\text { Services }\end{array}$ \\
\hline $\mathrm{N} 27$ & 38 & Chinese & Single & Degree & Designer & 0 & No & $\begin{array}{l}\text { Prof } \\
\text { Company }\end{array}$ \\
\hline $\mathrm{N} 28$ & 38 & Indian & Married & $\begin{array}{l}\text { Masters } \\
\text { (Postgrad) }\end{array}$ & Lawyer & $\begin{array}{l}\text { 2children } \\
\text { G- } 8 \text { yrs } \\
\text { G- } 5 \text { yrs }\end{array}$ & No & $\begin{array}{l}\text { Prof } \\
\text { Company }\end{array}$ \\
\hline N29 & 32 & Indian & Single & $\begin{array}{l}\text { Masters } \\
\text { (Postgrad) }\end{array}$ & Lecturer & 0 & No & University \\
\hline N30 & $\begin{array}{l}38 \\
\text { yrs }\end{array}$ & Chinese & Single & Degree & $\begin{array}{l}\text { Marketing } \\
\text { Manager }\end{array}$ & 0 & No & $\begin{array}{l}\text { Telecomm } \\
\text { unication }\end{array}$ \\
\hline
\end{tabular}

